LA-14362

Approved for public release;

distribution is unlimited.

Polychlorinated Biphenyls (PCBs) in Catfish and Carp Collected from the Rio Grande Upstream and Downstream of Los Alamos National Laboratory: Revision 1

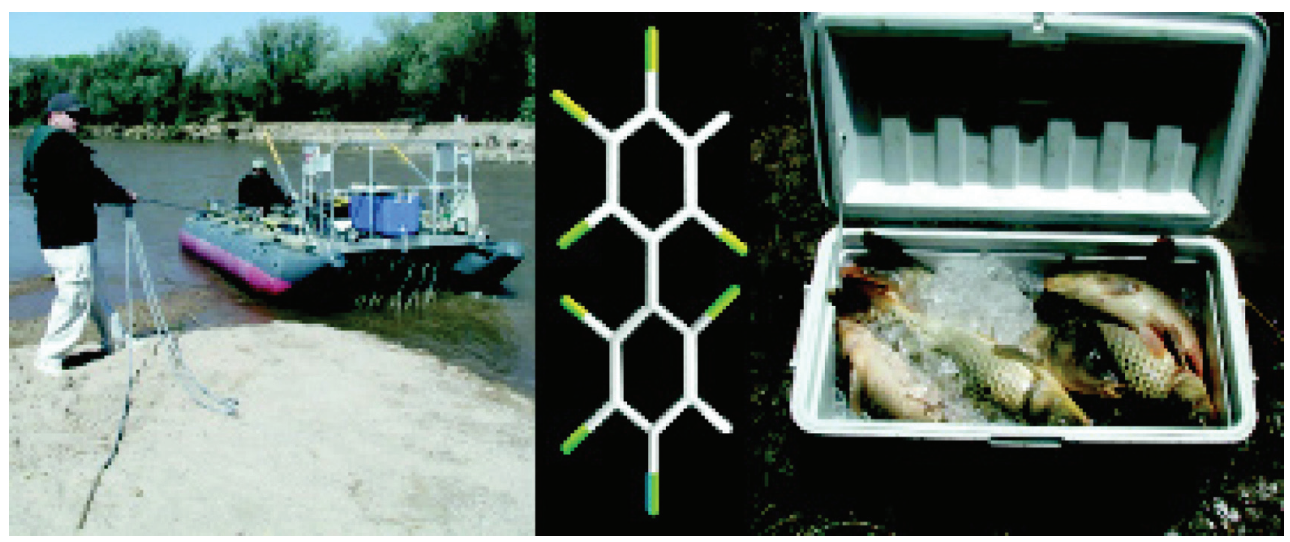


Edited by Hector Hinojosa, Group IRM-CAS.

Front Cover: Left to right-Sampling crew launching electroshocking vessel in the Rio Grande; characteristic biphenyl rings in the chemical structure of PCBs (Flynn 1997); and common carp sampled from the Rio Grande.

Los Alamos National Laboratory, an affirmative action/ equal opportunity employer, is operated by Los Alamos National Security, LLC, for the National Nuclear Security Administration of the U.S. Department of Energy under contract DE-AC52-06NA25396.

This report was prepared as an account of work sponsored by an agency of the U.S. Government. Neither Los Alamos National Security, LLC, the U.S. Government nor any agency thereof, nor any of their employees make any warranty, express or implied, or assume any legal liability or responsibility for the accuracy, completeness, or usefulness of any information, apparatus, product, or process disclosed, or represent that its use would not infringe privately owned rights. Reference herein to any specific commercial product, process, or service by trade name, trademark, manufacturer, or otherwise does not necessarily constitute or imply its endorsement, recommendation, or favoring by Los Alamos National Security, LLC, the U.S. Government, or any agency thereof. The views and opinions of authors expressed herein do not necessarily state or reflect those of Los Alamos National Security, LLC, the U.S. Government, or any agency thereof. Los Alamos National Laboratory strongly supports academic freedom and a researcher's right to publish; as an institution, however, the Laboratory does not endorse the viewpoint of a publication or guarantee its technical correctness. 
LA-14362

Issued: May 2008

Polychlorinated Biphenyls (PCBs) in Catfish and

Carp Collected from the Rio Grande Upstream and

Downstream of Los Alamos National Laboratory:

Revision 1

Gilbert J. Gonzales

Philip R. Fresquez 



\section{Preface}

The purpose of this revision is to correct an error associated with Table 4, section (b) Carp. Specifically, the polychlorinated biphenyl (PCB) data for carp collected upstream and downstream of Los Alamos National Laboratory (LANL) were inadvertently reversed. In this revision, the table heading and text referring to these carp comparisons were changed to reflect the correct data. Also, the supporting chain-of-custody documentation is added the beginning of Appendix 2, Fish Data. Revised results show that PCBs in carp collected upstream of LANL (RGSI) were slightly higher than PCBs in carp collected downstream of LANL (RGTRT). However, as reported in the original report, the mean concentrations of PCBs in carp collected upstream and downstream were not statistically different from one another; so no major conclusions were affected because of this error. 


\section{Contents}

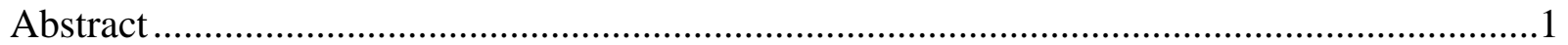

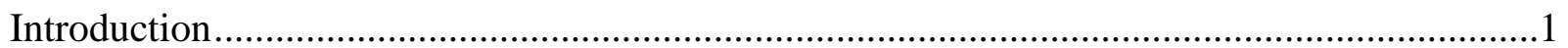

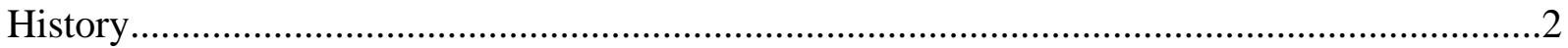

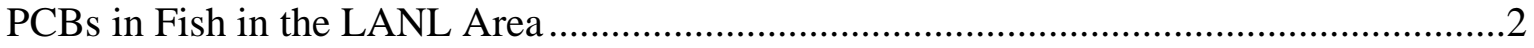

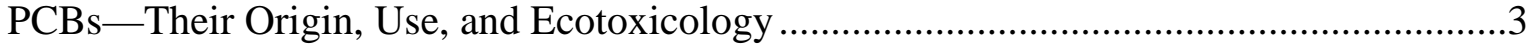

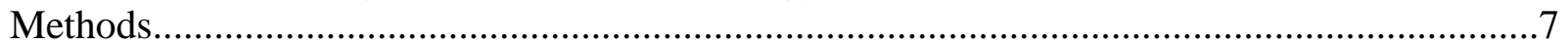

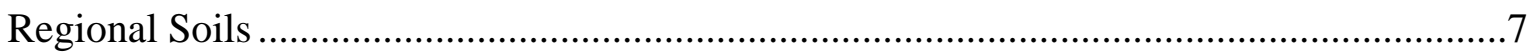

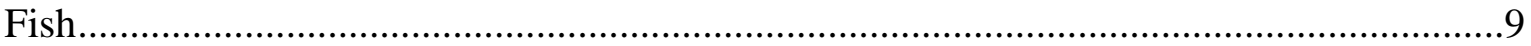

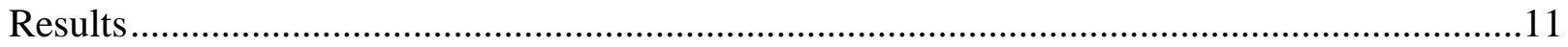

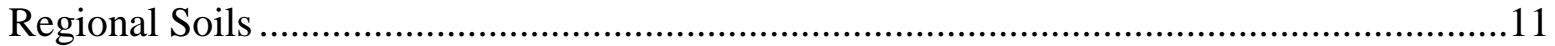

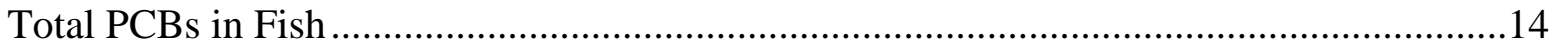

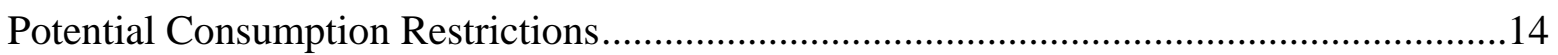

Homologues as Indicators of Aroclor Sources .........................................................14

Trend in Aroclor Concentrations Over Time....................................................................17

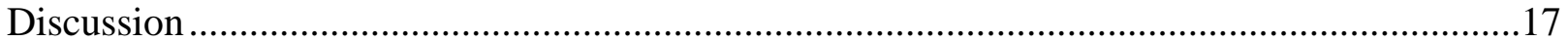

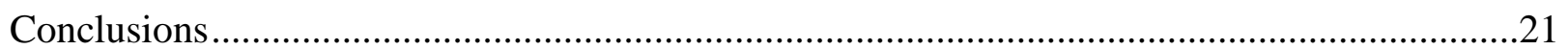

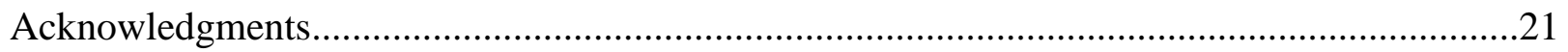

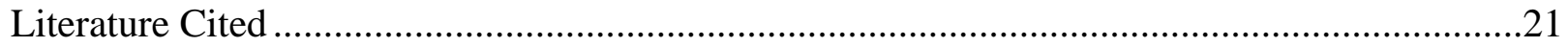

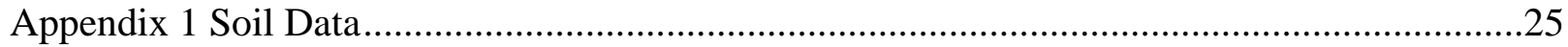

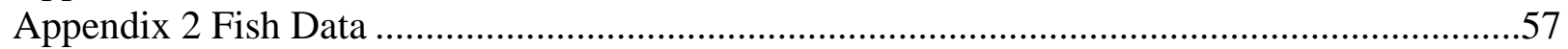

\section{List of Tables}

Table 1. Typical composition (\%) of some commercial PCB mixtures. ..................................4

Table 2. Domestic production (\%) of commercial PCB mixtures, 1957-1977.........................5

Table 3. CB homologue distribution and total PCBs in background soil along the Rio Chama and Rio Grande drainages................................................................................12

Table 4. Total PCB concentrations and TEQs in fillets of (a) catfish and (b) carp collected from

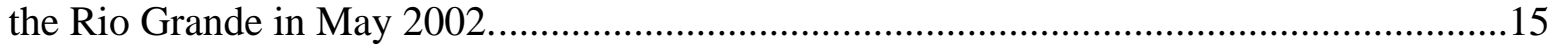

Table 5. Aroclor-equivalent PCB concentrations $(\mu \mathrm{g} / \mathrm{g})$ for catfish estimated from PCB

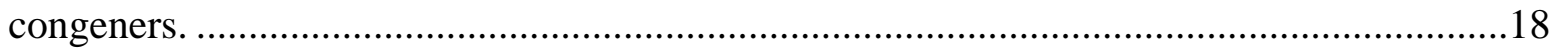

\section{List of Figures}

Figure 1. Locations of soil sampling along the Rio Grande and Rio Chama. ...........................8

Figure 2. Locations of fish sampling along the Rio Grande................................................10

Figure 3. PCB homologue distribution in (a) nine soil samples and (b) typical brand-name formulation.

Figure 4. Percentages of total PCB concentrations contributed by various homologues in catfish sampled upstream from the potential direct influence of LANL, catfish sampled downstream of the potential direct influence of LANL, and in brand name formulations of PCB mixtures.

Figure 5. Comparison of PCB levels in fish from the Rio Grande and Cochiti Reservoir from 1997 to 2002. 


\section{List of Acronyms}

B This compound was also detected in the method blank.

CBs chlorinated biphenyls

DOE U.S. Department of Energy

EPA Environmental Protection Agency

LANL Los Alamos National Laboratory

MDL minimum detection level

ND not detected

PCDFs polychlorinated dibenzofurans

ppm parts per million

ppt parts per trillion

RCA/SJ Rio Chama, Abiquiu to San Juan Pueblo

RCC/EV Rio Chama, Chama to El Vado

RCCO/NM Rio Chama, Colorado to New Mexico border

RCEV/A Rio Chama, El Vado to Abiquiu

RGCO/NM Rio Grande, Colorado to New Mexico border

RGNM/SC Rio Grande, New Mexico border to San Cristobal

RGO/C Rio Grande, Otowi Bridge to Cochiti

RGP/O Rio Grande, Pilar to Otowi Bridge

RGSC/P Rio Grande, San Cristobal to Pilar

RL

TCDD

TEF

TEQ

$\mathrm{U}$ reporting limit tetrachlorodibenzodioxin TCDD equivalency factors toxicity equivalent quotient Qualified nondetect; sample result was less than or equal to 5 times (5x) the amount detected in the laboratory blank. 


\title{
Polychlorinated Biphenyls (PCBs) in Catfish and Carp Collected from the Rio Grande Upstream and Downstream of Los Alamos National Laboratory: Revision 1
}

\author{
Gilbert J. Gonzales and Philip R. Fresquez
}

\begin{abstract}
Concern has existed for years that the Los Alamos National Laboratory (LANL), a complex of nuclear weapons research and support facilities, has released polychlorinated biphenyls (PCBs) to the environment that may have reached adjacent bodies of water through canyons that connect them. In 1997, LANL's Ecology Group began measuring PCBs in fish in the Rio Grande upstream and downstream of ephemeral streams that cross LANL and later began sampling fish in Abiquiu and Cochiti reservoirs, which are situated on the Rio Chama and Rio Grande upstream and downstream of LANL, respectively. In 2002, we electroshocked channel catfish (Ictalurus punctatus) and common carp (Carpiodes carpio) in the Rio Grande upstream and downstream of LANL and analyzed fillets for PCB congeners. We also sampled soils along the Rio Chama and Rio Grande drainages to discern whether a background atmospheric source of PCBs that could impact surface water adjacent to LANL might exist. Trace concentrations of PCBs measured in soil (mean $=4.7 \mathrm{E}-05 \mu \mathrm{g} / \mathrm{g}-\mathrm{ww}$ ) appear to be from background global atmospheric sources, at least in part, because the bimodal distribution of lowchlorinated PCB congeners and mid-chlorinated PCB congeners in the soil samples is interpreted to be typical of volatilized PCB congeners that are found in the atmosphere and dust from global fallout. Upstream catfish $(n=5)$ contained statistically $(\mathrm{P}=0.047$ ) higher concentrations of total $\mathrm{PCBs}$ (mean $=2.80 \mathrm{E}-02$ $\mu \mathrm{g} / \mathrm{g}-\mathrm{ww})$ than downstream catfish $(\mathrm{n}=10)$ (mean $=1.50 \mathrm{E}-02 \mu \mathrm{g} / \mathrm{g}-\mathrm{ww})$. Similarly, upstream carp $(\mathrm{n}=4)$ contained higher concentrations of total PCBs (mean = 7.98E-02 $\mu \mathrm{g} / \mathrm{g}-\mathrm{ww})$ than downstream carp $(\mathrm{n}=4)(3.07 \mathrm{E}-02 \mu \mathrm{g} / \mathrm{g}-\mathrm{ww})$; however, the difference was not statistically significant $(\mathrm{P}=0.42)$. The dominant PCB homologue in all fish samples was hexachlorobiphenyls. Total PCB concentrations in fish in 2002 are lower than 1997; however, differences in analytical methods and other uncertainties exist. A review of historical quantitative PCB data for fish from the Rio Grande and Abiquiu and Cochiti reservoirs does not indicate a distinct contribution of PCBs from LANL to fish in the Rio Grande or Cochiti. Analysis of homologue patterns for fish does not provide sufficient evidence of a LANL contribution. Nevertheless, concentrations of PCBs in fillets of fish sampled from the Rio Grande are indicative of potential adverse chronic health impact from consumption of these fish on a long-term basis.
\end{abstract}

\section{Introduction}

Department of Energy (DOE) Orders 5400.1 and 5400.5 mandate the monitoring of foodstuffs at DOE sites in order to protect humans and ecosystems (USDOE 1991). Previous data have shown that elevated concentrations of polychlorinated biphenyls (PCBs) occur in fish at Cochiti and Abiquiu reservoirs (Fresquez and Gonzales 2000; Fresquez et al. 2001, 2002). The 
concentrations previously measured in fish could present a potential risk that could result in consumption restrictions by the State of New Mexico according to U.S. Environmental Protection Agency (EPA) guidance (USEPA 2000). A concern that has repeatedly been posed is how much, if any, of this risk is contributed by the Los Alamos National Laboratory (LANL). This concern arises because LANL is situated adjacent to and upslope of the Rio Grande and has ephemeral streams in canyons that culminate at the Rio Grande (confluences) and have the potential to discharge into the Rio Grande. Like many other industrial sites, LANL historically used PCB-containing devices such as electrical transformers and unanticipated releases into the environment may have occurred.

The objectives of our study were to (1) gather information that will contribute, in part, to answering the question of LANL's contribution, if any, to PCB loads in bodies of water that are downstream of LANL, (2) continue to satisfy our federally mandated monitoring requirements, including the estimation of whether the Cerro Grande Fire had impacts to natural resources as related to legacy contamination at LANL, (3) establish the potential risk to humans from PCBs in fish, and (4) evaluate the dominant risk drivers (human risk versus ecological risk) in structuring the continued sampling and monitoring for our Environmental Surveillance Program.

In 2002, we collected fish from the Rio Grande at locations upstream and downstream of LANL stream confluences. We also collected soil along the Rio Chama and the Rio Grande from its origin in southern Colorado to north-central New Mexico downstream from LANL in order to establish background PCB levels from atmospheric sources that might affect PCBs in the fish we sampled. Previous sampling of whole-body fish from Cochiti Reservoir was done for the primary purpose of ecological risk screening, whereas in 2002 we sampled the edible portion of fish (fillets) for the primary purpose of human risk screening.

\section{History}

PCBs in Fish in the LANL Area. The presence of PCBs and other organic contaminants in fish worldwide and in the U.S. has been documented regionally since the 1970s (Stoker and Seager 1976, Schmitt et al. 1990), within New Mexico (Eisler 1986), and in the Rio Grande upstream and downstream from Los Alamos, as well as at Cochiti Reservoir (Roy et al. 1992, Carter 1997).

Fish tend to moderate the temporal and spatial variability of PCBs in abiotic environmental media such as sediment and soil and integrate, in a sense, PCB concentrations from surrounding areas. Fish and other organisms are also known to selectively retain certain PCBs while more effectively metabolizing and eliminating other PCBs.

Fish in waters adjacent to or potentially affected by LANL have been sampled and analyzed for organic contaminants intermittently since 1997 and yearly since 2000 (Gonzales et al. 1999; Fresquez and Gonzales 2000; Fresquez et al. 2001, 2002). This monitoring has been conducted as a component of LANL's Environmental Surveillance Program and most recently in response to the Cerro Grande Fire of 2000 as planned in a contaminant monitoring plan (Gonzales and Bare 2001). Emphasis on organic contaminants and PCBs, in particular, has resulted from concerns over the risk to humans from consuming fish from Cochiti Reservoir or the Rio Grande. And paramount to this issue of risk has always been interest in identifying and quantifying, if possible, the contributing sources of PCBs to the Rio Grande and Cochiti Reservoir.

The previous LANL studies on PCBs in fish have resulted in three main conclusions: (1) while the levels of PCBs measured in fish in the Rio Grande and Cochiti Reservoir did not exceed 
guidance limits for even the most sensitive piscivores or other biota in related food chains, restrictions on fish consumption by humans have been consistently indicated by the PCB levels measured in edible portions of fish on the basis of recent EPA guidance (USEPA 2000); (2) focus in future years regarding health risk from PCBs in fish in the Rio Grande and Cochiti Reservoir should be on humans, not biota; and (3) on the basis of sampling and analysis of fish for PCBs, there is no clear evidence that LANL has served as a contributor.

As a result of this intensified interest and recent publicity concerning PCBs in fish and in LANL surface water, a PCB cooperative working group was organized in March 2002 to attempt to

- quantify the contribution of PCBs, if any, by LANL to nearby bodies of water,

- determine the spatial variability in PCB concentrations (including background) in regional soils,

- determine the spatial variability in PCB concentrations in surface water, sediments, and fish from LANL watersheds, and

- determine the spatial variability in PCB concentrations in the Rio Grande upstream and downstream of LANL (Mullen et al. 2002).

The results of the fish and soil sampling reported in this report are a component of the cooperative study.

PCBs-Their Origin, Use, and Ecotoxicology. The following information about PCBs is obtained from the EPA (USEPA 2002, 1996) and from the Agency for Toxic Substances and Disease Registry (ATSDR 2000). This information also appears in a report by the Northern New Mexico PCB Cooperative Group (Mullen et al. 2002).

PCBs are a category of chemicals that were manufactured in the U.S. between about 1930 and 1977, predominantly for use as coolants and lubricants due to their general chemical inertness and heat stability in electrical equipment such as capacitors and transformers. PCBs are complex mixtures of chlorinated biphenyls (CBs) that vary in the degree of chlorination. For example, the commercial product Aroclor 1254 is a mixture of mono- through hepta-CB congeners with an average chlorine content of approximately 54\%. However, significant lot-to-lot differences in congeneric composition occurred among similar mixtures. The manufacture of PCBs in the U.S. was stopped because of evidence that they accumulate and persist in the environment and can be toxic.

PCBs are mixtures of synthetic organic chemicals that range from oily liquids to waxy solids. Due to their nonflammability, chemical stability, high boiling point, and electrical insulating properties, PCBs were used in hundreds of industrial and commercial applications. An important property of PCBs is their general inertness; they resist both acids and alkalis and have thermal stability. This made them useful in a wide variety of applications, including dielectric fluids in transformers and capacitors, heat transfer fluids, and lubricants. In general, PCBs are relatively insoluble in water, and the solubility decreases with increased chlorination. PCBs are also freely soluble in nonpolar organic solvents and biological lipids.

Before1974, PCBs were used both for nominally closed applications such as capacitors and transformers and heat transfer and hydraulic fluids. PCBs were also used in open-end applications such as flame retardants, inks, adhesives, microencapsulation of dyes for carbonless duplicating paper, paints, pesticide extenders, plasticizers, polyolefin catalyst carriers, slidemounting mediums for microscopes, surface coatings, wire insulators, and metal coatings. As of 
the late 1970s, Aroclors were no longer used in the production of capacitors and transformers. Nevertheless, the life expectancy of transformers containing PCBs is greater than 30 years, and the life expectancy of capacitors ranges from 10 to 20 years, depending on the electrical application. In 1981, an estimated 131,200 transformers containing PCBs were in service in the U.S., representing approximately 1\% of all operational transformers (ATSDR 2000).

Each PCB molecule consists of two 6-carbon rings, with one chemical bond joining a carbon from each ring (imagine sunglasses with hexagonal frames). Chlorine can attach to any of the other 10 carbons; these positions are said to be substituted. There are 209 possible arrangements, called congeners; congeners with the same number of chlorines are called isomers. The number and position of chlorines determine a molecule's physical and chemical properties. The 10 positions are numbered 2-6 on one ring and 2'-6' on the other. For example, the congener 2,4,2',5'-tetrachlorobiphenyl has chlorines in positions 2 and 4 of one ring and 2' and 5' of the other. (Standard chemical notation for this congener is 2,2',4,5'-tetrachlorobiphenyl; instead, this assessment lists chlorines on one ring, then the other, to emphasize each ring's chlorination pattern.) Positions 2, 6, 2', and 6', adjacent to the bond, are called ortho positions; 3, 5, 3', and 5', meta positions; 4 and 4' (the outermost), para positions. The International Union of Pure and Applied Chemists has adopted an alternative system for numbering congeners sequentially from 1 to 209.

A molecule's two rings can twist on the bond joining them; they are coplanar if aligned in the same plane. Chlorine in ortho positions inhibits a coplanar alignment. Coplanar molecules have dioxin-like properties. PCB mixtures manufactured in the U.S. carried the trademark "Aroclor" followed by a four-digit number; the first two digits are "12," and the last two digits indicate the percent chlorine content by weight. For example, Aroclor 1260 contains approximately 60 percent chlorine by weight. Aroclor 1016 is an exception to this scheme; it contains approximately 41 percent chlorine. "Clophens" and "Kanechlors" are PCB mixtures manufactured in Germany and Japan, respectively; these series have their own numbering schemes. Table 1 shows the overlapping composition of some commercially manufactured mixtures.

\begin{tabular}{lcccccccccc}
\hline \hline & \multicolumn{1}{c}{ Table 1. Typical composition (\%) of some commercial PCB mixtures. } \\
\hline & \multicolumn{3}{c}{} & \multicolumn{3}{c}{ Aroclor } & \multicolumn{6}{c}{ Clophen } & \multicolumn{3}{c}{ Kanechlor } \\
\hline & $\mathbf{1 0 1 6}$ & $\mathbf{1 2 4 2}$ & $\mathbf{1 2 4 8}$ & $\mathbf{1 2 5 4}$ & $\mathbf{1 2 6 0}$ & $\mathbf{A ~ 3 0}$ & $\mathbf{A ~ 6 0}$ & $\mathbf{3 0 0}$ & $\mathbf{4 0 0}$ & $\mathbf{5 0 0}$ \\
\hline Mono-CBs & 2 & 1 & - & - & - & - & - & - & - & - \\
Di-CBs & 19 & 13 & 1 & - & - & 20 & - & 17 & 3 & - \\
Tri-CBs & 57 & 45 & 21 & 1 & - & 52 & - & 60 & 33 & 5 \\
Tetra-CBs & 22 & 31 & 49 & 15 & - & 22 & 1 & 23 & 44 & 26 \\
Penta-CBs & - & 10 & 27 & 53 & 12 & 3 & 16 & 1 & 16 & 55 \\
Hexa-CBs & - & - & 2 & 26 & 42 & 1 & 51 & - & 5 & 13 \\
Hepta-CBs & - & - & - & 4 & 38 & - & 28 & - & - & - \\
Octa-CBs & - & - & - & - & 7 & - & 4 & - & - & - \\
Nona-CBs & - & - & - & - & 1 & - & - & - & - & - \\
Deca-CB & - & - & - & - & - & - & - & - & - & - \\
\hline \hline
\end{tabular}

Columns may not total $100 \%$ due to rounding; "--" signifies less than 1\%. Lot-to-lot variability exists but has not been quantified. Source USEPA (1996).

PCBs, though not considered very flammable, are combustible, and the products of combustion may be more hazardous than the material itself. By-products of combustion include hydrogen chloride, polychlorinated dibenzodioxins (PCDDs), and polychlorinated dibenzofurans 
(PCDFs) (ATSDR 2000). Because of their inflammability, chemical stability, and insulating properties, commercial PCB mixtures had been used in many industrial applications, especially in capacitors, transformers, and other electrical equipment. These chemical properties, however, also contribute to the persistence of PCBs after they are released into the environment. Because of evidence that PCBs persist in the environment and cause harmful effects, domestic manufacture of commercial mixtures was stopped in 1977. Existing PCBs, however, continue in use. Table 2 shows some commercial mixtures as a percentage of domestic production.

\begin{tabular}{cc}
\hline \hline Table 2. Domestic production (\%) of commercial PCB mixtures, 1957-1977. \\
Mixture & Percent of Production \\
Aroclor 1016 & 13 \\
Aroclor 1221 & 1 \\
Aroclor 1232 & $<1$ \\
Aroclor 1242 & 52 \\
Aroclor 1248 & 7 \\
Aroclor 1254 & 16 \\
Aroclor 1260 & 11 \\
Aroclor 1262 & 1 \\
Aroclor 1268 & $<1$ \\
\hline \hline
\end{tabular}

Source: USEPA 1996

From 1929 to 1977, unknown quantities of PCBs were released to the air during Aroclor production and processing and when PCB-contaminated equipment was incinerated. Similarly, transformer and capacitor producers discharged PCB-containing wastes to air during the various filling processes. Emissions are no longer discharged into the air through production activities; however, emissions may be discharged during the overhaul, repair, or reuse of materials containing PCBs. PCBs may have been released to the atmosphere from various past uses containing PCBs, for example, plasticizers, surface coatings, inks, adhesives, flame retardants, pesticide extenders, paints, and microencapsulation of dyes for carbonless duplicating paper; and, in addition, from the accidental losses of PCB fluids from capacitors and transformers (ATSDR 2000).

PCBs occur as mixtures of congeners, but in the environment, the composition differs from the original commercial mixtures. This is because after release into the environment, the composition of PCB mixtures changes over time, through partitioning, chemical transformation, and preferential bioaccumulation (USEPA 1996).

Partitioning refers to processes by which different fractions of a mixture separate into air, water, sediment, and soil. PCBs adsorb to organic materials, sediments, and soils; adsorption tends to increase with chlorine content of the PCBs and organic content of the other material. PCBs can volatilize or disperse as aerosols, providing an effective means of transport in the environment (Callahan et al. 1979). Congeners with low chlorine content tend to be more volatile and also more soluble in water. Vaporization rates and water solubility of different Aroclors and individual congeners vary over several orders of magnitude (USEPA 1996).

Atmospheric transport is the most important mechanism for global dispersion of PCBs. The lower CBs are more subject to volatilization and transport with major atmospheric currents. The higher CBs remain closer to the source. PCBs enter the atmosphere from volatilization from both soil and water surfaces. Once in the atmosphere, PCBs are present both in the vapor phase and 
sorbed to airborne particles. PCBs in the vapor phase appear to be more mobile and are transported further than particle-bound PCBs. Wet and dry deposition remove PCBs from the atmosphere. The dominant source of PCBs to surface waters is atmospheric deposition; however, redissolution of sediment-bound PCBs also accounts for water concentrations. PCBs in water are transported by diffusion and currents. PCBs are removed from the water column by sorption to suspended solids and sediments as well as by volatilization from water surfaces (ATSDR 2000).

Once in the environment, PCBs do not readily break down and therefore may remain for very long periods of time. They can easily cycle between air, water, and soil. For example, PCBs can enter the air by evaporation from both soil and water. In air, PCBs can be carried long distances and have been found in snow and sea water in areas far away from where they were released into the environment, such as in the Arctic. As a consequence, PCBs are found all over the world. In general, the lighter the type of PCBs, the further they may be transported from the source of contamination. PCBs are present as solid particles or as a vapor in the atmosphere. They will eventually return to land and water by settling as dust or in rain and snow. In water, PCBs may be transported by currents, attach to bottom sediment or particles in the water, and volatilize into air. Heavy PCBs are more likely to settle into sediments while lighter PCBs are more likely to evaporate to air. Sediments that contain PCBs can also release the PCBs into the surrounding water. PCBs stick strongly to soil and will not usually be carried deep into the soil with rainwater. They do not readily break down in soil and may stay in the soil for years; generally, the more chlorine atoms that the PCBs contain, the more slowly they break down. Evaporation appears to be an important way by which the lighter PCBs leave soil. As a gas, PCBs can accumulate in leaves and aboveground parts of plants and food crops (ATSDR 2000).

Biodegradation transforms the chemical composition of PCB mixtures in the environment. Anaerobic bacteria in sediments selectively remove chlorines from meta and para positions, appearing to reduce the toxicity and bioaccumulation potential of residues; the occurrence and extent of these dechlorinations can be limited by sediment PCB concentrations. Dechlorination is not synonymous with detoxication, as congeners having carcinogenic activity can be formed through dechlorination. Aerobic bacteria remove chlorines from PCBs with low chlorine content (1-4 chlorines) and break open the carbon rings through oxidation. PCBs with higher chlorine content are extremely resistant to oxidation and hydrolysis. Photolysis can slowly break down congeners with high chlorine content. Overall, dechlorination processes are slow and altered PCB mixtures can persist in the environment for many years (USEPA 1996).

PCBs can accumulate selectively in living organisms because PCBs are highly soluble in lipids and are absorbed by fish and other animals. Rates of metabolism and elimination are slow and vary by congener. Bioaccumulation through the food chain tends to concentrate congeners of higher chlorine content, producing residues that are considerably different from the original Aroclors. PCB residues in fish and turtles, changed through environmental or metabolic alteration, may be difficult to characterize by Aroclor 1242, 1248, 1254, or 1260 standards, especially in higher trophic level animals. Congener distributions in higher trophic level species, including humans, do not resemble any Aroclor, because some congeners are preferentially retained. However, for low trophic level organisms (e.g., sturgeon [Acipenser spp.]), there is a strong correlation between the sum of Aroclors and the total PCBs obtained from full congener determinations (Sather et al. 2001). Bioaccumulated PCBs appear to be more toxic than commercial PCBs.

PCBs are widespread in the environment, and humans are exposed through multiple pathways. Levels in air, water, sediment, soil, and foods vary over several orders of magnitude, often 
depending on proximity to a source of release into the environment. Average daily intake by humans via ambient air is about $100 \mathrm{ng}$, and about an order of magnitude higher if indoor concentrations are considered. Average daily intake via drinking water is less than $200 \mathrm{ng}$ (ATSDR 1993). Estimates of average daily intake via diet vary widely depending on geographic area, food habits, and sampling methodology; 5-15 fg is considered a good estimate of average daily intake via diet in industrialized countries.

Although environmental mixtures are often characterized in terms of Aroclors, this can be both imprecise and inappropriate. Qualitative and quantitative errors can arise from judgments in interpreting the results of gas chromatography/mass spectrometry analyses, which reveal a spectrum of peaks that are compared with characteristic patterns for different Aroclors. For environmentally altered mixtures, an absence of these characteristic patterns can suggest the absence of Aroclors, even though some congeners may be present in high concentrations. Large differences have been found in results reported by laboratories analyzing the same sediment samples (USEPA 1996).

As nonpolar compounds, PCBs are hydrophobic and have strong particle and organic matter affinities. Until recently, analytical methods for the quantitation of PCBs relied upon gas chromatographic identification of isomeric mixtures (Aroclors). Identifying Aroclors in environmental samples is difficult because isomers weather at different rates altering the mixture composition. Newer analytical methods identify PCB congeners, which are individual compounds, not mixtures. These methods provide more reliable compound identification and have substantially lower method detection limits, on the order of 100 to $500 \mathrm{pg} / \mathrm{L}$ in water and 10 to $50 \mathrm{ng} / \mathrm{kg}$ in soil, tissue, and mixed-phase samples. With the advent of lower detection limits for PCB congeners, it is now becoming apparent that there is a widely distributed PCB signature in environmental media.

In 1976, Congress enacted the Toxic Substances Control Act (TSCA) that included, among other things, prohibitions on the manufacture, processing, and distribution in commerce of PCBs. TSCA legislated manufacture to disposal management of PCBs in the U.S.

The EPA has established a limit of $0.0005 \mathrm{mg} / \mathrm{L}$ PCBs in drinking water $(0.5 \mu \mathrm{g} / \mathrm{L})$. Discharges, spills, or accidental releases of one pound or more of PCBs into the environment must be reported to the EPA. The Food and Drug Administration requires that infant foods, eggs, milk and other dairy products, fish and shellfish, and poultry and red meat contain no more than 0.2-3 parts per million (ppm) in food. Many states have established fish and wildlife consumption advisories for PCBs (ATSDR 2000). Guidance on dietary limits for biota has been recommended by various authorities, most notably by Eisler (1986).

\section{Methods}

Regional Soils. Soil samples were collected in southern Colorado and north-central New Mexico within the Rio Chama and Rio Grande drainages (Fig. 1). Soils were analyzed for 209 PCBs to determine background PCB concentrations that might affect PCB concentrations in the waters of the Rio Grande and that can be assumed to contribute to PCB concentrations in the fish. Nine composite soil samples, each consisting of five subsamples, were collected. Five of the nine samples were collected from relatively undisturbed mesa top sites adjacent to the Rio Grande, starting from the Rio Grande Reservoir in Colorado to near Cochiti Reservoir in Santa Fe County, New Mexico. Four of the nine samples were collected from relatively undisturbed 


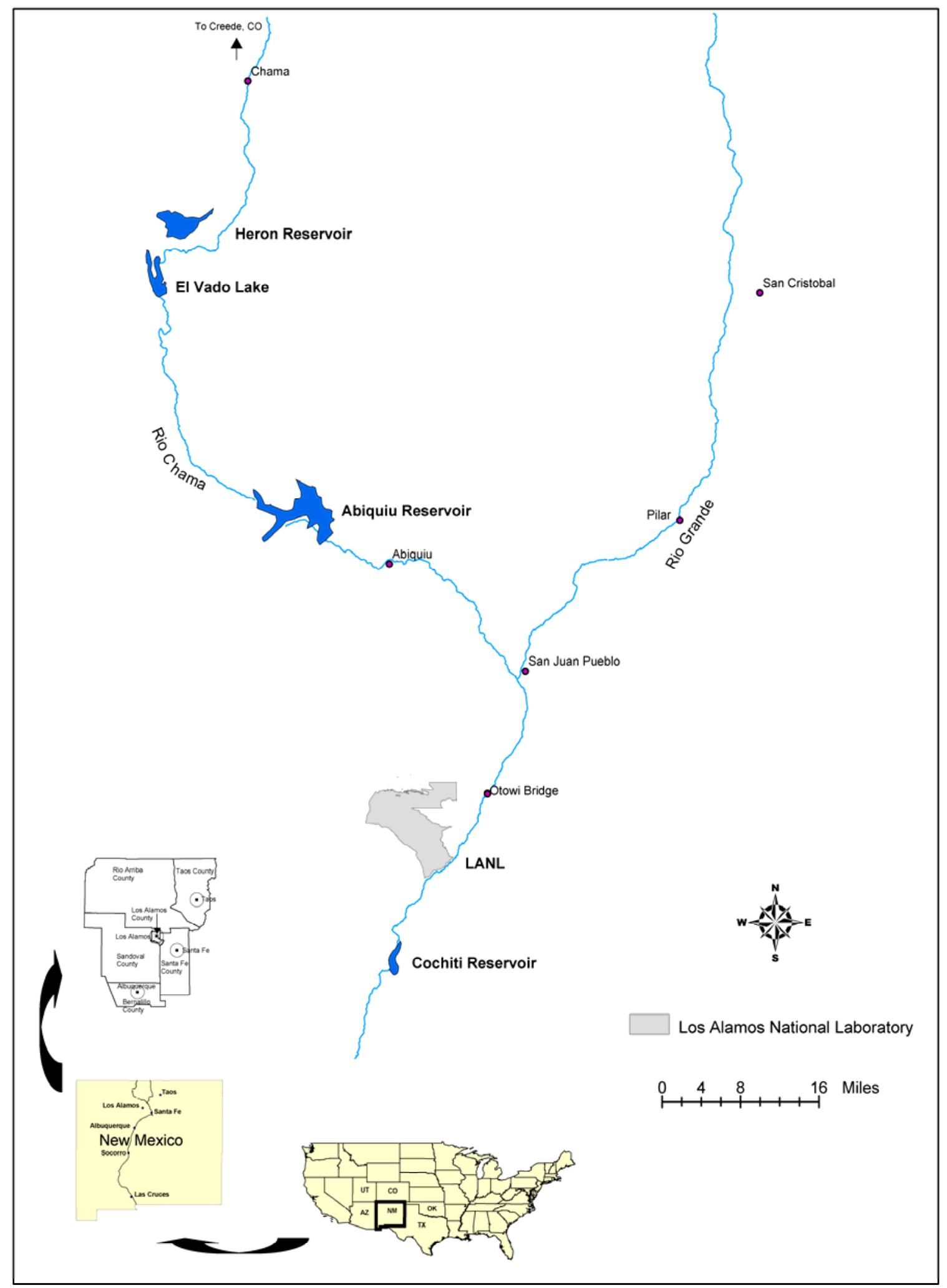

Figure 1. Locations of soil sampling along the Rio Grande and Rio Chama. 
mesa top sites adjacent to the Rio Chama, from the head of the Rio Chama in Colorado to the San Juan Pueblo in Rio Arriba County, New Mexico. Data were validated following the guidelines recommended by the U.S. Environmental Protection Agency (USEPA 1999). As discussed below in the methods dealing with fish, Aroclor-equivalent concentrations were estimated and PCB homologues were summed and compared with plots of the homologue distribution of typical Aroclor formulations. No dioxin-like PCBs were detected, therefore toxicity equivalent quotients (TEQs) were not calculated.

Fish. In May 2002, a total of 15 channel catfish (Ictalurus punctatus) and eight common carp (Carpiodes carpio) were captured in the Rio Grande using a 5.0-kilowatt generator-powered pulsator electroshock device mounted on an SR-17 Cataraft research vessel. All fish kept for analysis were mature adults. Of the 15 catfish, 10 were caught in the Rio Grande from approximately $1 \mathrm{~km}$ upriver from the Otowi Bridge to the point where the Pojoaque River meets the Rio Grande (Fig. 2). This location is referred to as upstream from LANL. Of the eight carp, four were captured at the upstream locations. The remaining five catfish and four carp were captured downstream of the Otowi Bridge, between the confluence of Capulin Canyon and the inlet to Cochiti Reservoir (Fig. 2). This location is referred to as downstream from LANL. The fish were filleted (leaving the skin on) and frozen, and the fillets were submitted for analysis. Fillet samples were homogenized and analyzed for 209 possible congeners of PCBs using EPA Method 1668-high-resolution gas chromatography and high-resolution mass spectrometry. Reporting limits (the level above which the level of an analyte can be quantified with confidence) ranged from $0.005-0.04 \mathrm{ng} / \mathrm{g}$ (parts per billion [ppb]). Data were validated following the guidelines recommended by the U.S. Environmental Protection Agency (USEPA 1999).

To assess the possible contribution by LANL to PCBs in fish, we made statistical comparisons of the results from downstream samples to upstream samples. To obtain information about the dominant PCBs absorbed and stored by the fish, we summed congener concentrations into PCB homologues and compared homologue concentration patterns to homologue patterns of brandname formulations. Fish and other biota selectively store the higher chlorinated PCB congeners more than lower chlorinated congeners and degrade other congeners making them subject to elimination from the body. Thus, biota skew the original Aroclor homologue patterns, or "fingerprints," such that the makeup of a PCB mixture in a fish is different than the pattern that they ingested (Sather et al. 2001).

To assess the toxicity of PCBs, we summed the total PCB congener concentrations, calculated dioxin-like PCBs, and computed Aroclor equivalents, all three of which were compared to various human health benchmarks or protective limits. We also computed TEQs. Some structurally related aromatic hydrocarbons, such as the 12 dioxin-like PCBs and dioxins, invoke a number of common toxic responses. The relative toxicity or potency of the 12 dioxin-like PCBs compared with the toxicity of tetrachlorodibenzodioxin (TCDD) is known. On this basis, the World Health Organization has developed TCDD equivalency factors (TEFs) for the 12 congeners and a method by which their toxicity can be assessed. To evaluate the dioxin-like toxicity that PCBs can cause, the concentration of each congener in the tissue was multiplied by a TEF (Van den Berg et al. 1998), and the 12 resulting values were summed, resulting in a total TEQ. The TEQ can then be used in a number of ways such as comparison with a screening value or other benchmarks for TCDD. The 12 dioxin-like PCB congeners are PCB No. 77 (3,3',4,4'TeCB), 81 (3,4,4',5-TeCB), 105 (2,3,3',4,4'-PeCB), 114 (2,3,4,4',5-PeCB), 118 (2,3',4,4',5PeCB), 123 (2',3,4,4',5-PeCB), 126 (3,3',4,4',5-PeCB), 156 (2,3,3',4,4',5-HxCB), 157 (2,3,3',4,4',5'-HxCB), 167 (2,3',4,4',5,5'-HxCB), 169 (3,3',4,4',5,5'-HxCB), and 189 


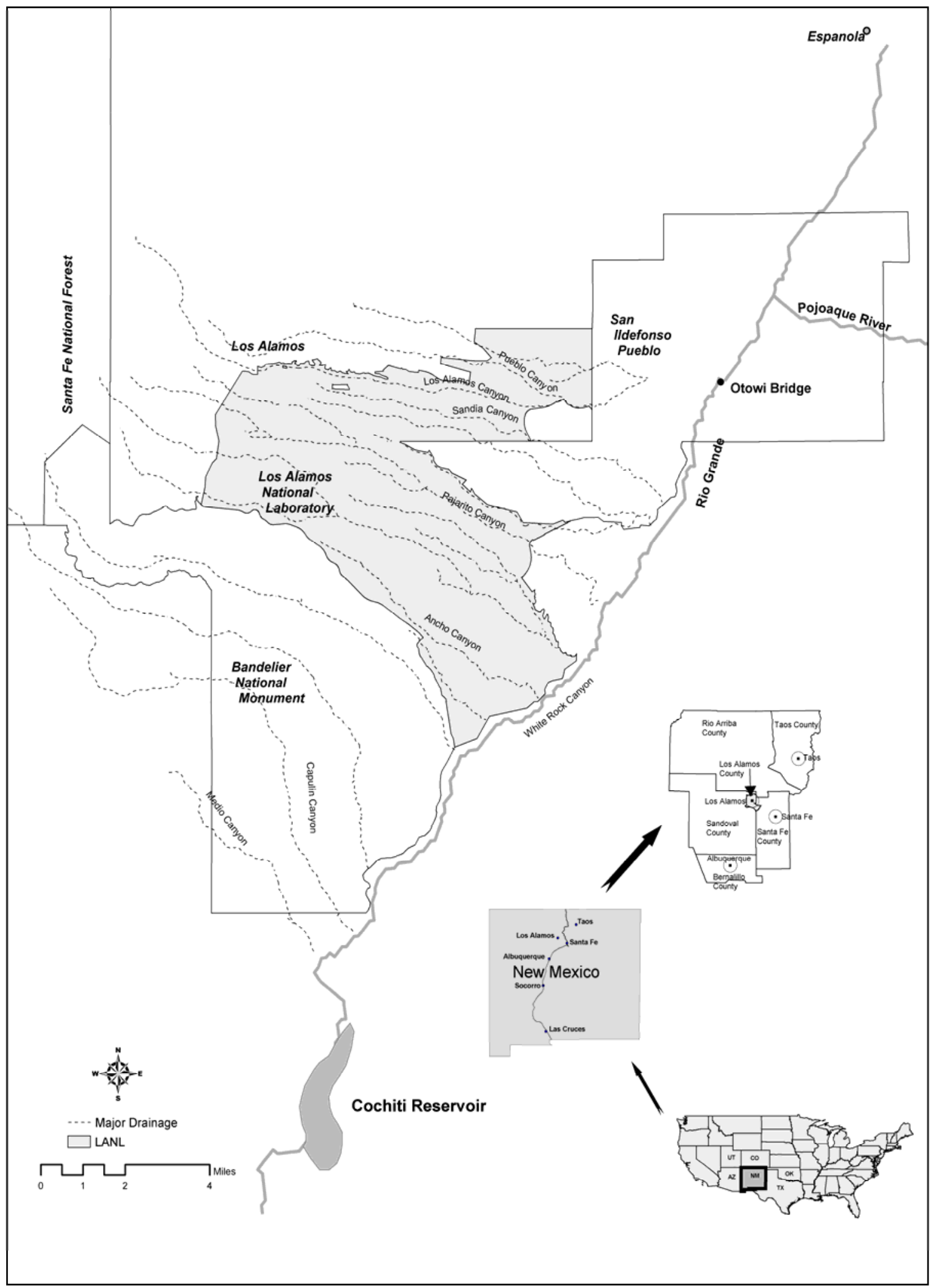

Figure 2. Locations of fish sampling along the Rio Grande and Rio Chama. 
(2,3,3',4,4',5,5'-HpCB). TEQs from dioxins and other dioxin-like chemicals should also be added to PCB-based TEQs; however, we have been previously shown the TEQ contribution from dioxins and furans to be negligible, adding a maximum of $8.7 \mathrm{E}-07 \mathrm{pg} / \mathrm{g}$ to the total TEQ (Fresquez et al. 2002).

To assess trend, or change in PCB levels over time, we estimated Aroclor-equivalent concentrations from congener data and compared to our 1997 study of Aroclors in fish from the Rio Grande (Gonzales et al. 1999). We also estimated Aroclor-equivalent concentrations for fish captured at Cochiti Reservoir in 2000 and 2001. We estimated Aroclor-equivalent concentrations in the fish samples using the following equations (Axys 1999):

Aroclor $1242=\Sigma \mathrm{PCB}_{8,18,31,28} \times 3.8$,

Aroclor $1254=\Sigma \mathrm{PCB}_{87,97,99} \times 15$,

Aroclor $1260=\Sigma \mathrm{PCB}_{183,180,170} \times 7.1$, and

Aroclor $1248=\Sigma \mathrm{PCB}_{66,44,49} \times 5.5$.

Other studies have shown a strong correlation between total PCBs from Aroclors and the total PCBs from congeners (Sather et al. 2001). Where data from previous studies were in units of PCB congener concentrations for whole-body fish (including tissue that is not normally eaten), we first estimated congener concentrations in edible tissue (fillets) and then converted to Aroclor-equivalent concentrations as described above. Fresquez et al. (2002) compared PCB concentration ratios in edible (fillet) with nonedible (viscera [gills, gut, and organs] and carcass [bone, head, tail, and fins]) partitions of catfish and found that nonedible fish tissue contains about $75 \%$ of the whole-body total PCB concentration and skin-on fillet contains about $25 \%$ of the PCBs. This compares to the range in concentration of 0.026 to $97 \mathrm{ng} / \mathrm{g}$-dry measured by Meijer et al. (2002) in soils at the 0 to 5-cm depth in a worldwide study of PCBs in background surface soils.

\section{Results}

Regional Soils. Summary data on total PCBs for the nine soil samples and one duplicate sample are shown in Table 3. Appendix 1 presents all of the soils data. Mean total PCBs for the nine samples was $0.047 \mathrm{ng} / \mathrm{g}$-ww (0.045 ng/g-dry), with a standard deviation of $0.080 \mathrm{ng} / \mathrm{g}$-ww, a detected minimum of $0.0050 \mathrm{ng} / \mathrm{g}-\mathrm{ww}$, and a maximum (Sample ID "Rio Grande/San Cristobal to Pilar") of $0.25 \mathrm{ng} / \mathrm{g}$-ww. Concentrations per unit dry weight (dw) are also reported. One duplicate sample yielded good precision. The Rio Chama mean (0.018 ng/g-ww) total PCB concentration in soils was not statistically different $(P=0.37)$ from the Rio Grande mean $(0.070$ ng/g-ww). No dioxin-like PCBs were detected in the soil samples and the sample nearest LANL ("Rio Grande/Otowi Bridge to Cochiti") contained the lowest total PCB concentration.

PCB homologue totals for the nine soil samples are also shown in Table 3. The PCB distribution is dominated by low- (mostly tri-CBs) and high-chlorinated (mostly hexa-CB) PCBs. The low-chlorinated CBs are most subject to volatilization/suspension into air and atmospheric transport.

In Figure 3 we compare the PCB homologue distribution in the nine soils to the typical composition of commercial PCB mixtures. The homologue plots are complex, but several of the soil samples might be dominated by Aroclor 1260 and weathered PCB mixtures, possibly 


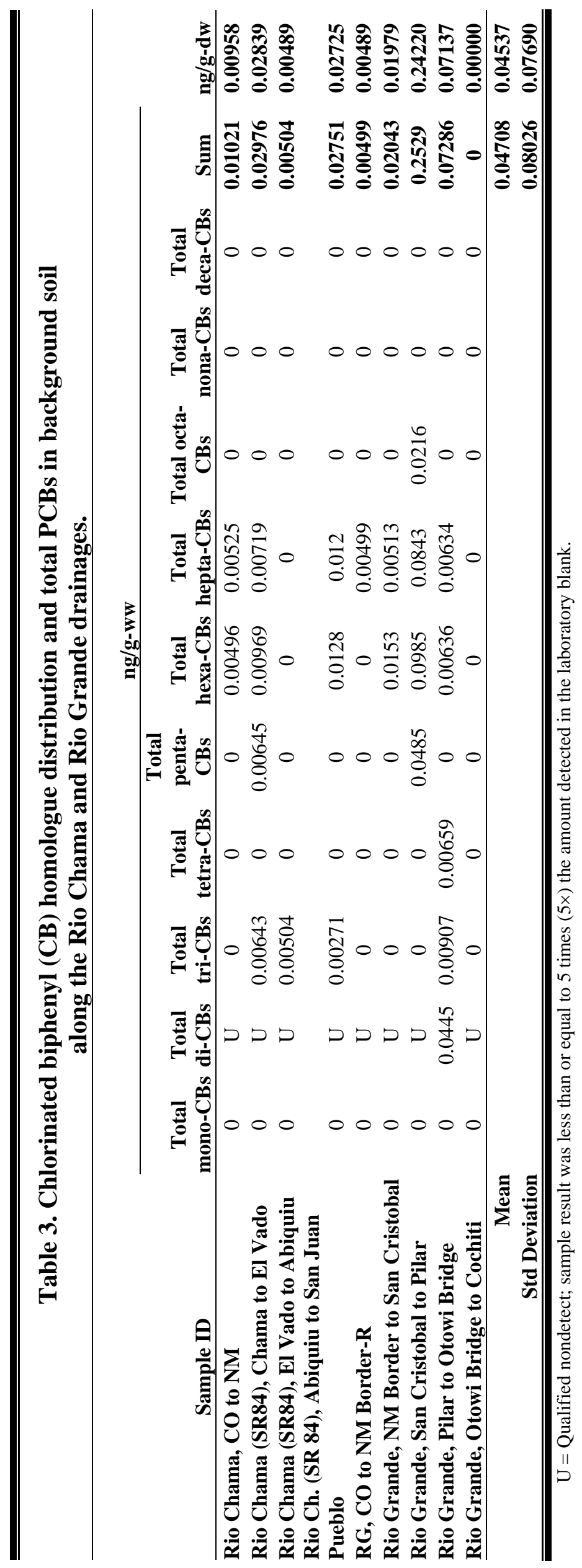



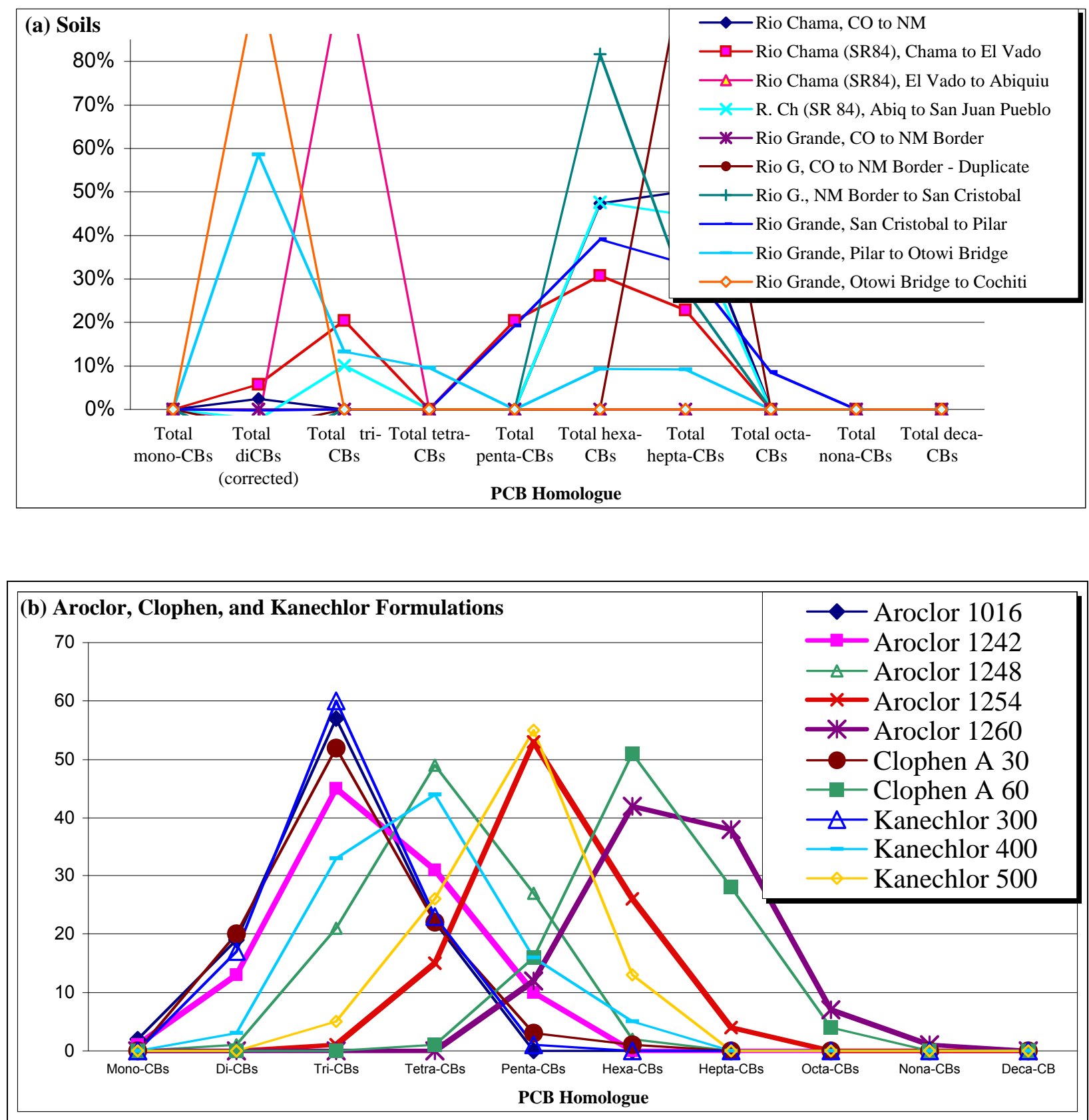

Figure 3. PCB homologue distribution in (a) nine soil samples and (b) typical brand-name formulations. 
Aroclors 1242 and 1016. When we estimate Aroclor-equivalent concentrations in soil from congeners, Aroclor 1260 was dominant in terms of the number of samples (six out of nine) that had congener(s) tracking to that particular type of Aroclor; however, again it is important to note that the distribution of PCB congeners in Aroclors can be altered considerably by physical, chemical, and biological processes. Aroclor 1242 was next most common, estimated to be present in four of nine samples; Aroclor 1254 had one of nine, and none of the congeners that make up Aroclor 1248 were detected. Thus, our interpretation on the class of PCB mixture based on homologue distribution appears to be supported by the Aroclor-equivalent concentration estimation. Note that between 1957 and 1977, production of PCBs in the U.S. was dominated by Aroclor 1242 (see Table 2) (USEPA 1996). Clophens and Kanechlors are PCB mixtures manufactured in Germany and Japan, respectively, and were used very little in the U.S.

Total PCBs in Fish. A summary of the results for fish is in Table 4 and detailed results are tabulated in the Appendix 2. The upstream mean $(n=5)$ total PCB concentration in catfish was 2.80E-02 $\mu \mathrm{g} / \mathrm{g}-\mathrm{ww}(\mathrm{ppm})$, and the downstream mean $(\mathrm{n}=10)$ was $1.50 \mathrm{E}-02 \mu \mathrm{g} / \mathrm{g}-\mathrm{ww}$. The upstream mean total PCB concentration was $86 \%$ higher than the downstream mean, and the difference was statistically significant $(P=0.047)$. Similarly, the mean total PCB concentration for carp collected downstream of LANL was 3.07E-02 $\mu \mathrm{g} / \mathrm{g}-\mathrm{ww}$ and was slightly lower than the upstream mean of $7.98 \mathrm{E}-02 \mu \mathrm{g} / \mathrm{g}-\mathrm{ww}$; the difference was not statistically significant $(\mathrm{P}=0.21)$, however.

Potential Consumption Restrictions. Catfish results were compared to EPA guidance on restricting the consumption of fish based on measured PCB concentrations. On the basis of the guidance (USEPA 2000), all data types (mean total PCB concentrations, Aroclor 1254 equivalents, and dioxin TEQs) would result in fish consumption restrictions for both sample sets (upstream and downstream) of fish. The TEQ concentration at or below which no consumption restrictions would be recommended is $0.019 \mathrm{pg} / \mathrm{g}-\mathrm{FW}$ (ppt); the Aroclor 1254 concentration at or below which no consumption restriction would be recommended neither on a cancer nor noncancer basis is $0.0015 \mu \mathrm{g} / \mathrm{g}-\mathrm{FW}$. The most limiting of the three data types are the TEQs, which are shown in Table 4. The mean total TEQ of $1.55 \mathrm{pg} / \mathrm{g}$ for catfish upstream of LANL would limit the consumption to $<0.5$ meals per month, and the downstream mean total TEQ of $0.29 \mathrm{pg} / \mathrm{g}$ for catfish would limit the consumption of those fish to two meals per month. The limiting EPA values are on the basis of cancer health endpoints and have several conservatisms (factors, assumptions, or values that result in higher risk estimates than would occur in reality) built in that provide extra protection of human health. TEQs from dioxins and furans have been previously shown to be very insubstantial, adding a maximum of $8.7 \mathrm{E}-07 \mathrm{pg} / \mathrm{g}$ (Fresquez et al. 2002). TEQs for carp were computed but we did not calculate consumption restrictions because people rarely eat carp due to their high bone and fat content and their low palatability. Consumption limits of carp on the basis of noncancer health endpoints would be less restrictive than for catfish.

Homologues as Indicators of Aroclor Sources. Summed PCB homologues for each fish sample were compared to homologue patterns of brand-name formulations in an attempt to gain information about the dominant PCB absorbed and stored by the catfish. Plots of the measured homologue concentrations (as percentage of total) and of various Aroclor-brand PCB mixtures are shown in Figure 4. Accumulation of PCBs by both the downstream and upstream fish would appear to have been dominated by Aroclor 1260 because the peak in homologue distribution is at 
Table 4. Total PCB concentrations and TEQs in fillets of (a) catfish and (b) carp collected from the Rio Grande in May 2002. Values are based on full congener determinations.

(a) Catfish

\begin{tabular}{|c|c|c|c|c|c|}
\hline \multicolumn{3}{|c|}{ Downstream of LANL } & \multicolumn{3}{|c|}{ Upstream of LANL } \\
\hline Sample ID & $\begin{array}{c}\text { Concentration } \\
(\mu g / g-w w)\end{array}$ & $\begin{array}{c}\text { TEQ } \\
\text { (pg/g) }\end{array}$ & Sample ID & $\begin{array}{c}\text { Concentration } \\
(\mu g / g-w w)\end{array}$ & $\begin{array}{l}\text { TEQ } \\
\text { (pg/g) }\end{array}$ \\
\hline \#1 САТСАР (A) & 4.54E-02 & 0.97 & \#8 CATREF (A) & 3.04E-02 & 1.89 \\
\hline \#2 САТСАР (A) & $0.991 \mathrm{E}-02$ & 0.19 & \#18 CATREF (A) & 1.36E-02 & 0.26 \\
\hline \#3 CATMED (A) & $1.14 \mathrm{E}-02$ & 0.22 & \#19 CATREF (A) & 3.75E-02 & 1.90 \\
\hline \#4 CATMED & $0.967 \mathrm{E}-02$ & 0.14 & \#10 CATREF (A) & 3.04E-02 & 1.69 \\
\hline \#5 CATMED & $0.850 \mathrm{E}-02$ & 0.12 & \#21 CATREF (A) & 2.79E-02 & 2.01 \\
\hline \# 6 CATMED (A) & $0.986 \mathrm{E}-02$ & 0.15 & & & \\
\hline \# 7 CATMED (A) & 2.06E-02 & 0.57 & & & \\
\hline \# 8 CATMED (A) & $1.82 \mathrm{E}-02$ & 0.33 & & & \\
\hline \#18 CATSED & 0.985E-02 & 0.08 & & & \\
\hline \#12 CATSED & $0.679 \mathrm{E}-02$ & 0.15 & & & \\
\hline Mean & $1.50 \mathrm{E}-02$ & 0.29 & & $2.80 \mathrm{E}-02$ & 1.55 \\
\hline Std Deviation & 1.09E-02 & & & $0.788 \mathrm{E}-02$ & \\
\hline
\end{tabular}
(b) Carp

\begin{tabular}{lcclcc}
\multicolumn{2}{c}{ Downstream of LANL } & & \multicolumn{3}{c}{ Upstream of LANL } \\
\hline Sample ID & $\begin{array}{c}\text { Concentration } \\
\mathbf{( \mu g / g - w w )}\end{array}$ & $\begin{array}{c}\text { TEQ } \\
\mathbf{( p g / g )}\end{array}$ & Sample ID & $\begin{array}{c}\text { Concentration } \\
\mathbf{( \mu g / g}-\mathbf{w w})\end{array}$ & $\begin{array}{c}\text { TEQ } \\
\mathbf{( p g / g})\end{array}$ \\
RGTRTCARP1 & $2.02 \mathrm{E}-02$ & 2.88 & RGSI 1C & $3.44 \mathrm{E}-02$ & 0.410 \\
RGTRTCARP2 & $8.66 \mathrm{E}-02$ & 9.80 & RGSI 2C & $3.14 \mathrm{E}-02$ & 0.375 \\
RGTRTCARP3 & $1.34 \mathrm{E}-02$ & 1.40 & RGSI 3C & $1.05 \mathrm{E}-02$ & 0.170 \\
RGTRTCARP4 & $1.73 \mathrm{E}-02$ & 1.56 & RGSI 4C & $2.43 \mathrm{E}-01$ & 9.640 \\
\hline & $3.52 \mathrm{E}-02$ & 3.91 & Mean & $7.98 \mathrm{E}-02$ & 2.65 \\
& $3.93 \mathrm{E}-02$ & & Std Deviation & $1.09 \mathrm{E}-01$ & \\
\hline \hline
\end{tabular}

Note: PCB concentration at which no consumption limits would be recommended on either a cancer or noncancer health endpoint basis is $0.0015 \mu \mathrm{g} / \mathrm{g}$. Dioxin TEQ concentration at which no consumption limits would be recommended on a cancer health endpoint basis is $0.019 \mathrm{pg} / \mathrm{g}$. Also note that full dose and risk assessments are recommended before considering advisories of any type. 

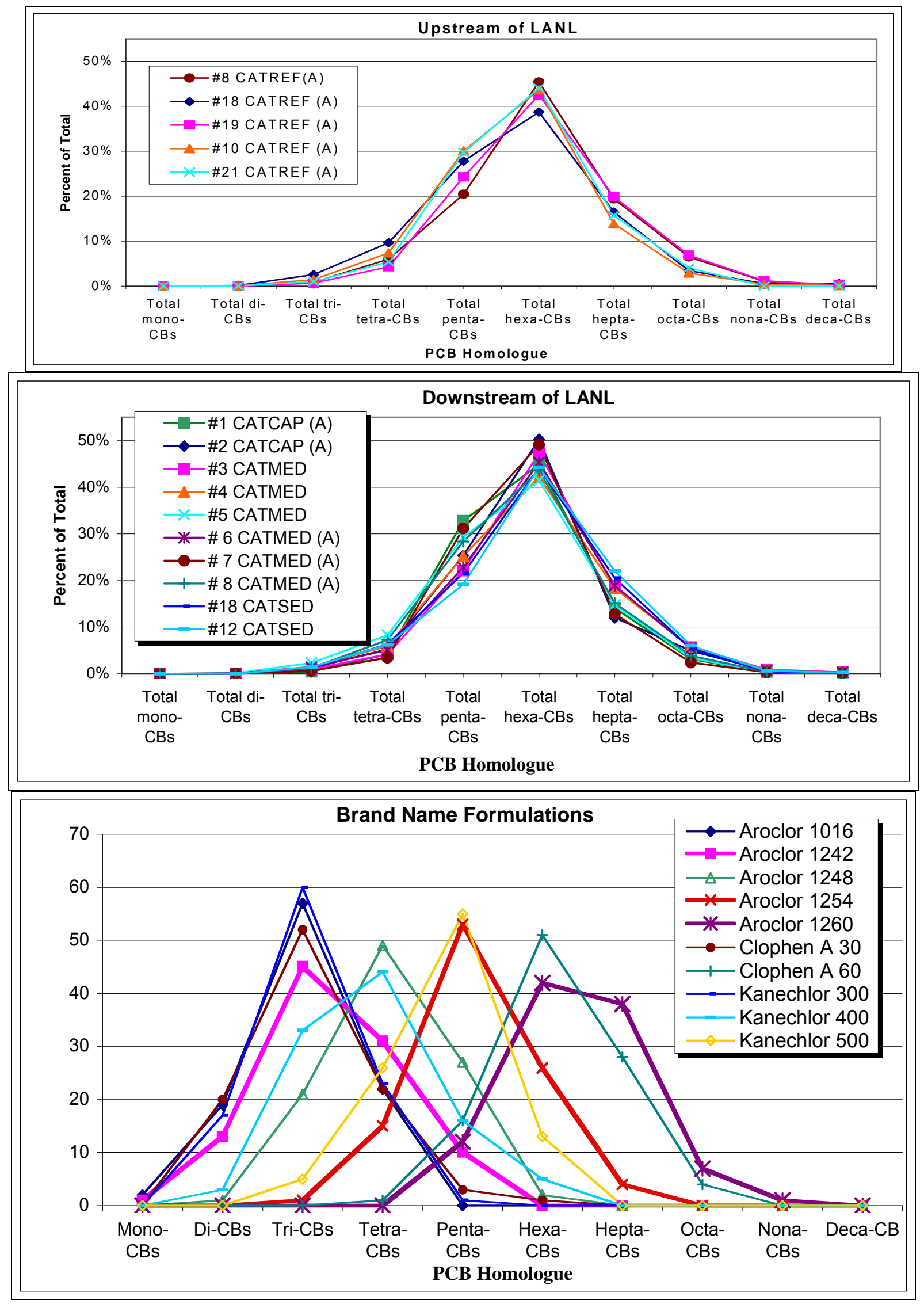

Figure 4. Percentages of PCB homologue concentrations in catfish sampled upstream of LANL, catfish sampled downstream of LANL, and in name-brand formulations of PCB mixtures. 
the hexa-CBs. The distribution of PCB congeners in Aroclor mixtures can be altered considerably by biological processes; however, this effect is greater in animals of higher trophic levels. For animals of lower trophic level, there is a strong correlation between the sum of Aroclors and the total PCBs obtained from full congener determinations (Sather et al. 2001). Examples of lower trophic level animals include sturgeon. Catfish would also be considered lower trophic level as compared to predatory fish.

Table 5 shows the Aroclor-equivalent concentrations estimated from congeners measured in catfish. In Aroclor analyses performed in 1997 on carp, catfish, and carp sucker (Gonzales et al. 1999) from four sampling locations downstream from Otowi Bridge, Aroclor 1254 was detected in seven out of 15 fish and Aroclor 1260 was detected in only one out of 15 fish, but detection limits were high (0.03-0.22 $\mu \mathrm{g} / \mathrm{g}$ or $\mathrm{ppm})$ and fish can differentially partition congeners that make up Aroclors. At one sampling location upstream from Otowi Bridge, Aroclor 1254 was detected in one out of three fish and Aroclor 1260 was not detected, again using high detection limits in the analytical method.

Trend in Aroclor Concentrations Over Time. Figure 5 compares our congener-based Aroclor estimates for fish collected in 2002 with measured Aroclor concentrations in fish collected in 1997 and to estimated Aroclors in fish collected from Cochiti Reservoir in 2000 and 2001. Aroclor 1254 and 1260 concentrations are lower by about a factor of 10 from 1997 to 2002; however, the comparison is crude because of high detection limits for the 1997 Aroclor analyses. As in 1997, our 2002 carp had higher mean concentrations of PCBs than catfish. Ignoring differences in fish species, Aroclor and total PCB concentrations in fish from Cochiti Reservoir in 2001 are slightly higher compared with 2000. Aroclor 1254 in Rio Grande fish (2002) is higher than in reservoir fish (2000 and 2001), and Aroclor 1260 concentrations in Rio Grande fish (2002) are lower than in previous years.

\section{Discussion}

We sampled soils along the Rio Chama and Rio Grande drainages to discern whether a background atmospheric source of PCBs into bodies of water adjacent to LANL might exist. The distribution of homologues was distinctly bimodal with peaks at the tri-CB homologues and the hexa-CB homologues. Low-chlorinated PCBs typically volatilize, enter atmospheric macroscale wind patterns, and then are deposited with precipitation to land surfaces or bodies of water. This atmospheric deposition was the likely source of the low-chlorinated PCBs in soil that we measured. High-chlorinated PCBs can become entrained in suspended dust and other particulates and then deposited by eolian transport at more localized distances from the original source. The high-chlorinated PCBs that we measured in soils were most likely of eolian origin rather than from local sources because soil sample locations were chosen to avoid localized surface sources such as runoff. Also, there is strong evidence based on stratigraphy that the origin of soils on mesa tops, at least in the Pajarito Plateau, is from eolian transport and atmospheric deposition (Reneau et al. 1995, 1996).

Comparison of upstream fish to downstream fish had similar results in that, when means were compared, upstream catfish and carp contained higher mean PCB concentrations than downstream catfish and carp. Our years of data provide evidence that contributions of PCBs into 


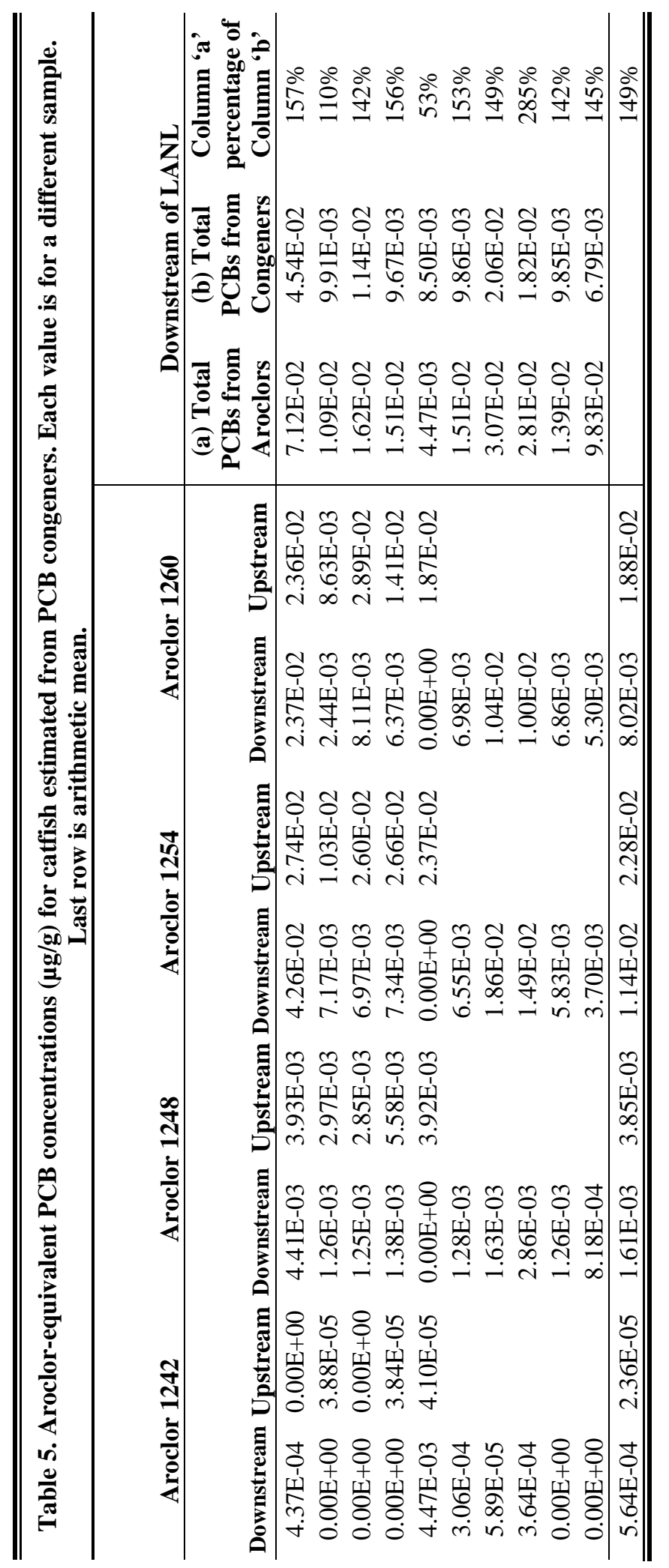




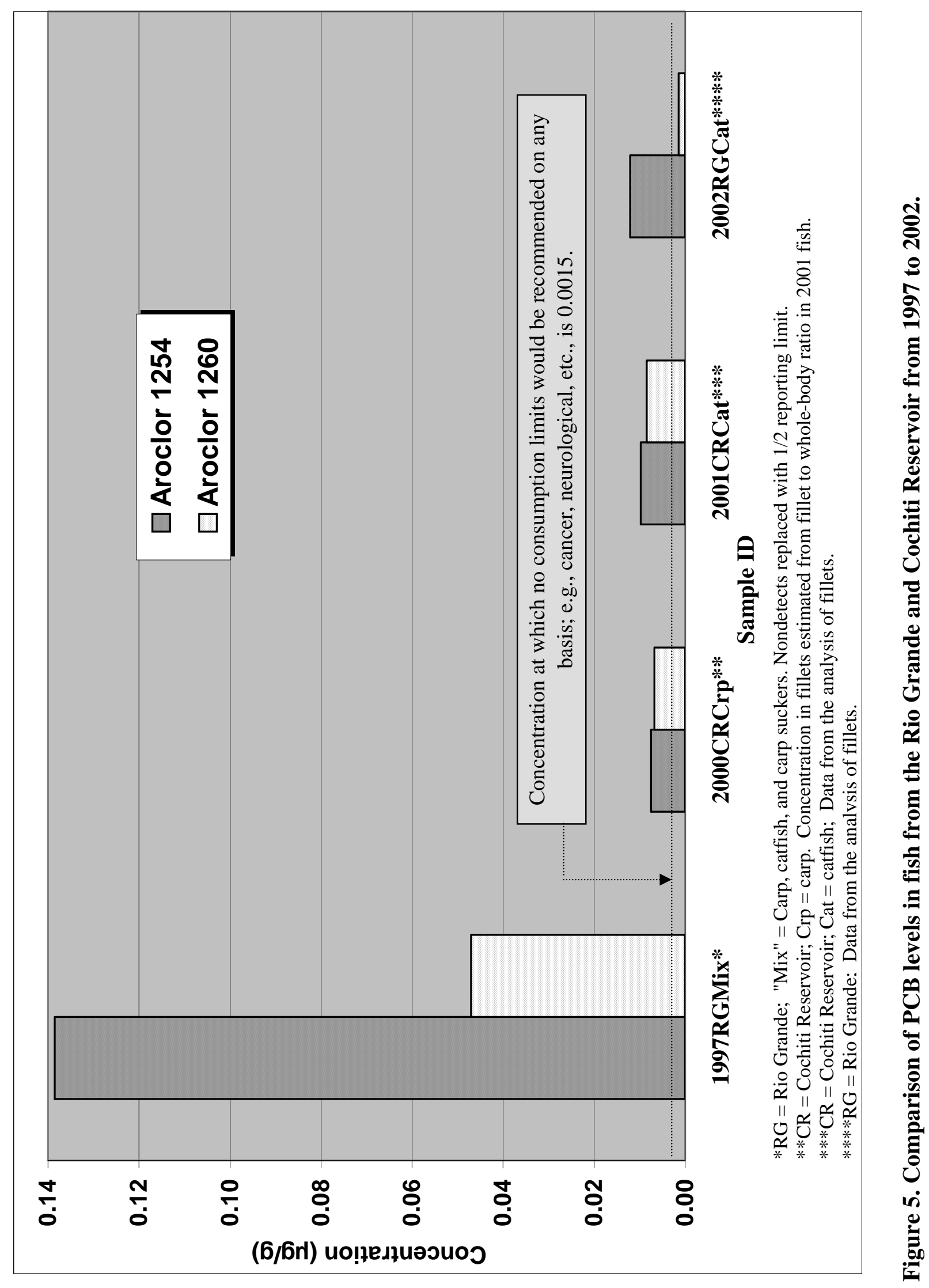


the Rio Grande have occurred upstream of LANL from non-LANL sources. LANL is an industrial site with facilities intermingled with conifer forest across $43 \mathrm{mi}^{2}$, and many uses of PCB-containing devices and other applications have occurred similar to other industrial sites across the U.S. There are over 100 solid waste management units at the Laboratory that contain PCB concentrations in excess of a $\mathrm{mg} / \mathrm{kg}$ and they could have been sources of PCBs into canyons; however, only one canyon (Sandia) that cuts through the $43 \mathrm{mi}^{2}$ of DOE/LANL property has a consistent flow of water-an effluent-supported base flow. None of the canyon drainages consistently flow into the Rio Grande as they are mostly dominated by periodic or ephemeral flow from storm water runoff.

Aroclor 1260 has been identified in Sandia Canyon, and several Aroclors have been detected and quantified in different species and classes of biota sampled from LANL (Gonzales et al. 2000, Gonzales and Podolsky, in preparation). If fish from both upstream and downstream of LANL contain Aroclor 1260, then LANL (at least Sandia Canyon) is not the only source of PCBs to Cochiti fish. Other studies centered on this issue of source contributions are currently underway and involve the sampling of surface water, sediment, and strategically placed semipermeable membrane devices (Mullen et al. 2002). Preliminary analyses of a limited number of water samples to date in the same general areas of the fish sampling do not appear to contain Aroclor 1260 (Mullen and Koch 2002), which differ from our results on fish. However we acknowledge that PCB source determination based on analysis of chlorohomologue distribution specifically in biota can be misleading because of their enrichment and exclusion of certain PCBs.

The objectives of our study were to (1) gather information that will contribute, in part, to answering the question of LANL's contribution, if any, to PCB loads in bodies of water that are in the direct sphere of potential direct influence by LANL, (2) continue to satisfy our federally mandated monitoring requirements, including the estimation of whether the Cerro Grande Fire had impacts to natural resources as related to legacy contamination at LANL, and (3) implicate the potential risk to humans from PCBs in fish so that we continue to evaluate the dominant risk concern (human risk versus ecological risk) in structuring our Environmental Surveillance Program. Regarding implications about the risk of consuming catfish from the Rio Grande, we have not conducted a dose-response assessment nor risk assessment. The EPA consumption advisory tables were consulted simply to infer whether more-complete assessments might be needed and as information that would help in our continued evaluation of where we place emphasis within our Environmental Surveillance Program. There are several conservatisms in the EPA guidance on this subject and in how we used the guidance that would tend to overestimate the risk. First, the effects of PCB exposure in humans are less clear than the effects to animals on which the consumption limit tables are based (USEPA 2000). To account for this uncertainty, the EPA applies an uncertainty factor to the chronic exposure limits that the consumption limits are derived from and, in effect, this lowers the consumption limits making them more protective of human health. Uncertainty factors are also applied for the inability of any study to consider all toxic endpoints, for extrapolating results of low effects toxicity values to no effects toxicity values, and for variability of response from one human to another (e.g., the limits are based on responses of the most vulnerable age groups such as children and fetuses). Lastly, although the exposure dose on which the consumption limits are based for PCBs was based on the toxicity of Aroclor 1254, total PCBs are often compared to the limits. For a full discussion of uncertainty in risk assessment and the application of uncertainty factors the reader is referred to Chapters 2, 3, and 5 in Volume 2 of the EPA guidance (USEPA 2000). 
Total PCBs from the sum of estimated Aroclors agreed well with the total PCBs from the full congener determinations. For the downstream catfish totals, the mean total PCBs from Aroclors was $149 \%$ of the mean total PCBs from congeners. This supports the finding that for low trophic level organisms, there is usually a strong correlation between the sum of Aroclors and the total PCBs obtained from full congener determinations (Sather et al. 2001).

\section{Conclusions}

PCB concentrations in fish in the Rio Grande in 2002 were lower than in 1997, however, differences in analytical methods and other uncertainties exist in generating the data that were compared. Comparison of historical PCB data at LANL and the more recent PCB congener data as well as analyses of PCB homologue data do not indicate a distinct contribution of PCBs from LANL to fish in the Rio Grande. PCB homologue distributions in soil along the upstream areas of the Rio Chama and Rio Grande suggest that PCBs appear to be from background global atmospheric sources, at least in part, because the presence of low-chlorinated PCBs is typical of atmospheric congener distributions. The soil samples also had congener distributions that are typically associated with eolian transport and deposition of global atmospheric dust. The dominant PCB homologue in all fish samples was hexa-CBs; low-chlorinated PCB congeners were not detected in fish fillets, most likely because low-chlorinated PCBs are typically metabolized and excreted by biota. Regardless of the source, the concentrations of PCBs in fillets of fish sampled from the Rio Grande indicate the potential for adverse chronic health impact from consuming these fish on a long-term basis.

\section{Acknowledgments}

Partial funding for this study was from the Cerro Grande Recovery Project, Steve Mee, Program Manager. Carey Bare of LANL's Ecology Group provided guidance in the integration of the study with the Biological Resources Management Plan. Keith Greene of the Environmental Restoration Project validated the data. Ken Mullen and Richard Koch of the Water Quality and Hydrology Group provided critical reviews and are coordinating integration of the data with the PCB Cooperative Study. Thanks to Ralph Ford-Schmid of the New Mexico Environment Department for reviewing the report. Rick Velasquez, Louis Naranjo, Patrick Valerio, Jennifer Montoya, and Guillermo Vigil of the Ecology Group operated the research vessel on the Rio Grande and conducted electroshocking and sampling operations.

\section{Literature Cited}

ATSDR (Agency for Toxic Substances and Disease Registry). 1993. Toxicological Profile for Polychlorinated Biphenyls. Atlanta: ATSDR report TP-92/16, update.

ATSDR (Agency for Toxic Substances and Disease Registry). 2000. Toxicological Profile for Polychlorinated Biphenyls (PCBs). Prepared by Syracuse Research Corporation for the U.S. Department of Health and Human Services, Public Health Service. Available on the Internet at http://www.atsdr.cdc.gov/toxprofiles/tp17.html.

Axys (Axys Analytical Services, Ltd.). 1999. Statement of Qualifications to Conduct Organic Analyses. Sidney, British Columbia, Canada (April).

Callahan, M.A., M.W. Slimak, N.W. Gabel, I.P. May, C.F. Fowler, J.R. Freed, P. Jennings, R.L. Durfee, F.C. Whitmore, B. Maestri, W.R. Mabey, B.R. Holt, and C. Gould. 1979. Water- 
related Environmental Fate of 129 Priority Pollutants, Vol. I, Ch. 36. U.S. Environmental Protection Agency report EPA-440/4-79-029a, Washington, D.C.

Carter, L.F. 1997. Water-Quality Assessment of the Rio Grande Valley, Colorado, New Mexico, and Texas: Organic Compounds and Trace Elements in Bed Sediment and Fish Tissue, 1992-93. U.S. Geological Survey Water Resources Investigations report 97-4002, Albuquerque, NM.

Eisler R. 1986. Polychlorinated Biphenyl Hazards to Fish, Wildlife, and Invertebrates: A Synoptic Review. U.S. Fish and Wildlife Service biological report 85(1.7):72.

Fresquez, P.R. and G.J. Gonzales. 2000. Soil, Foodstuffs, and Associated Biota, pp. 309-360, in Environmental Surveillance at Los Alamos during 1999. Los Alamos National Laboratory report LA-13777-ENV, Los Alamos, NM.

Fresquez, P., G. Gonzales, T. Haarmann, J. Nyhan, and B. Gallaher. 2001. Soil, Foodstuffs, and Associated Biota, pp. 407-489, in Environmental Surveillance at Los Alamos during 2000. Los Alamos National Laboratory report LA-13861-ENV, Los Alamos, NM.

Fresquez, P., G. Gonzales, J. Nyhan, T. Haarmann, L. Soholt, and B. Gallaher. 2002. Soil, Foodstuffs, and Associated Biota, pp. 421-521, in Environmental Surveillance at Los Alamos during 2001. Los Alamos National Laboratory report LA-13979-ENV, Los Alamos, NM.

Gonzales, G.J., P.R. Fresquez, and J.W. Beveridge. 1999. Organic Contaminant Levels in Three Fish Species Downchannel from the Los Alamos National Laboratory. Los Alamos National Laboratory report LA-13612-MS, Los Alamos, NM.

Gonzales, G., C. Bare, K. Bennett, T. Haarmann, L. Hansen, C. Hathcock, D. Keller, S. Loftin, and R. Ryti. 2000. Organic Biocontaminants in Food Chains at Two Canyons at the Los Alamos National Laboratory. Los Alamos National Laboratory report LA-CP-01-33, Los Alamos, NM.

Gonzales, G. and C. Bare. 2001. Three-Year Cerro Grande Fire Biocontaminant Monitoring Plan for the Los Alamos National Laboratory. Los Alamos National Laboratory report LA-UR01-672, Los Alamos, NM.

Gonzales, G.J. and J. Podolsky. In preparation. Organic and Metal Contaminants in a Food Chain of the American Peregrine Falcon (Falco peregrinus) at the Los Alamos National Laboratory. Ecology Group, Los Alamos National Laboratory.

Meijer, S.N., W.A. Ockenden, A.J. Sweetman, K. Breivik, J.O. Grimalt, and K.C. Jones. 2002. Global Distribution and Budget of PCBs in Background Soils: Implications for Sources and Environmental Processes. Twenty-third Annual Meeting of the Society of Environmental Toxicology and Chemistry, November 16-20, 2002, Salt Lake City, UT.

Mullen, K. and R. Koch. 2002. Personal communication, e-mail from Richard Koch (Science Applications International Corporation) to Ken Mullen (LANL/RRES-WQH) and Gil Gonzales (LANL/RRES-ECO), "PCB Congener - preliminary results," dated Sept. 16, 2002. 
Mullen, K., R. Koch, G. Gonzales, R. Ford-Schmid, and P. Fresquez. 2002. PCB Congener Sampling Plan. Los Alamos National Laboratory report LA-UR-02-6409, Northern New Mexico PCB Cooperative Group (July 2002).

Reneau, S.L., E.V. McDonald, J.N. Gardner, T.R. Kolbe, J.S. Carney, P.M. Watt, and P.A. Longmire. 1996. Erosion and Deposition on the Pajarito Plateau, New Mexico, and Implications for Geomorphic Responses to Late Quaternary Climatic Changes, in Goff, F., Kues, B. S., Rogers, M. A., McFadden, L. D., and Gardner, J. N., (eds.). The Jemez Mountains Region: New Mexico Geological Society Forty-Seventh Annual Field Conference Guidebook, p. 391-397.

Reneau, S.L., T. Kolbe, D. Simpson, J.S. Carney, J.N. Gardner, S.S. Olig, and D.T. Vaniman. 1995. Surficial Materials and Structure at Pajarito Mesa, in Reneau, S.L., and Raymond, R., Jr., editors, Geological Site Characterization for the Proposed Mixed Waste Disposal Facility, Los Alamos National Laboratory. Los Alamos National Laboratory report LA13089-MS, Los Alamos, NM, p. 31-69.

Roy, R., T.F. O’Brien, and M. Rusk-Maghini. 1992. Organochlorine and Trace Element Contaminant Investigation of the Rio Grande, New Mexico. U.S. Dept. of the Interior, Fish and Wildlife Service, New Mexico Field Office, Albuquerque, NM.

Sather, P.J., M.G. Ikonomou, R.F. Addison, T. He, P.S. Ross, and B. Fowler. 2001. Similarity of an Aroclor-Based and a Full Congener-Based Method in Determining Total PCBs and A Modeling Approach to Estimate Aroclor Speciation from Congener-Specific PCB Data. Environ. Sci. Technol. 35:4874-4880.

Schmitt, C.J., J.L. Zajicek, and P.H. Peterson. 1990. National Contaminant Biomonitoring Program - Residues of Organochlorine Chemicals in U.S. Freshwater Fish, 1976-1984. Archives of Environ. Contam. Toxicol. 19, 748-781.

Stoker, H.S. and S.L. Seager. 1976. Environmental Chemistry: Air and Water Pollution. Scott, Foresman, and Co., Glenview, IL.

USDOE (U.S. Department of Energy). 1991. Environmental Regulatory Guide for Radiological Effluent Monitoring and Environmental Surveillance. U.S. Department of Energy report DOE/EH-0173T.

USEPA (U.S. Environmental Protection Agency). 1996. PCBs: Cancer Dose-Response Assessment and Application to Environmental Mixtures. National Center for Environmental Assessment, Office of Research and Development report EPA/600/P-96/001F, Washington, D.C.

USEPA (U.S. Environmental Protection Agency). 1999. USEPA Contract Laboratory Program National Functional Guidelines for Organic Data Review, OSWER 9240.1-05 A-P (October 1999).

USEPA (U.S. Environmental Protection Agency). 2000. Guidance for Assessing Chemical Contaminant Data for Use in Fish Advisories, Vol. 2: Risk Assessment and Fish Consumption Limits, $3^{\text {rd }}$ Ed., EPA 823-B-00-008.

USEPA (U.S. Environmental Protection Agency). 2002. PCB Programs, Internet Information available at URL: http://www.epa.gov/opptintr/pcb, Last update: February 27, 2002. 
Van den Berg, M., L. Birnbaum, A.T.C. Bosveld et al. 1998. Toxic Equivalency Factors (TEFs) for PCBs, PCDDs, PCDFs for Human and Wildlife. Environ. Health Perspect. 106(12):775-792. 
Appendix 1

Soils Data 


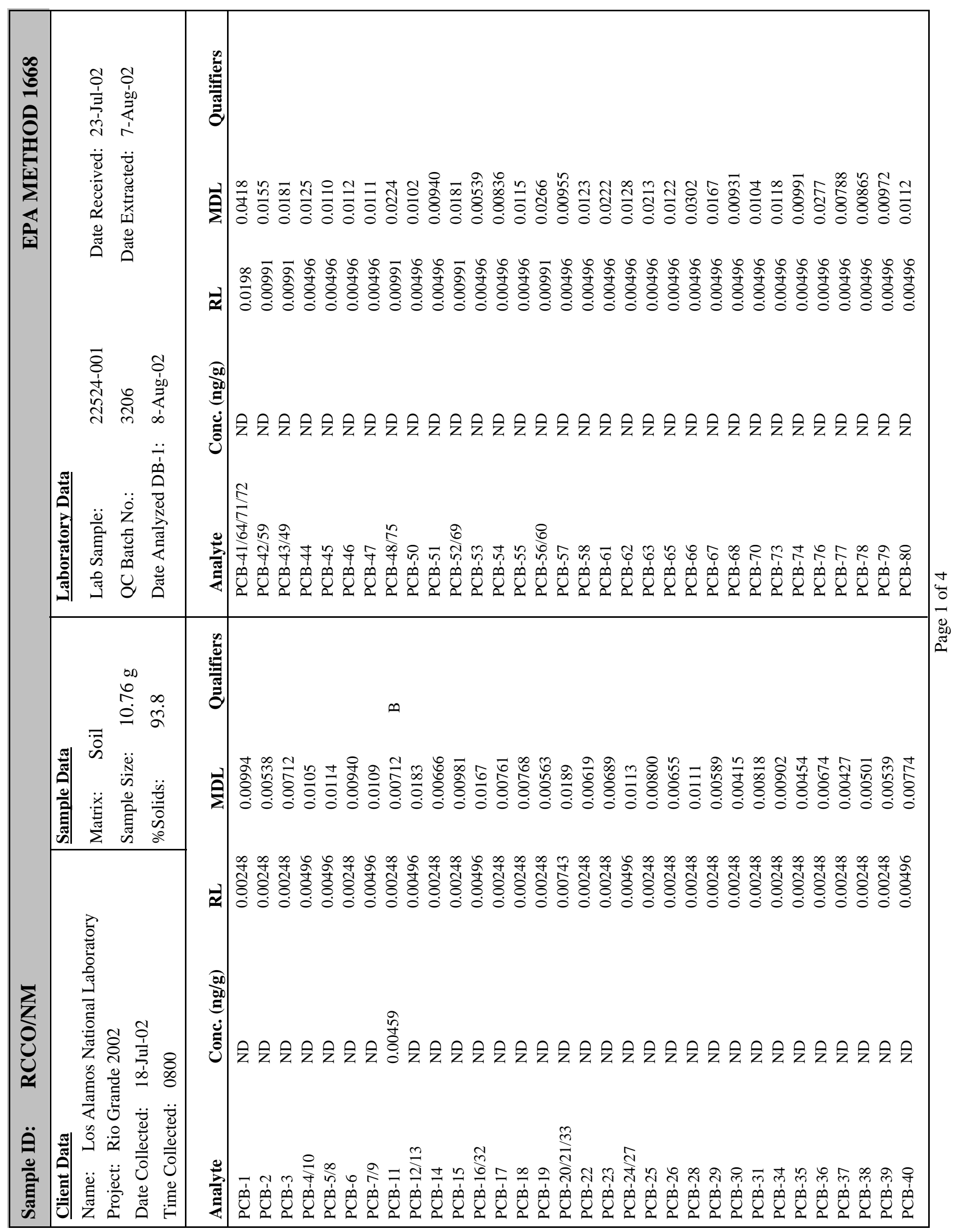




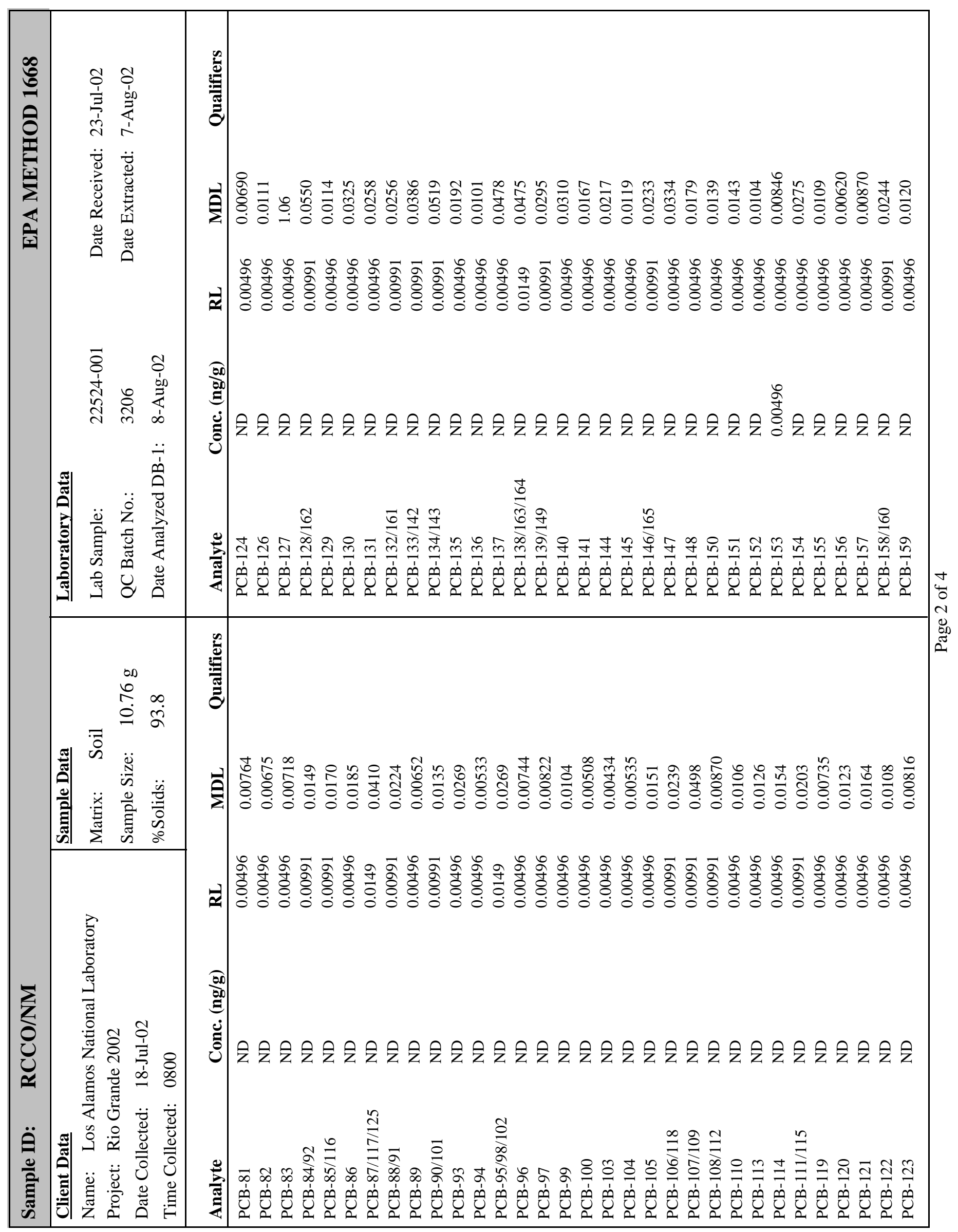




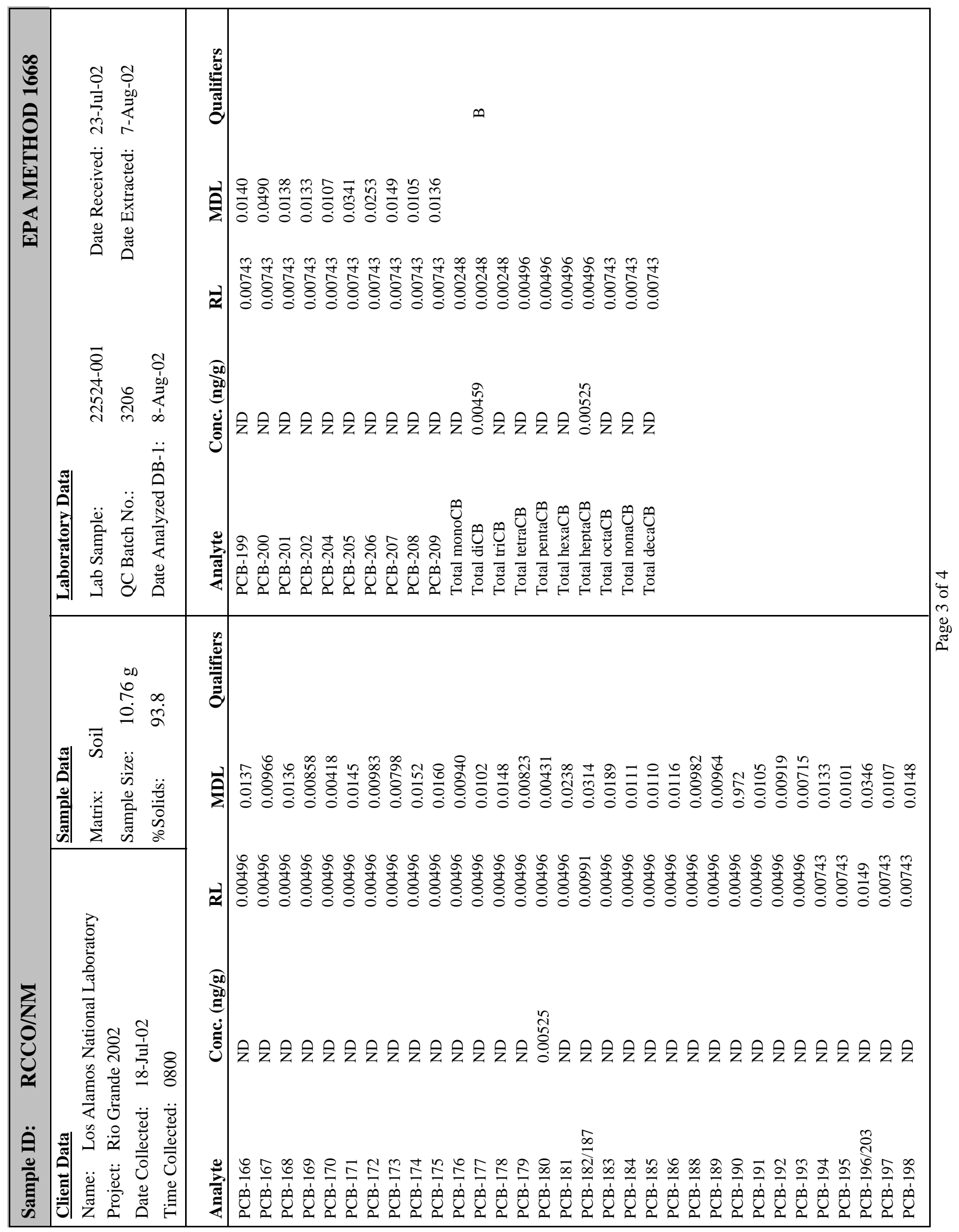




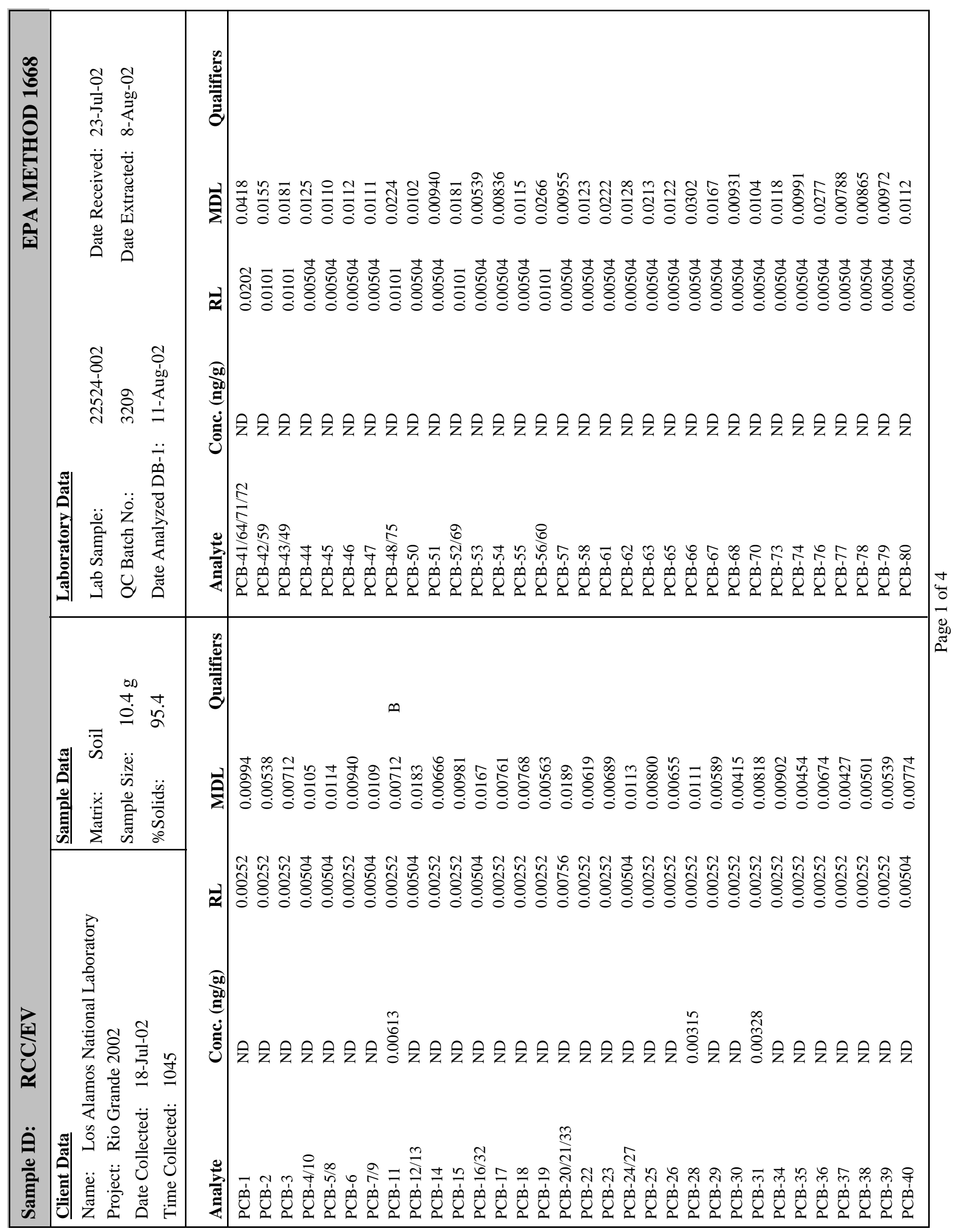




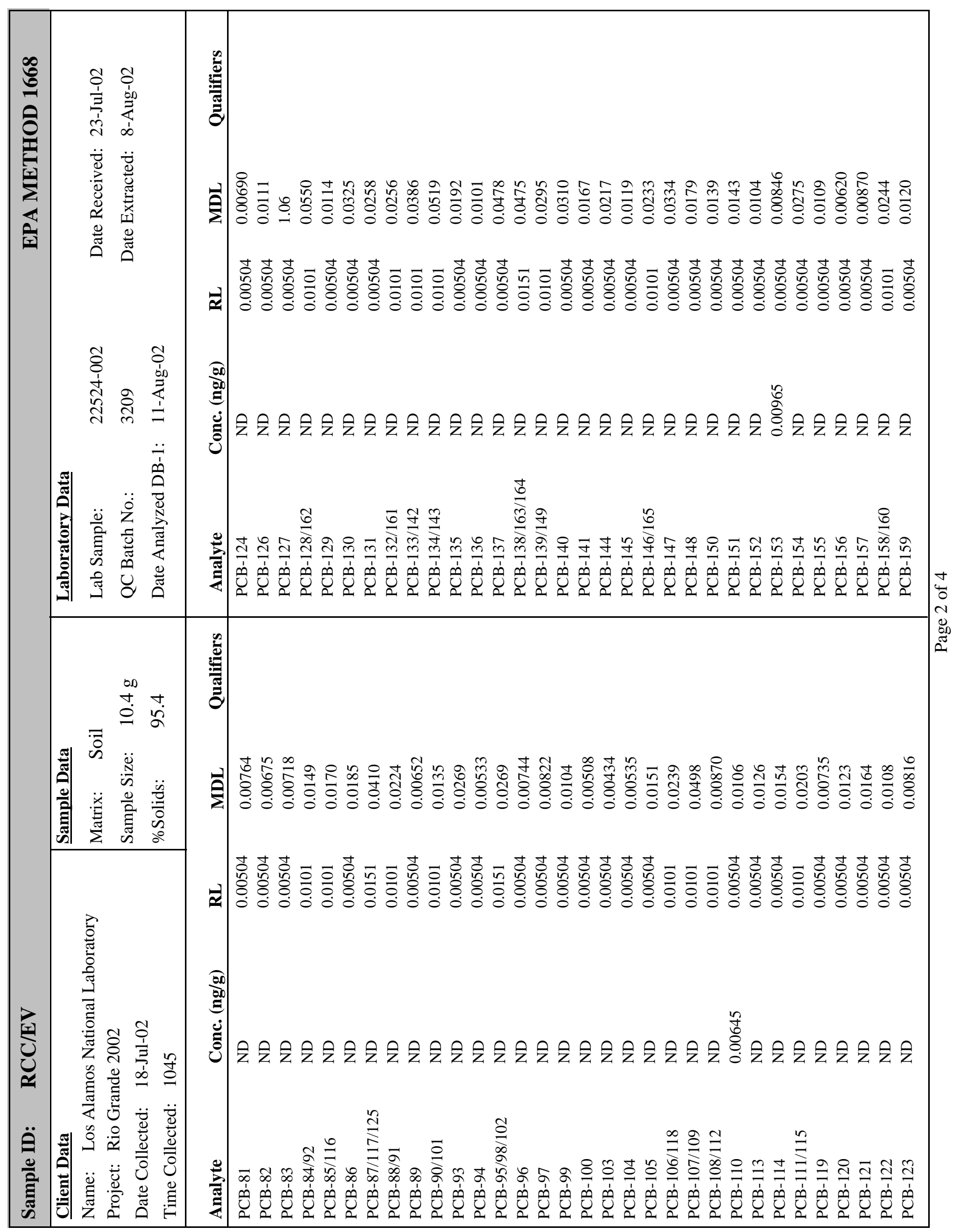




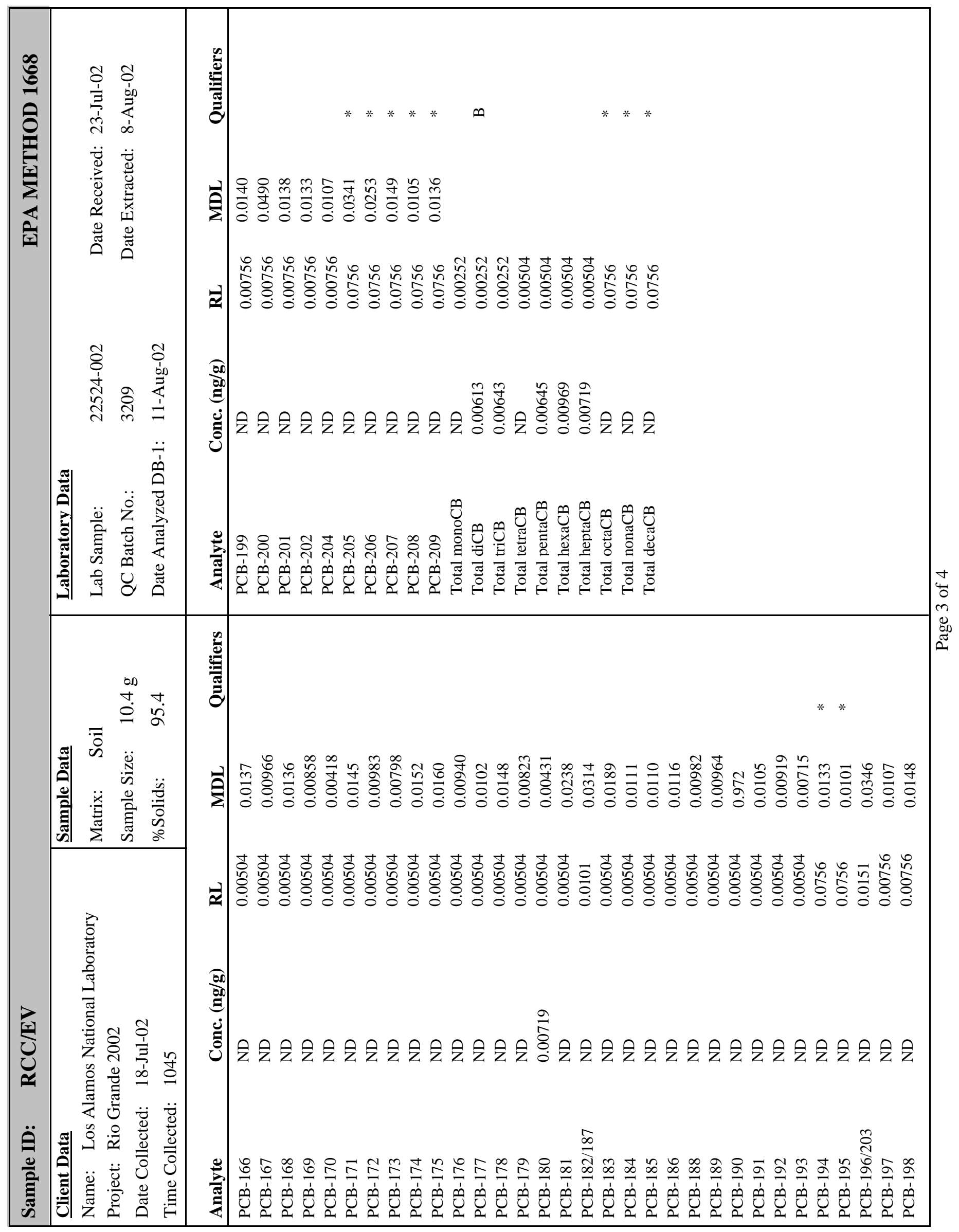




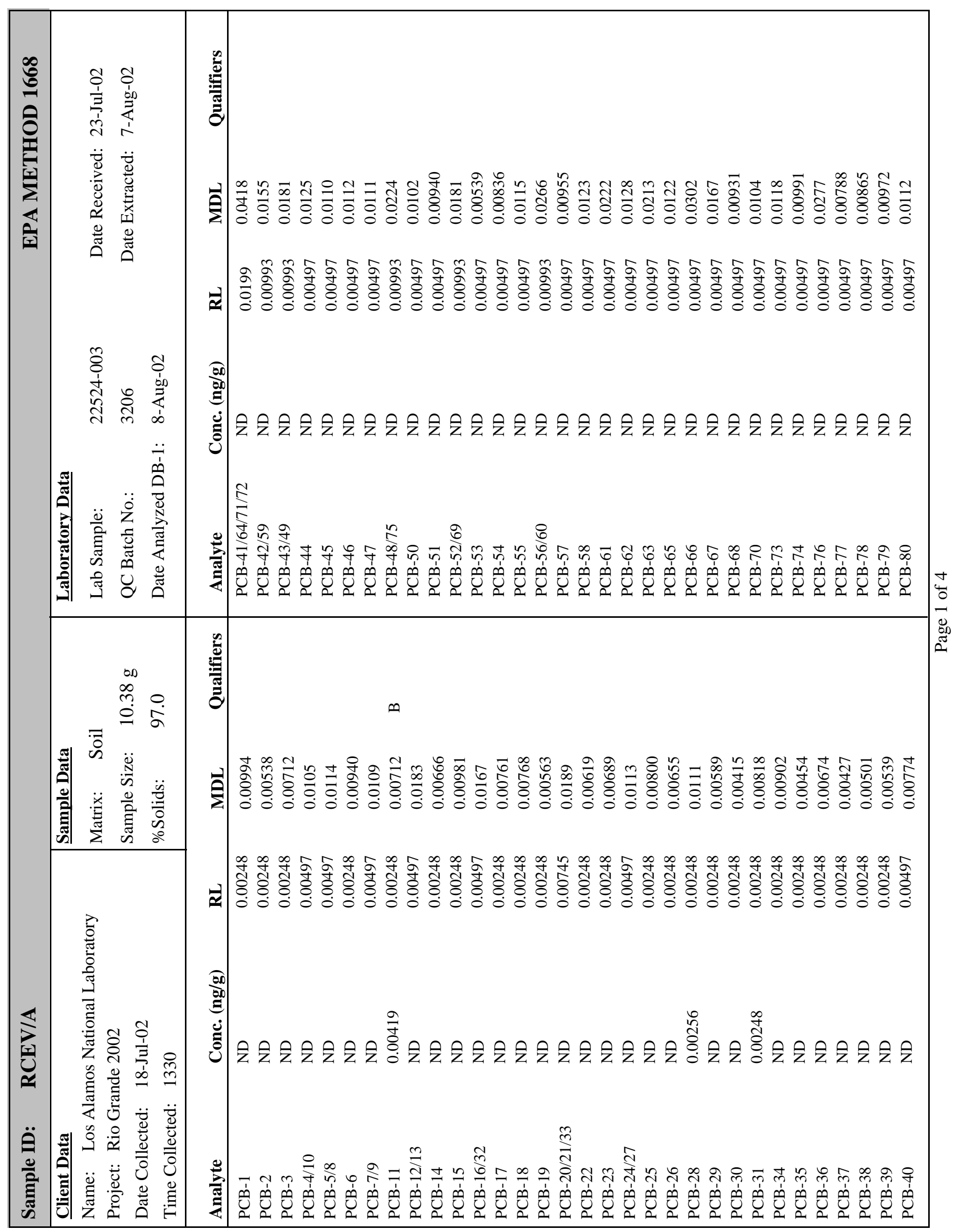




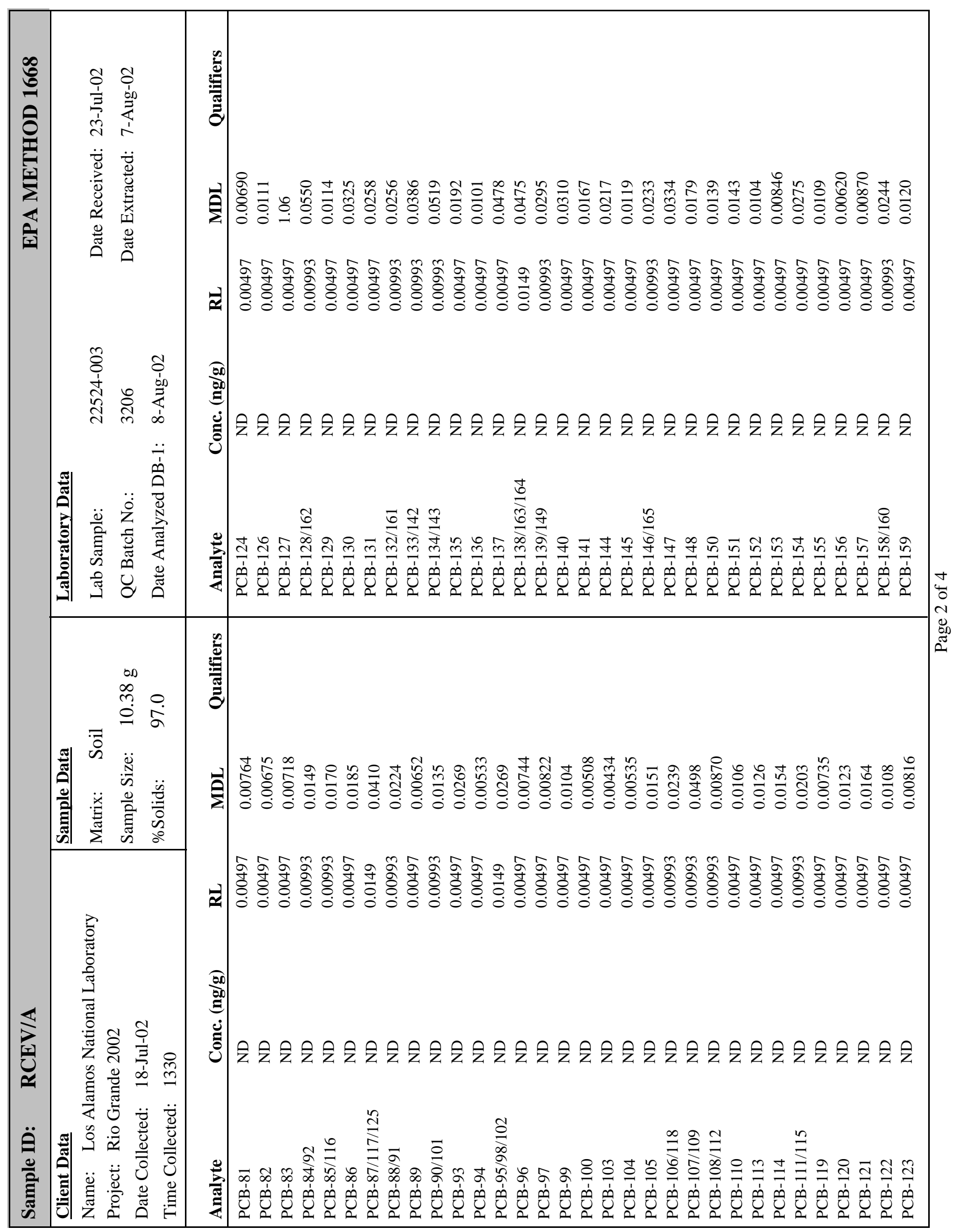




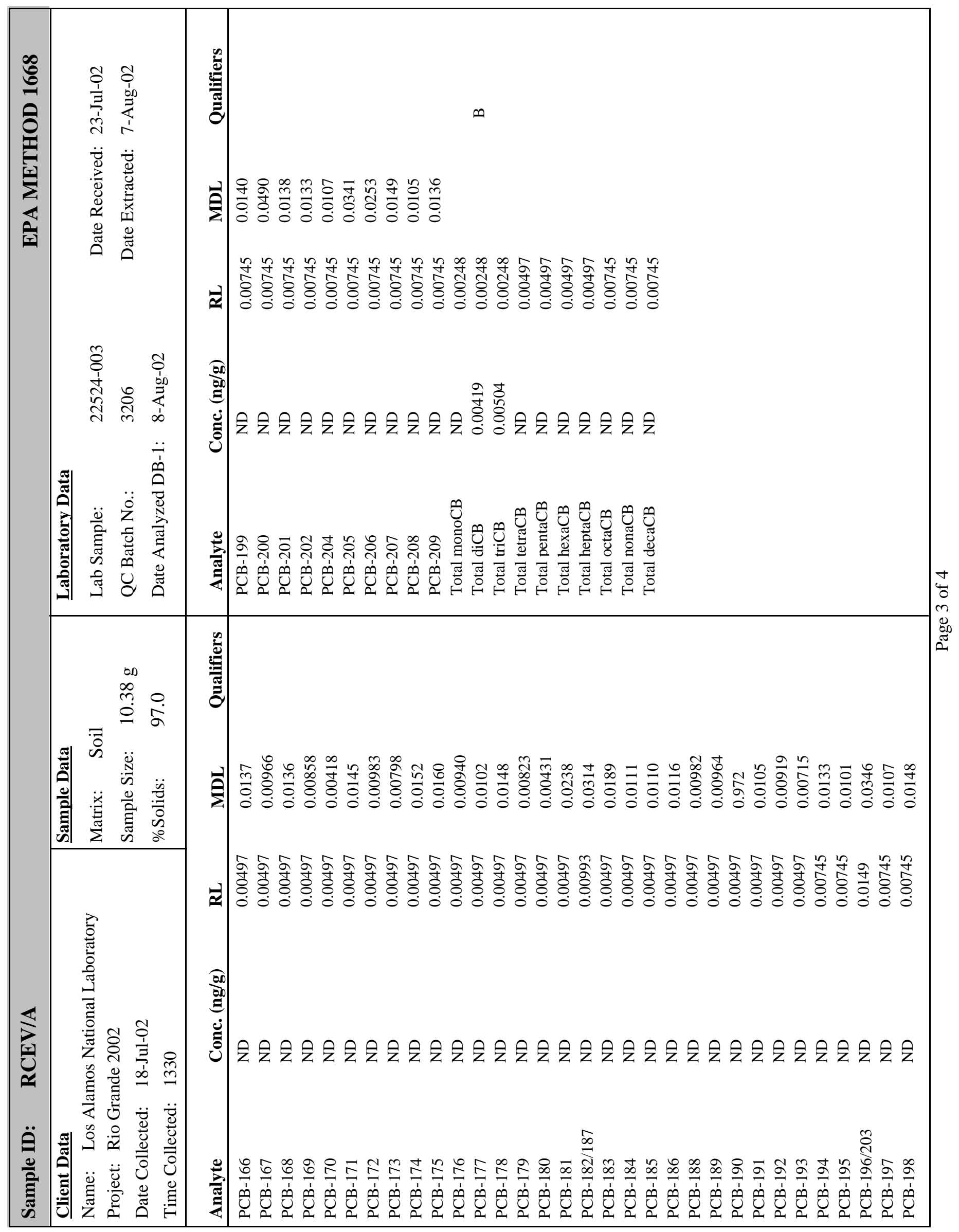




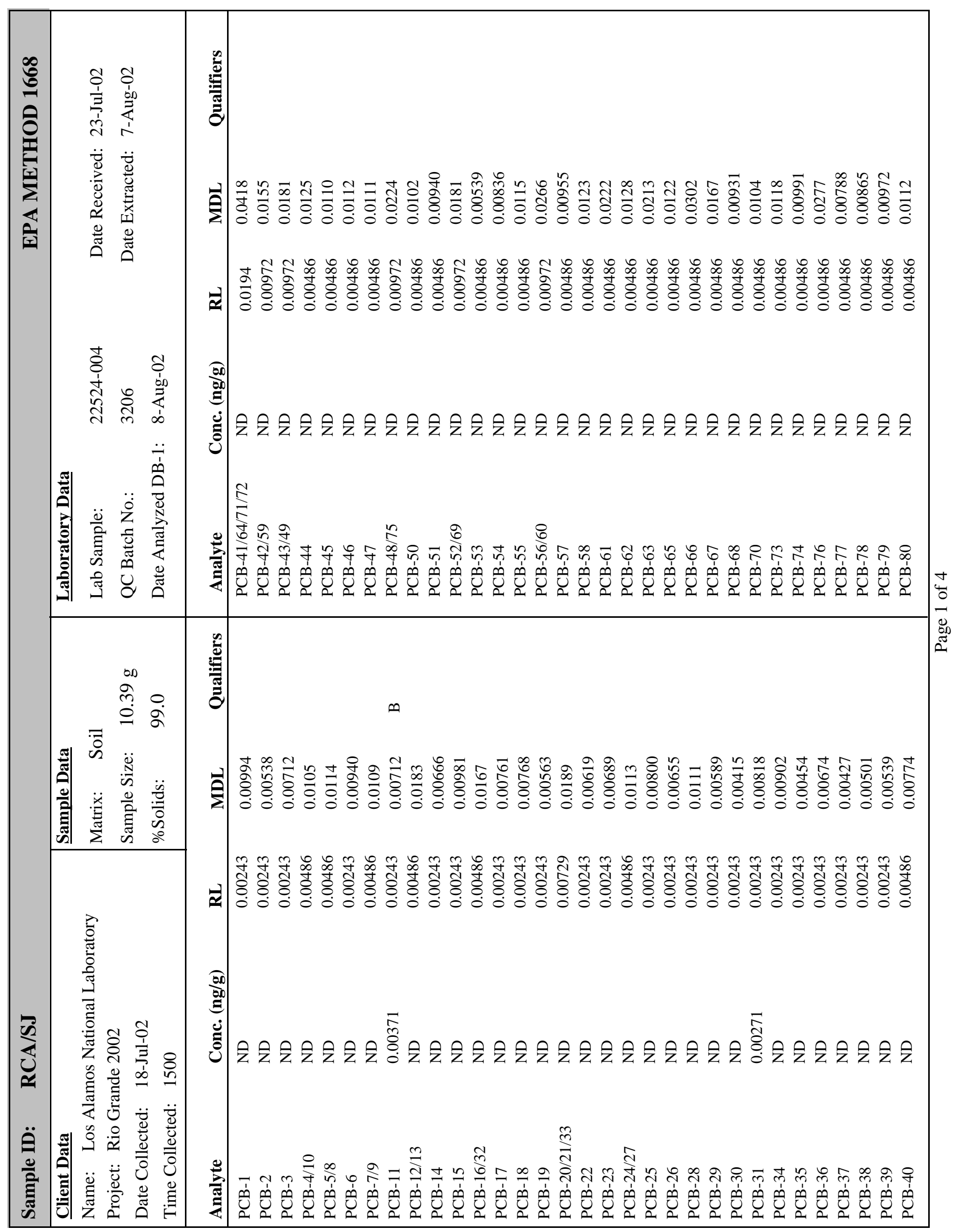




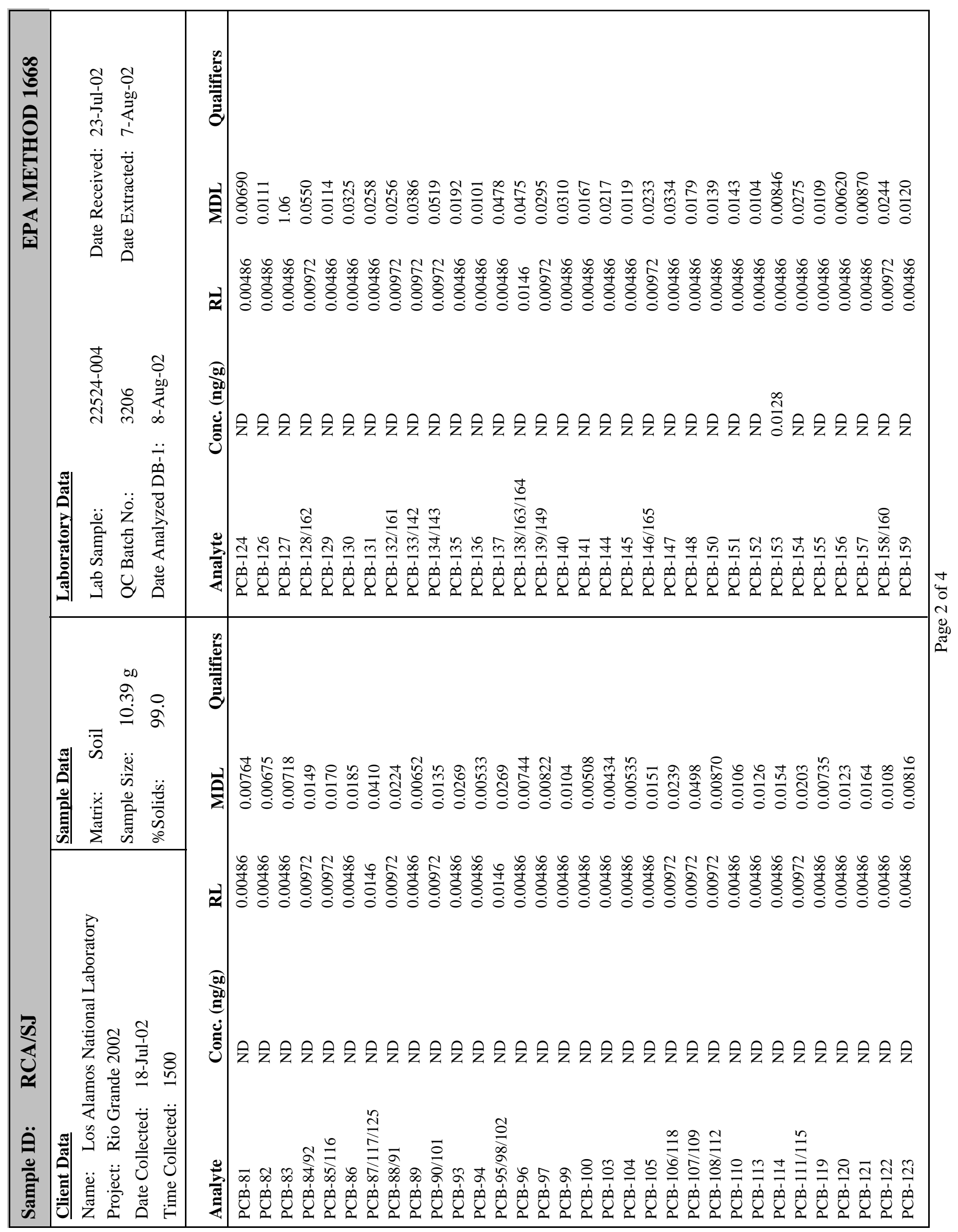




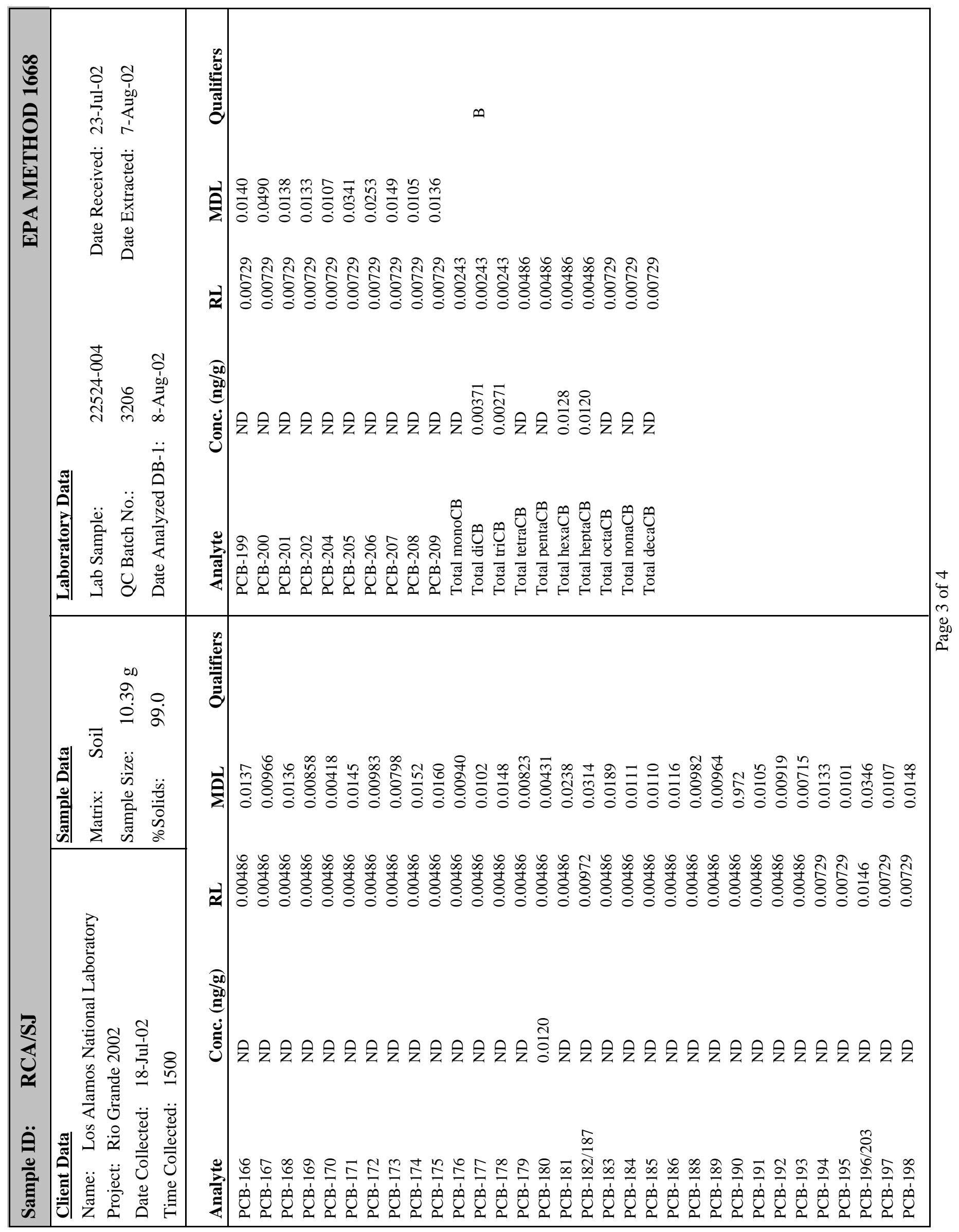




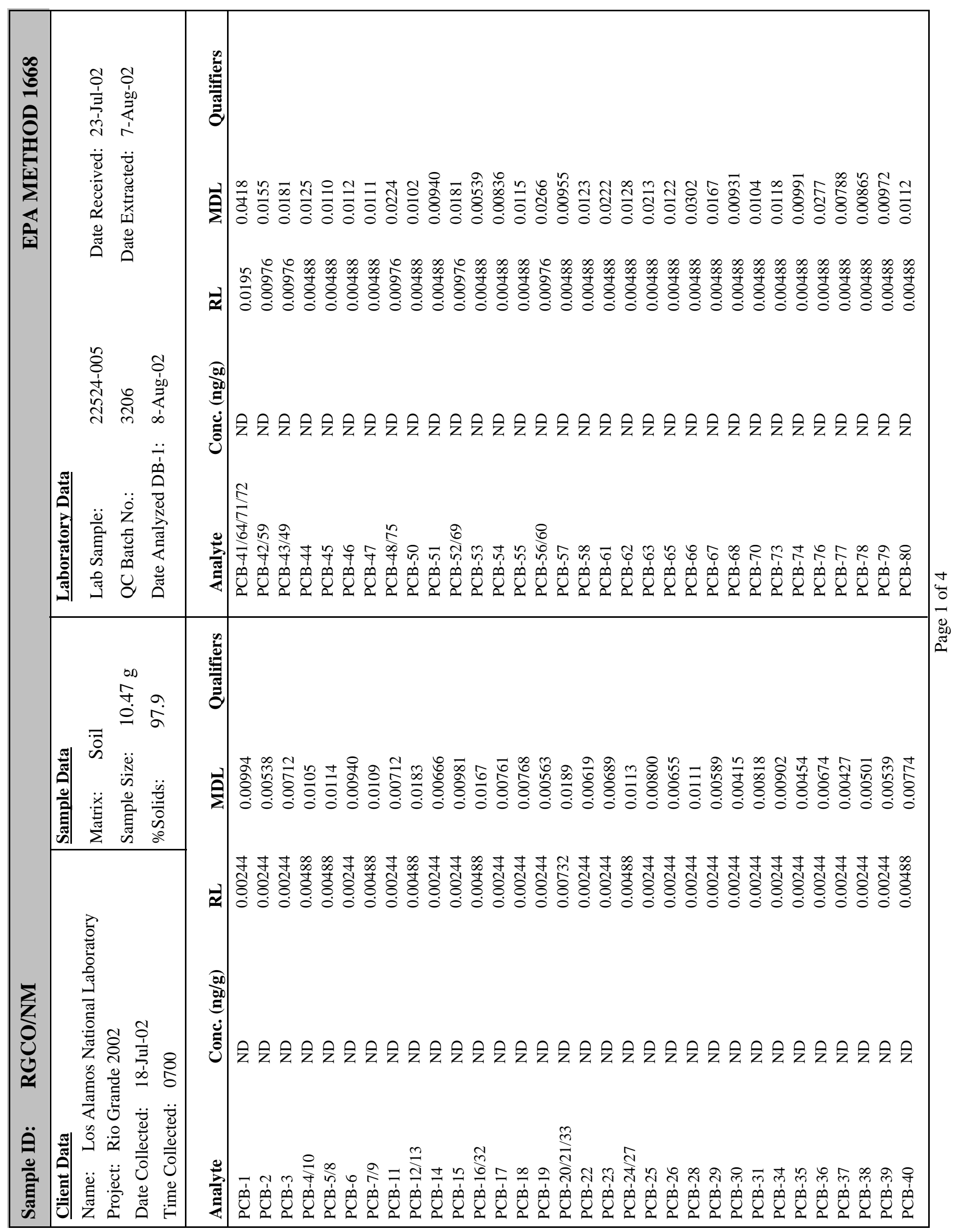




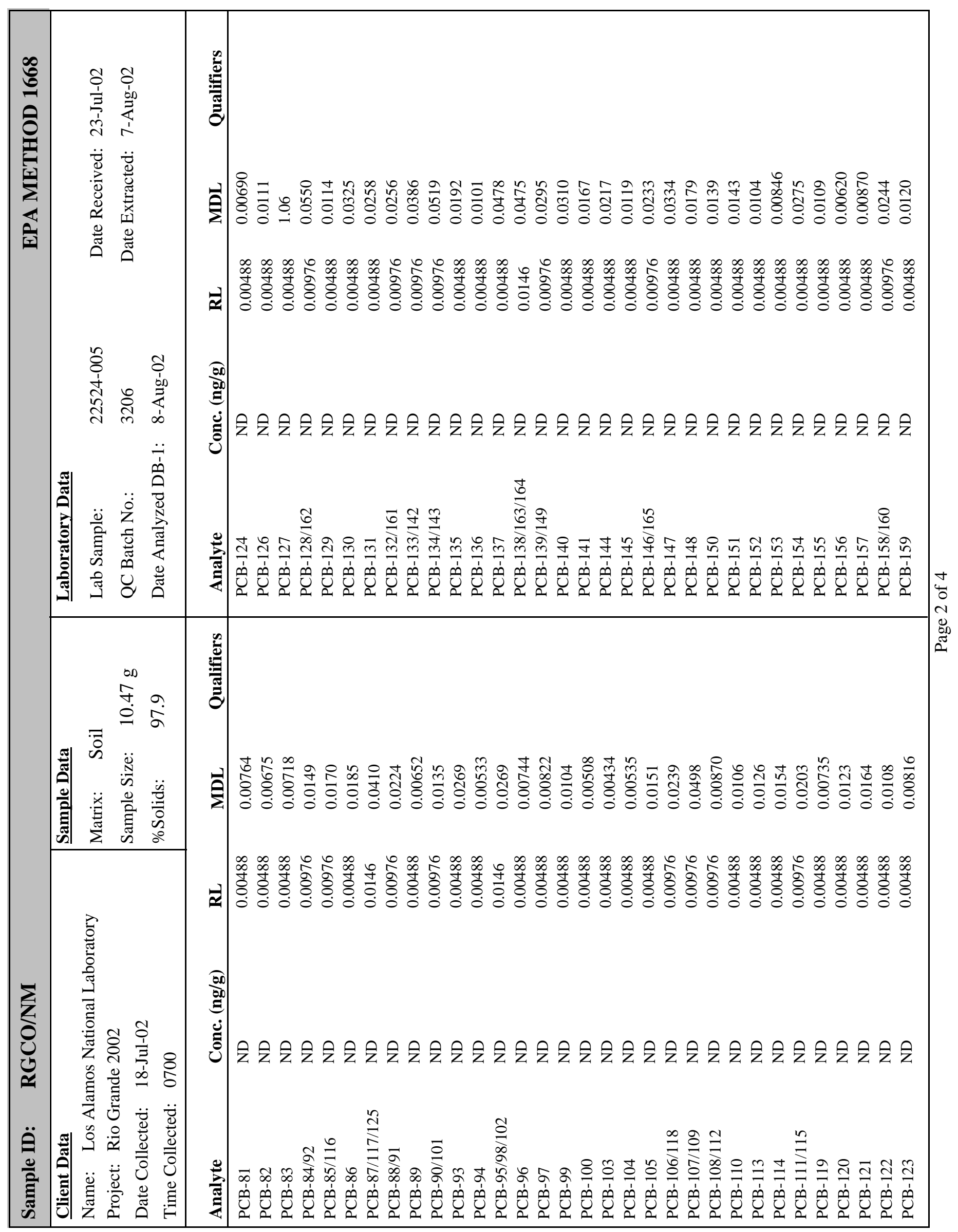




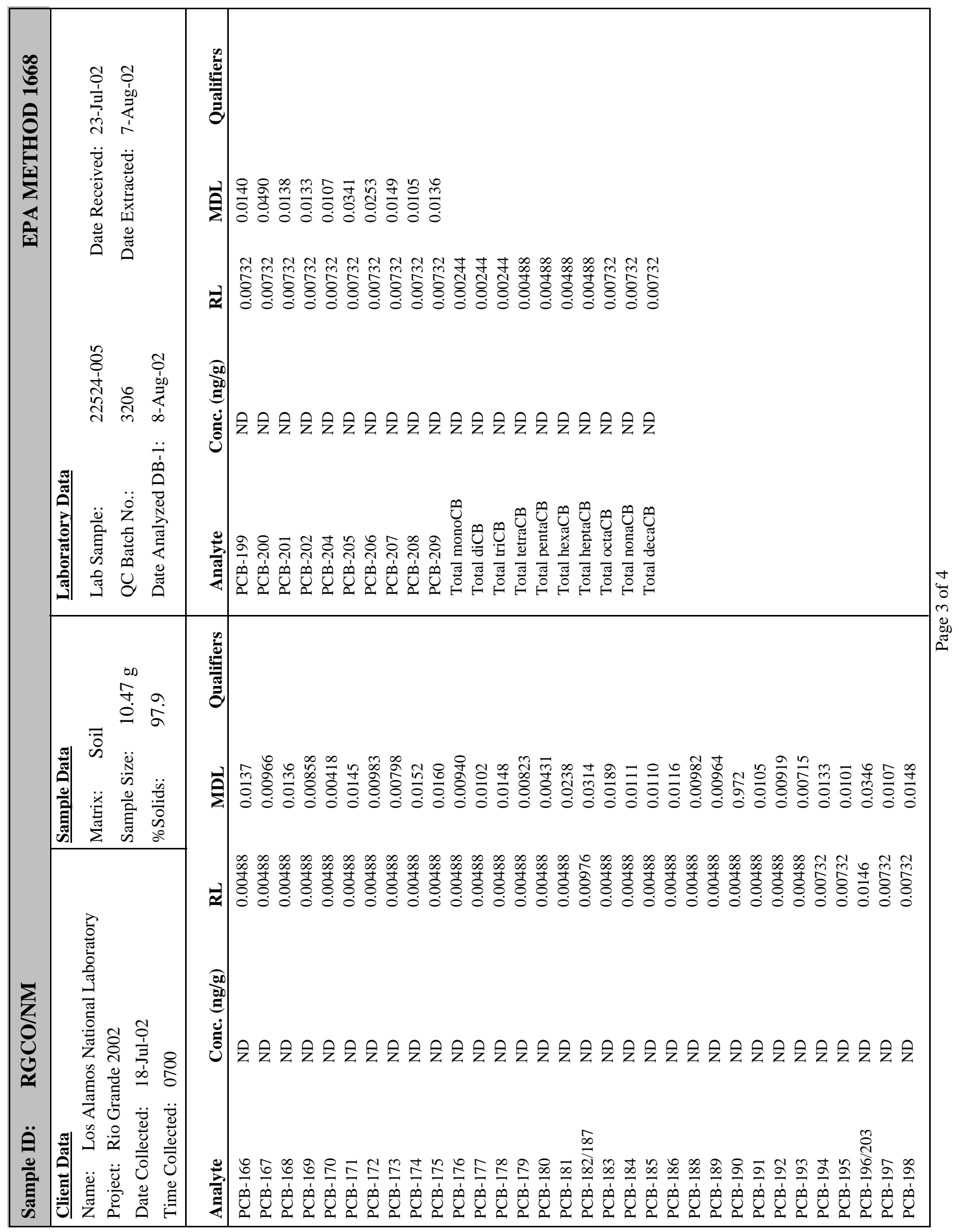




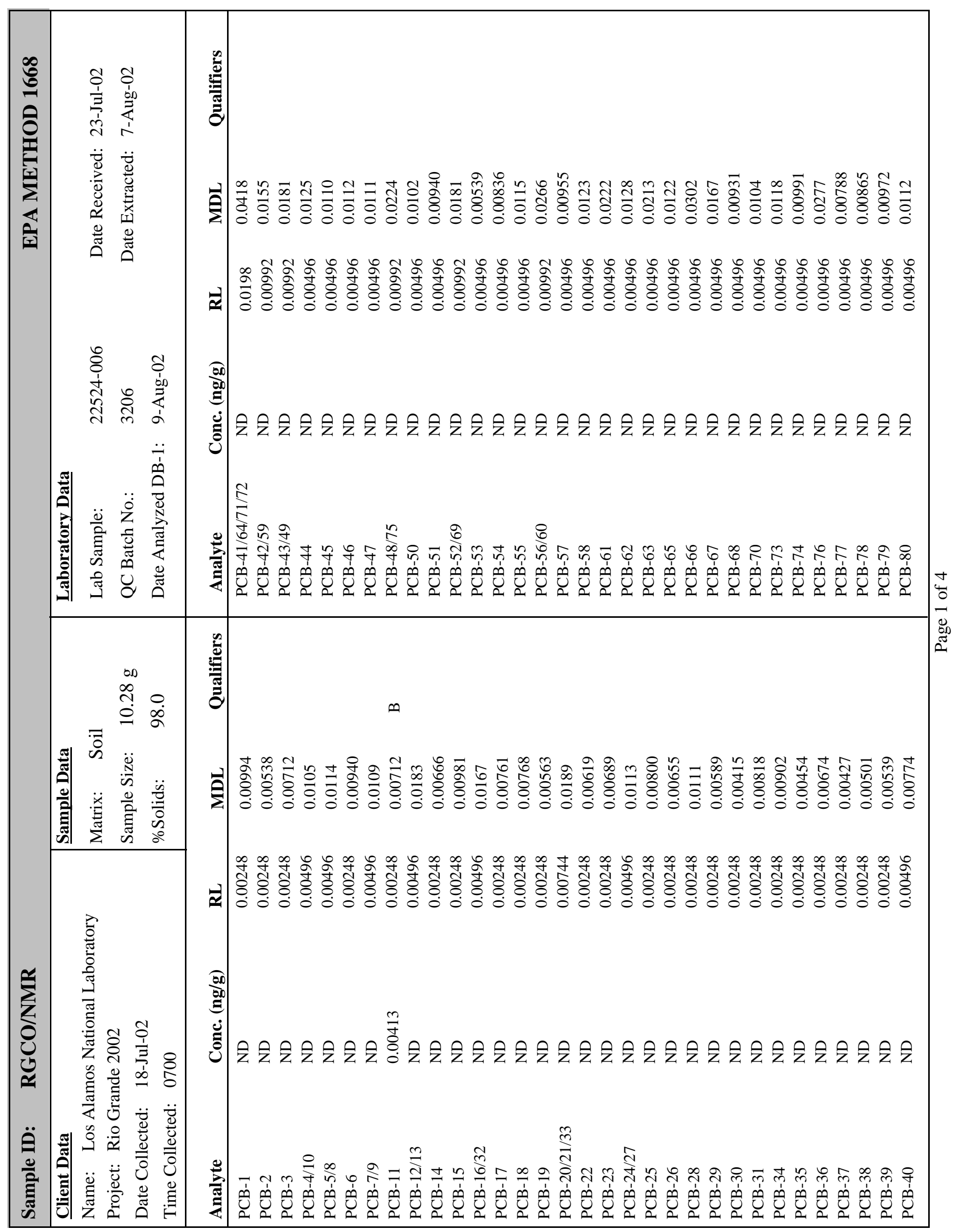




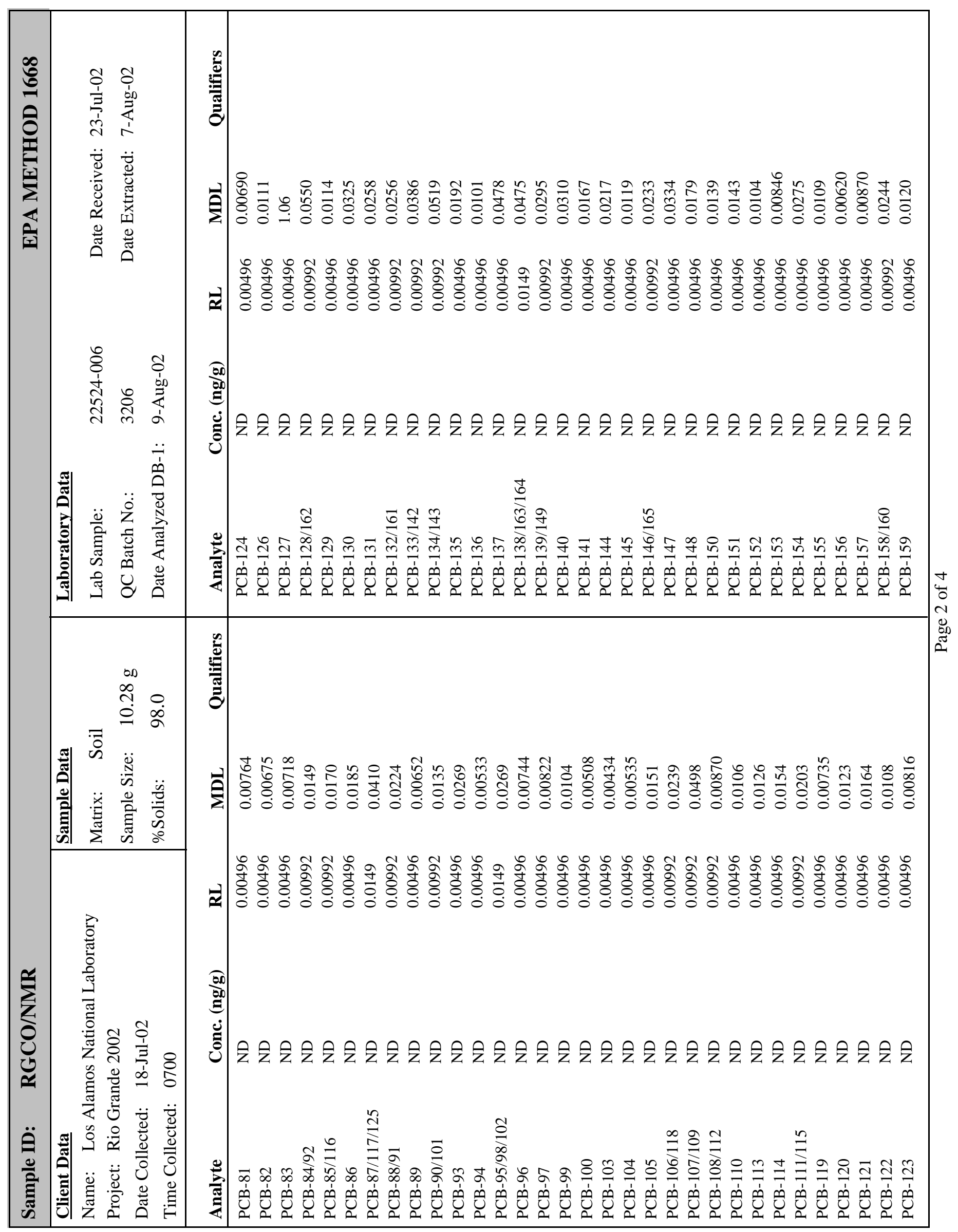




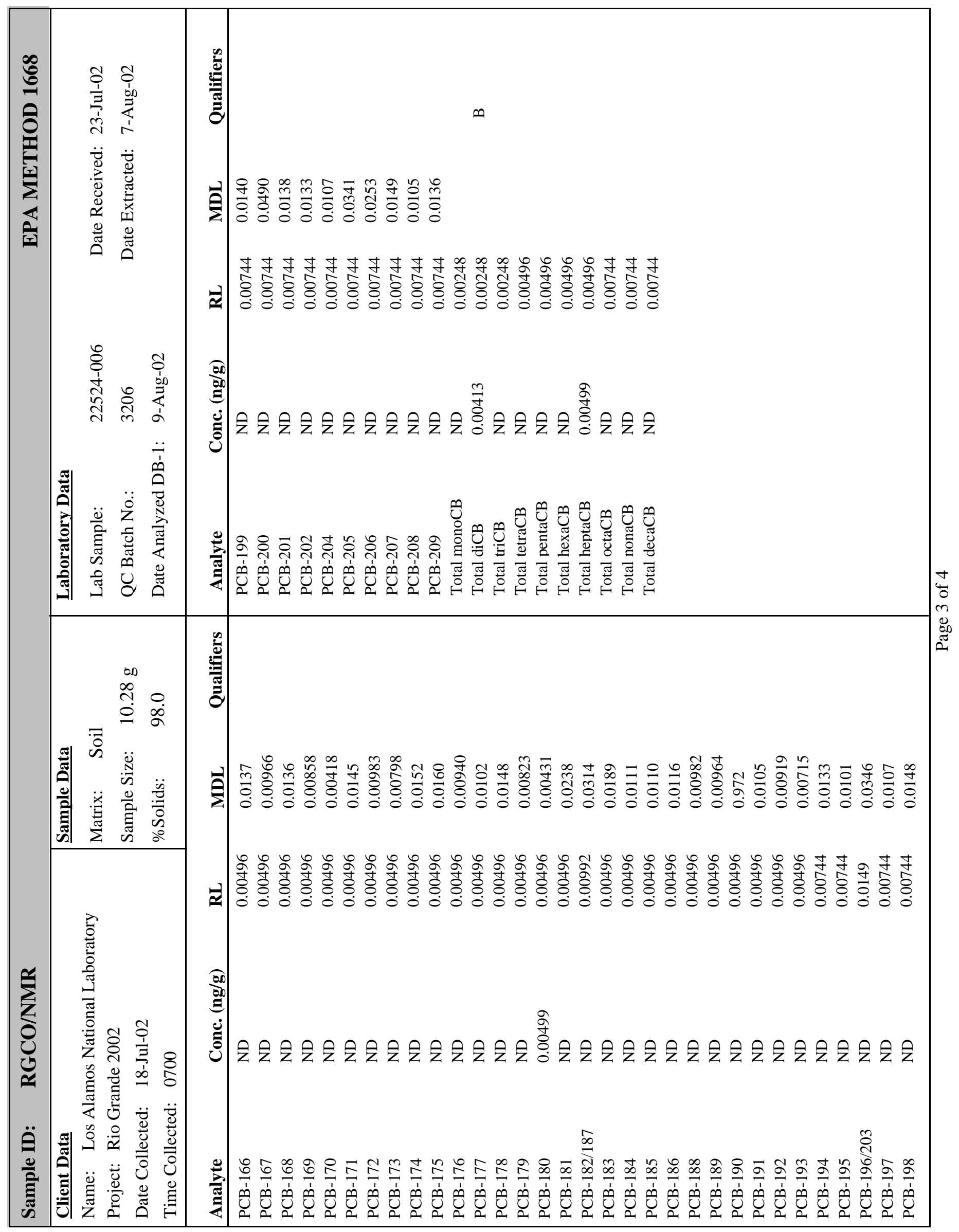




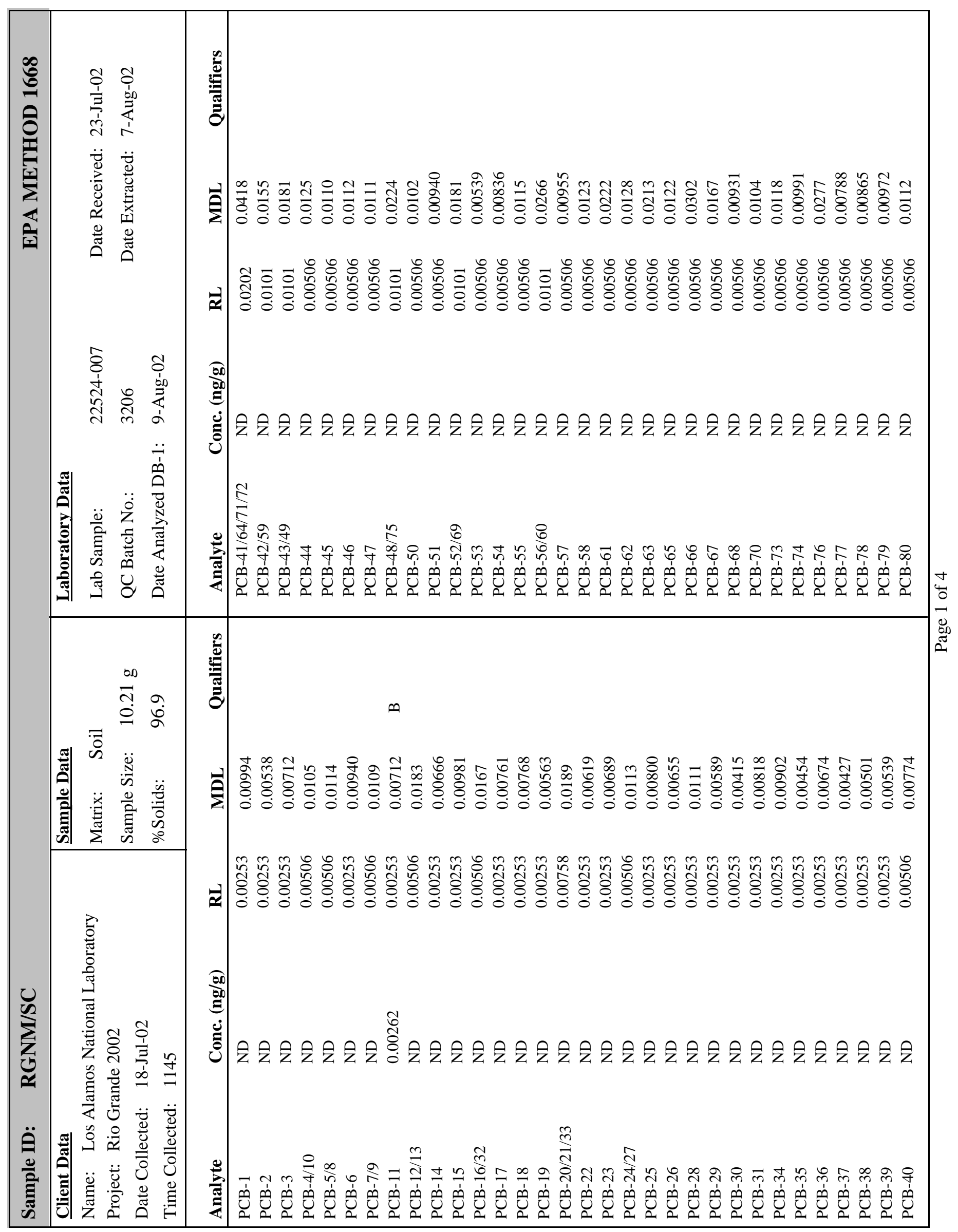




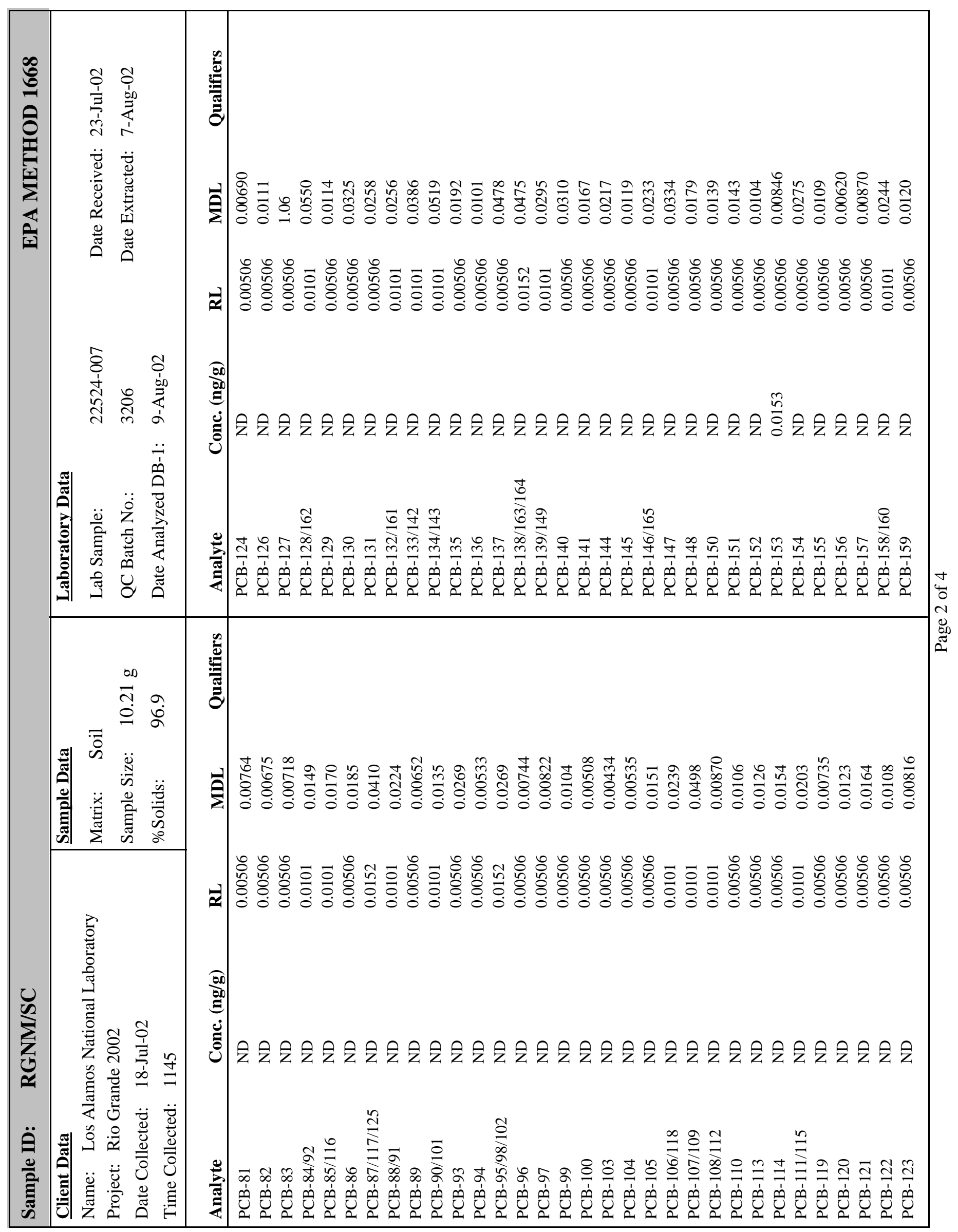




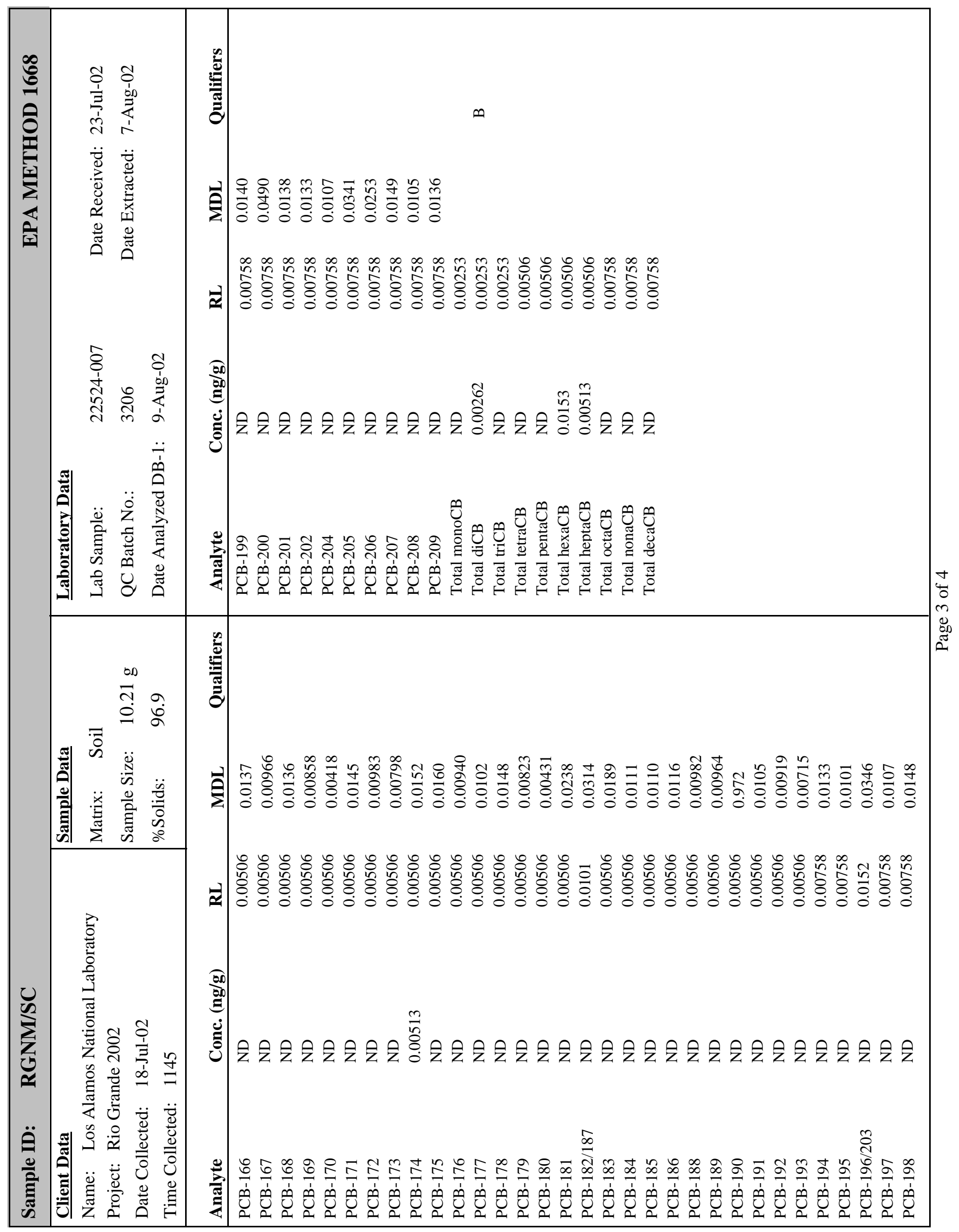




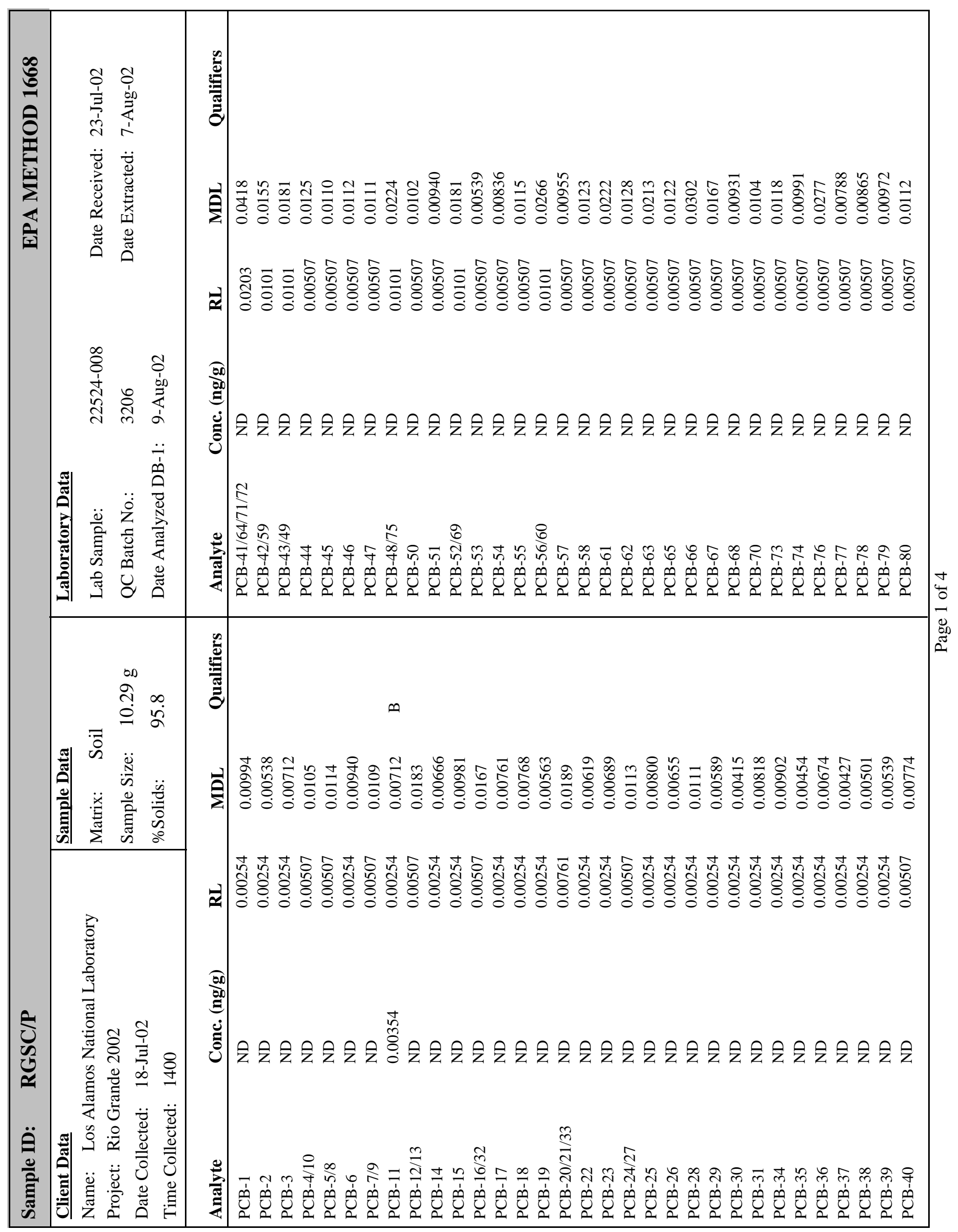




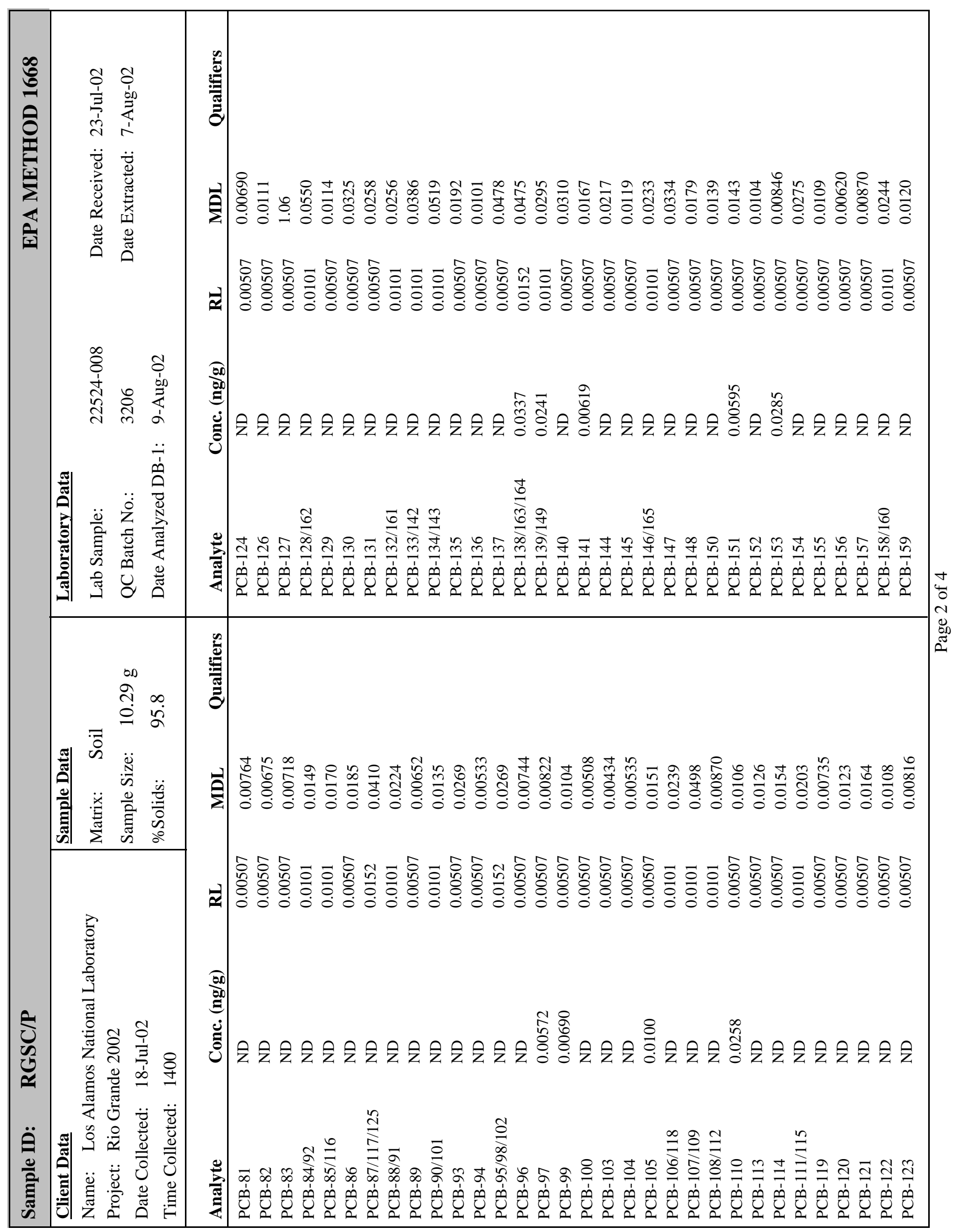




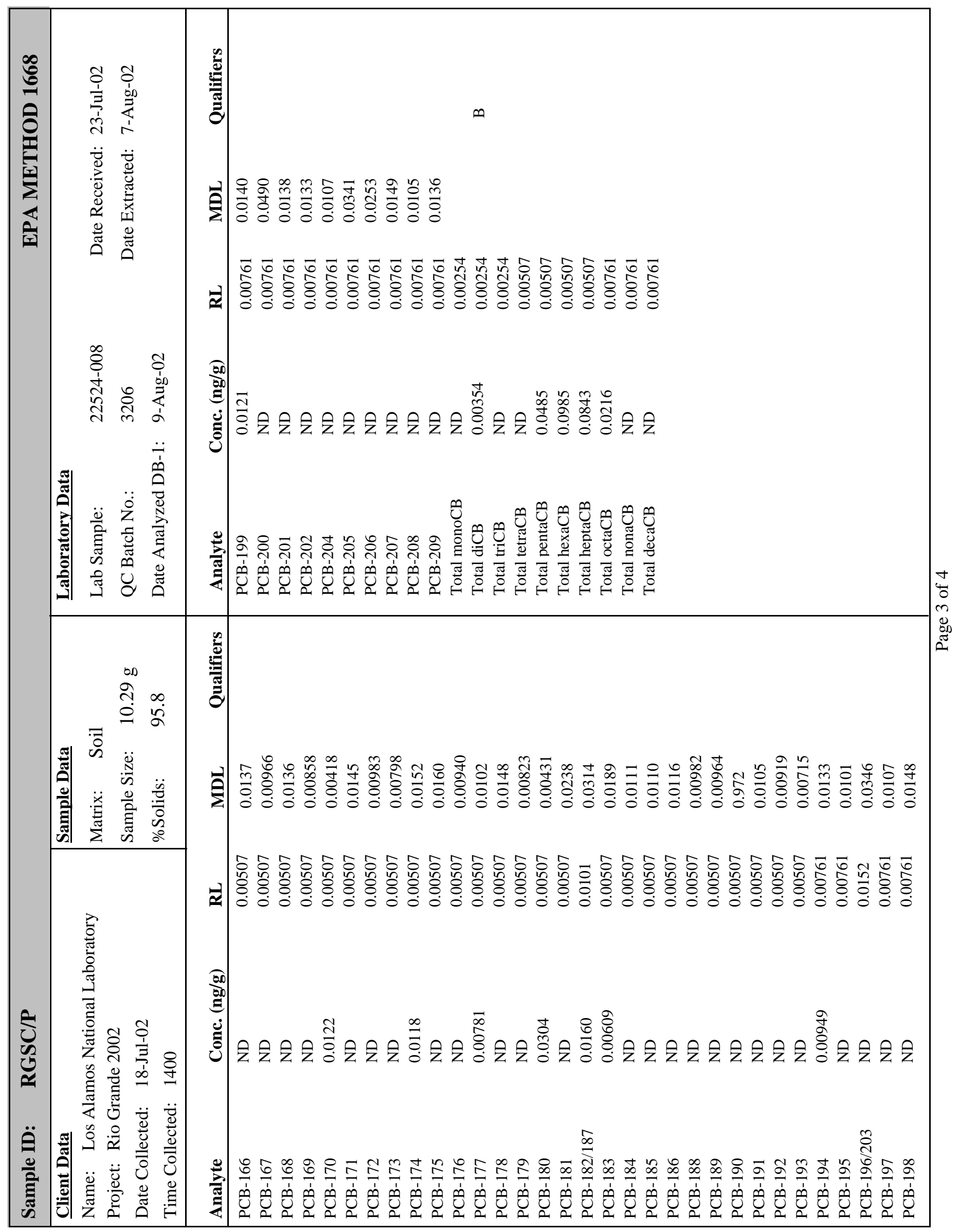




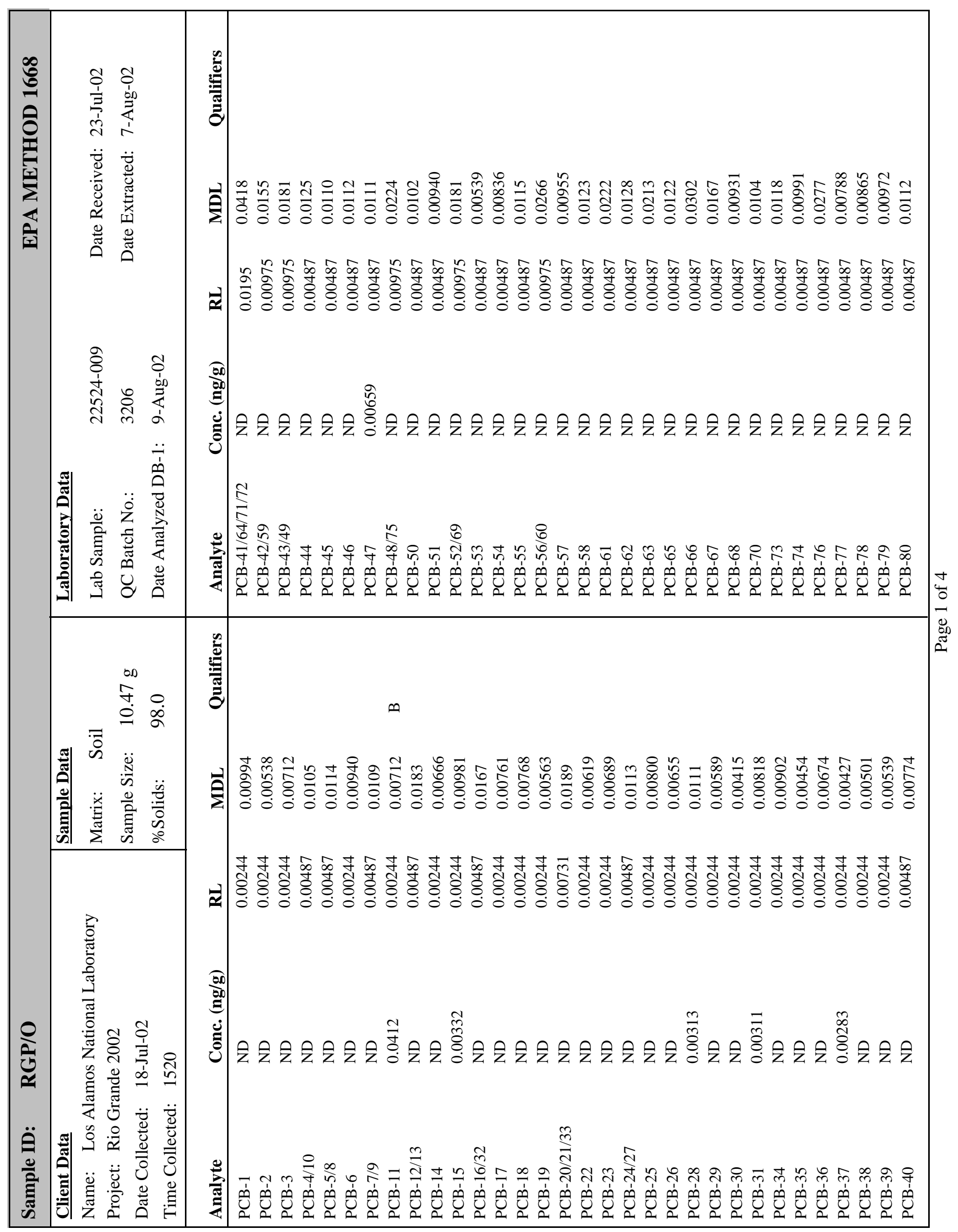




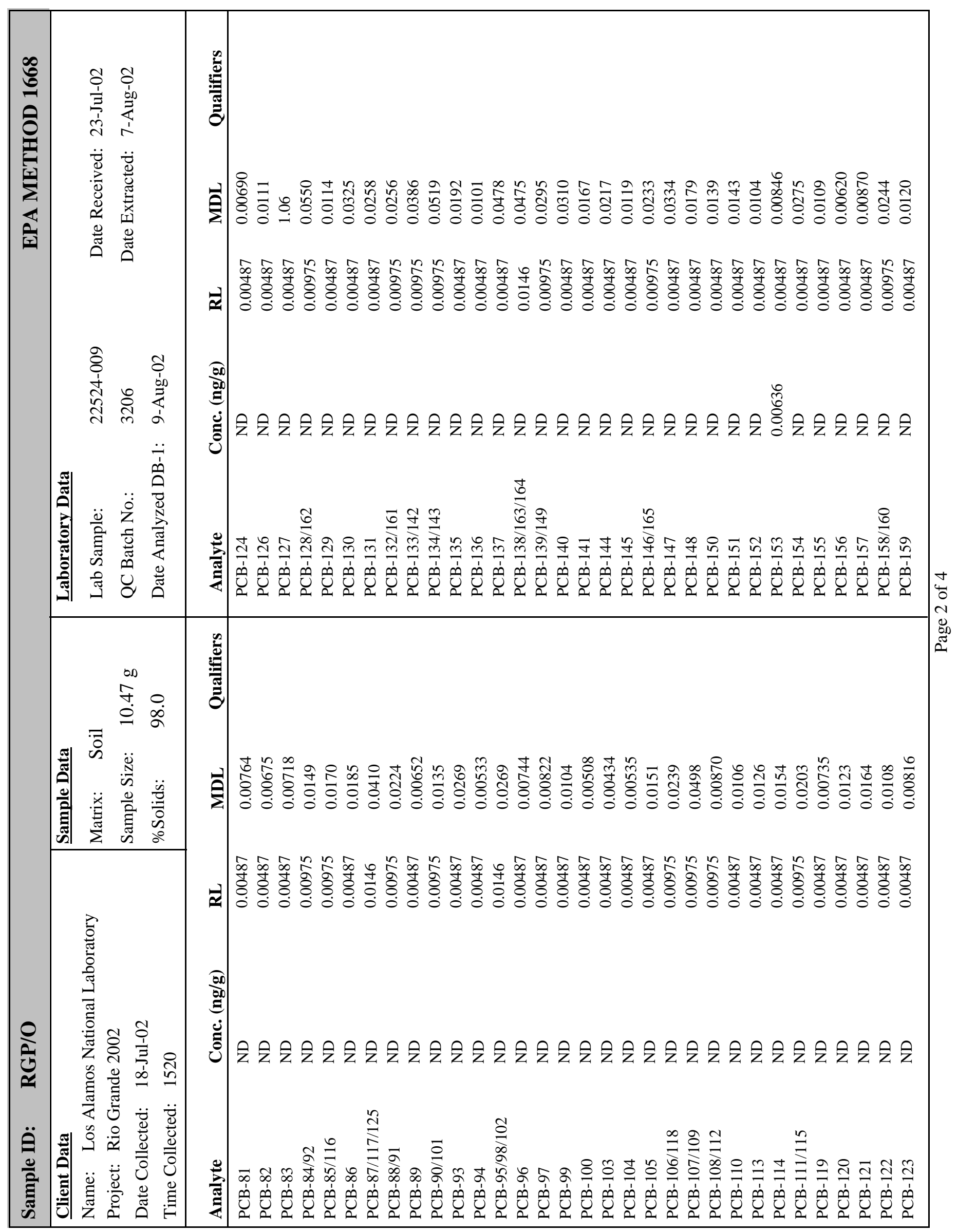




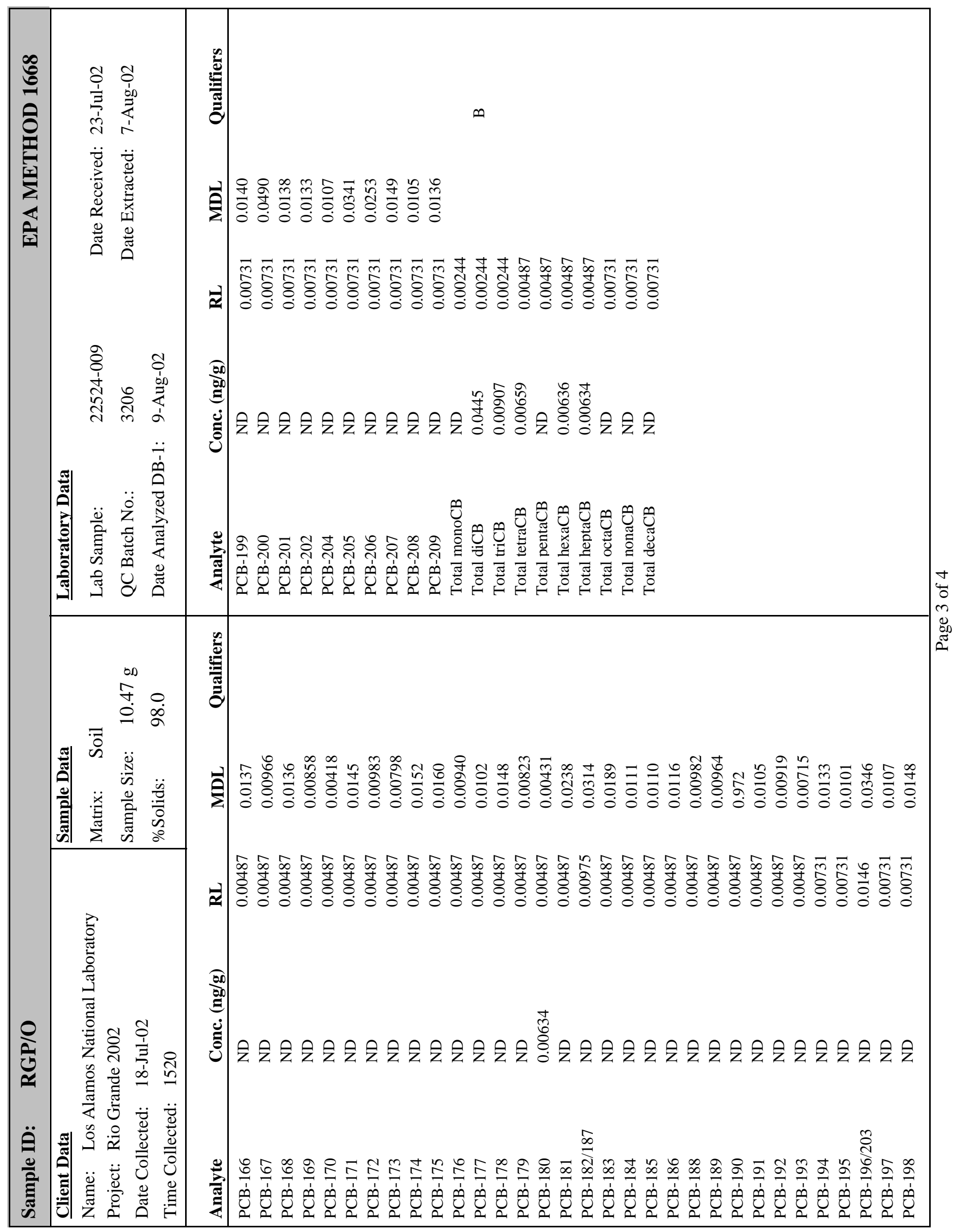




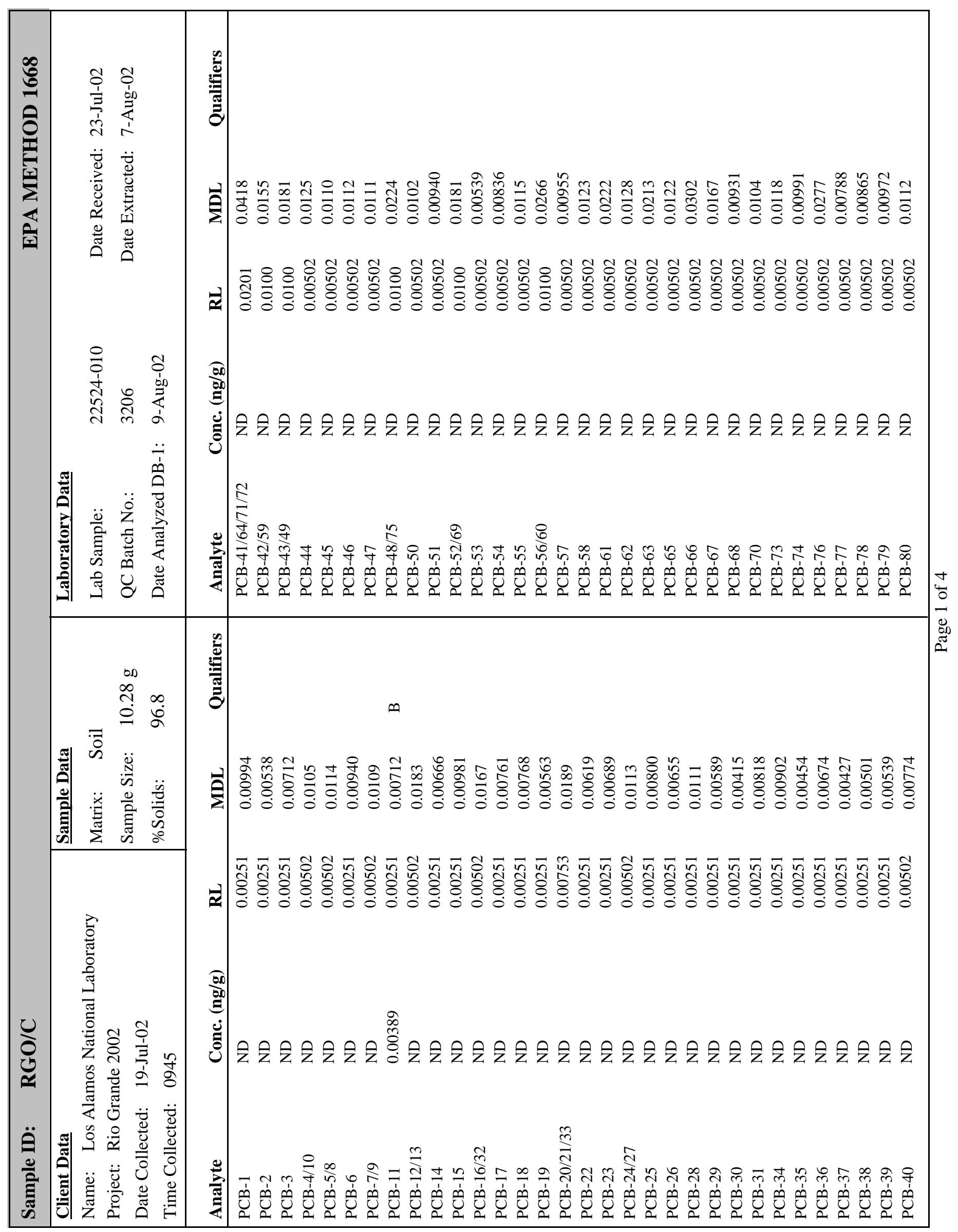




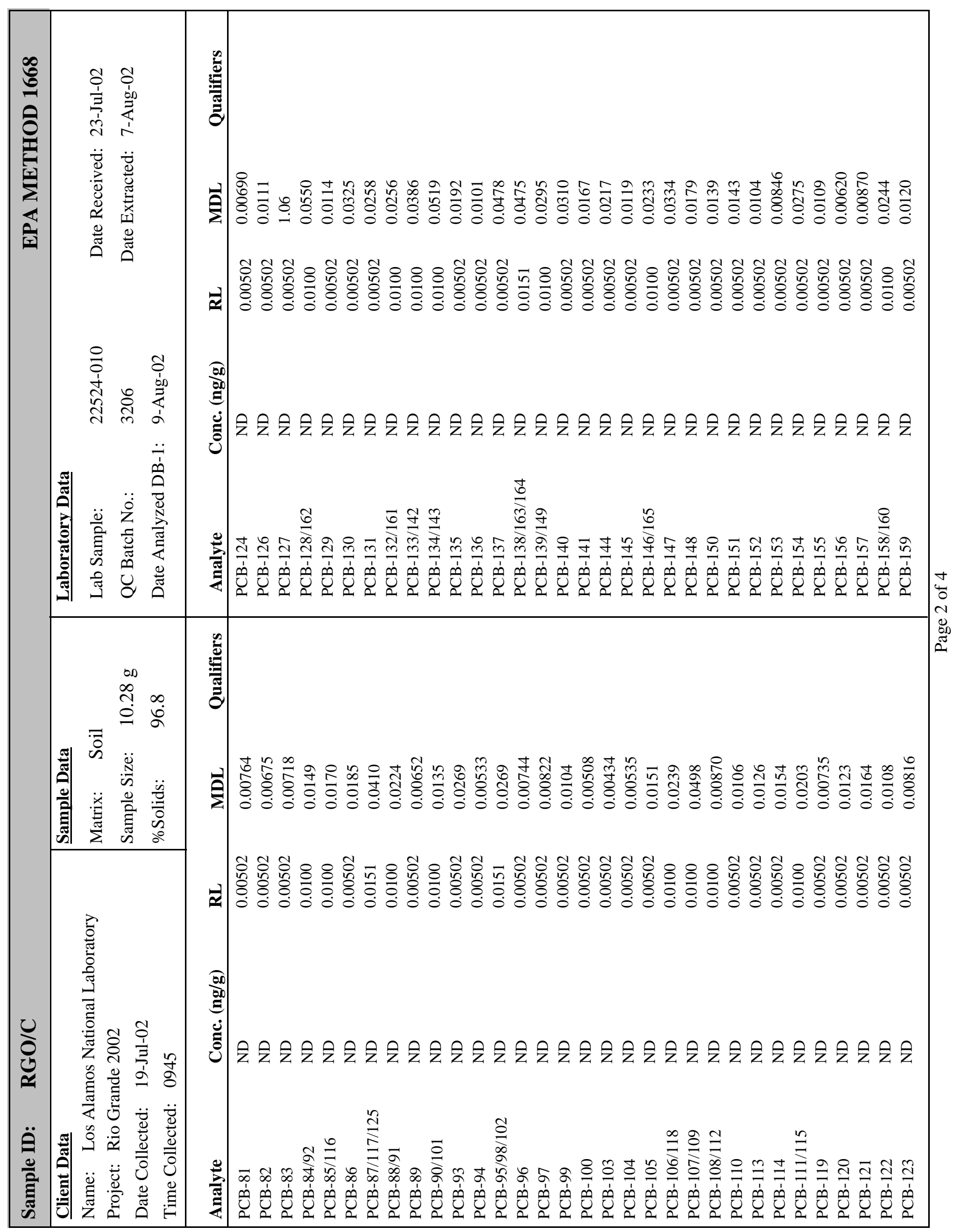




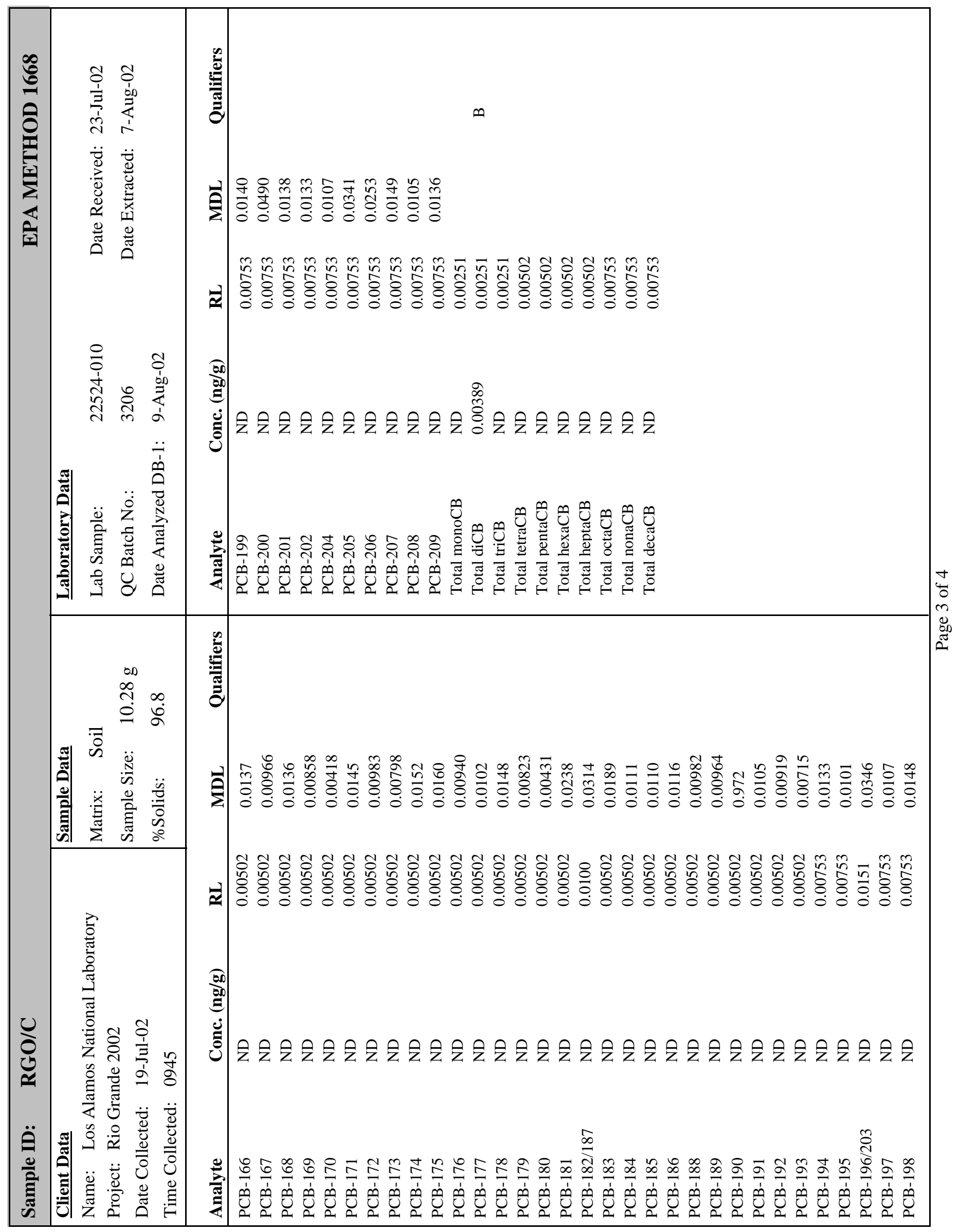


Appendix 2

Fish Data 


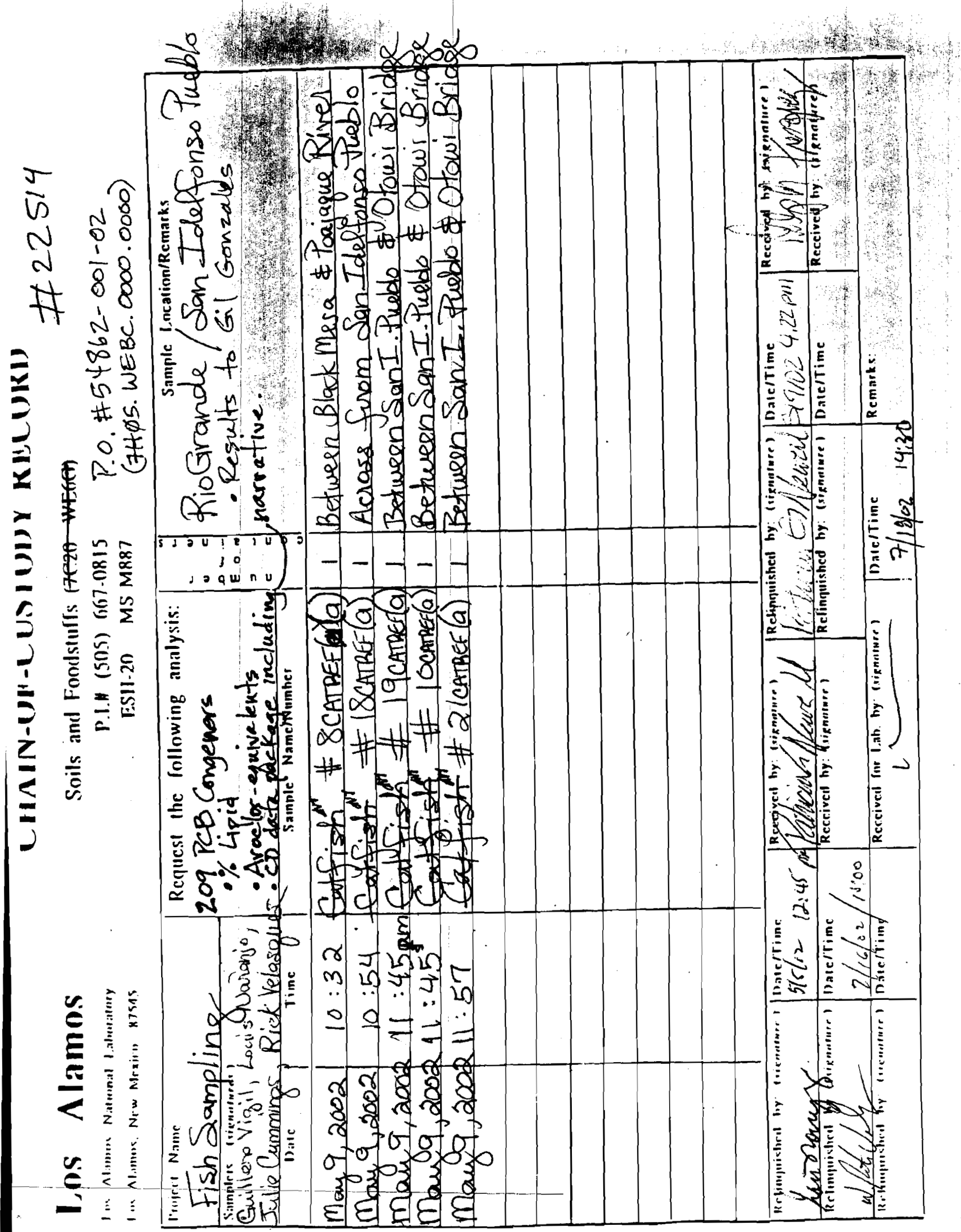




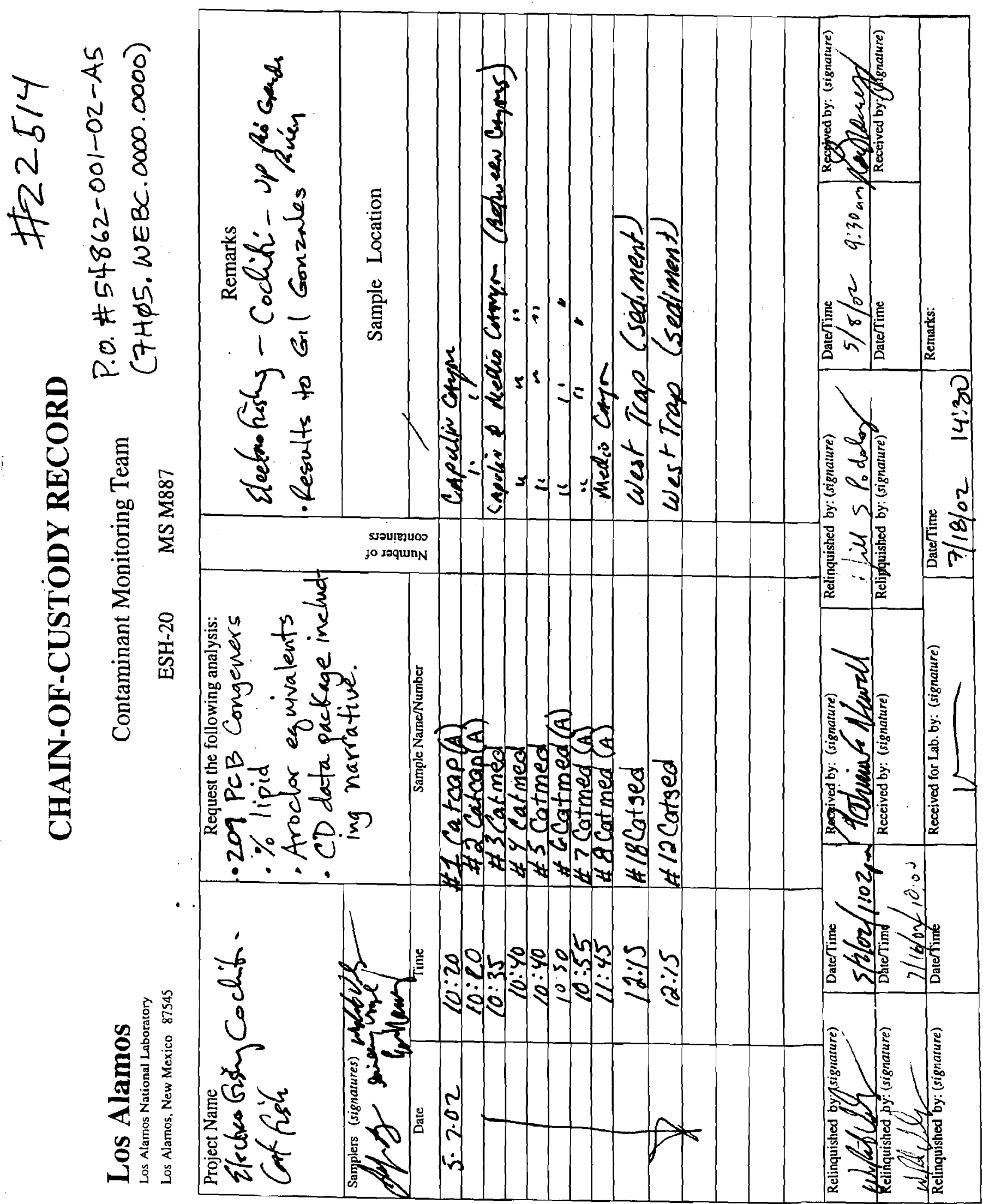




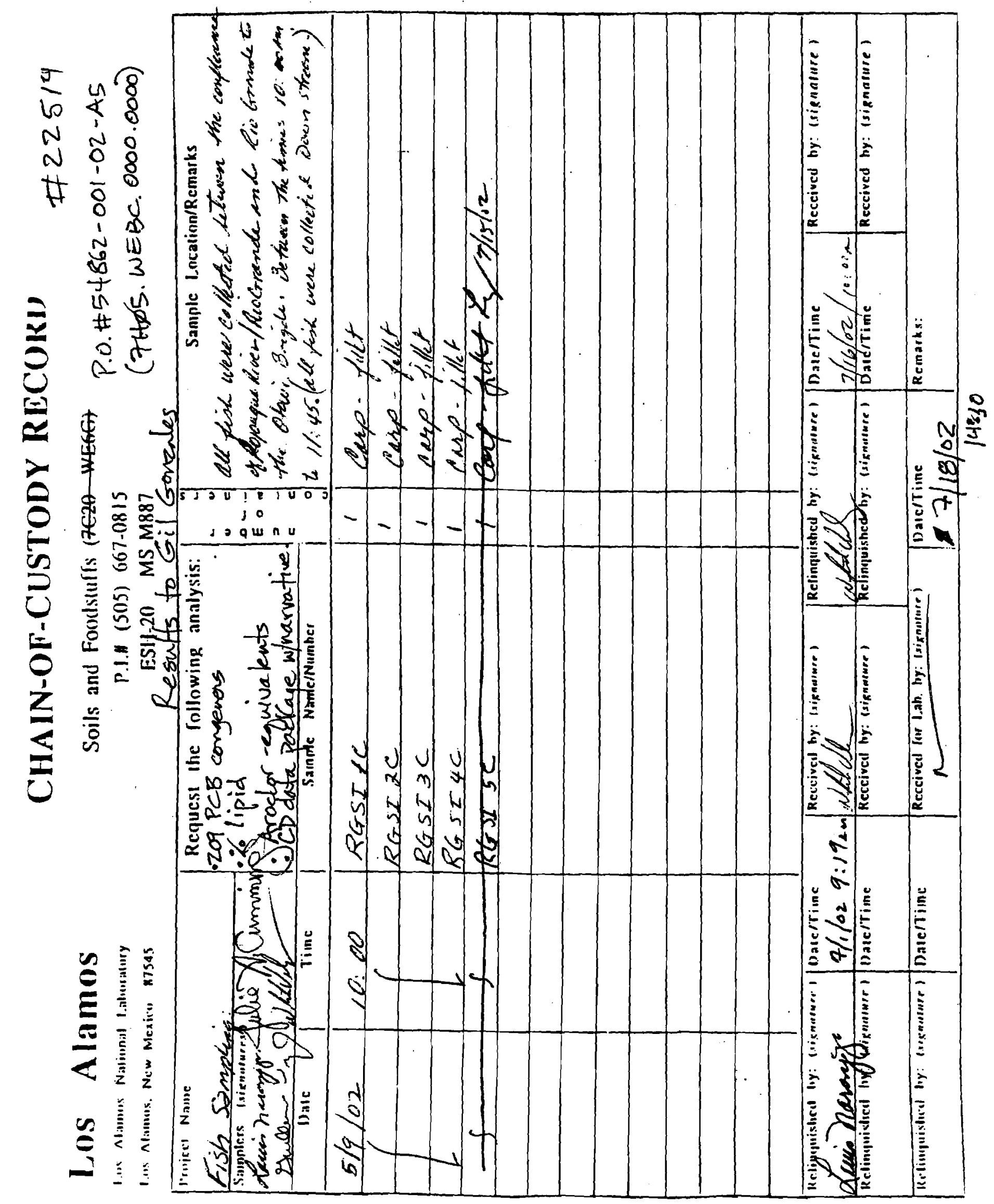




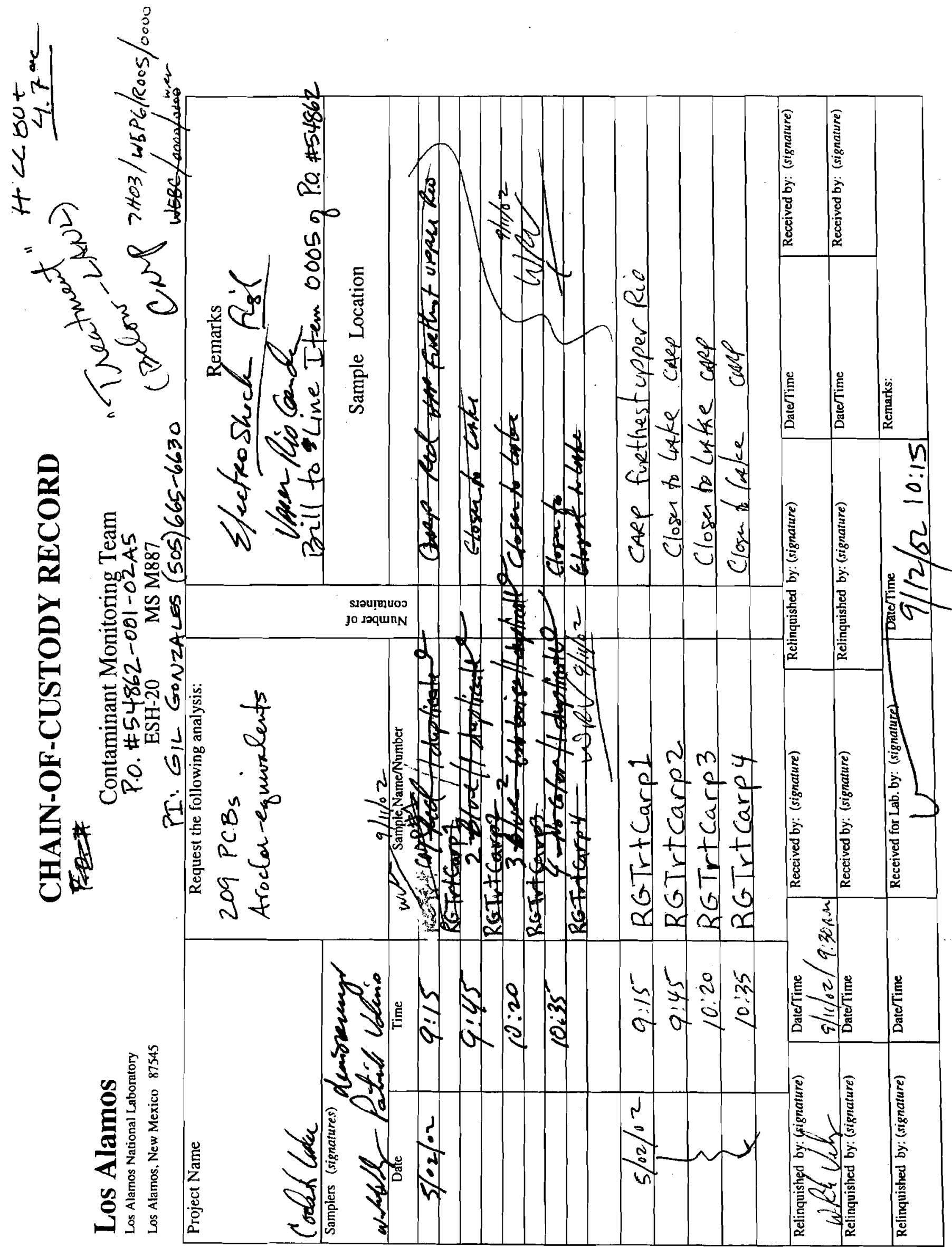




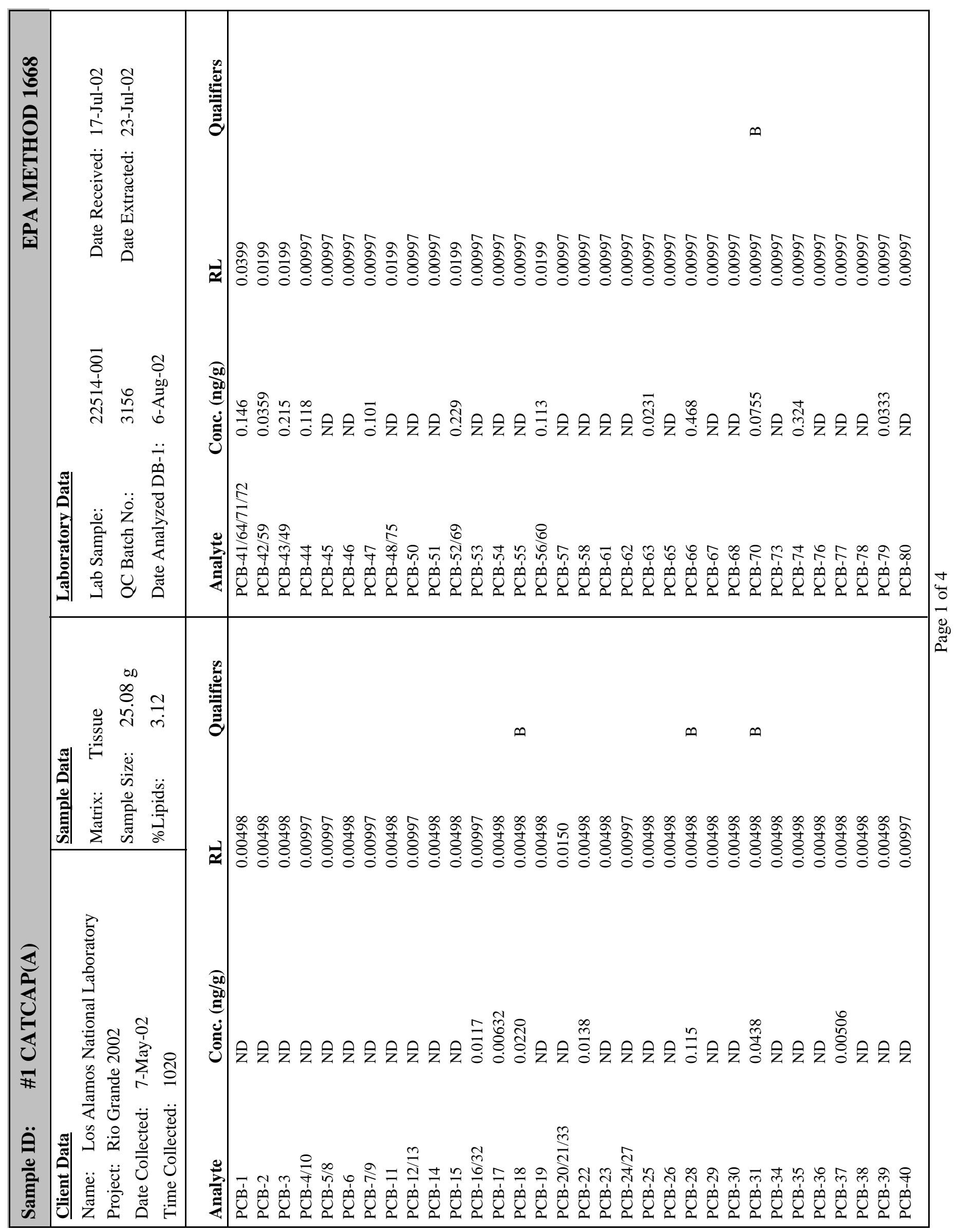




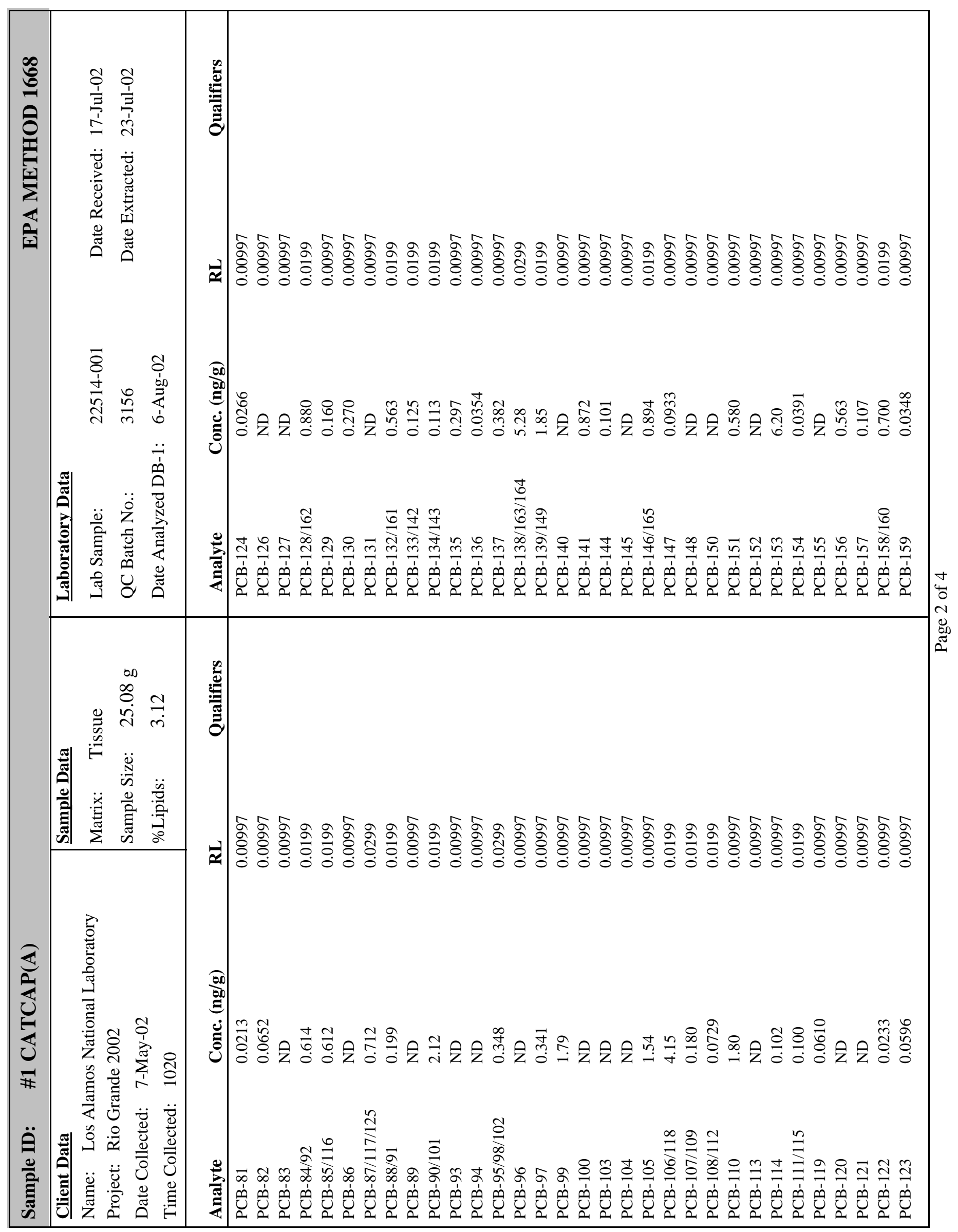




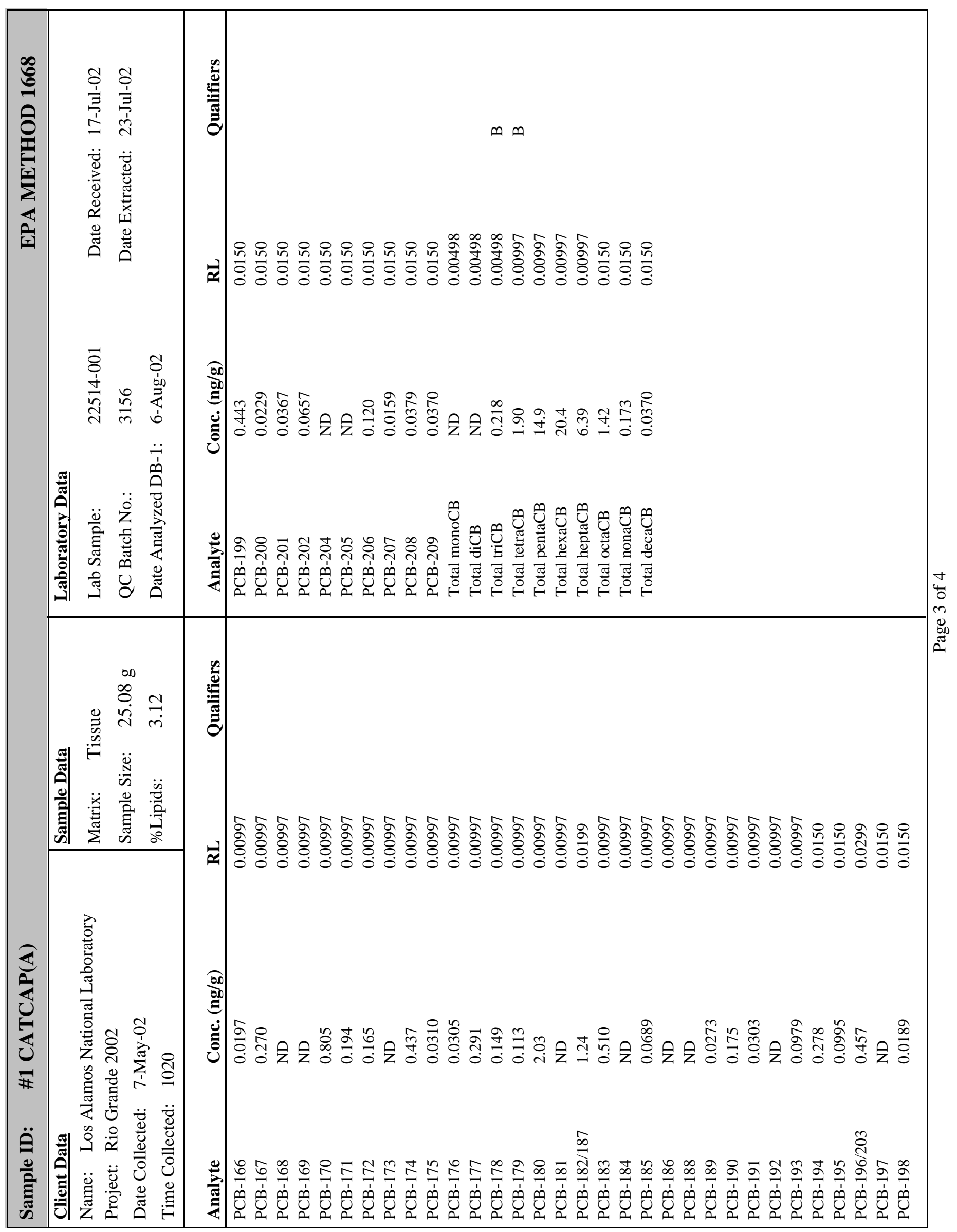




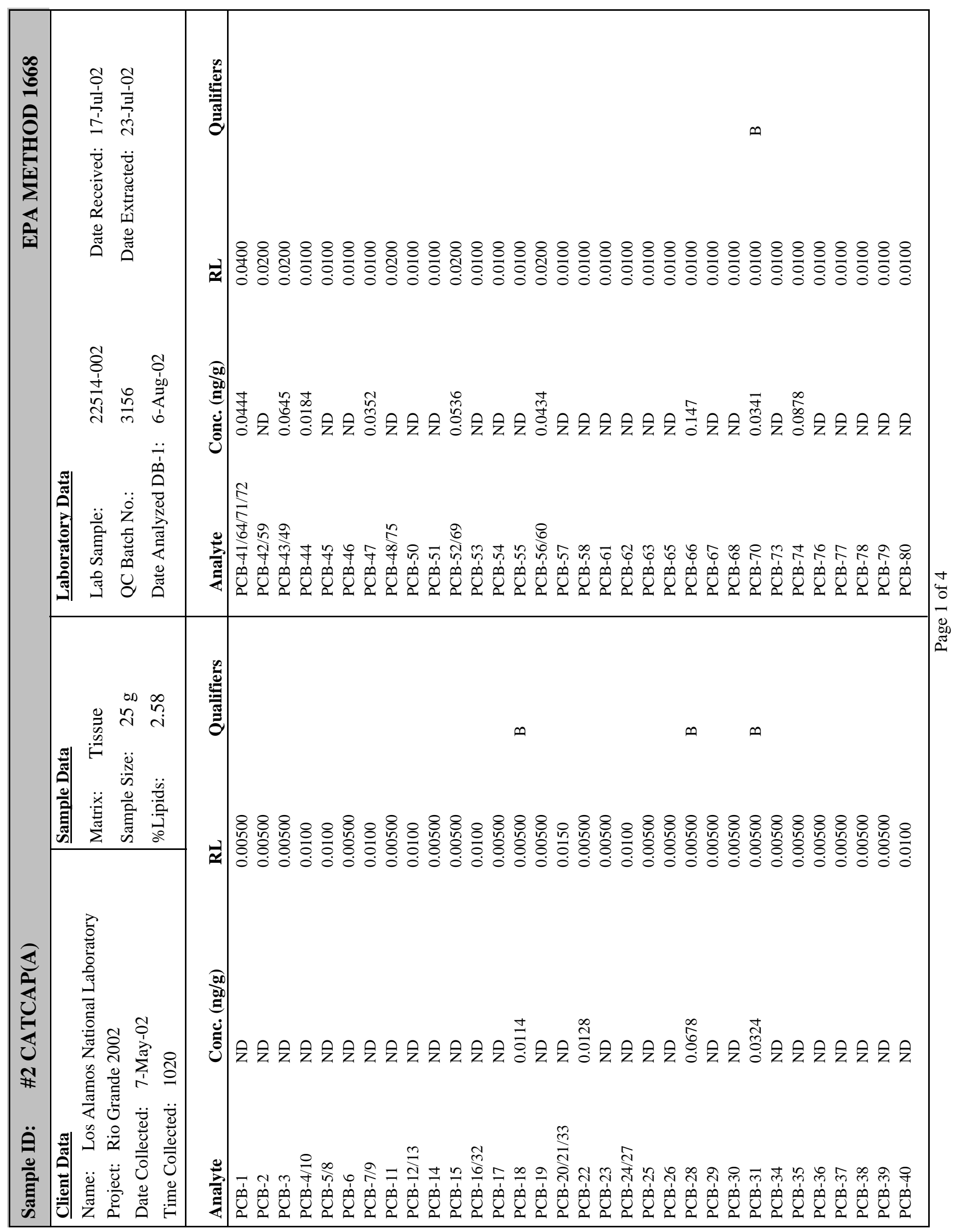




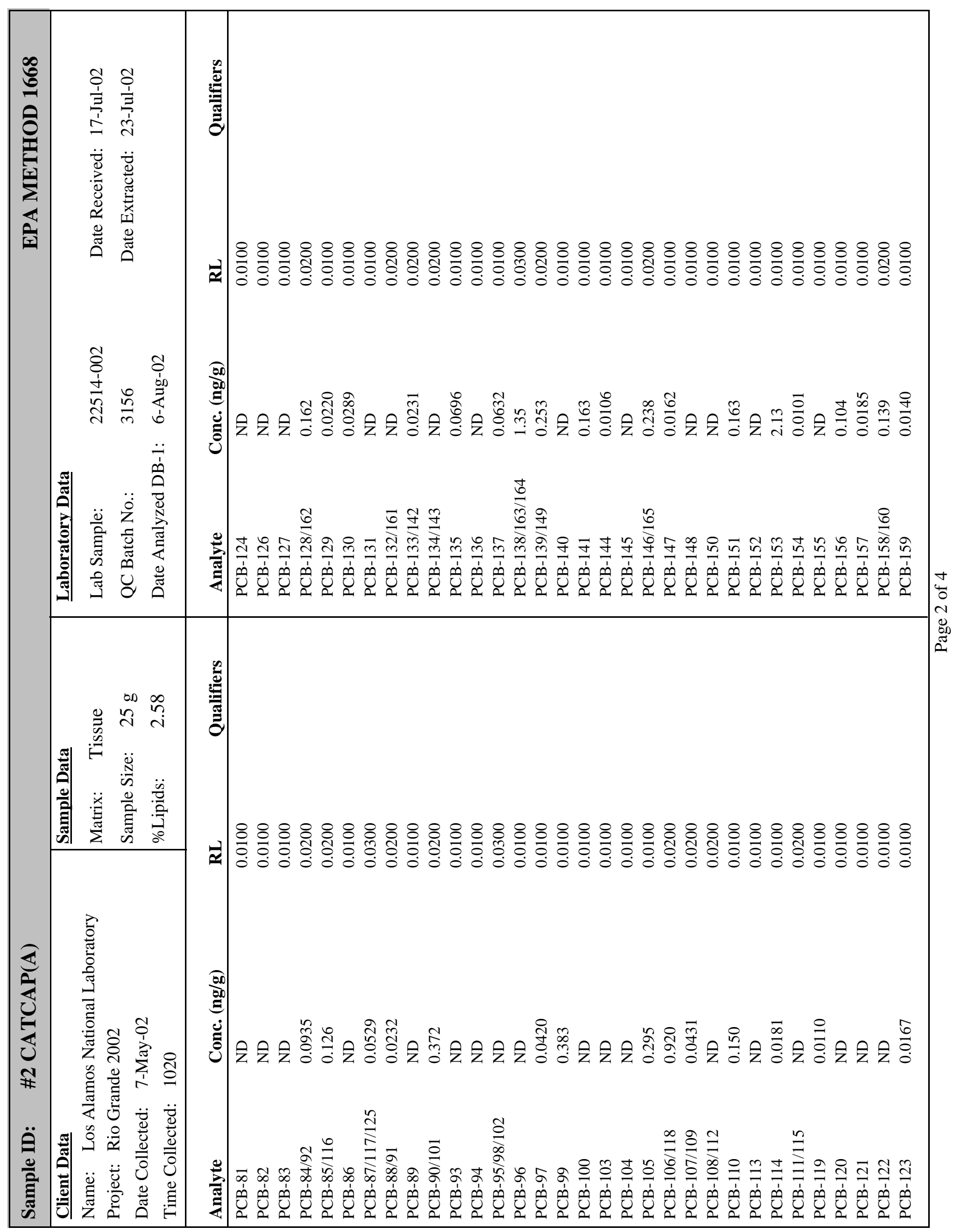




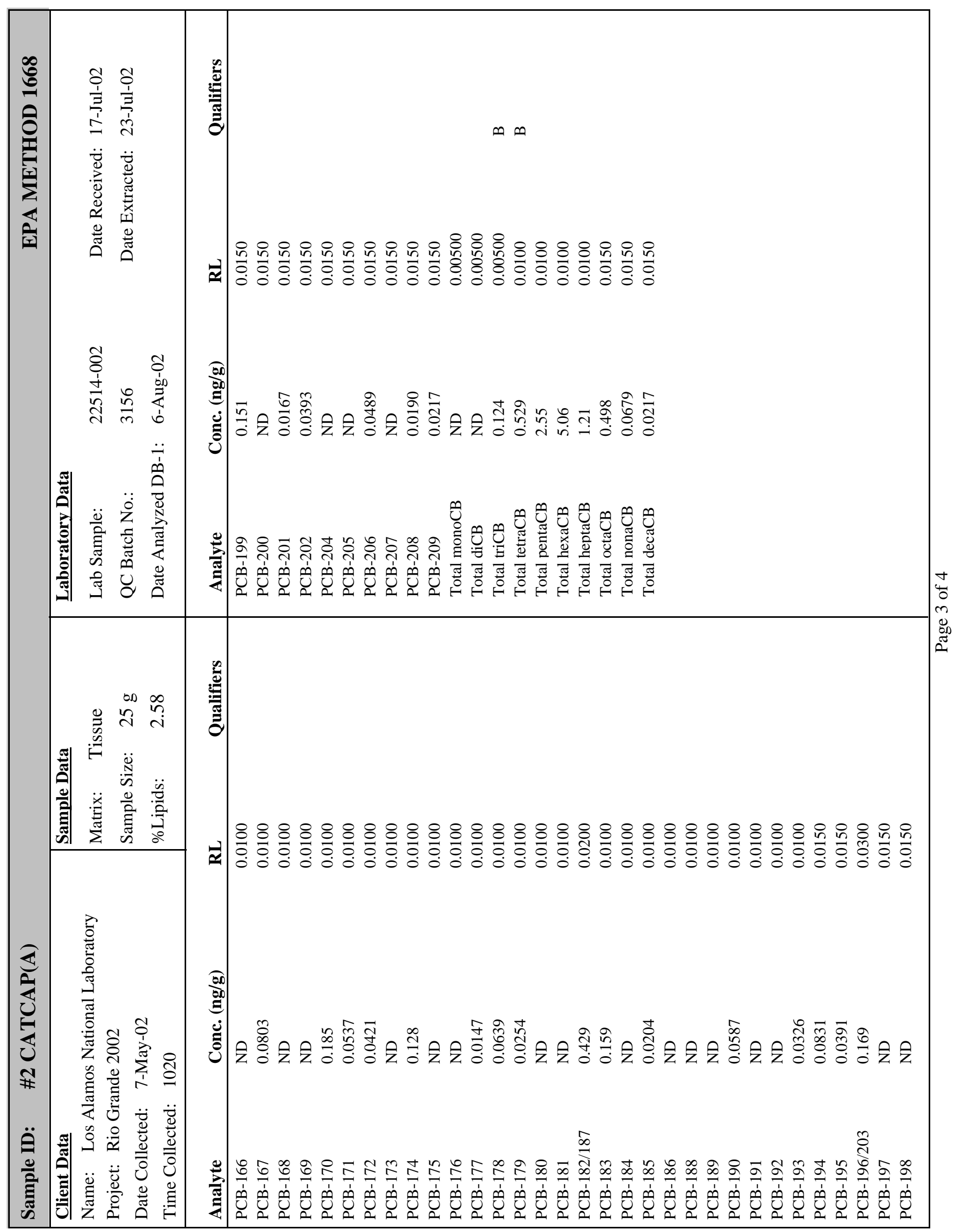




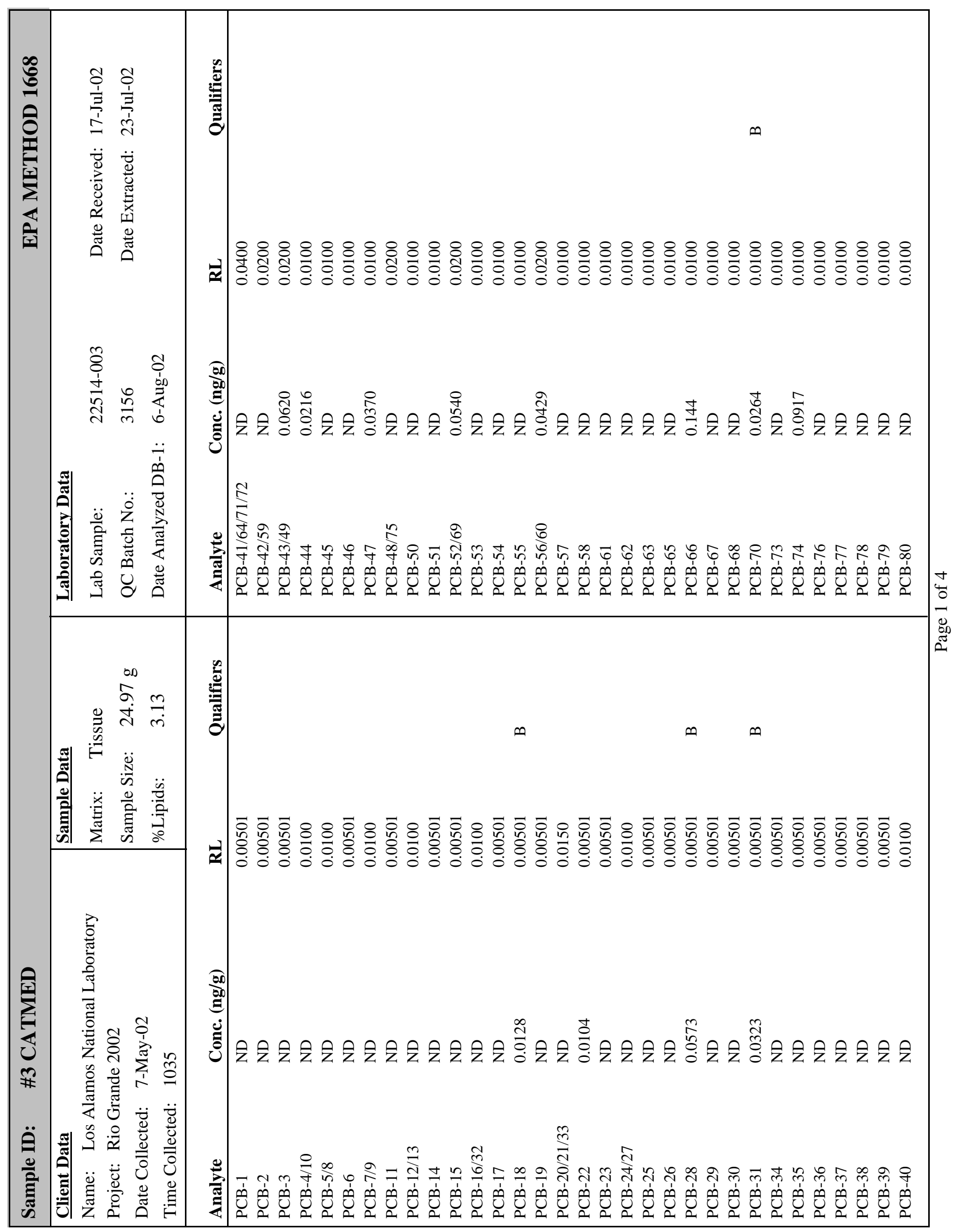




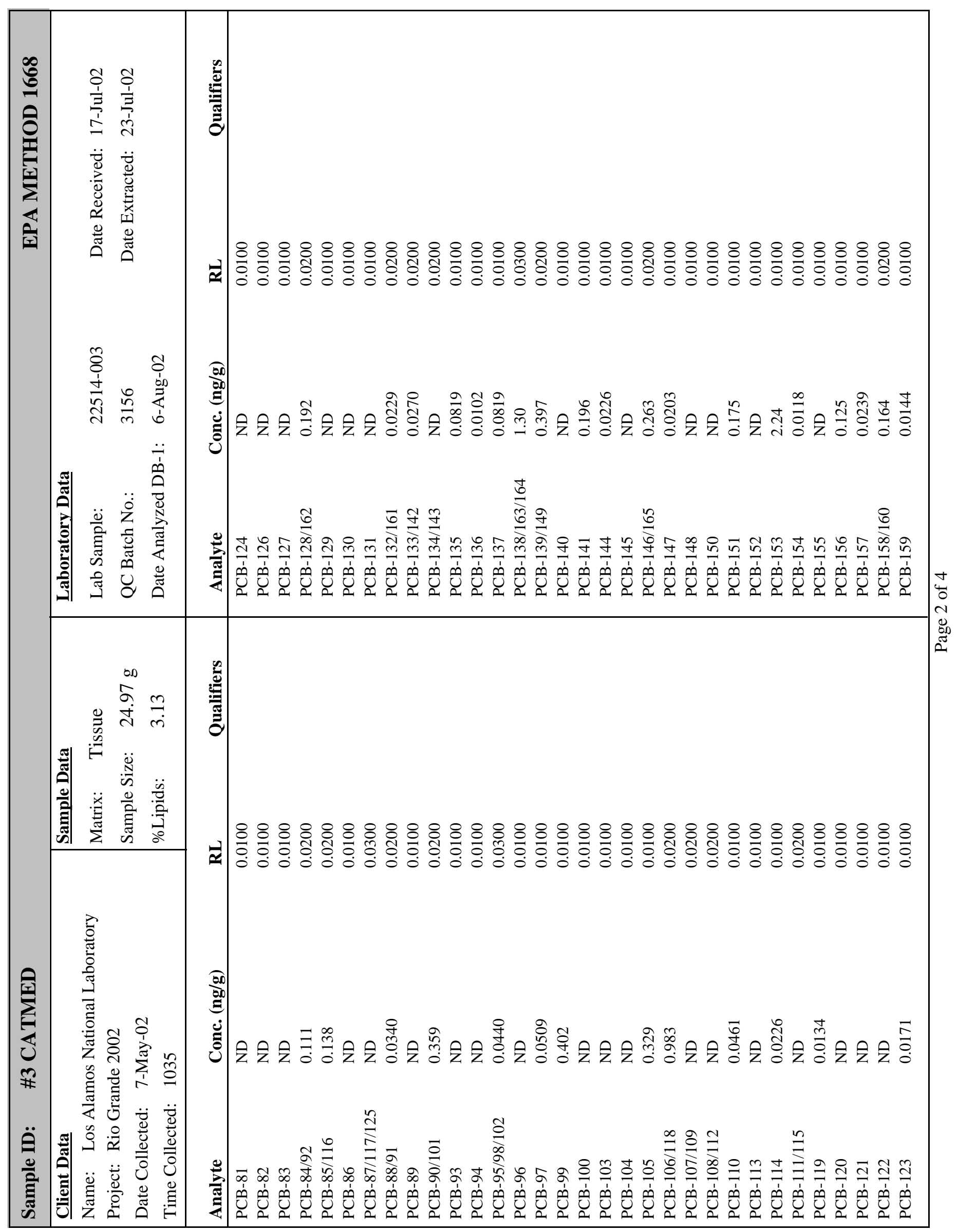




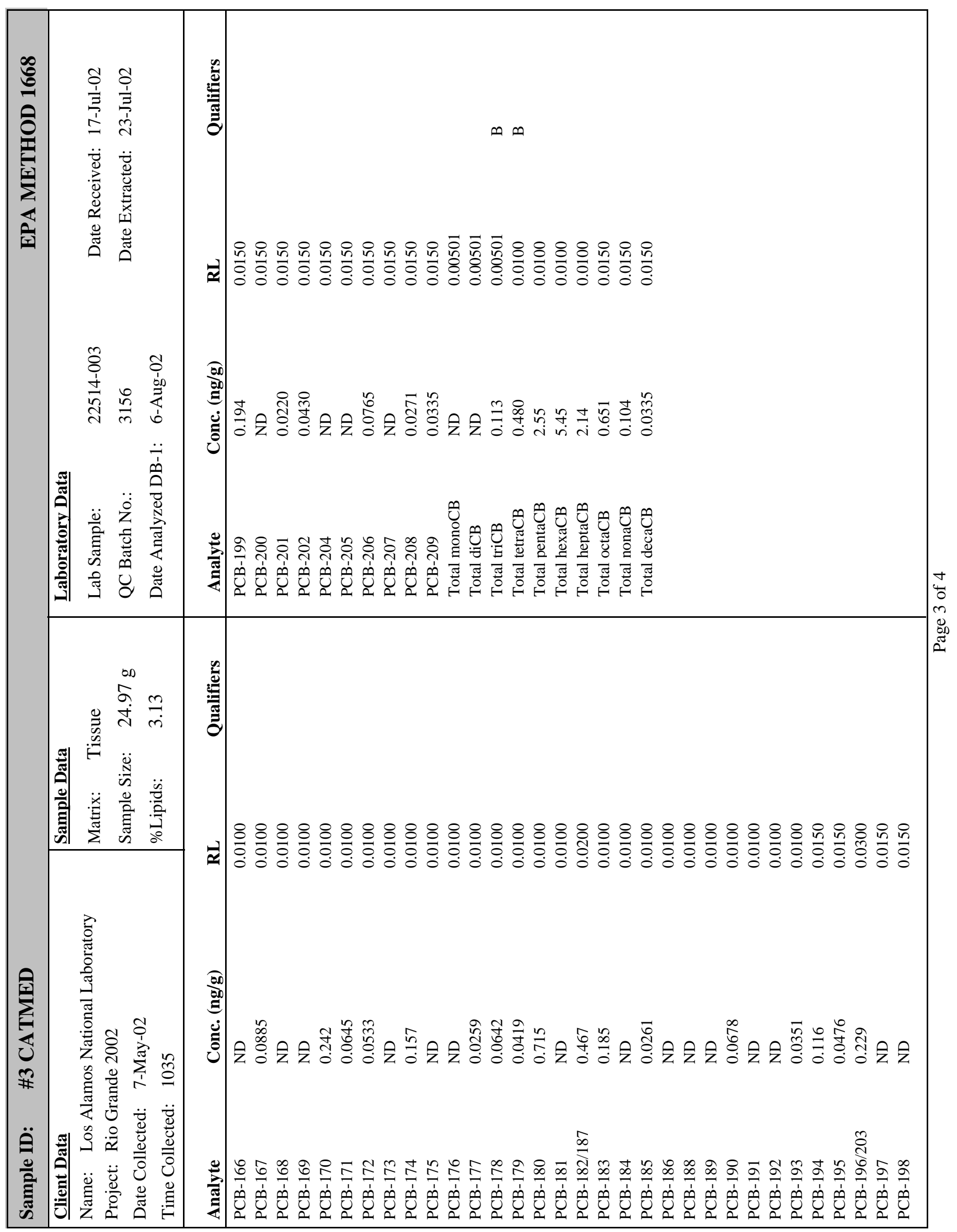




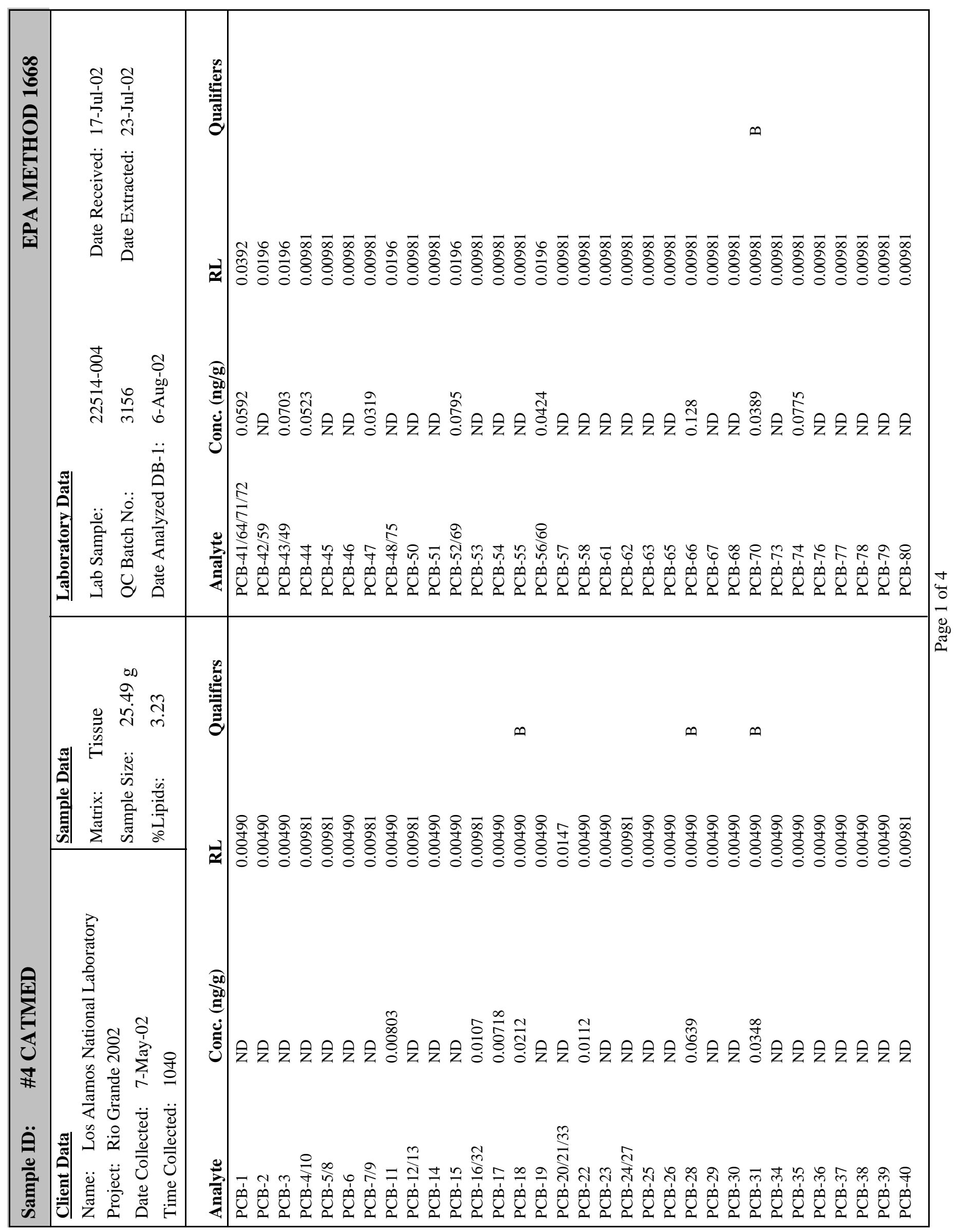




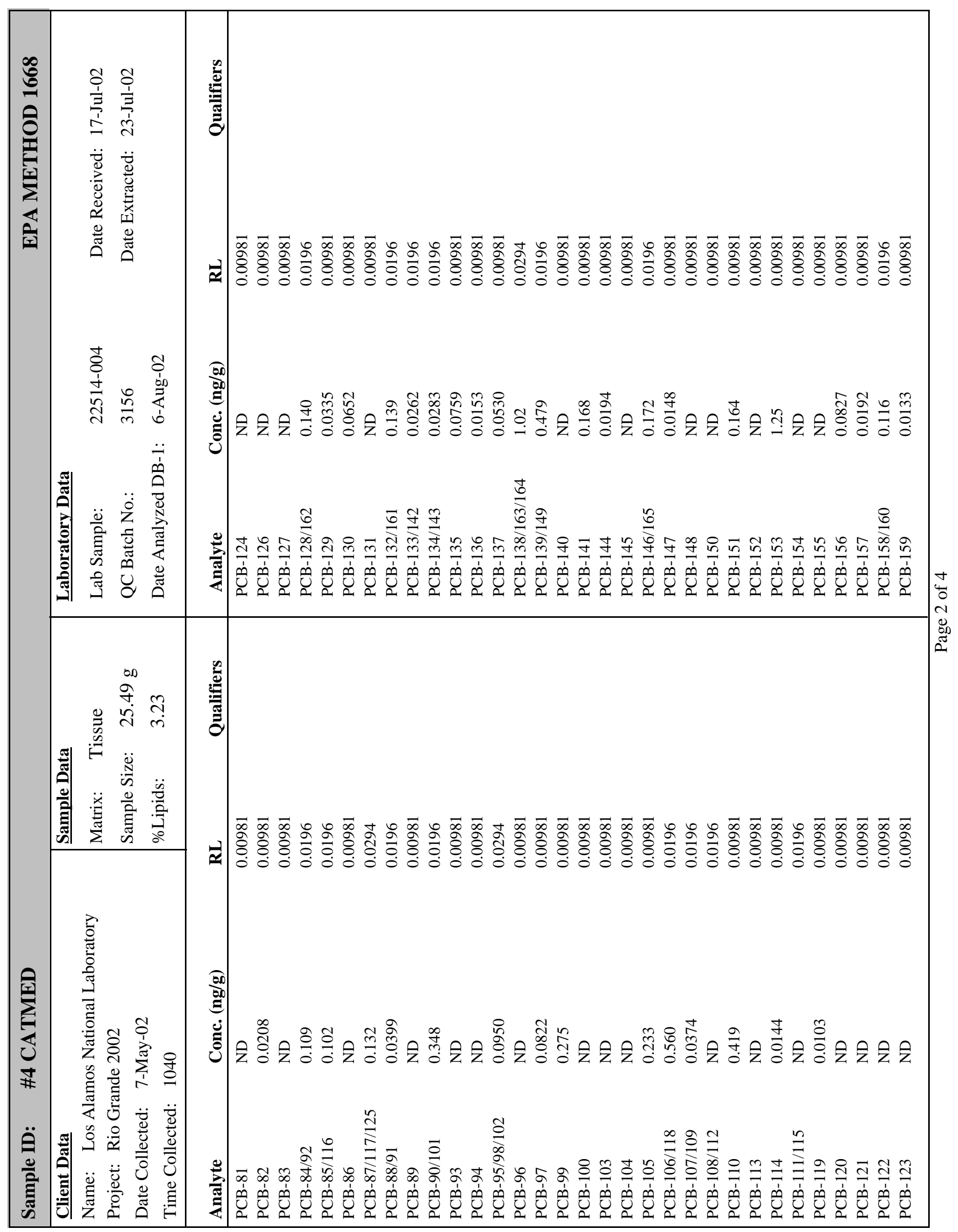




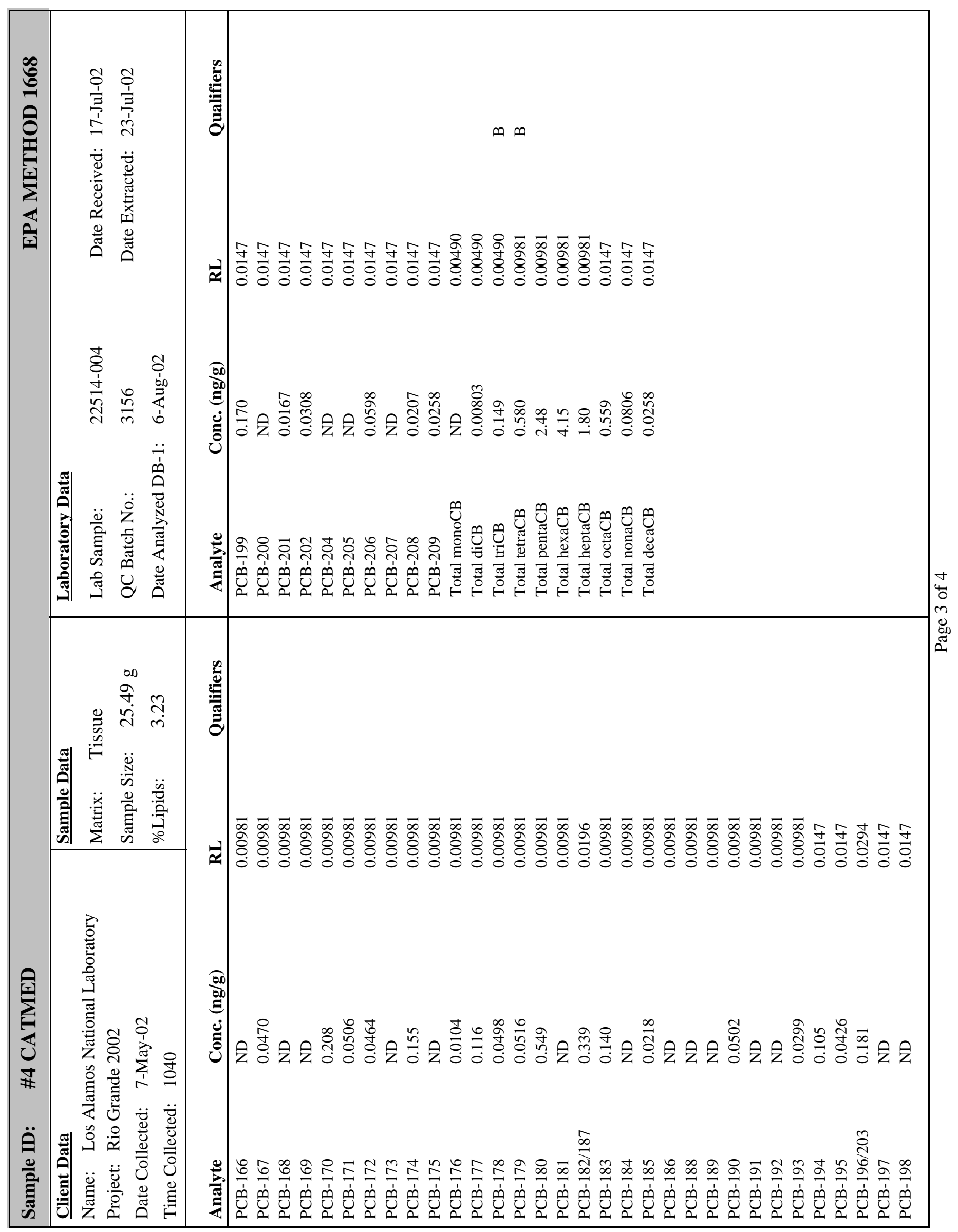




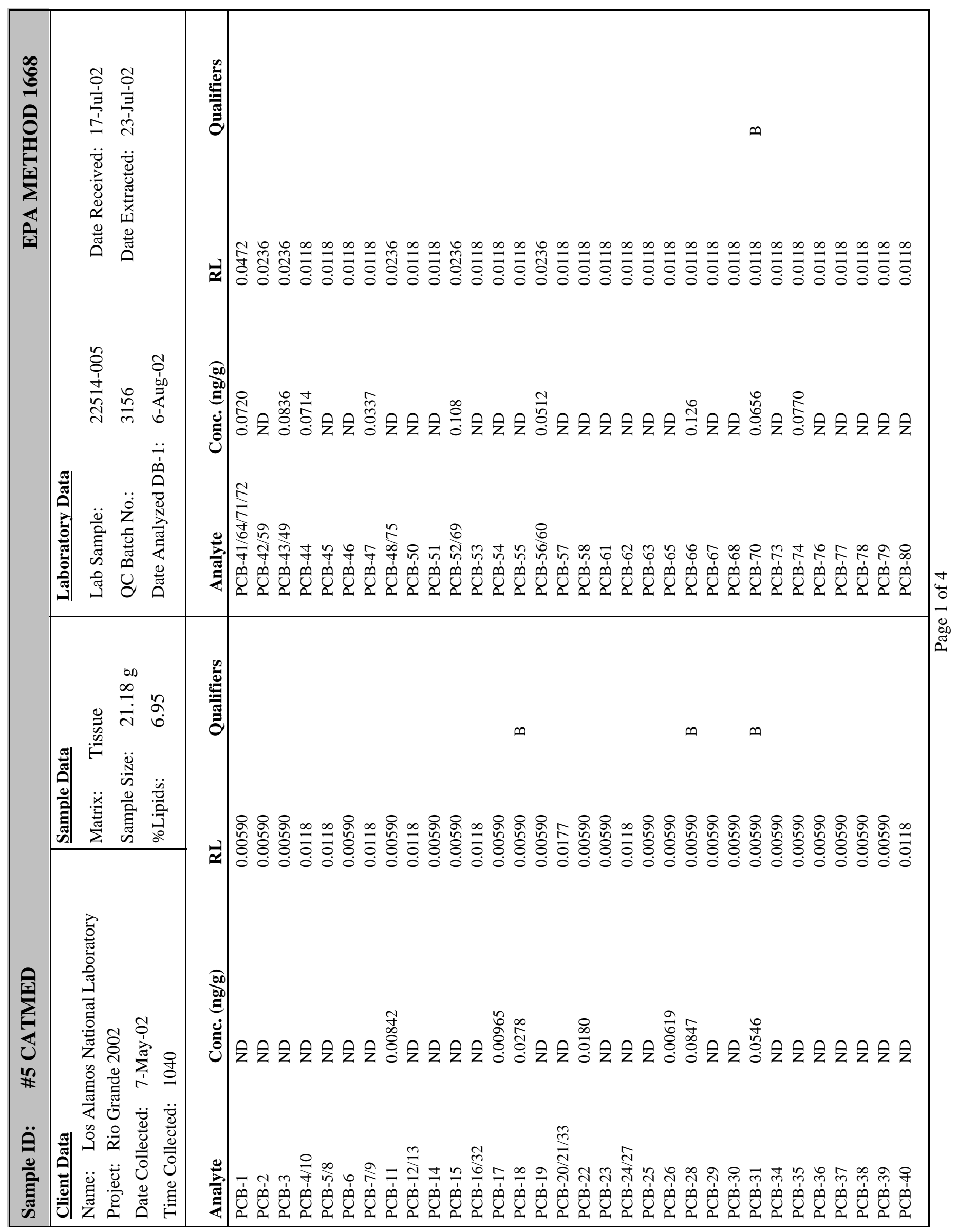




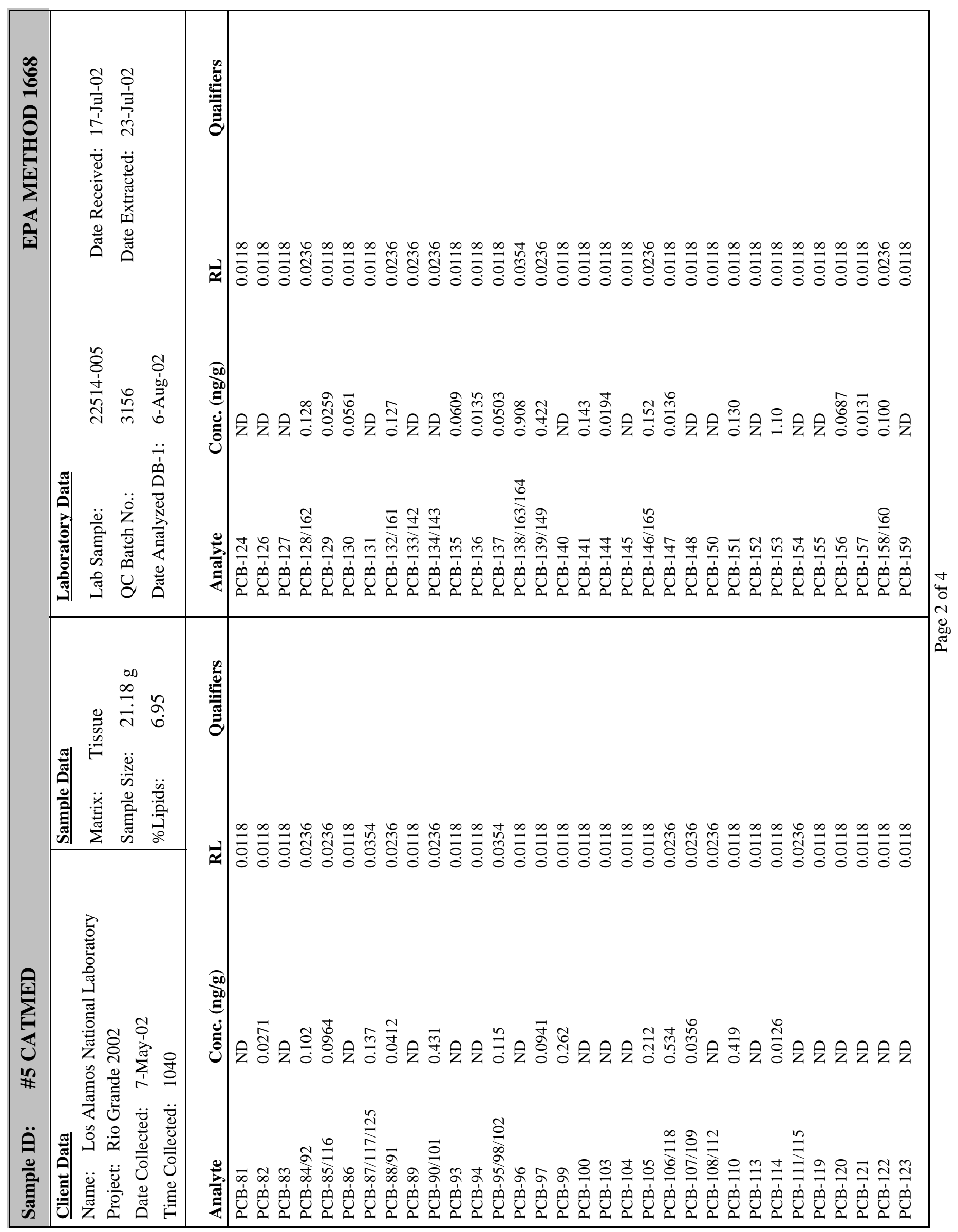




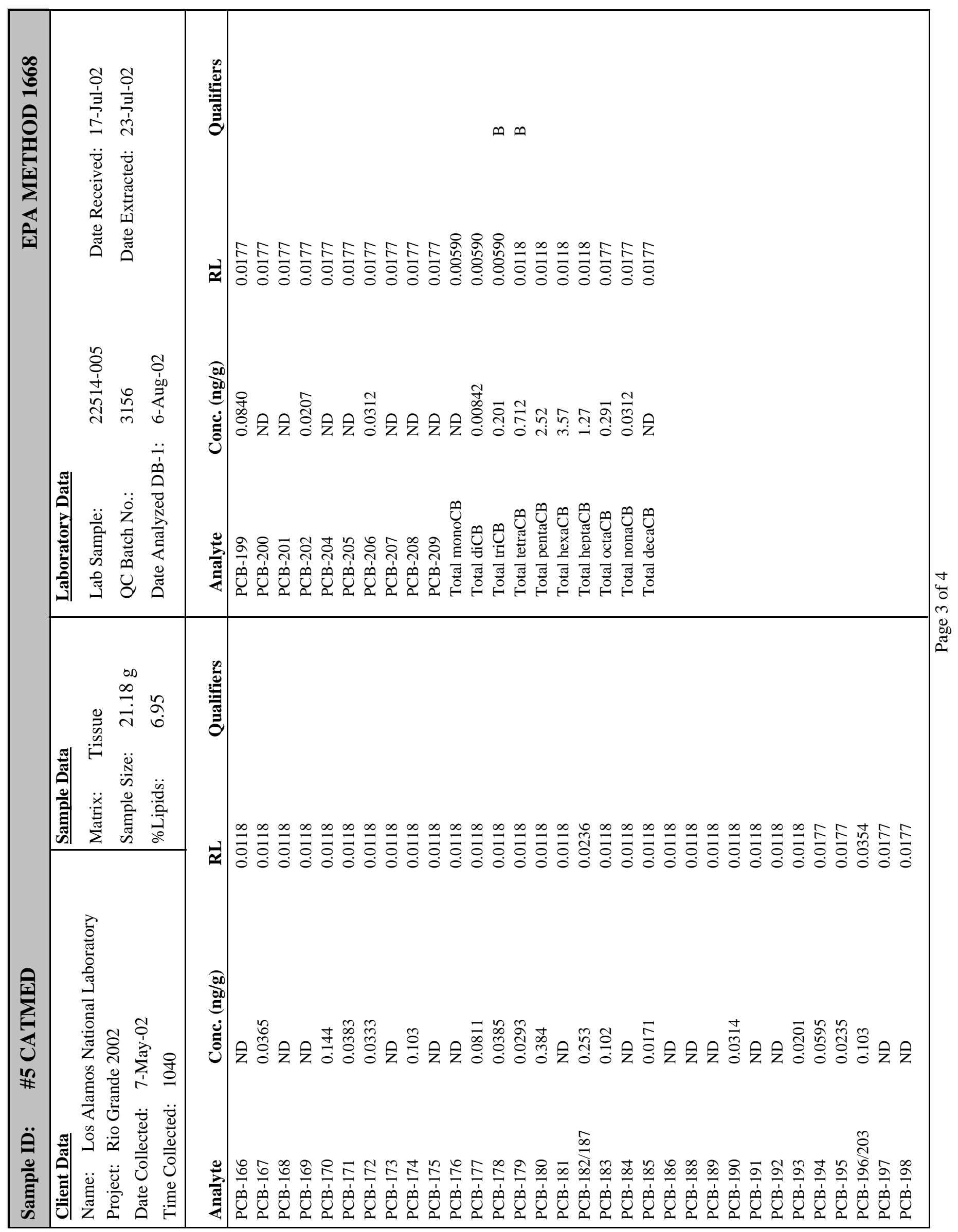




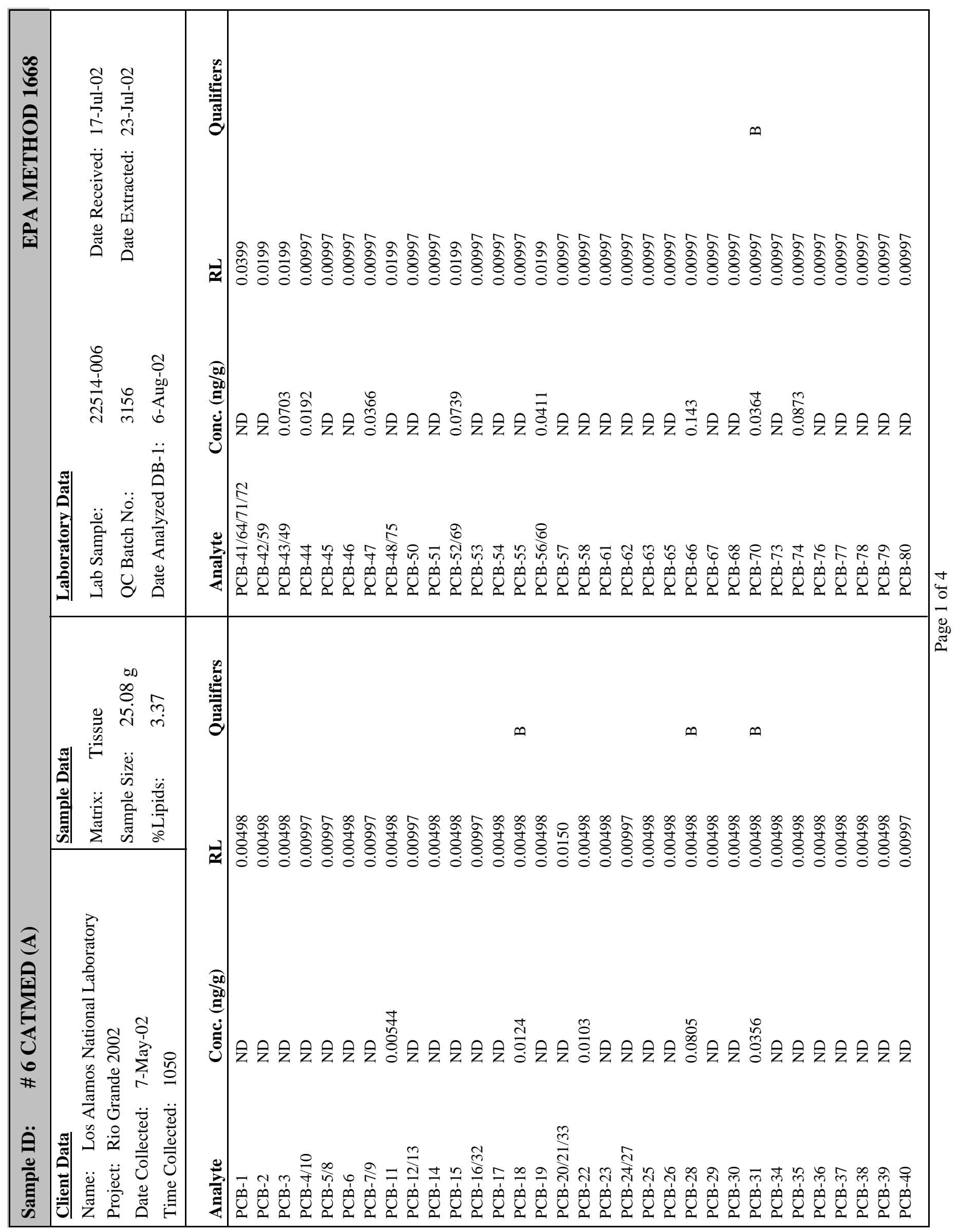




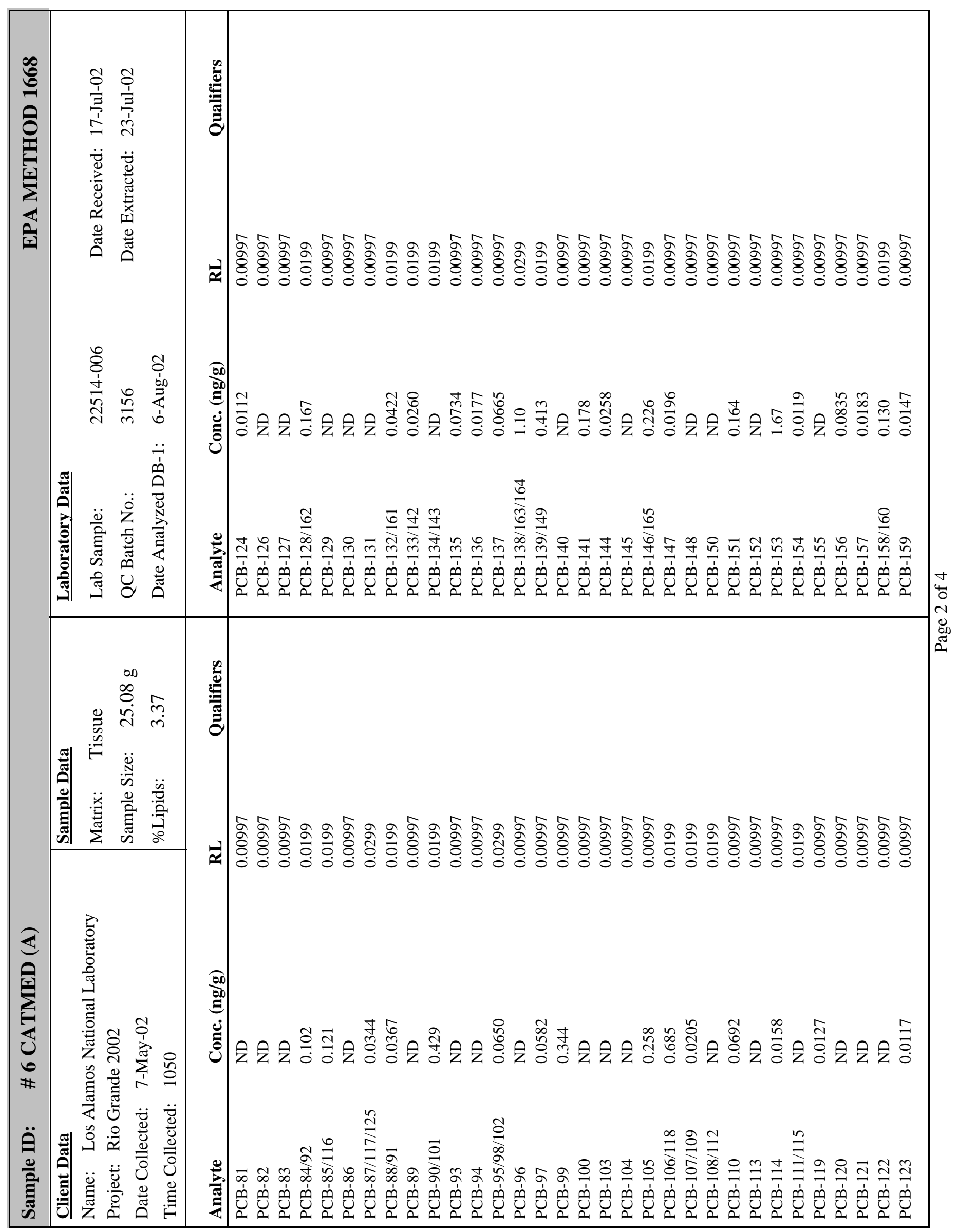




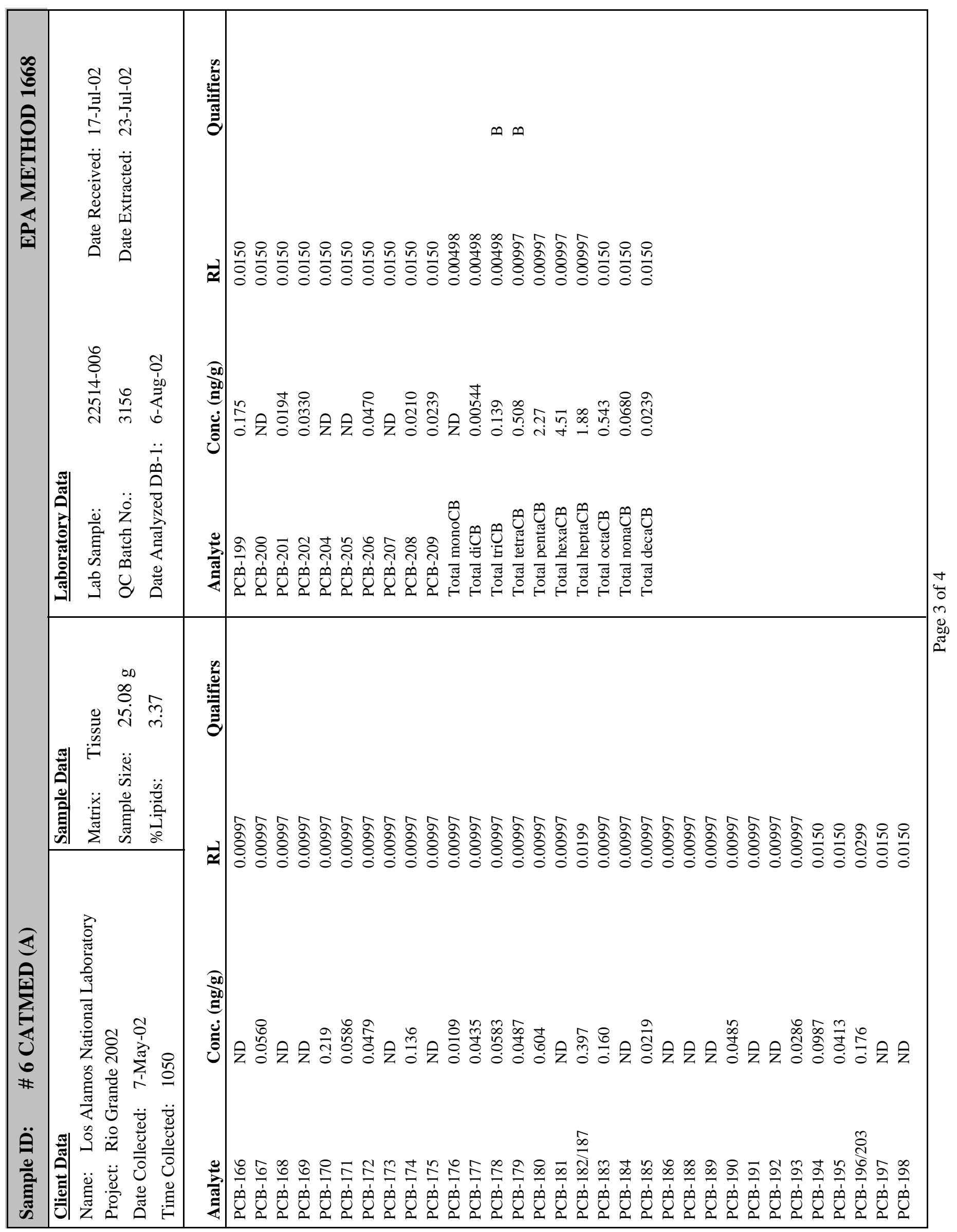




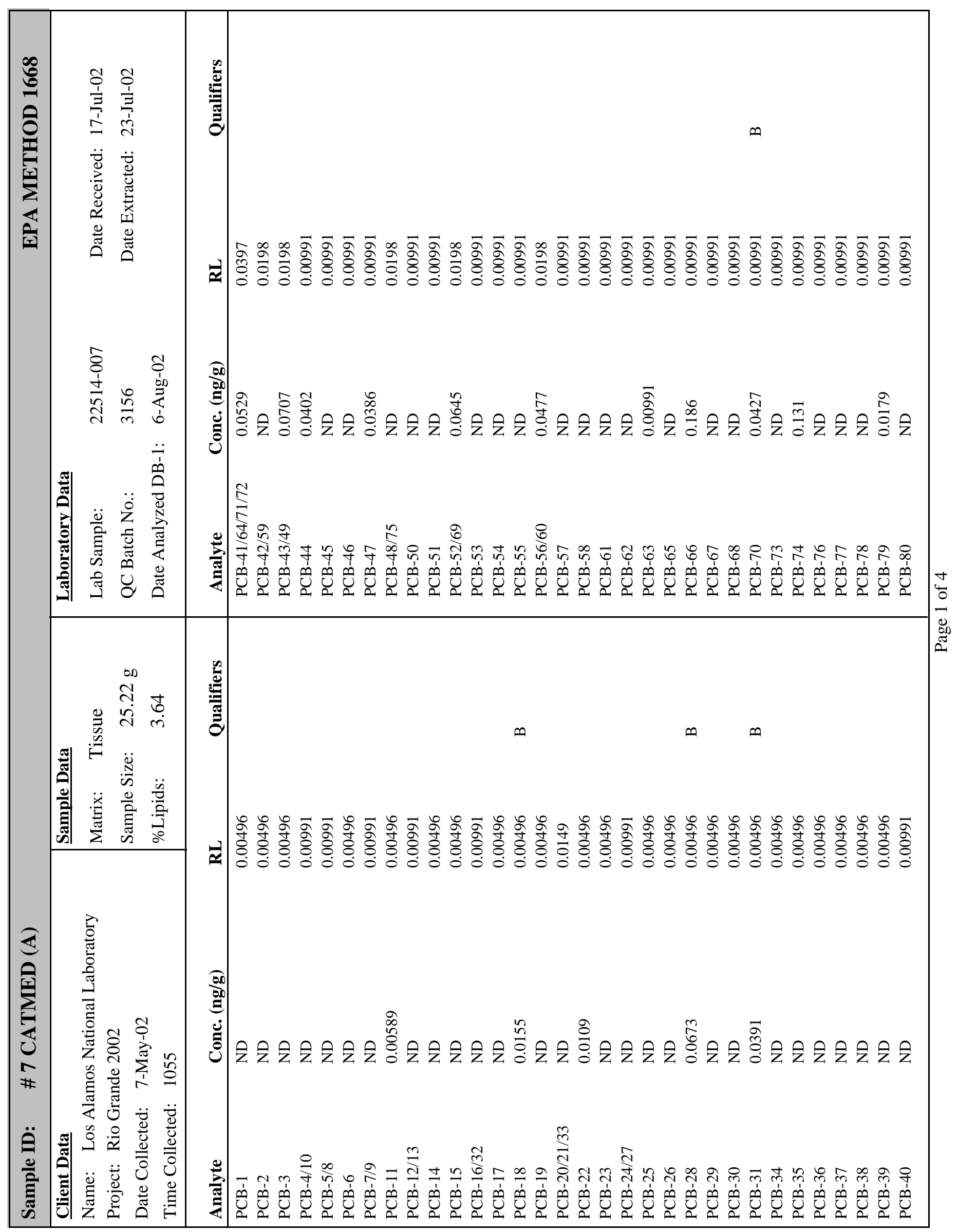




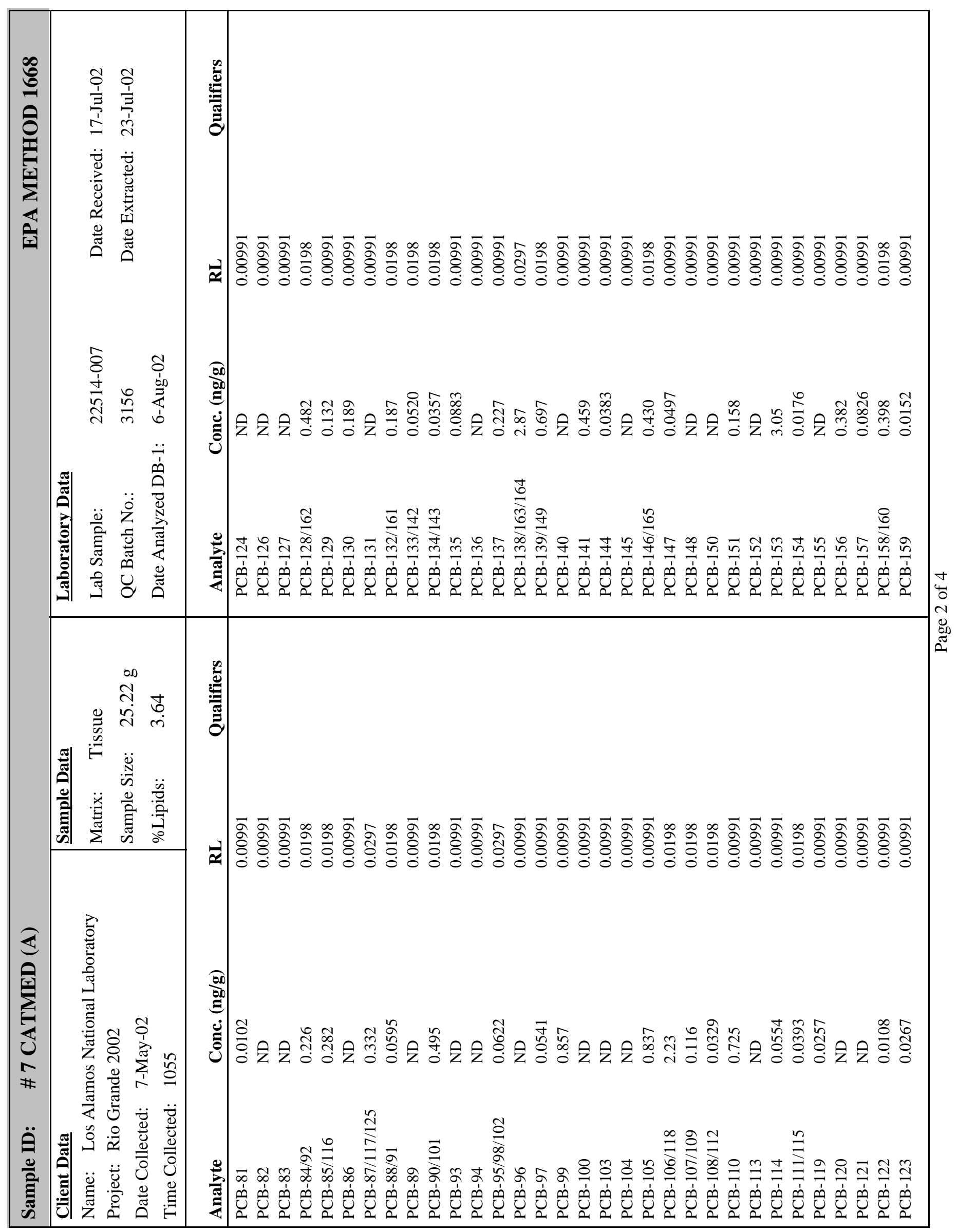




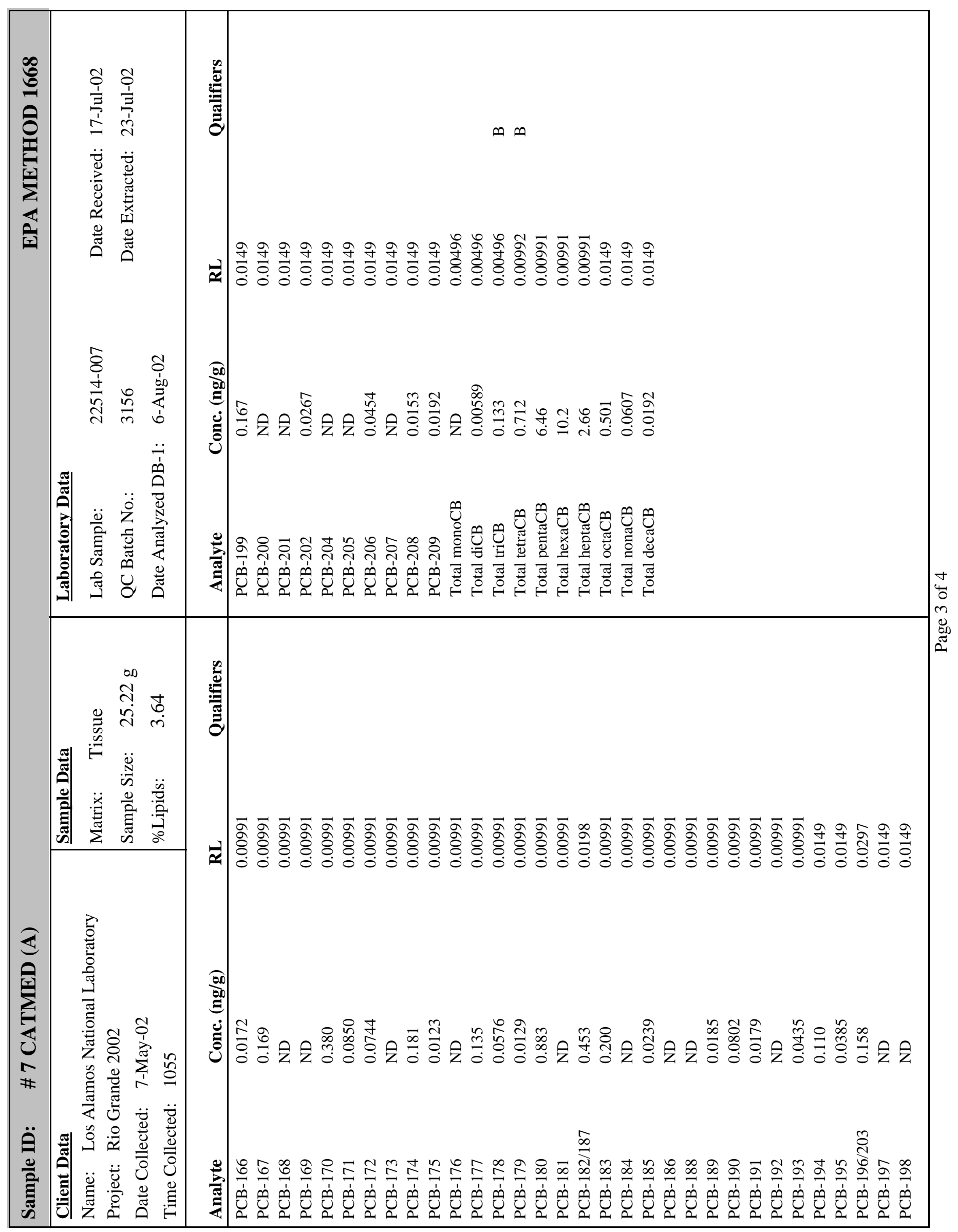




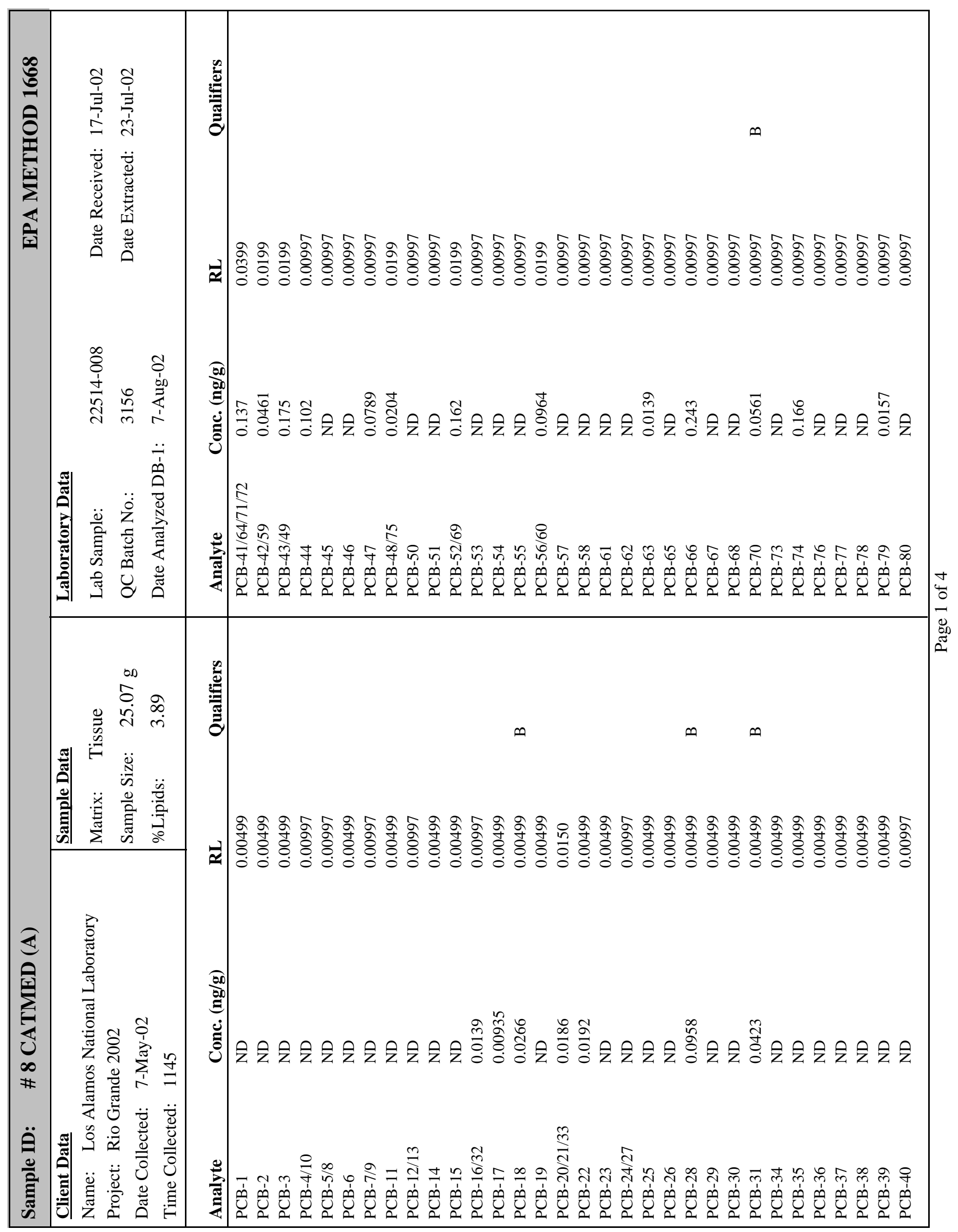




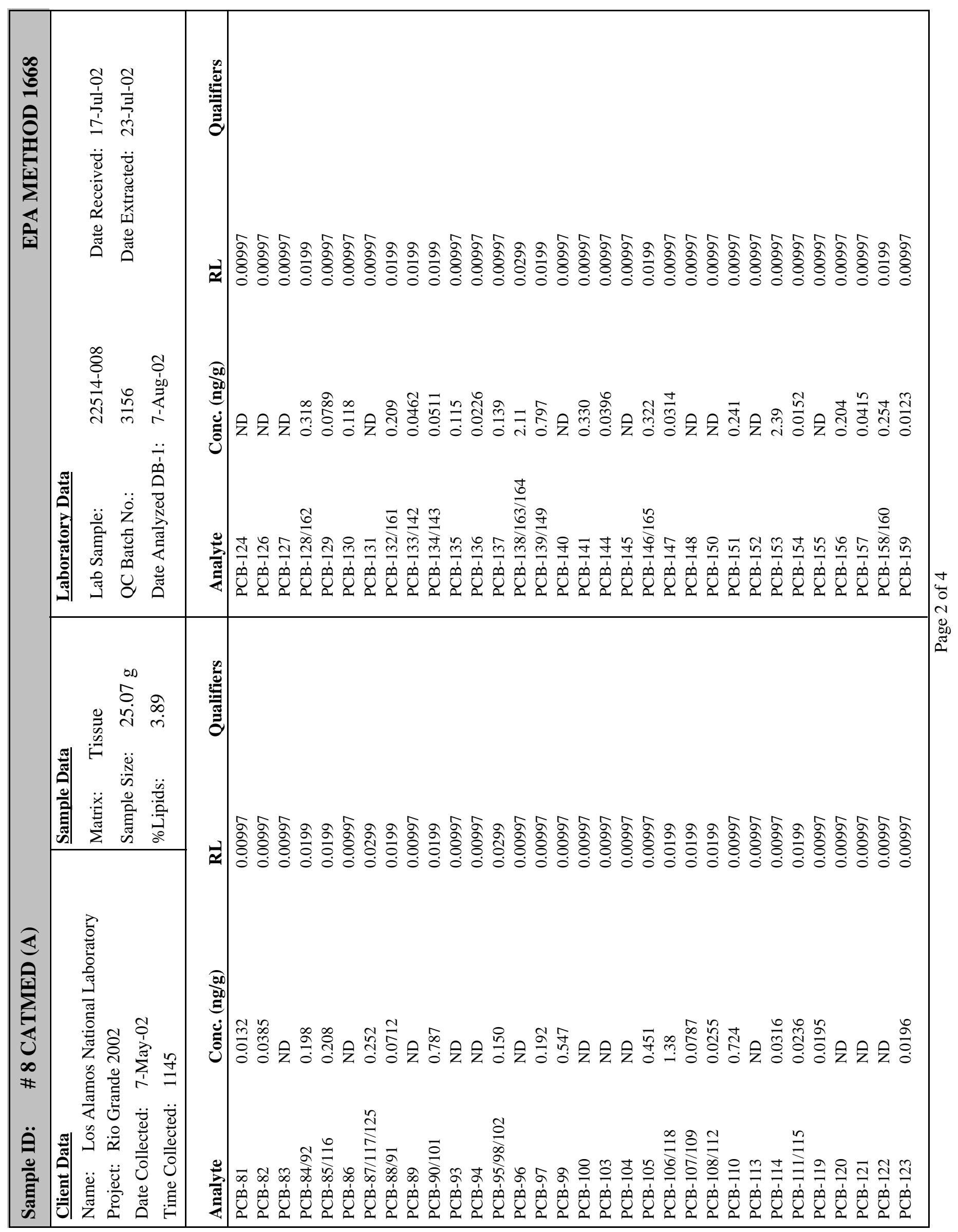




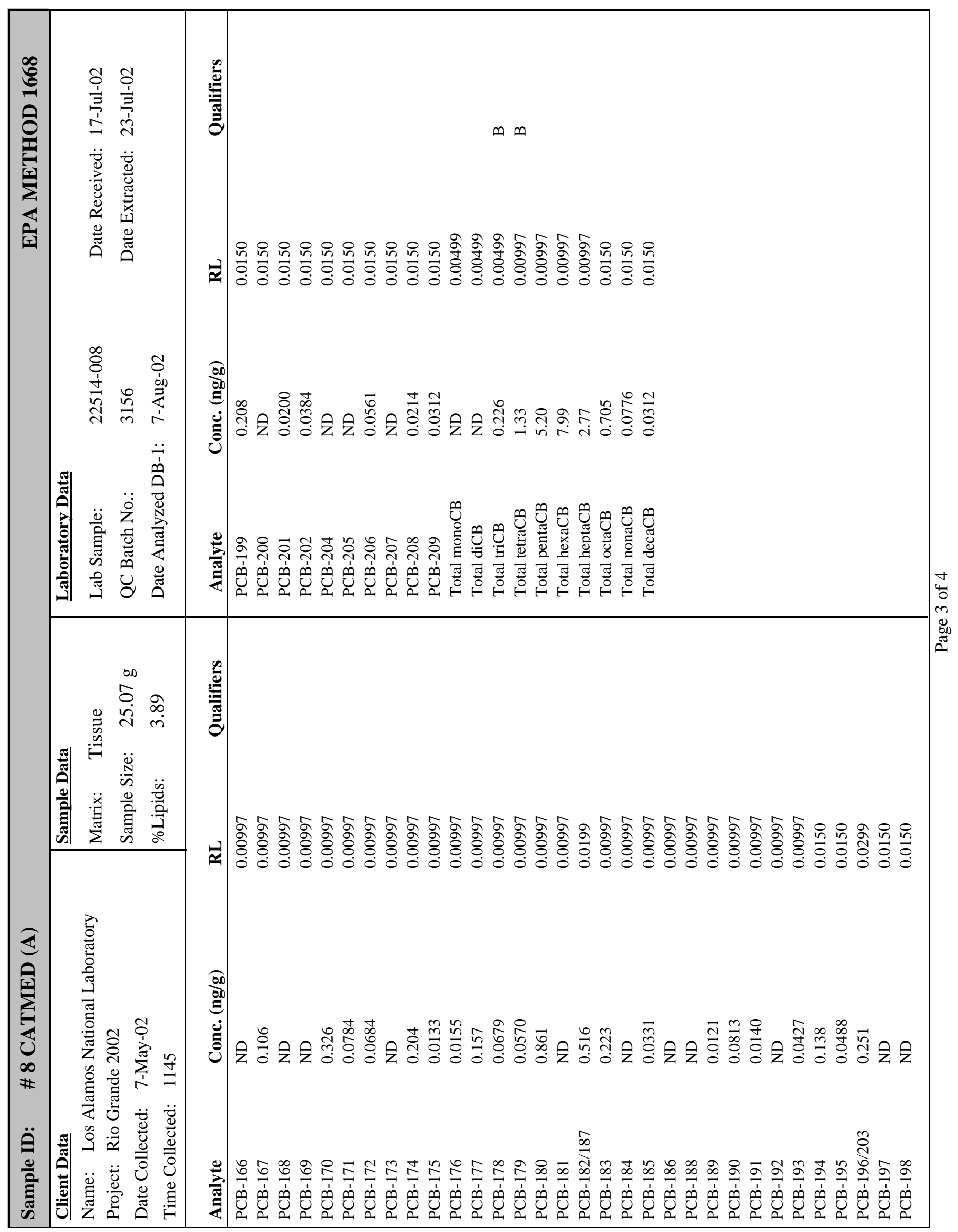




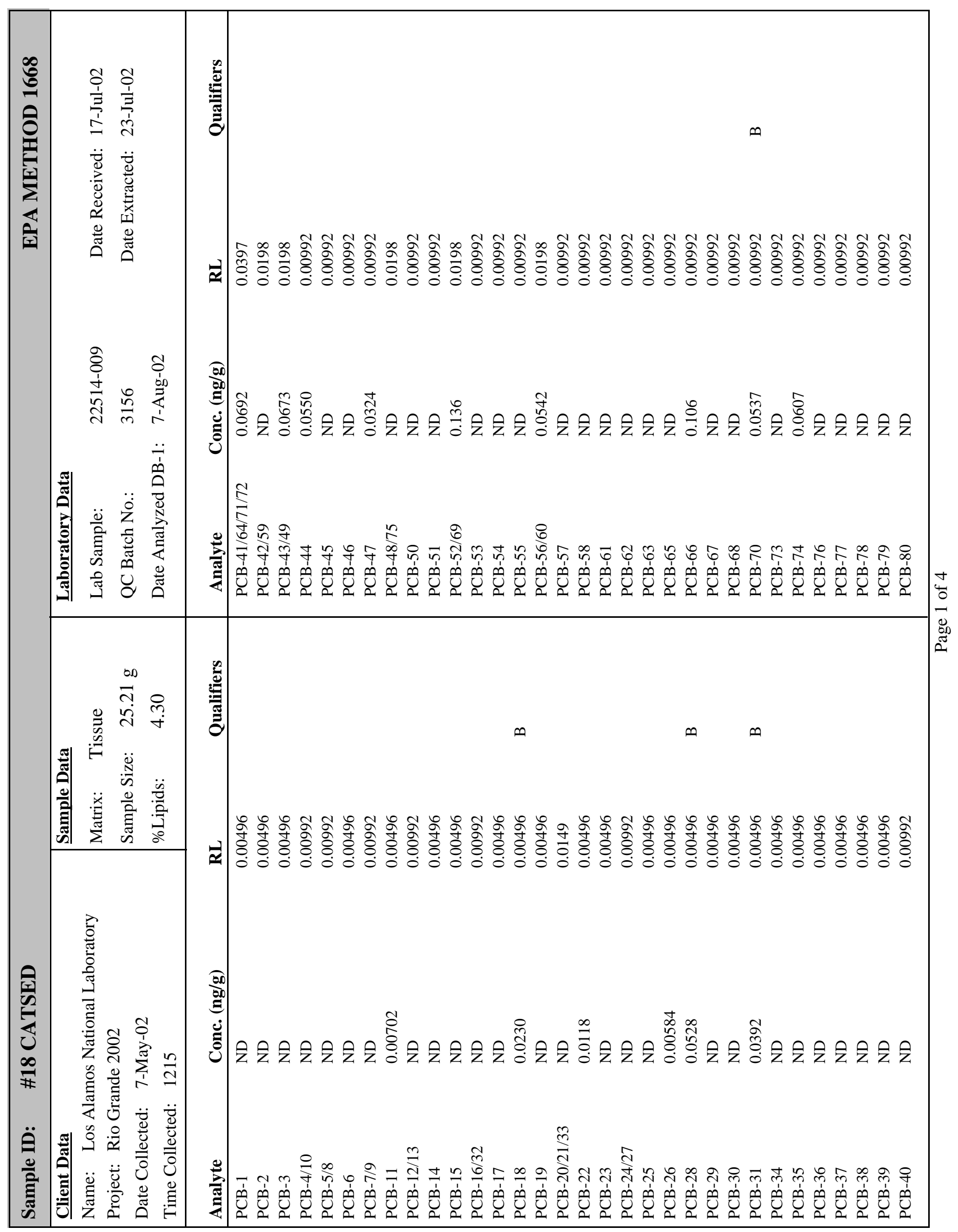




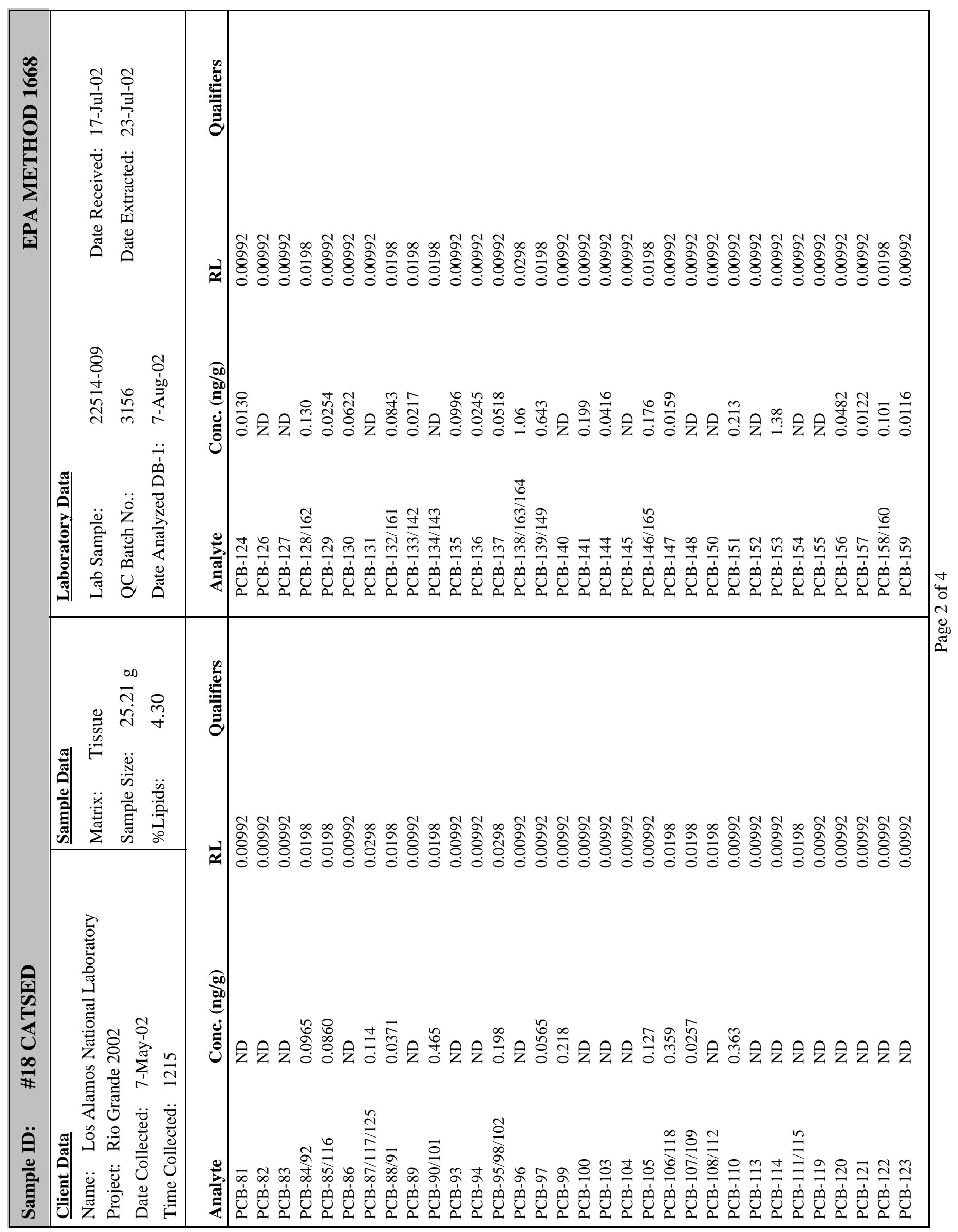




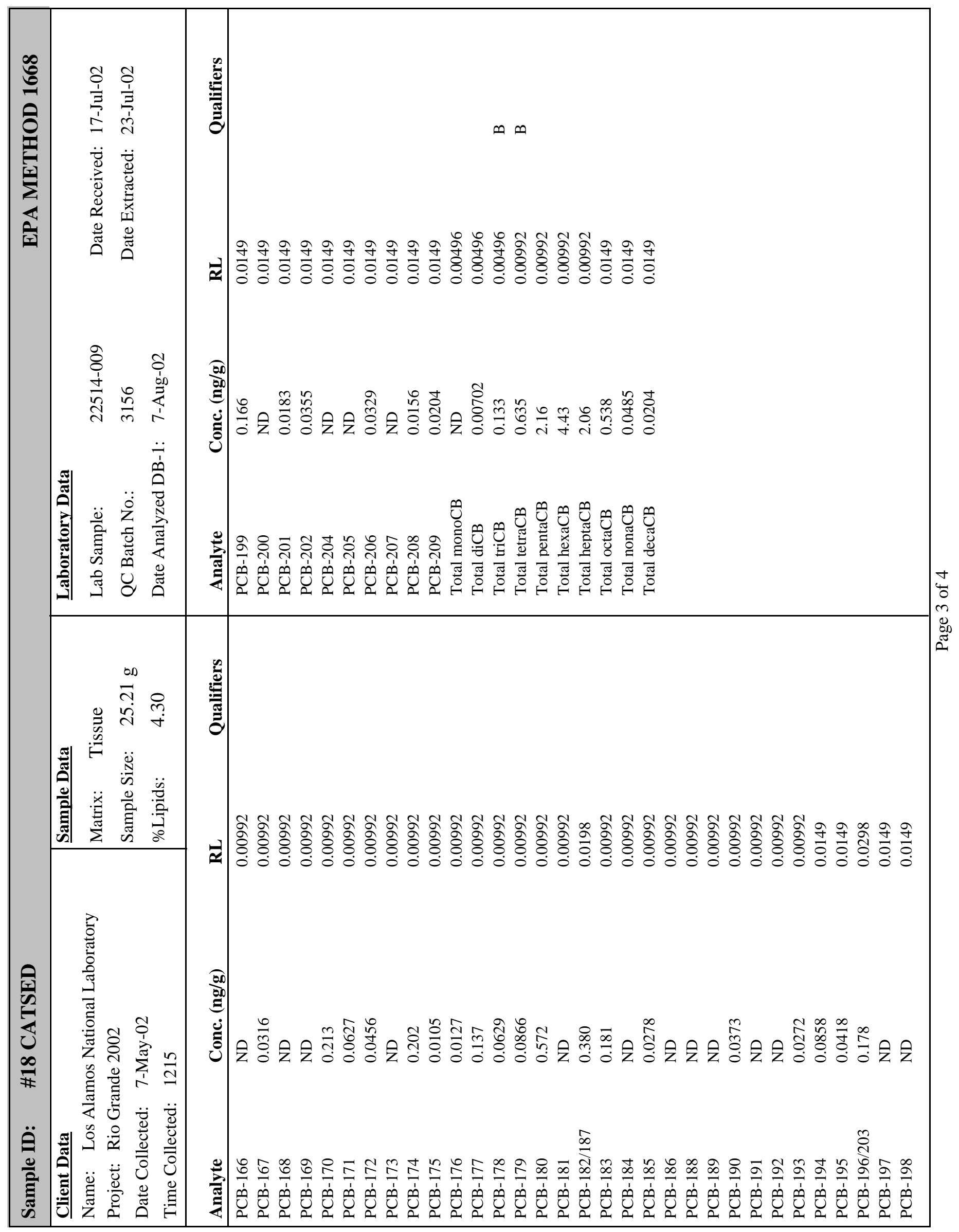




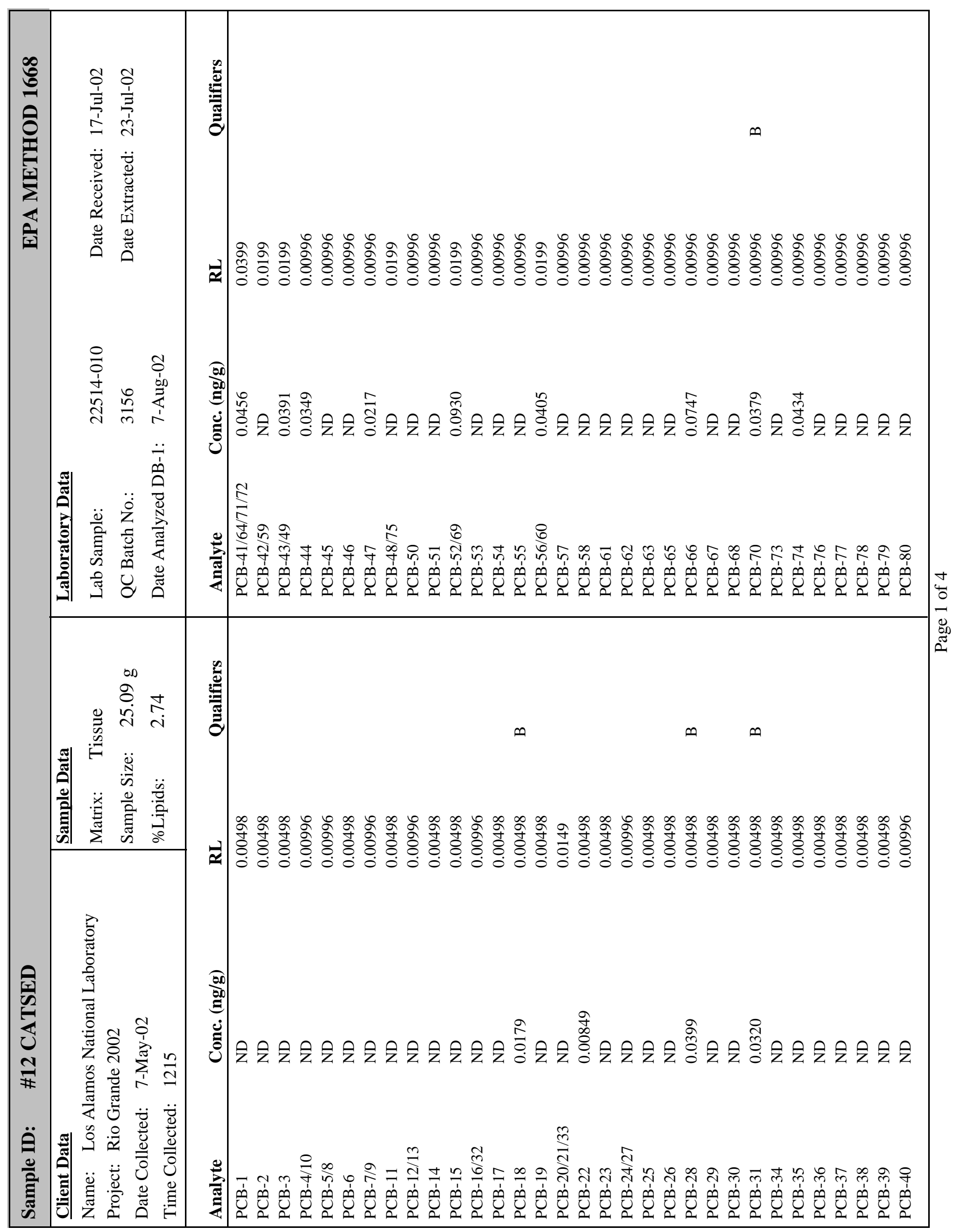




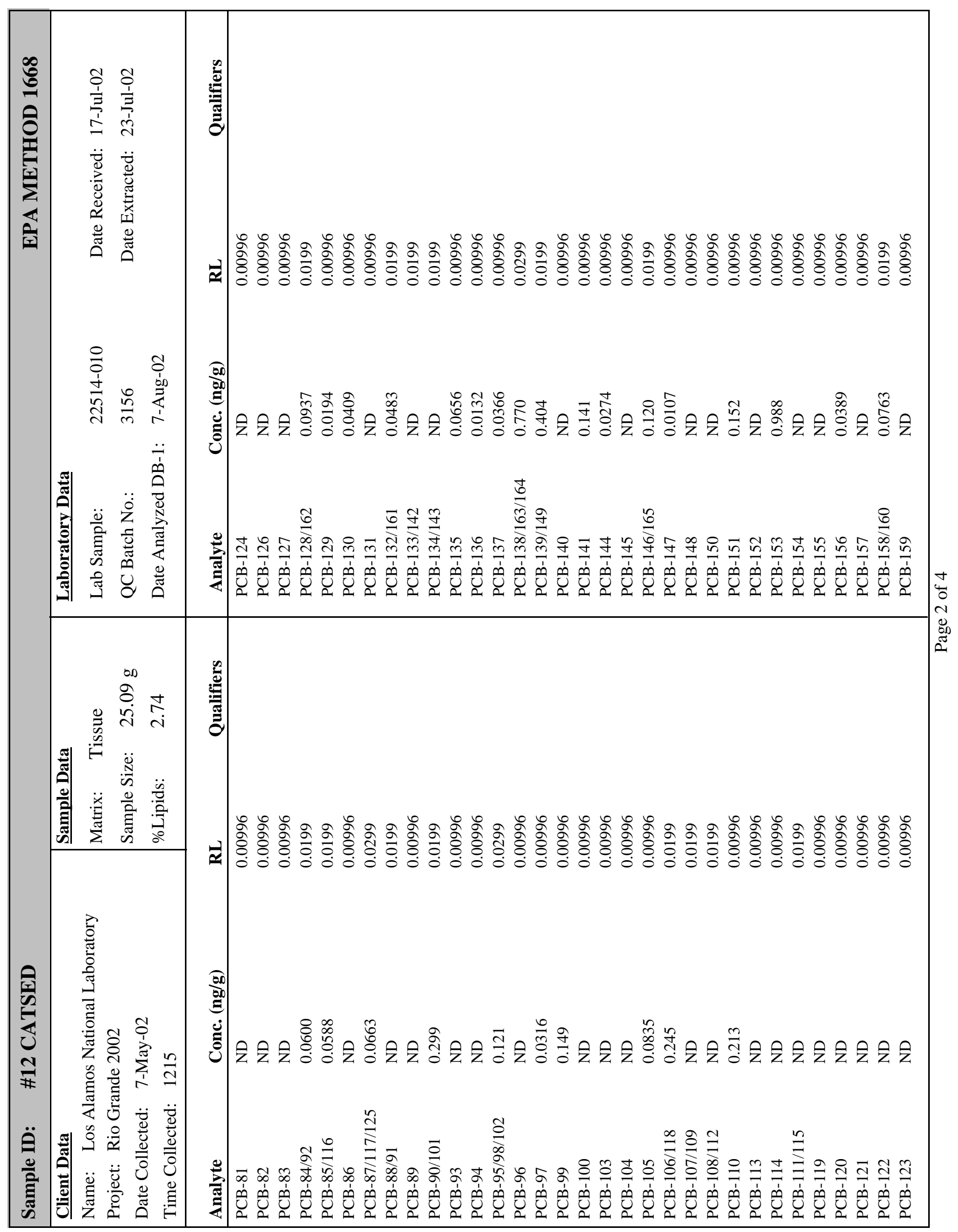




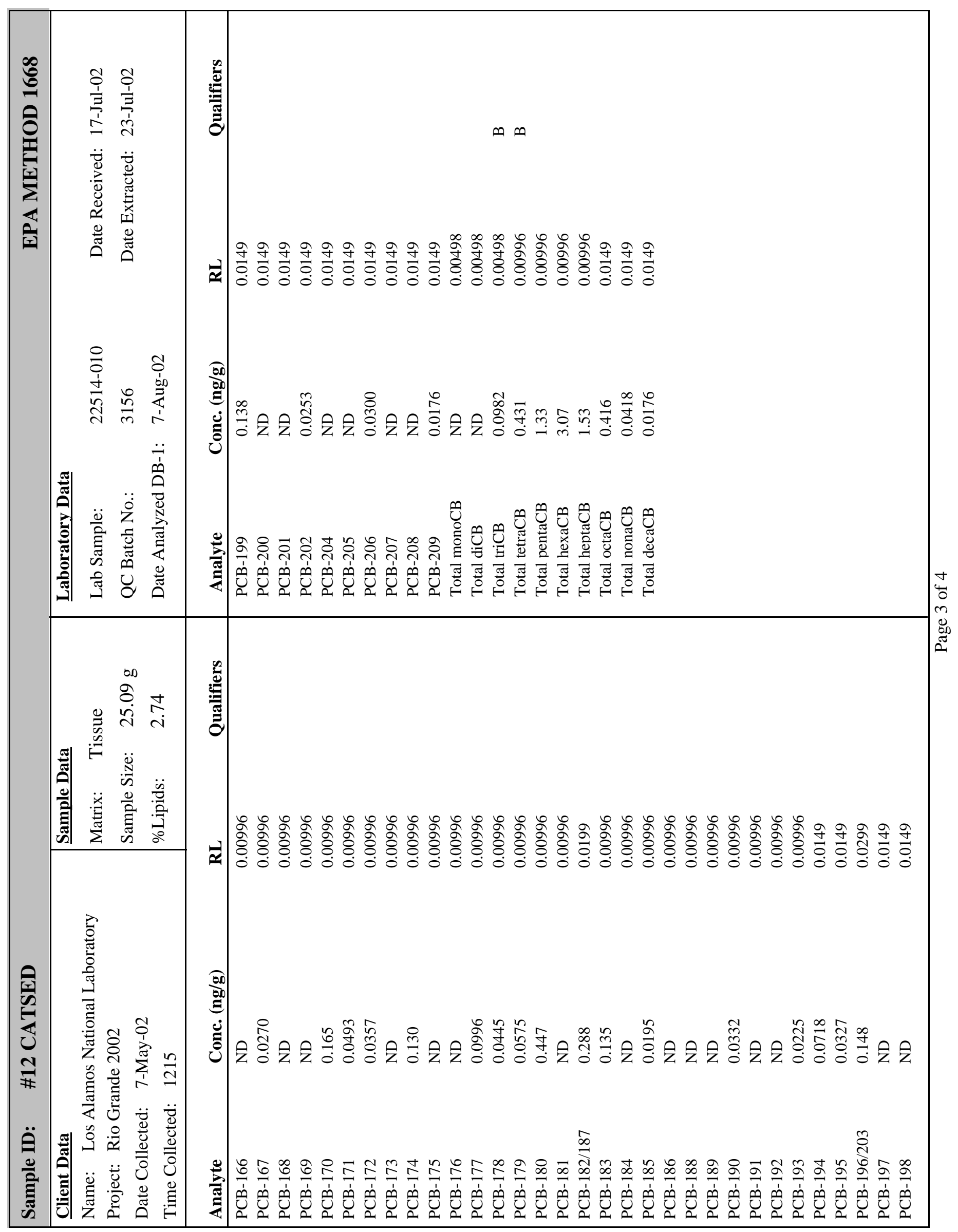




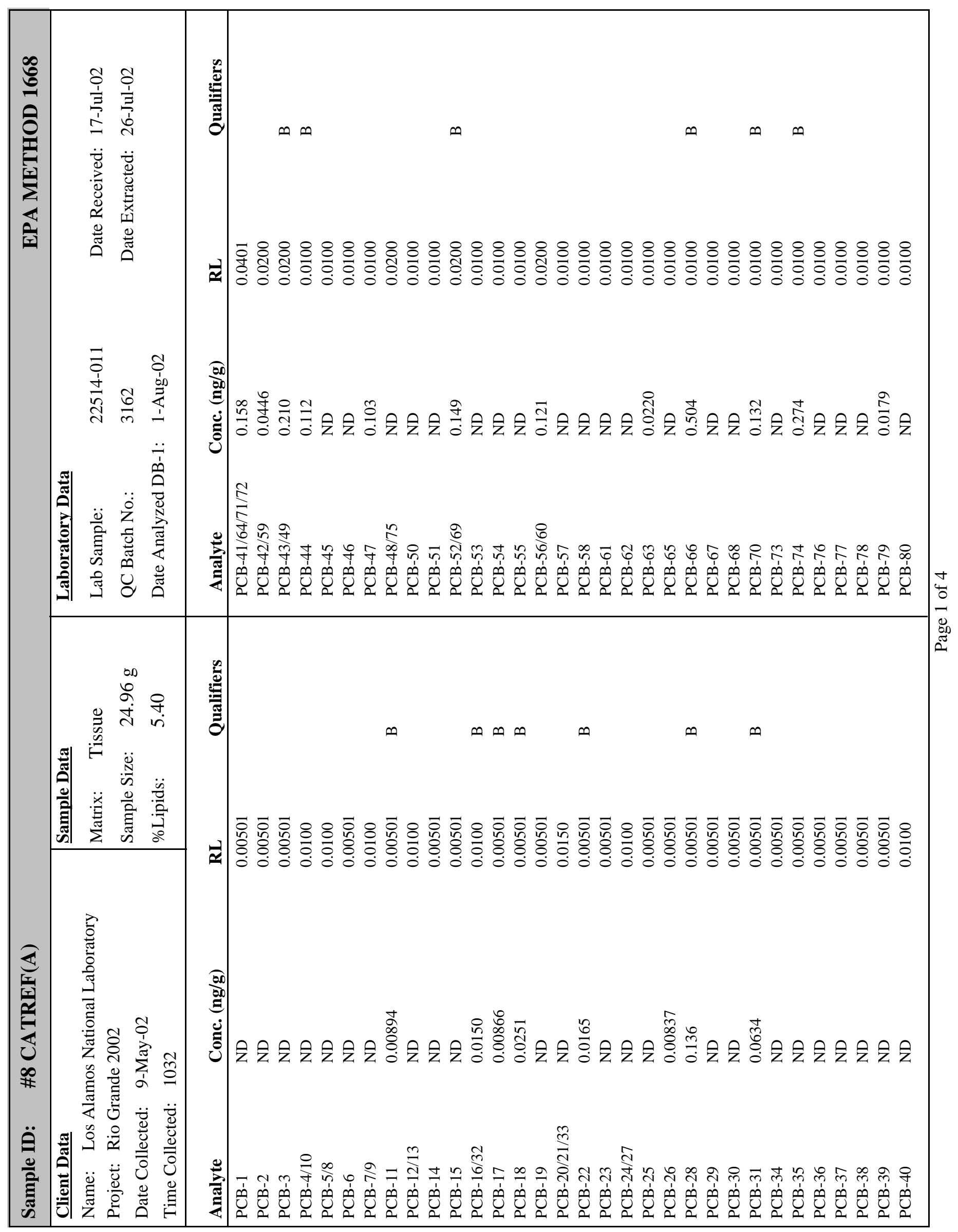




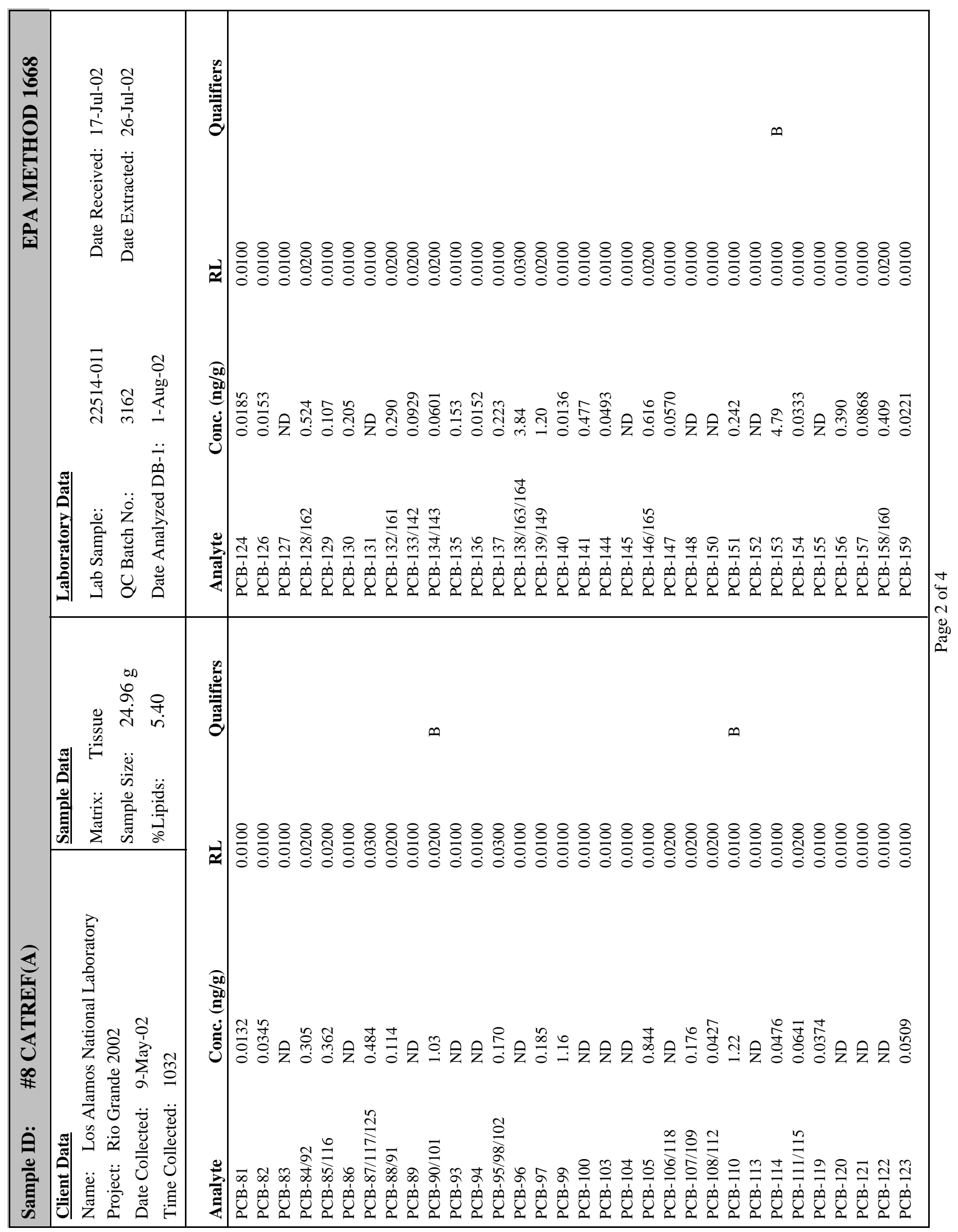




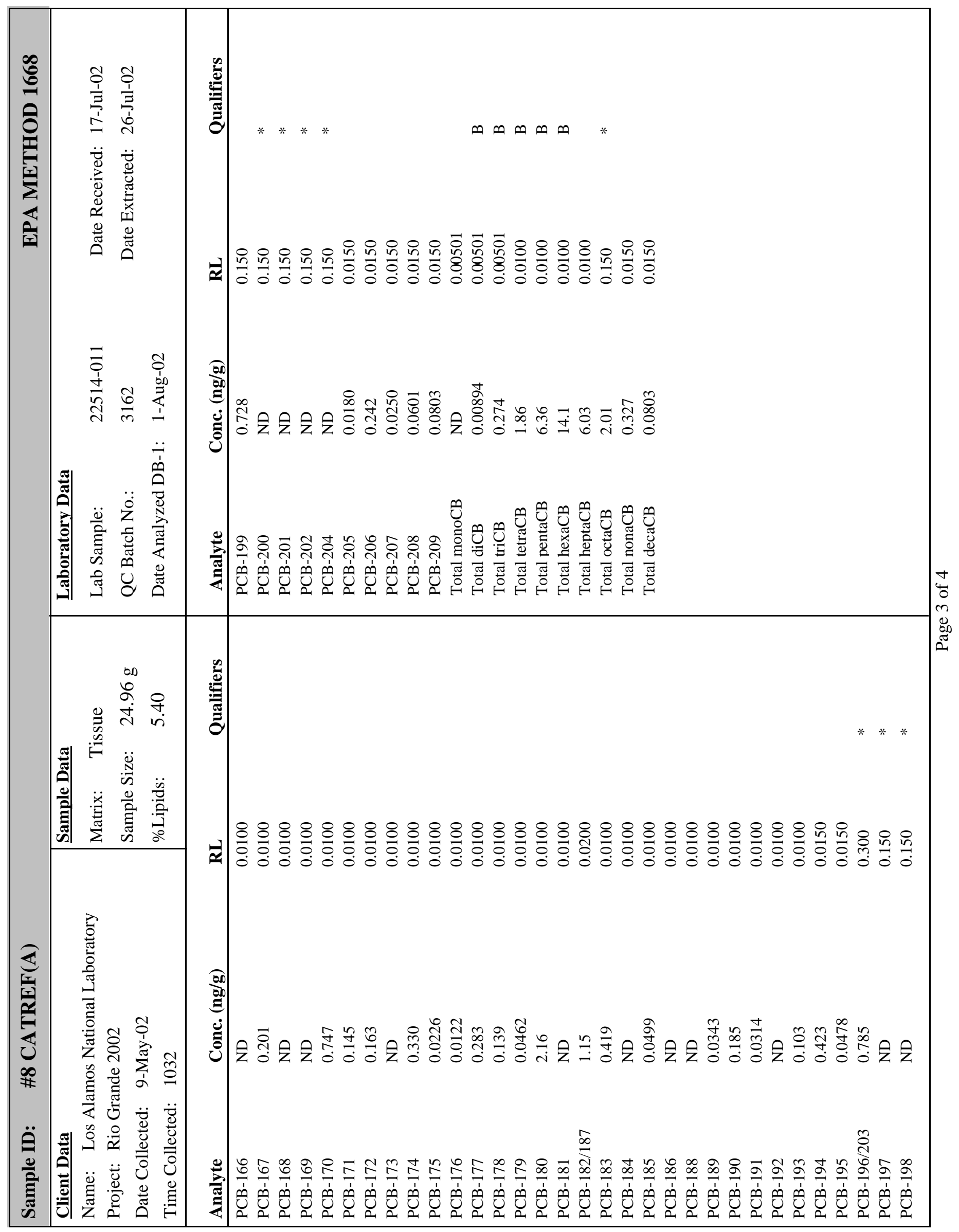




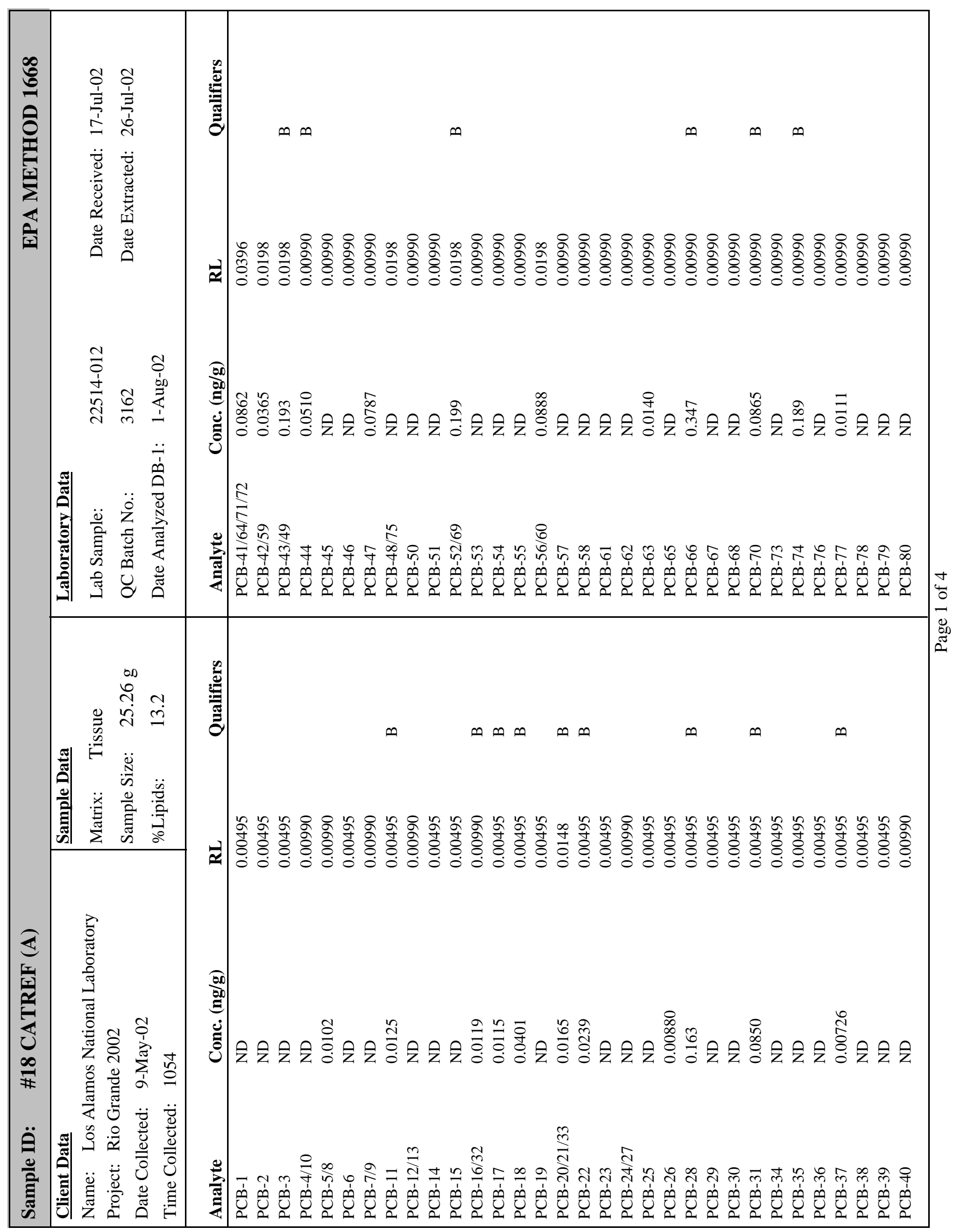




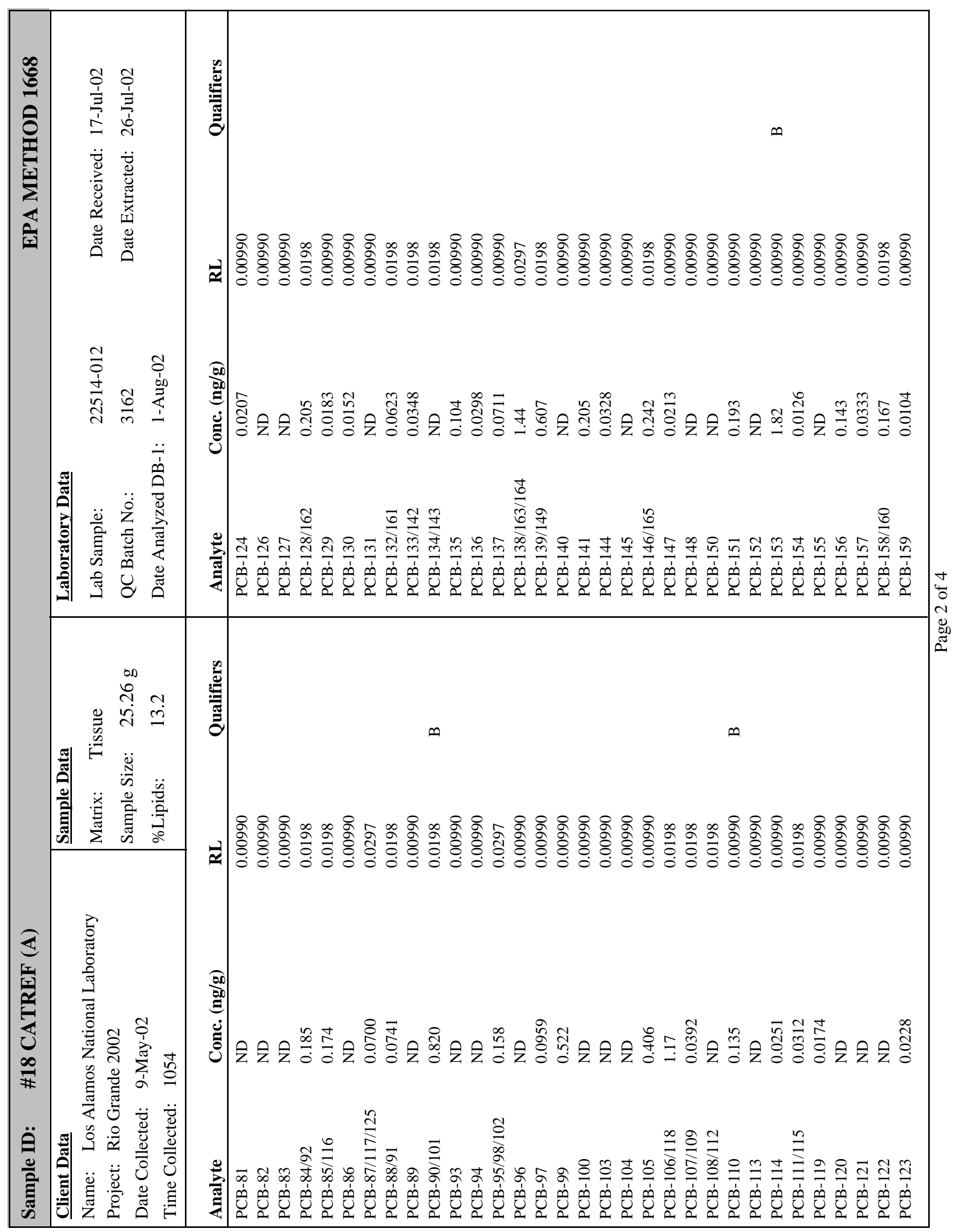




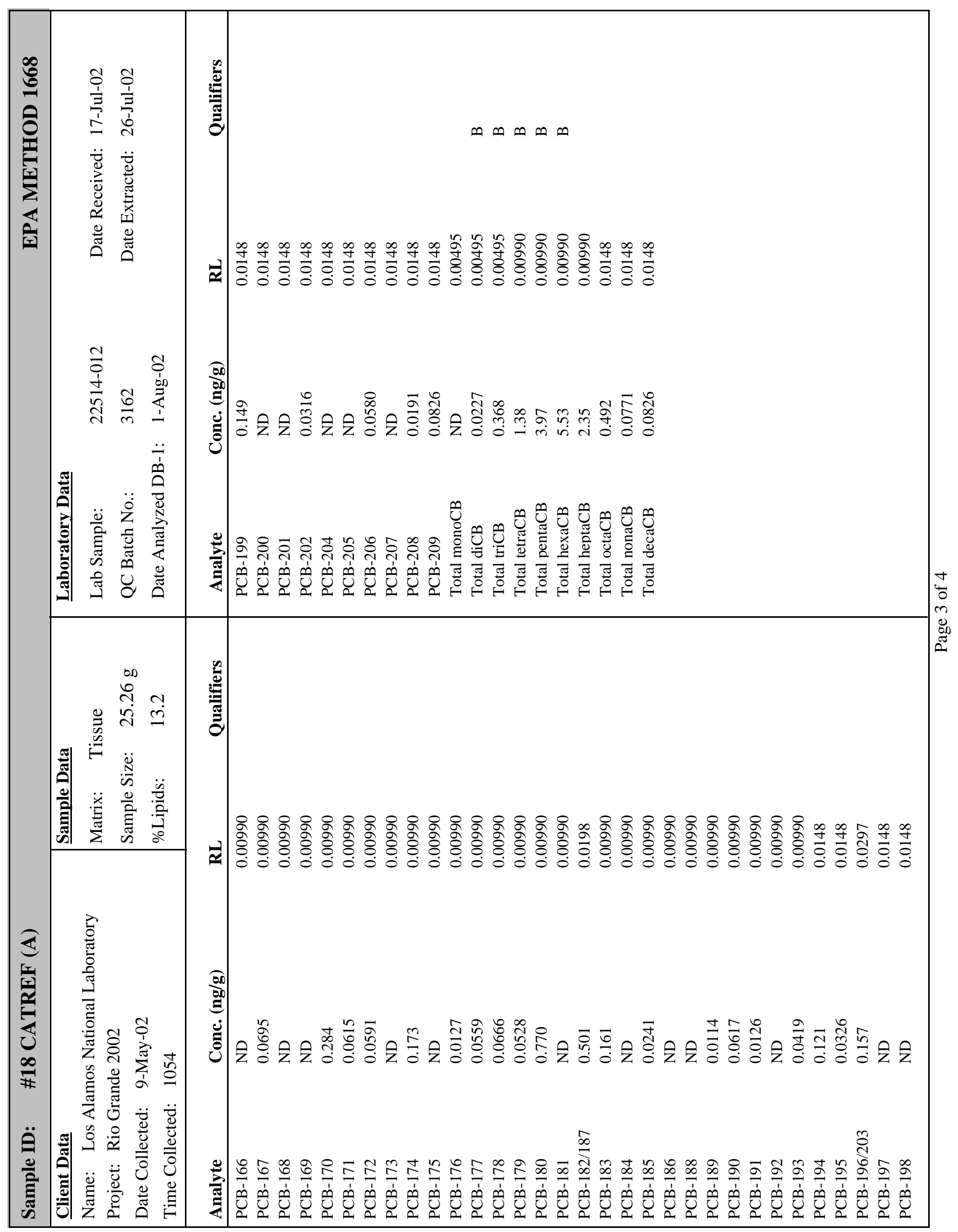




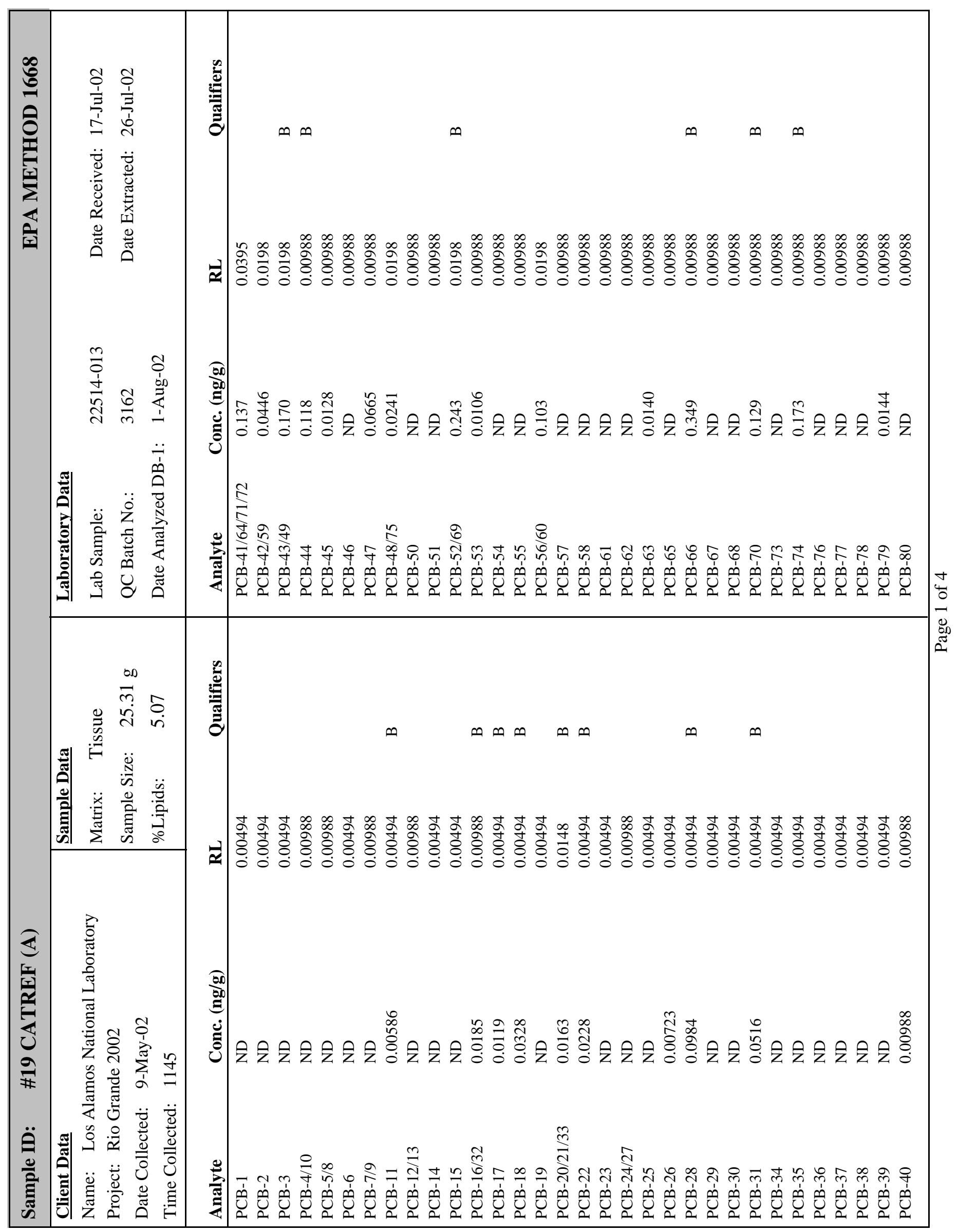




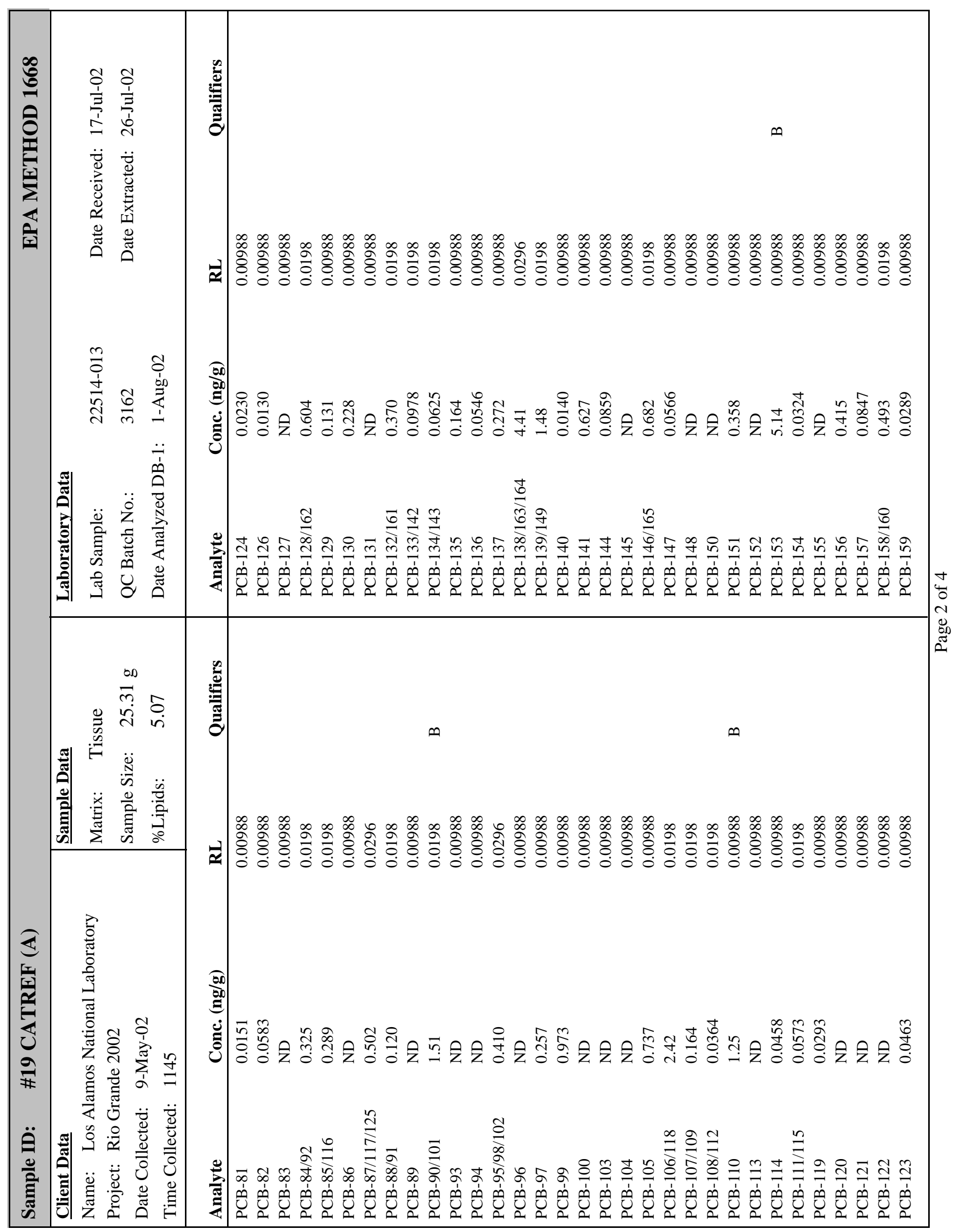




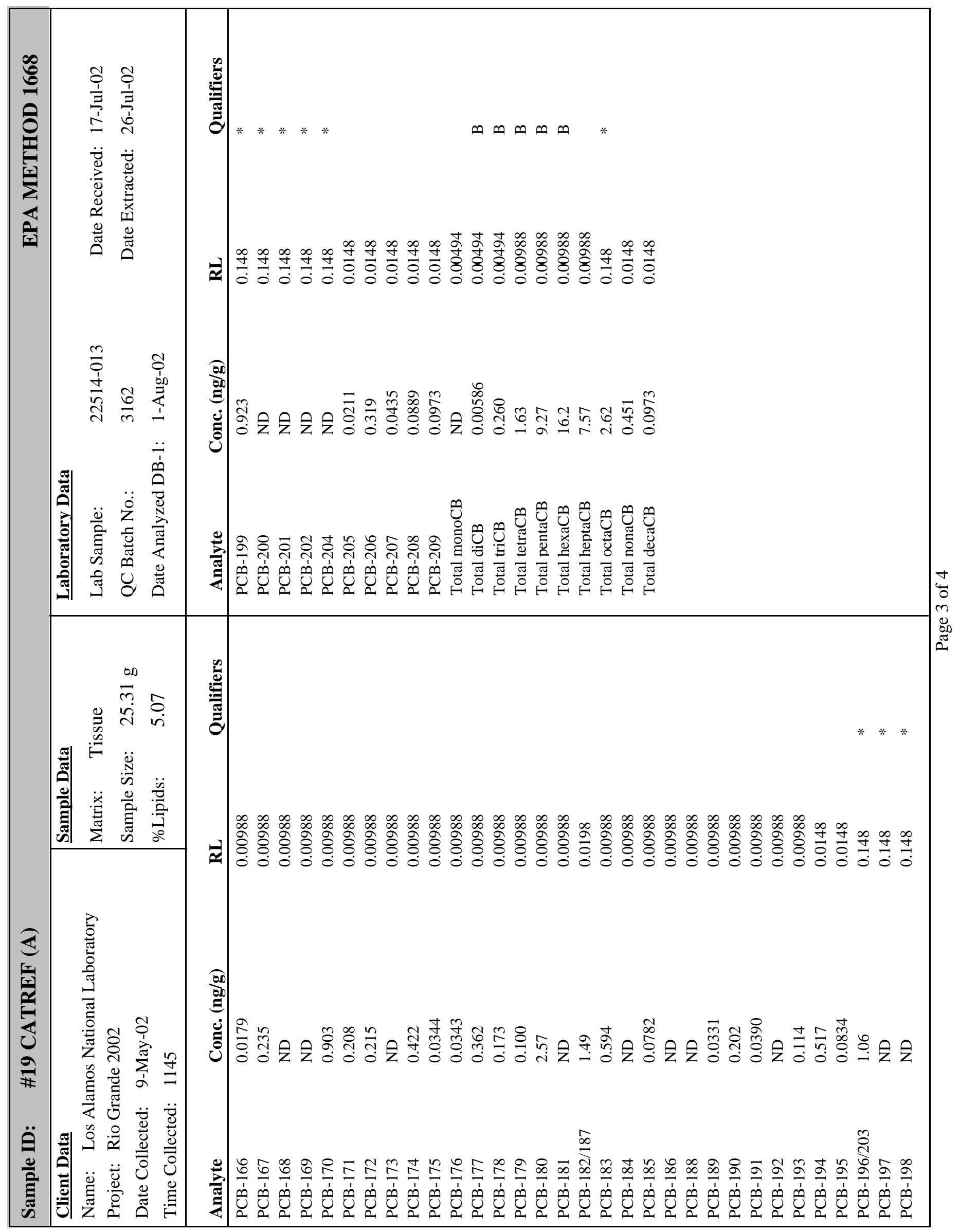




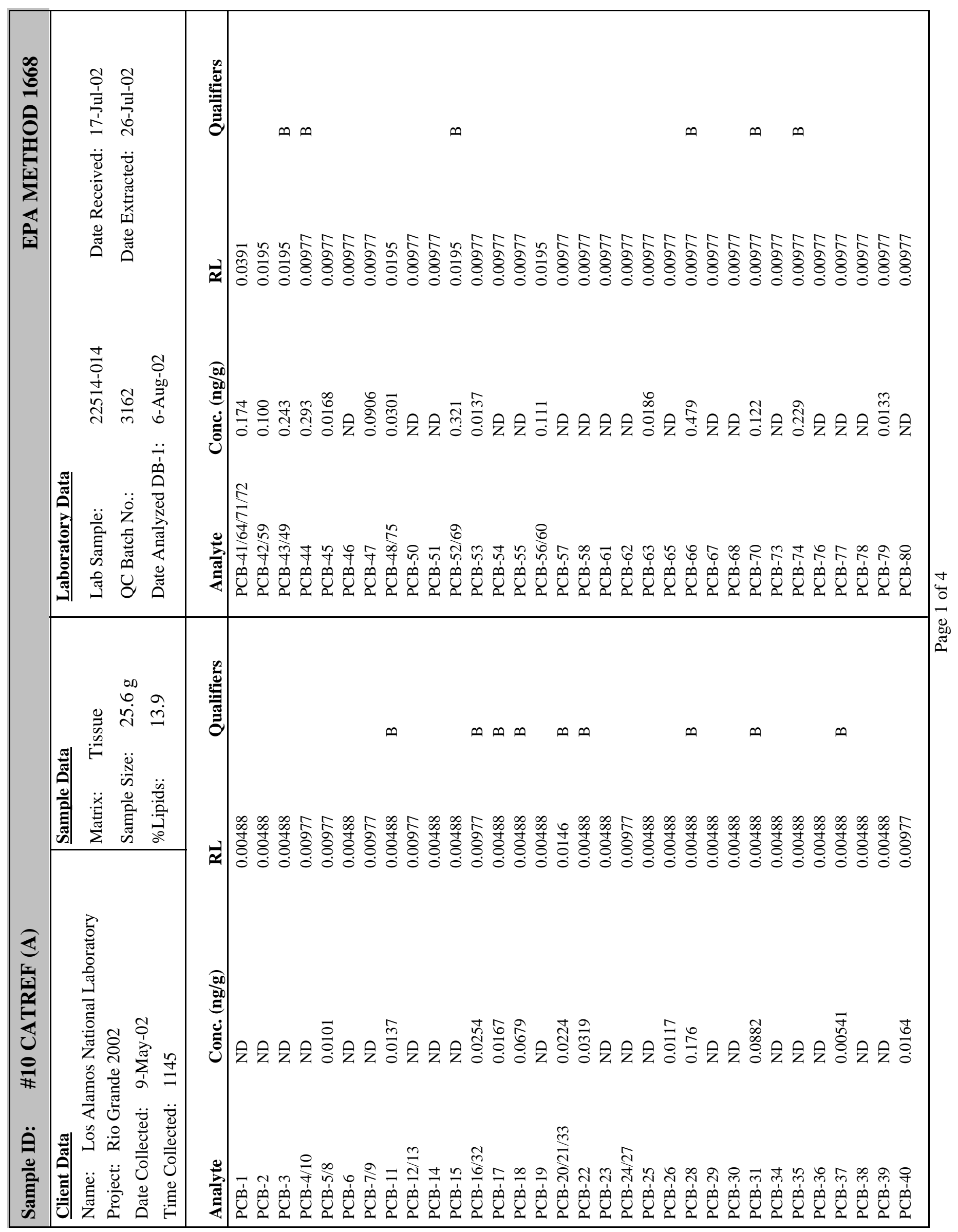




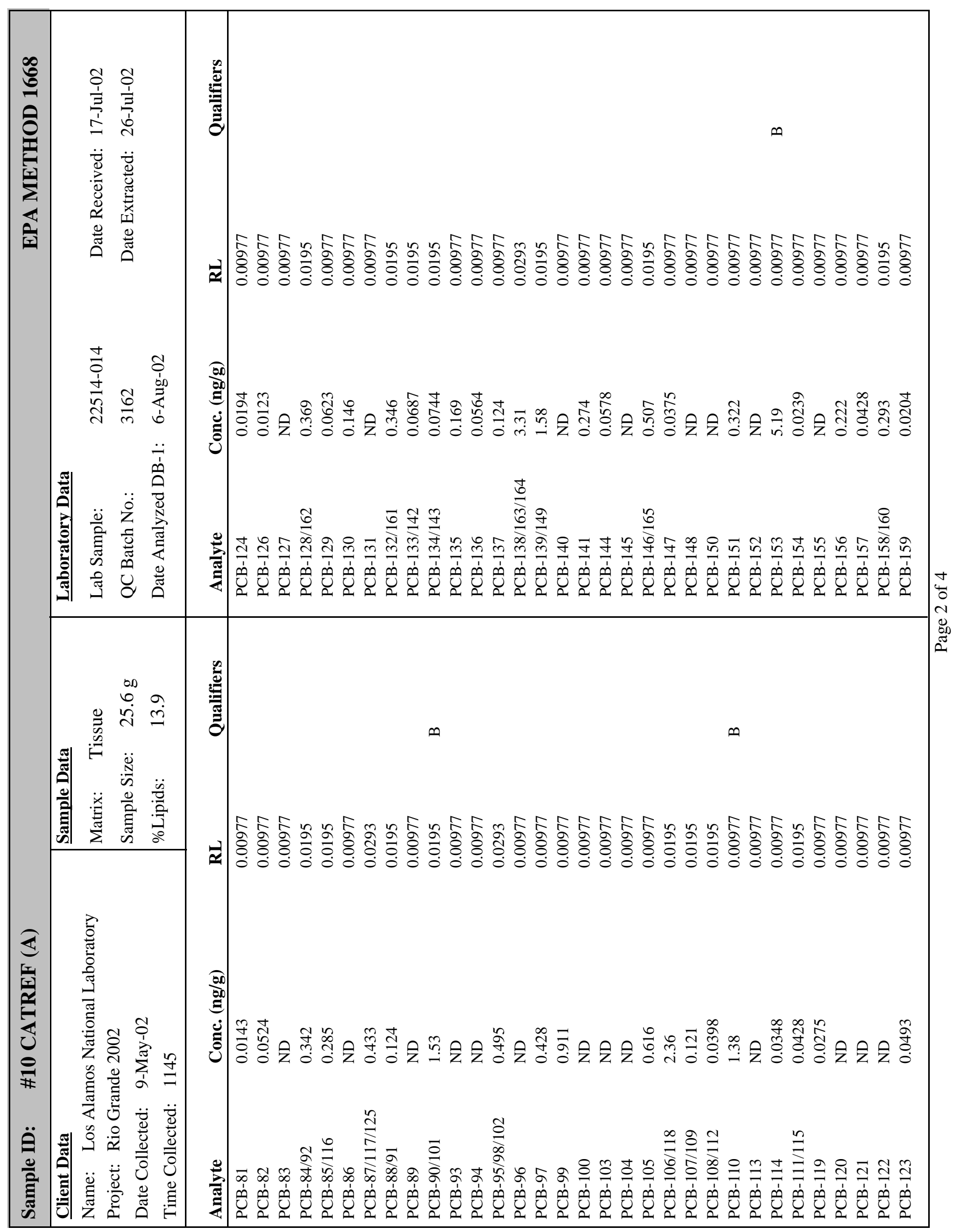




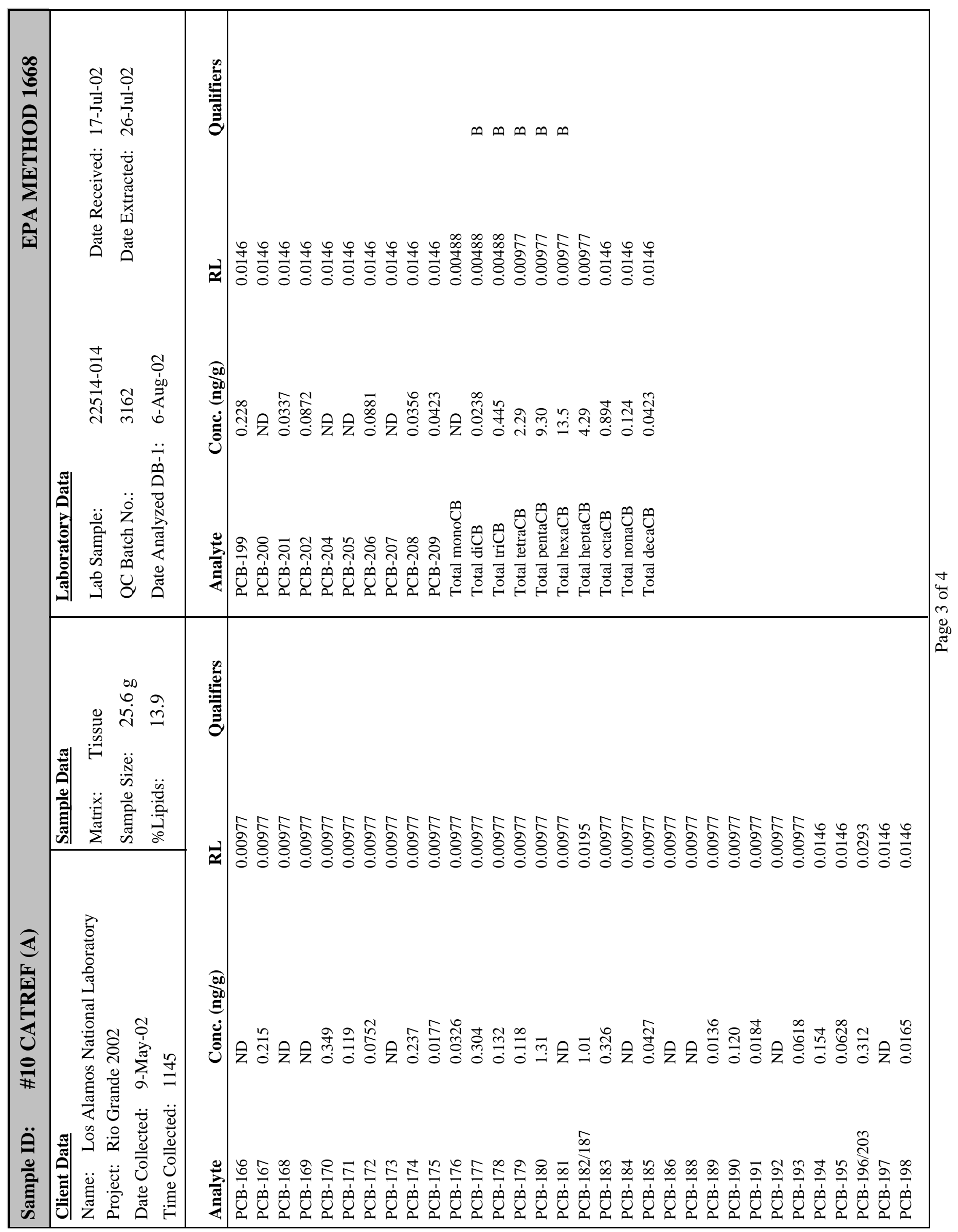




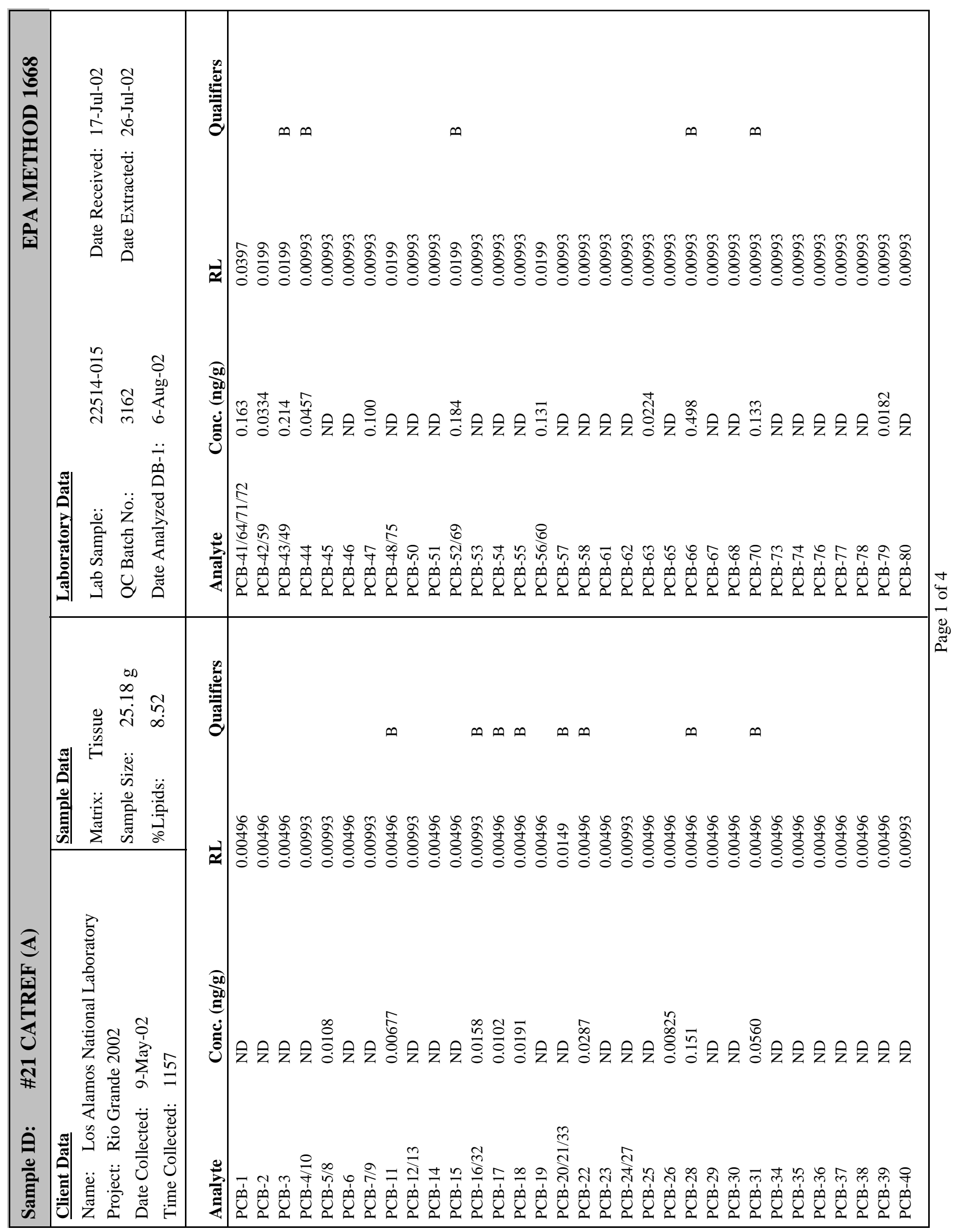




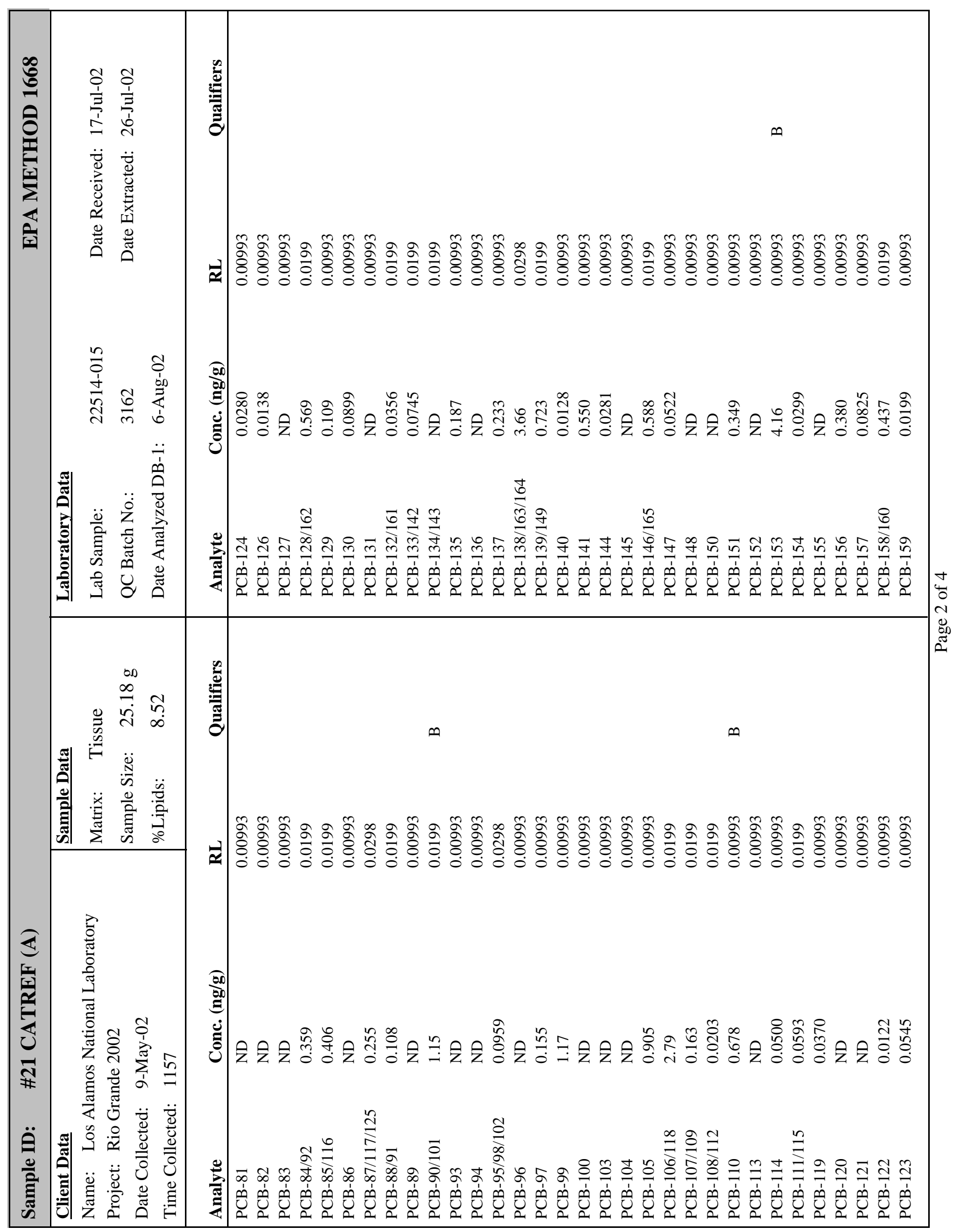




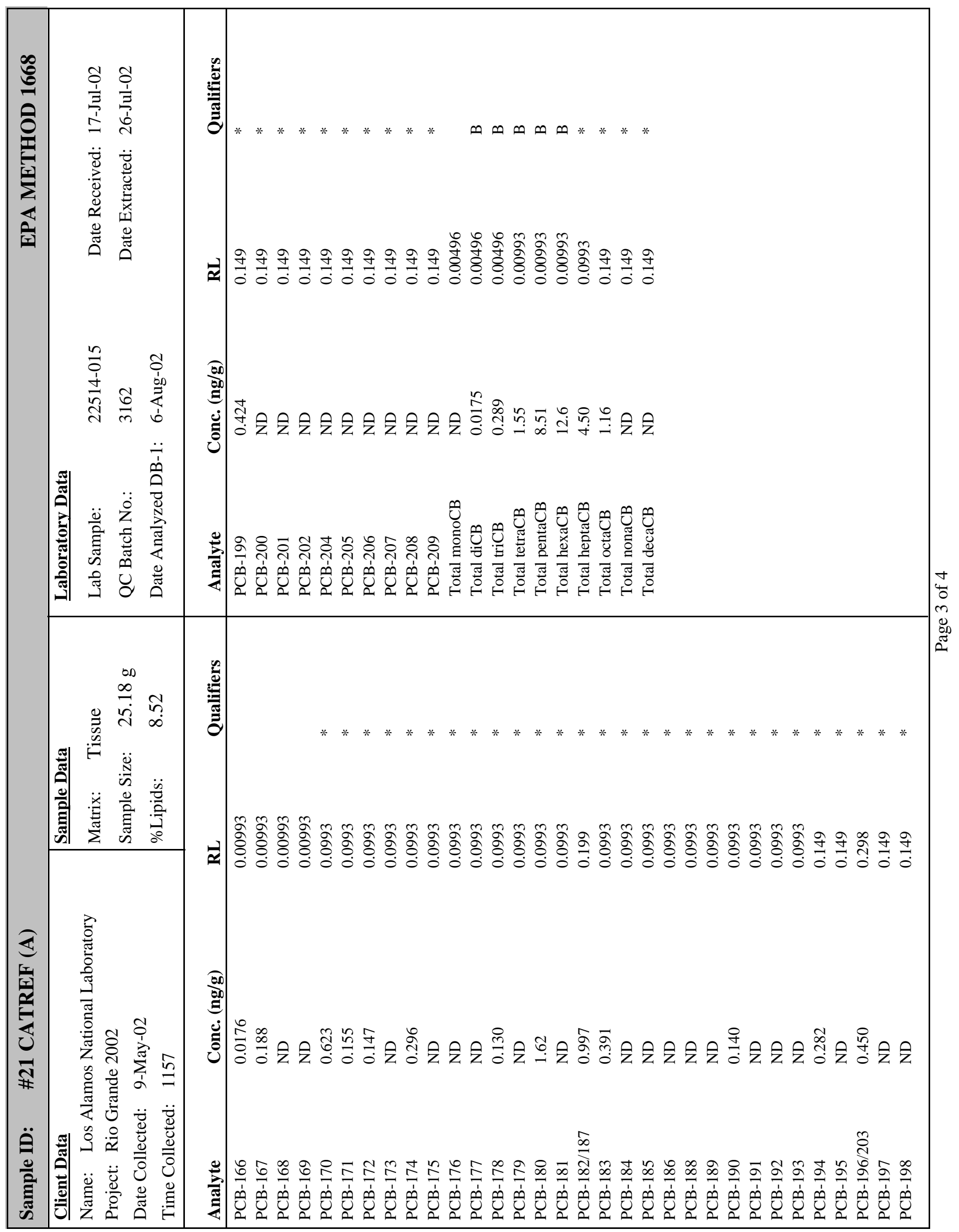




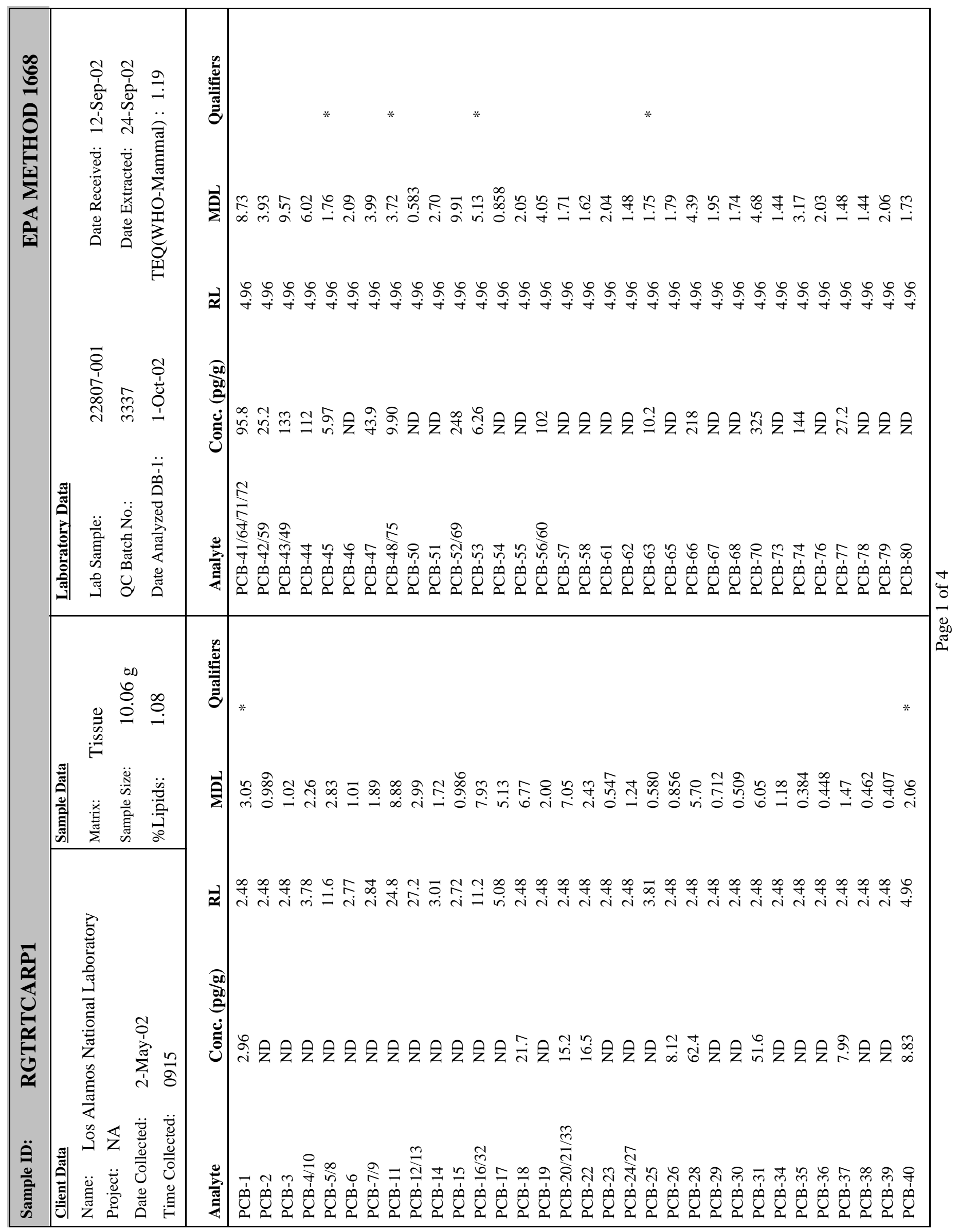




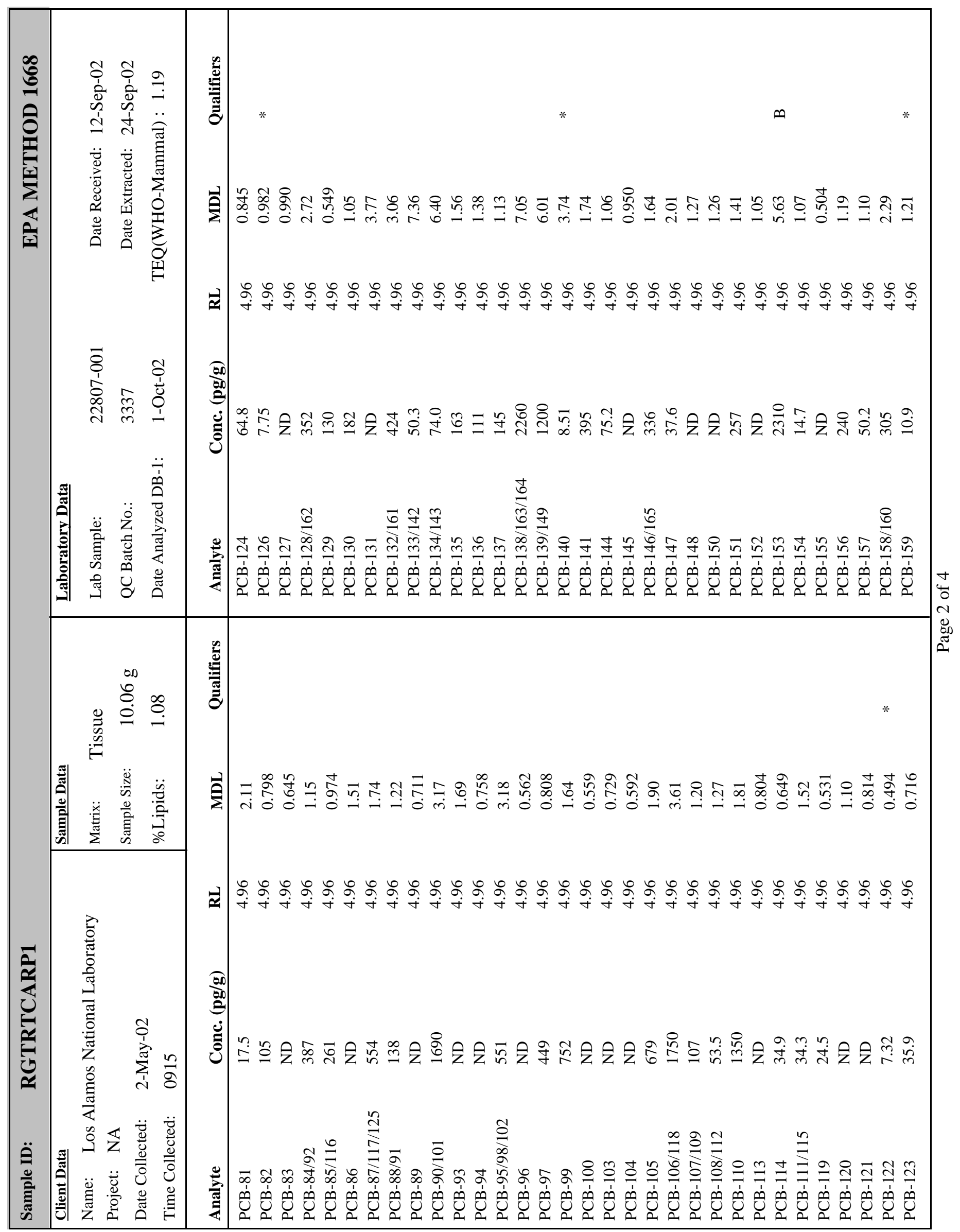




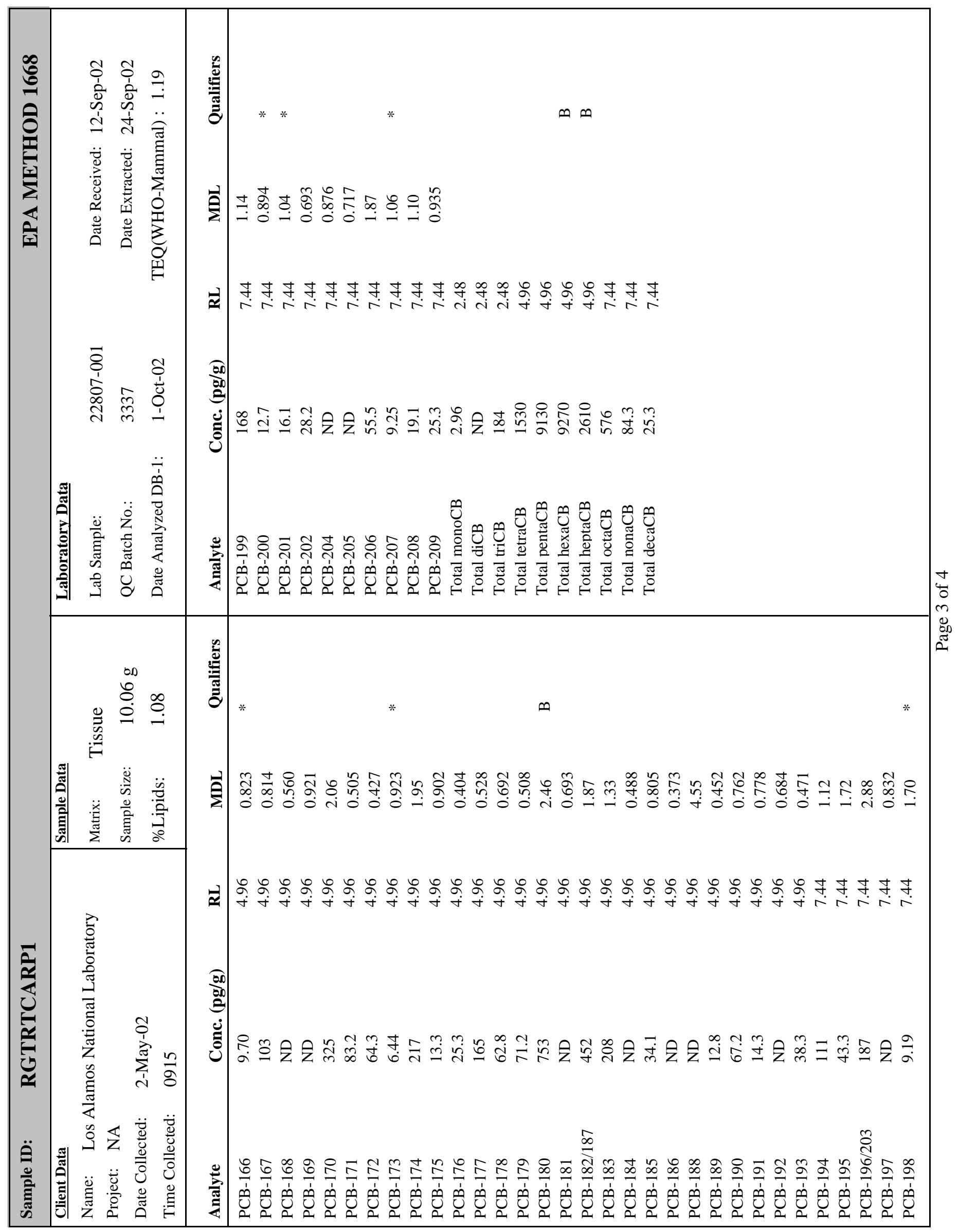




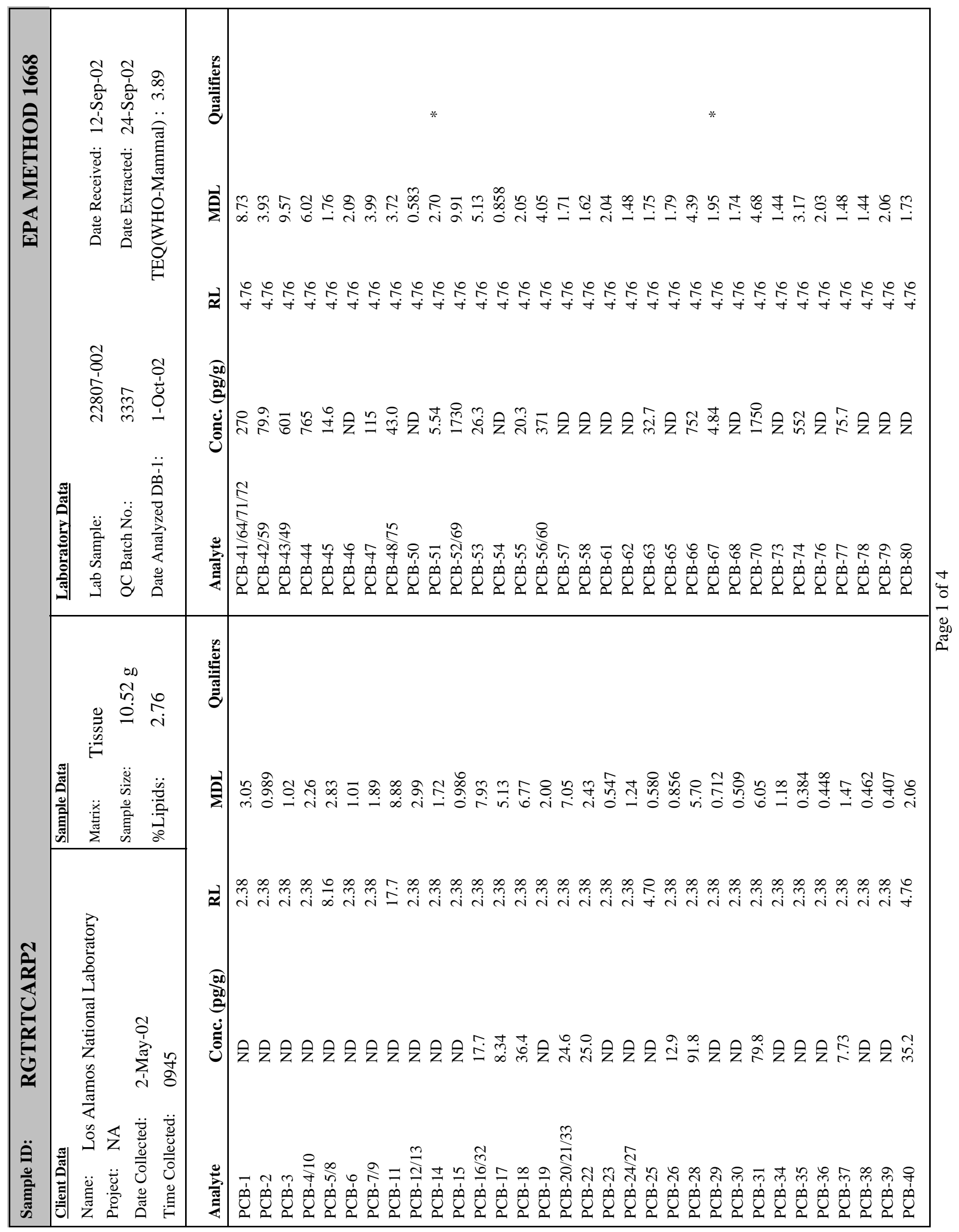




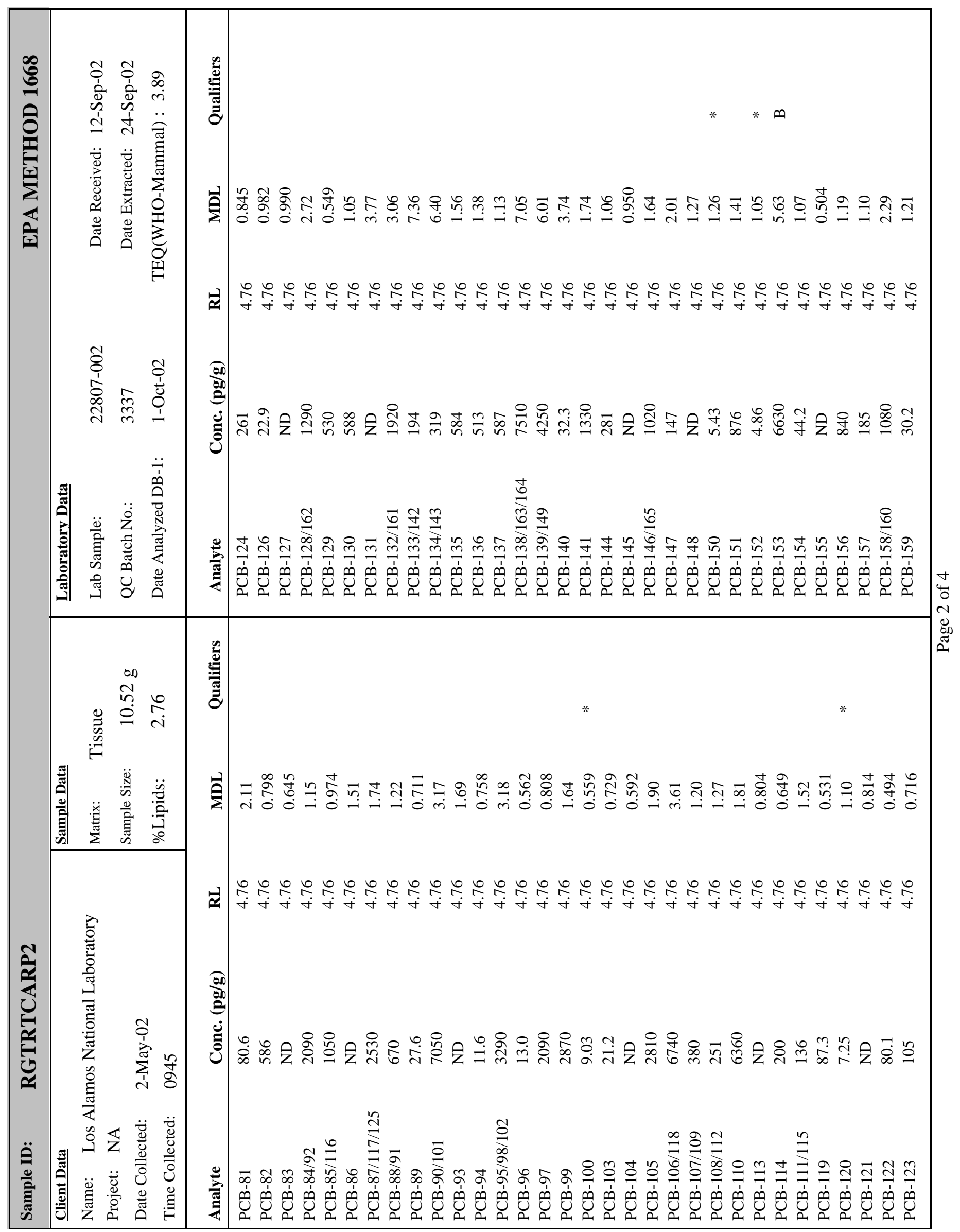




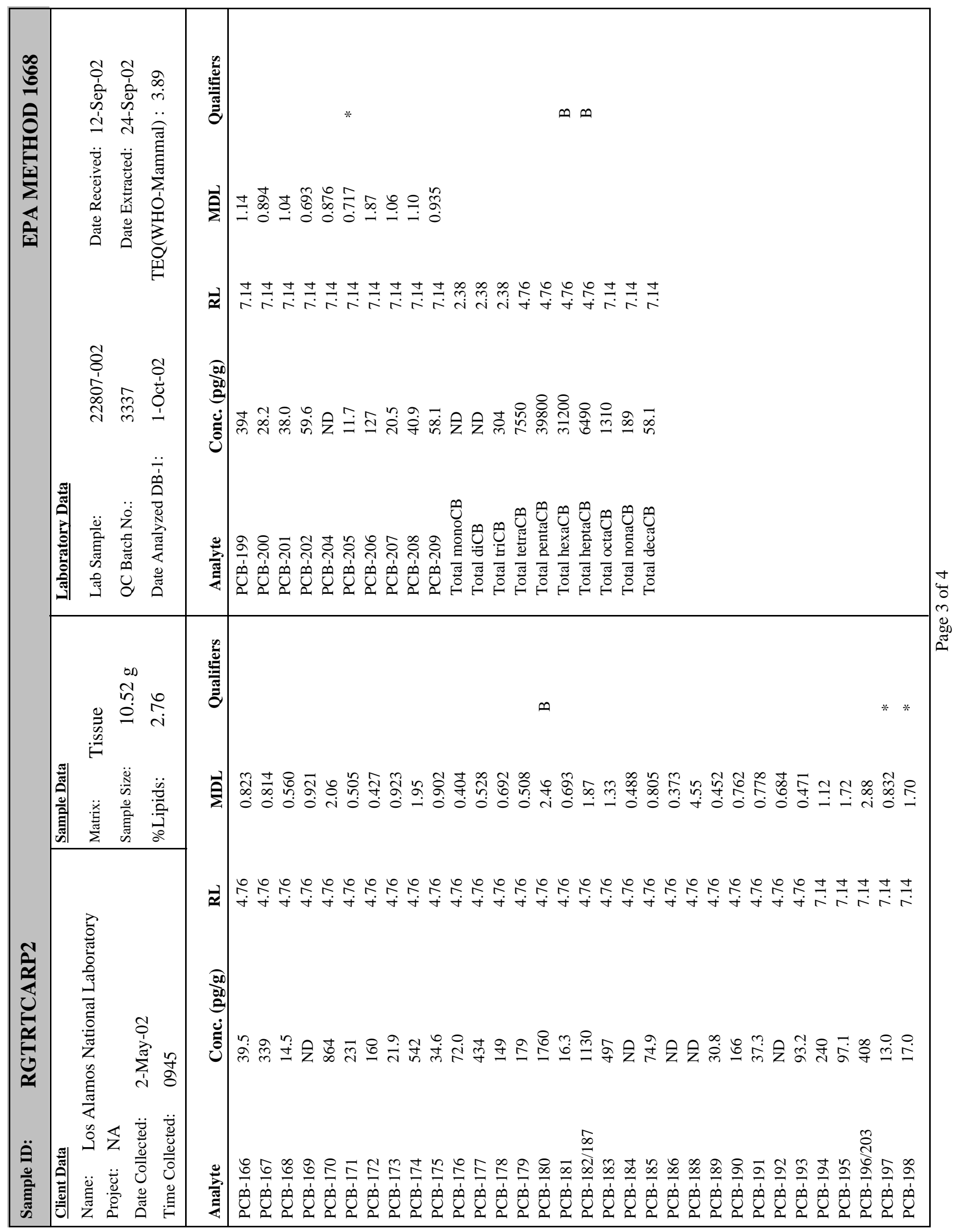




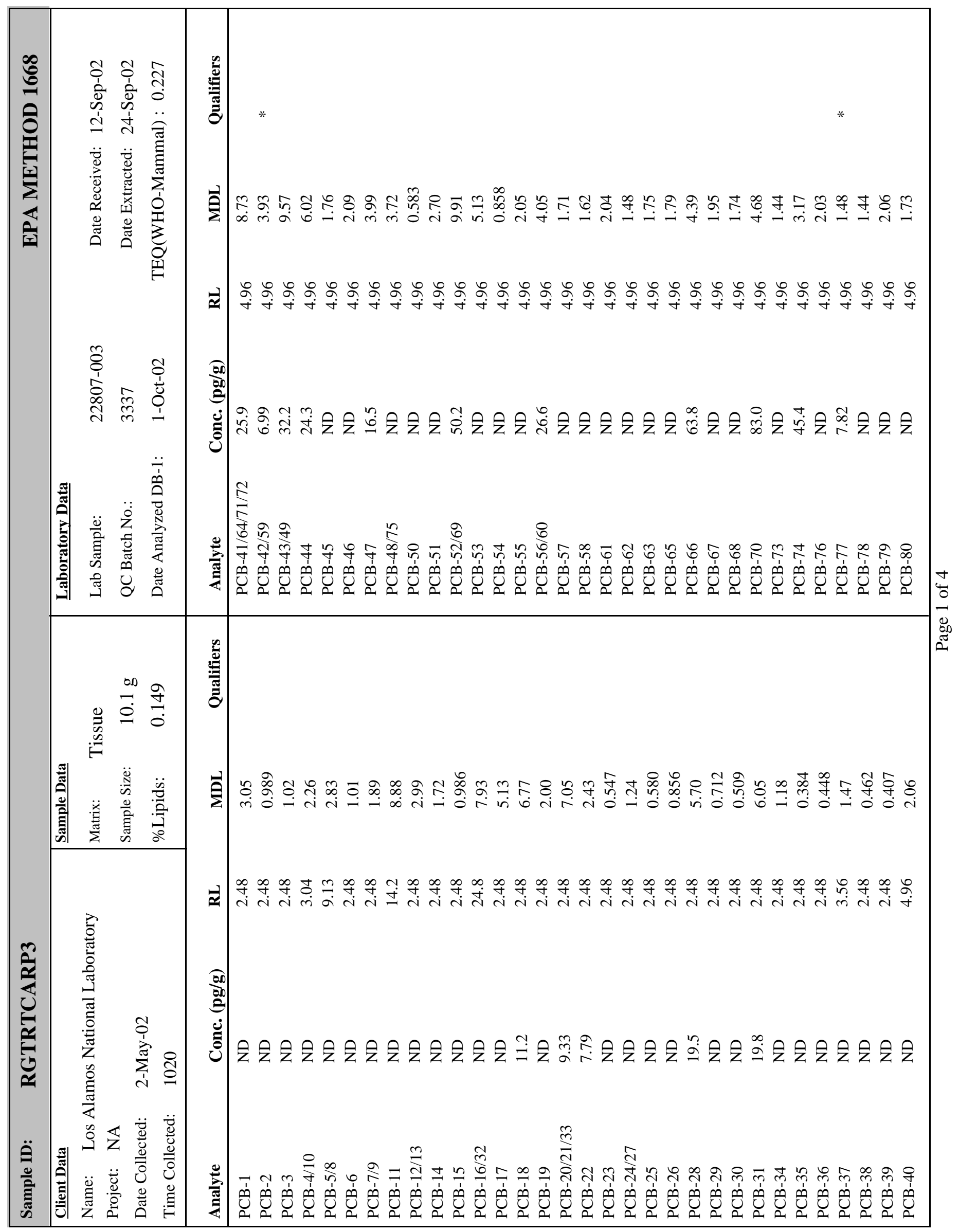




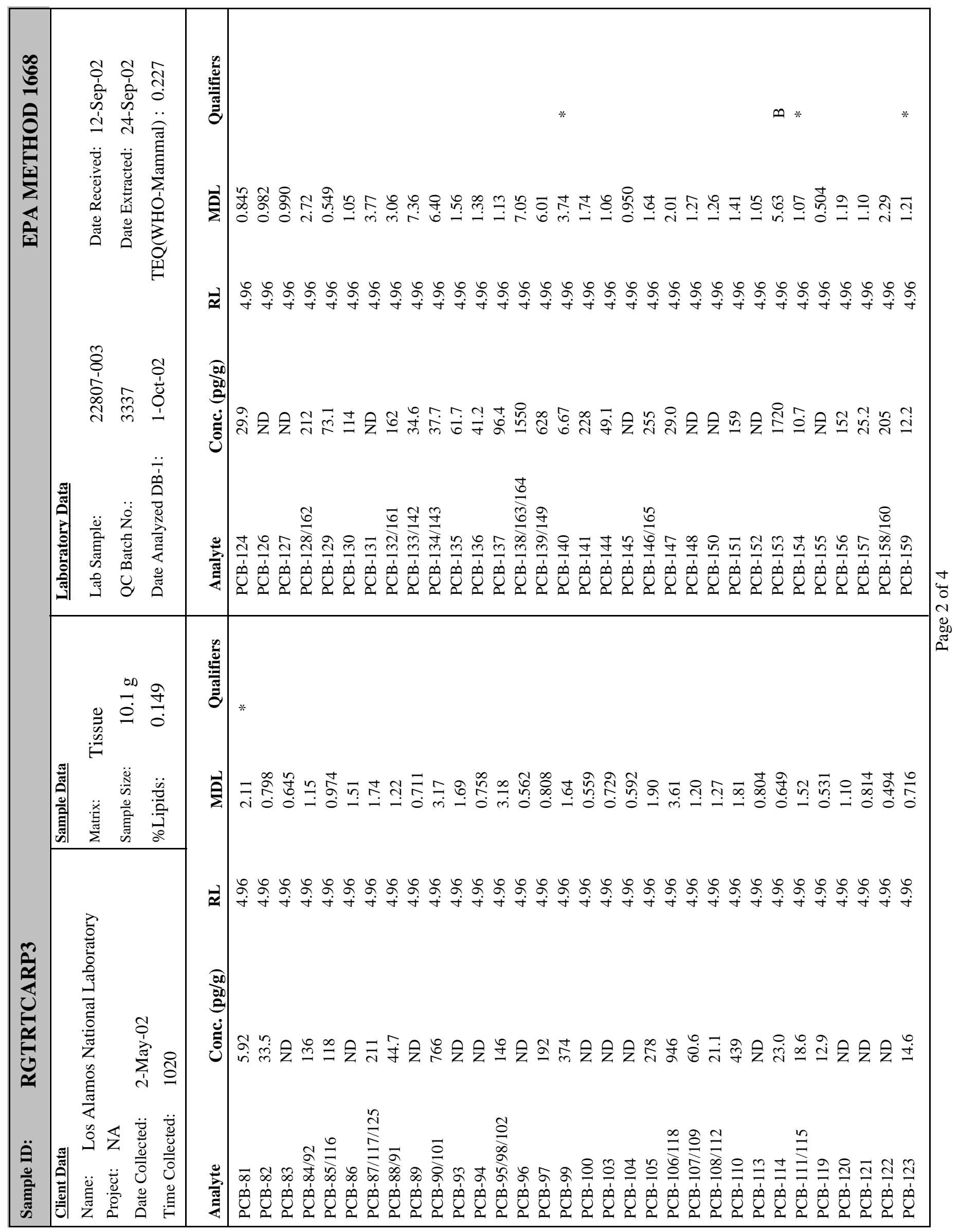




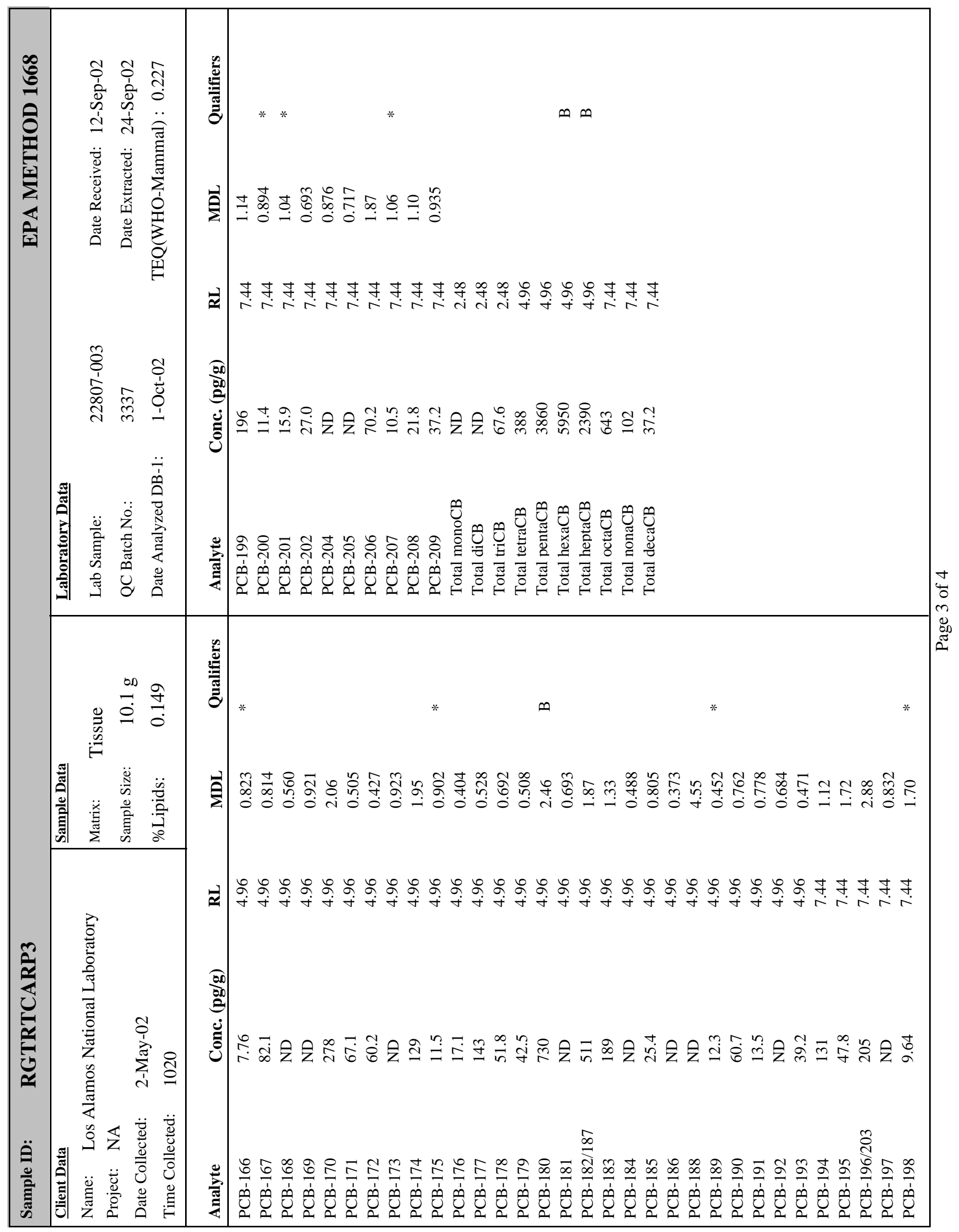




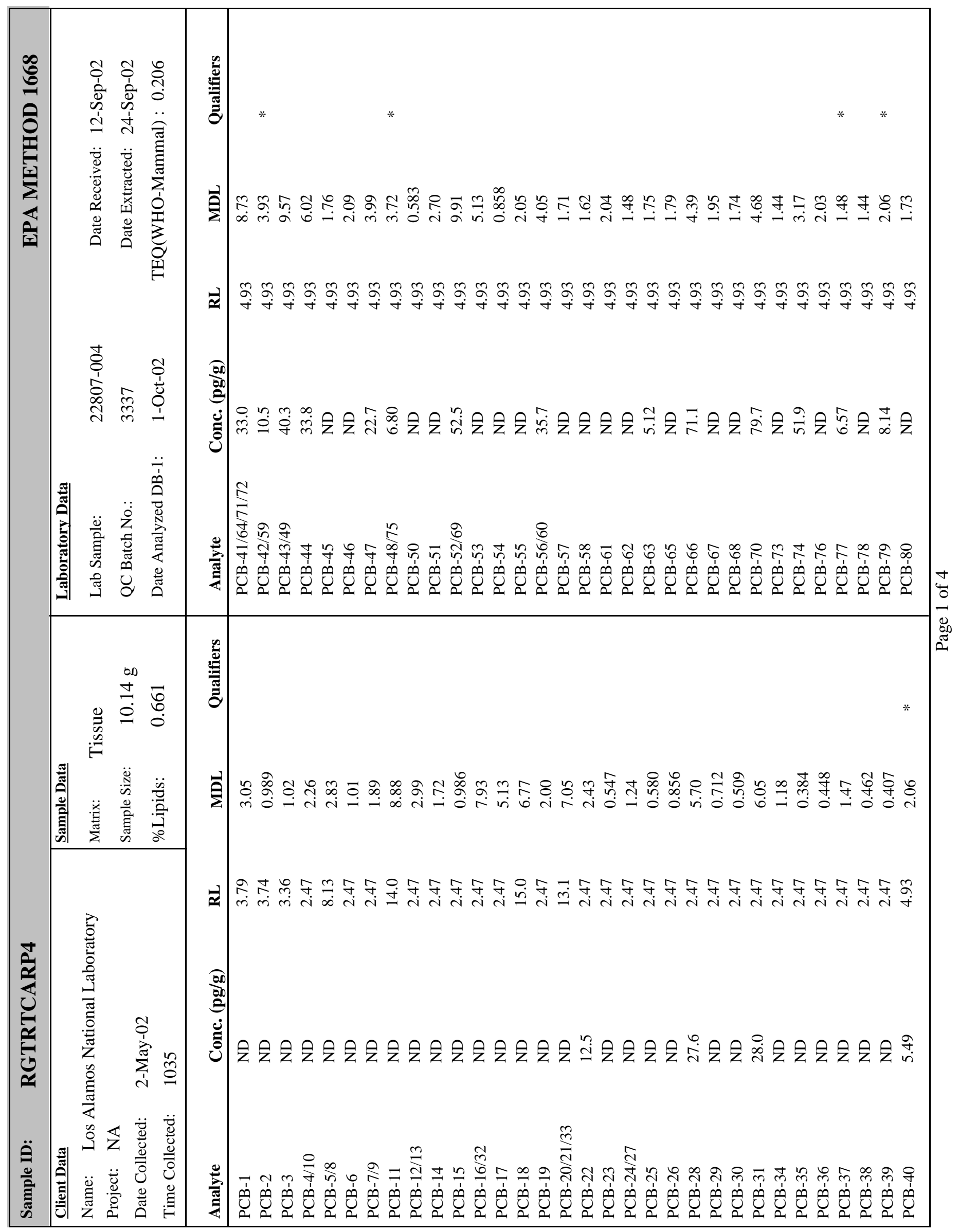




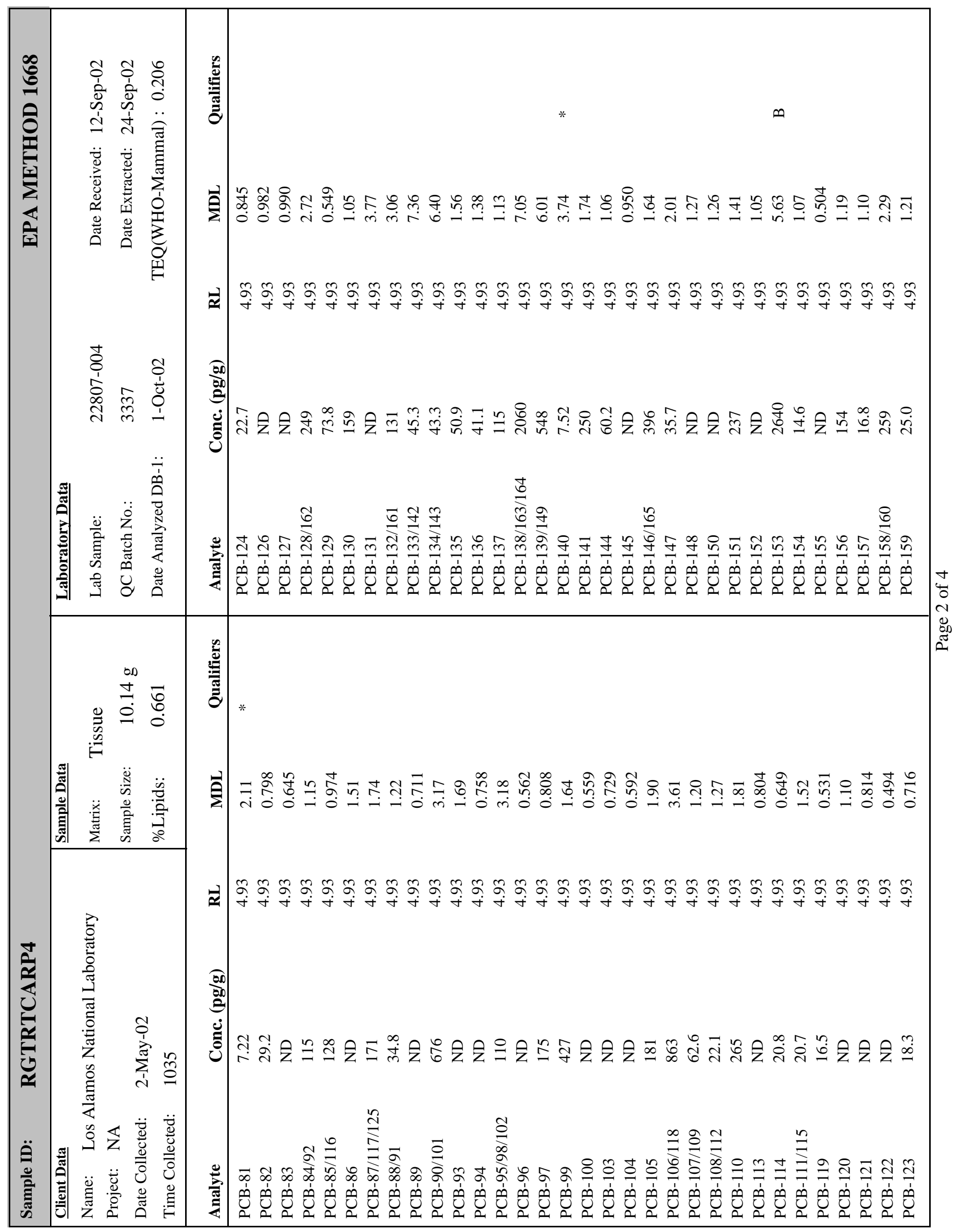




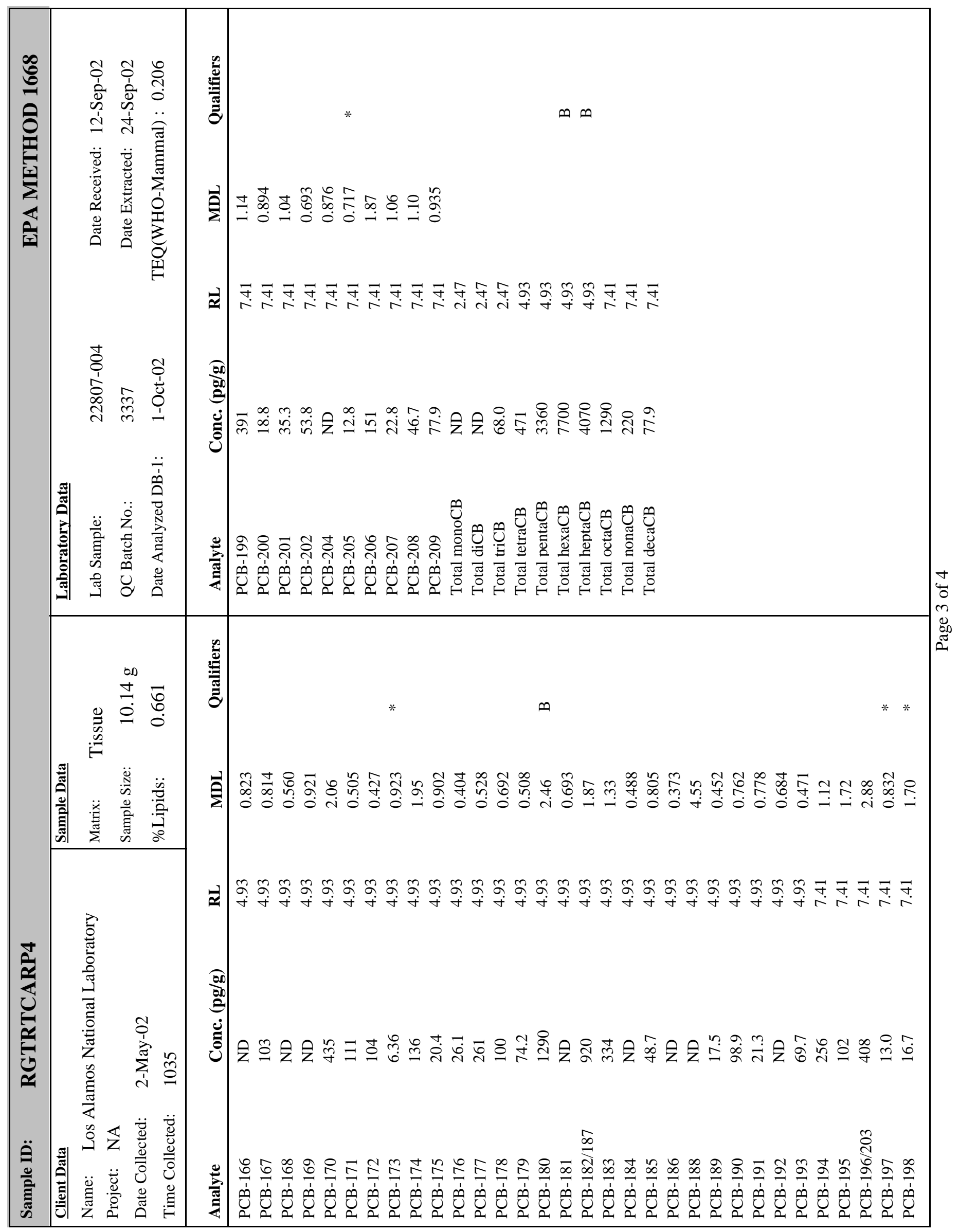




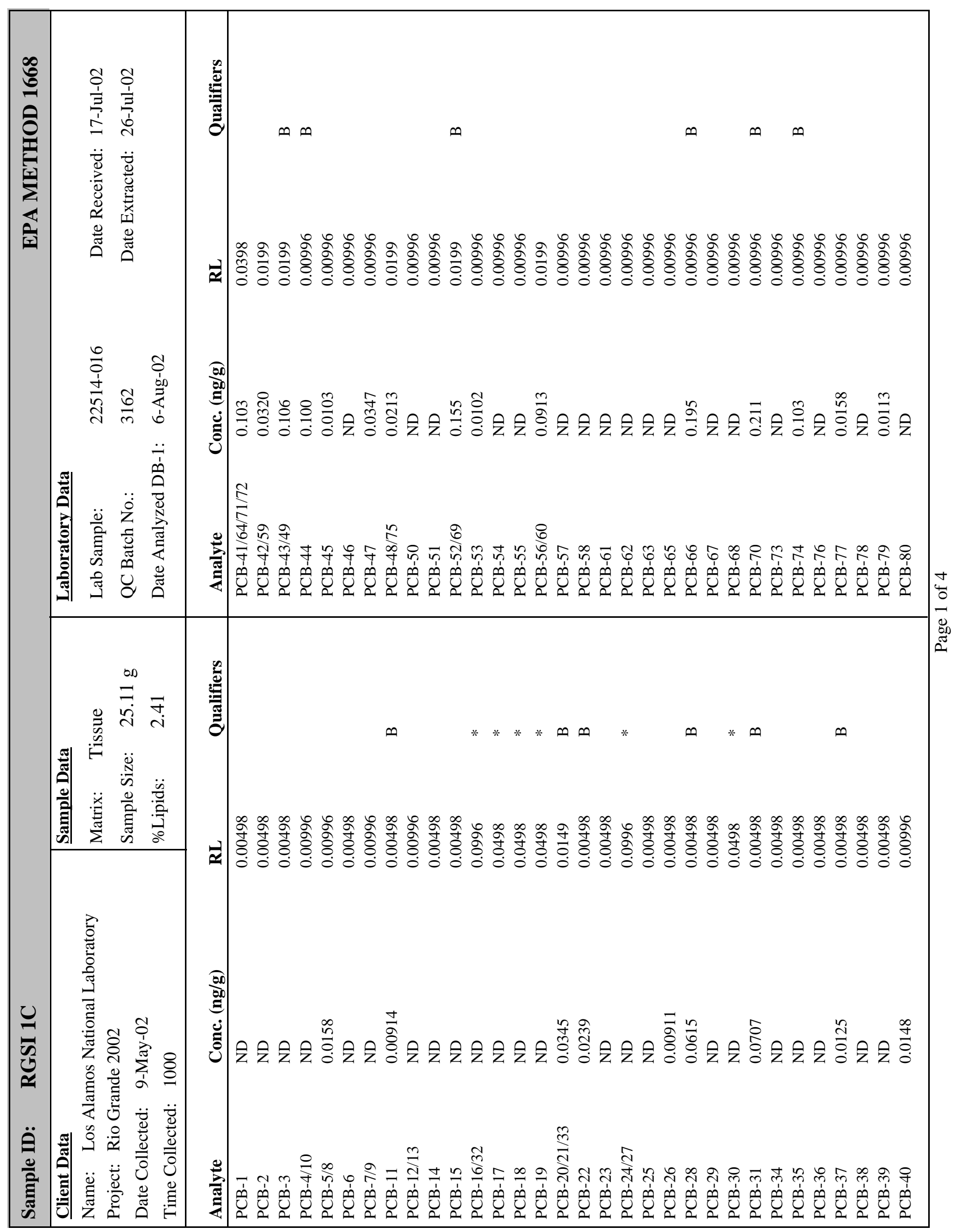




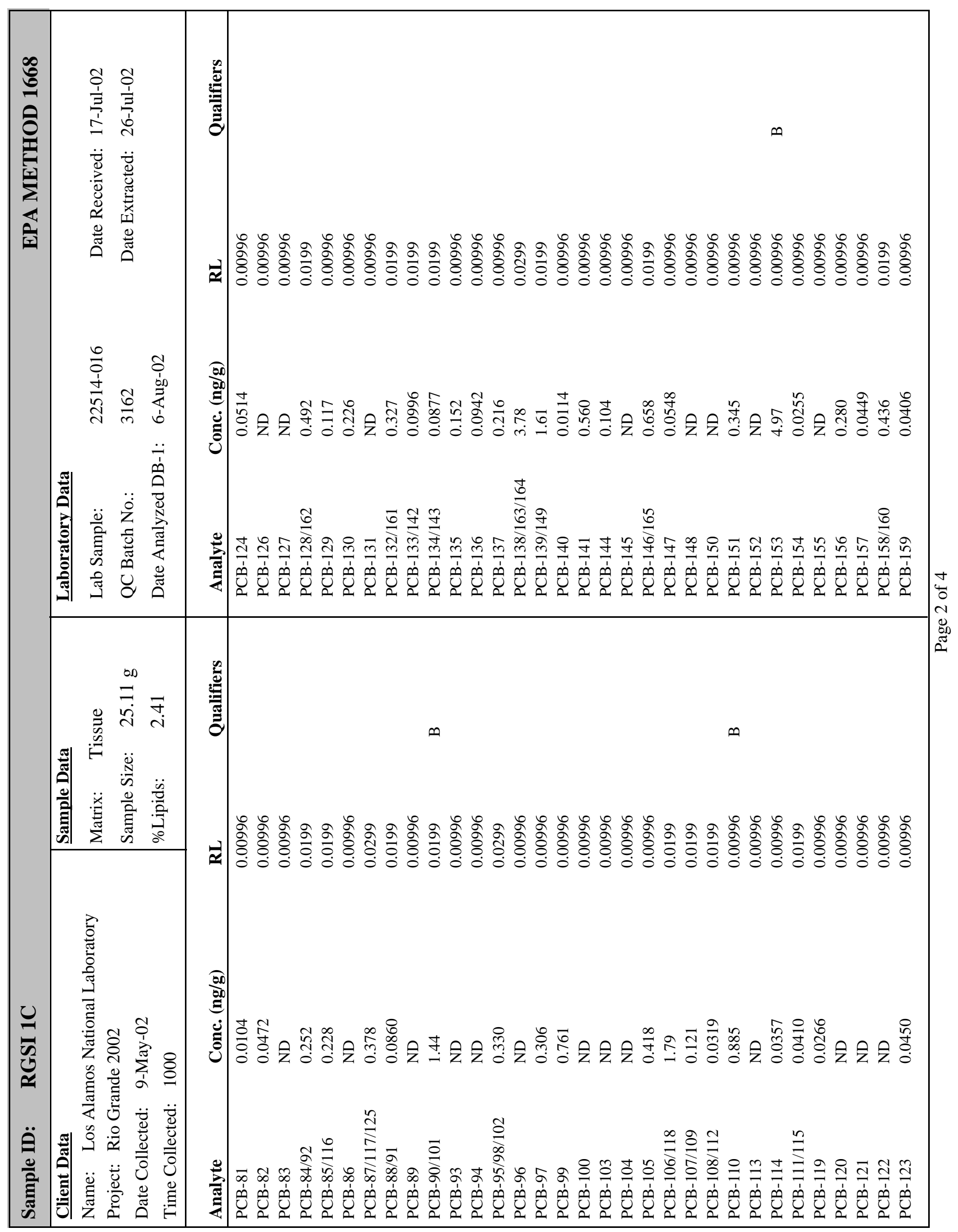




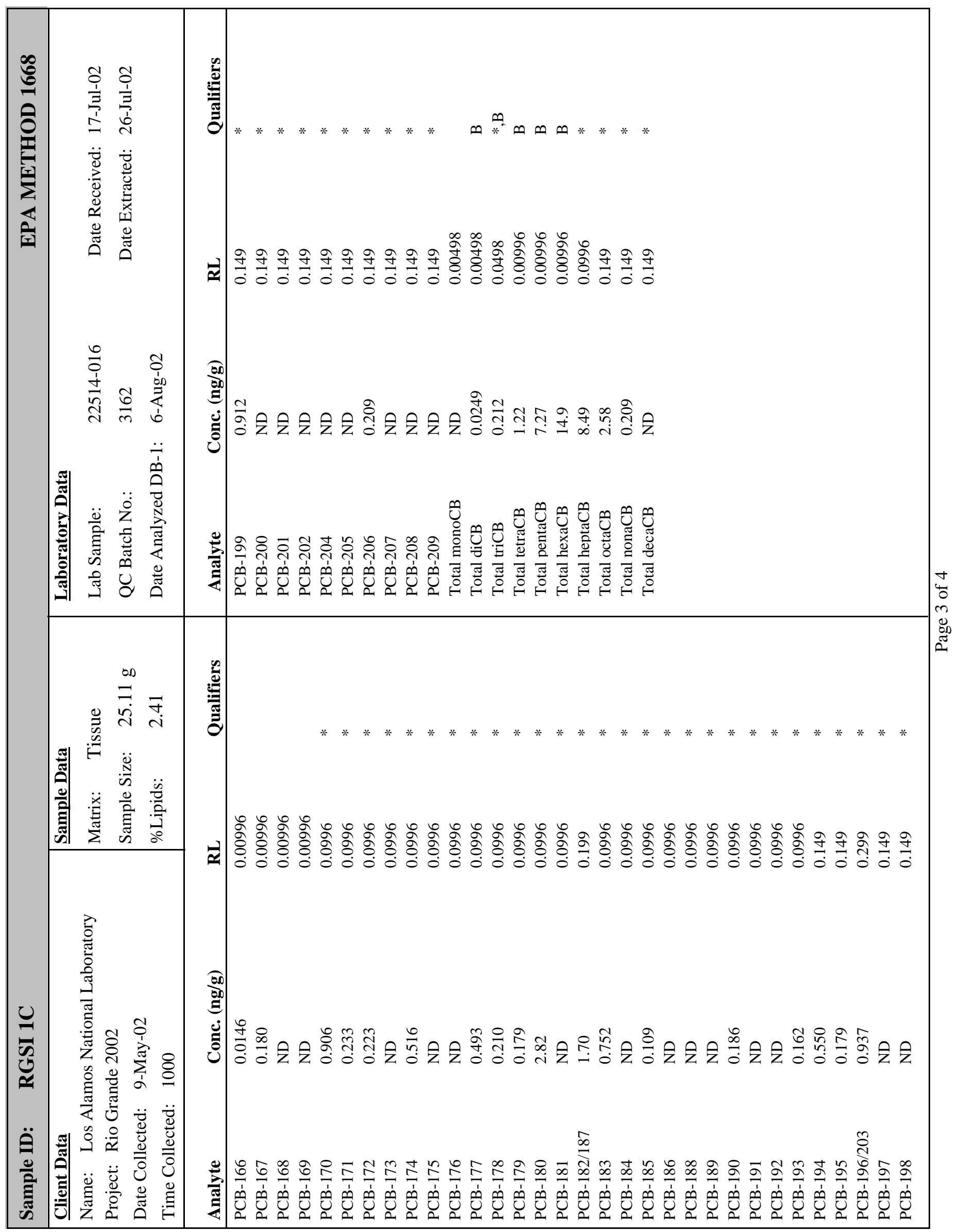




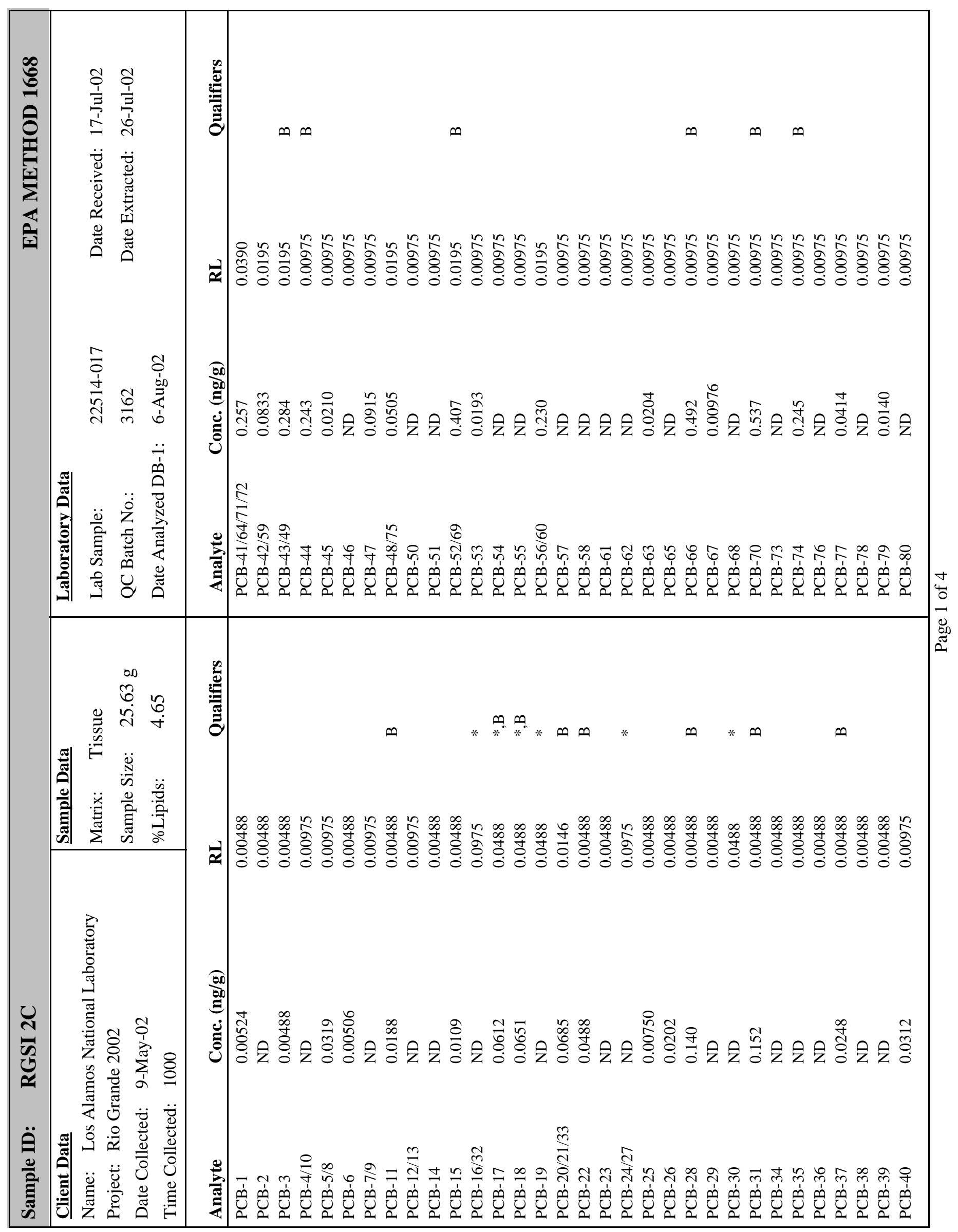




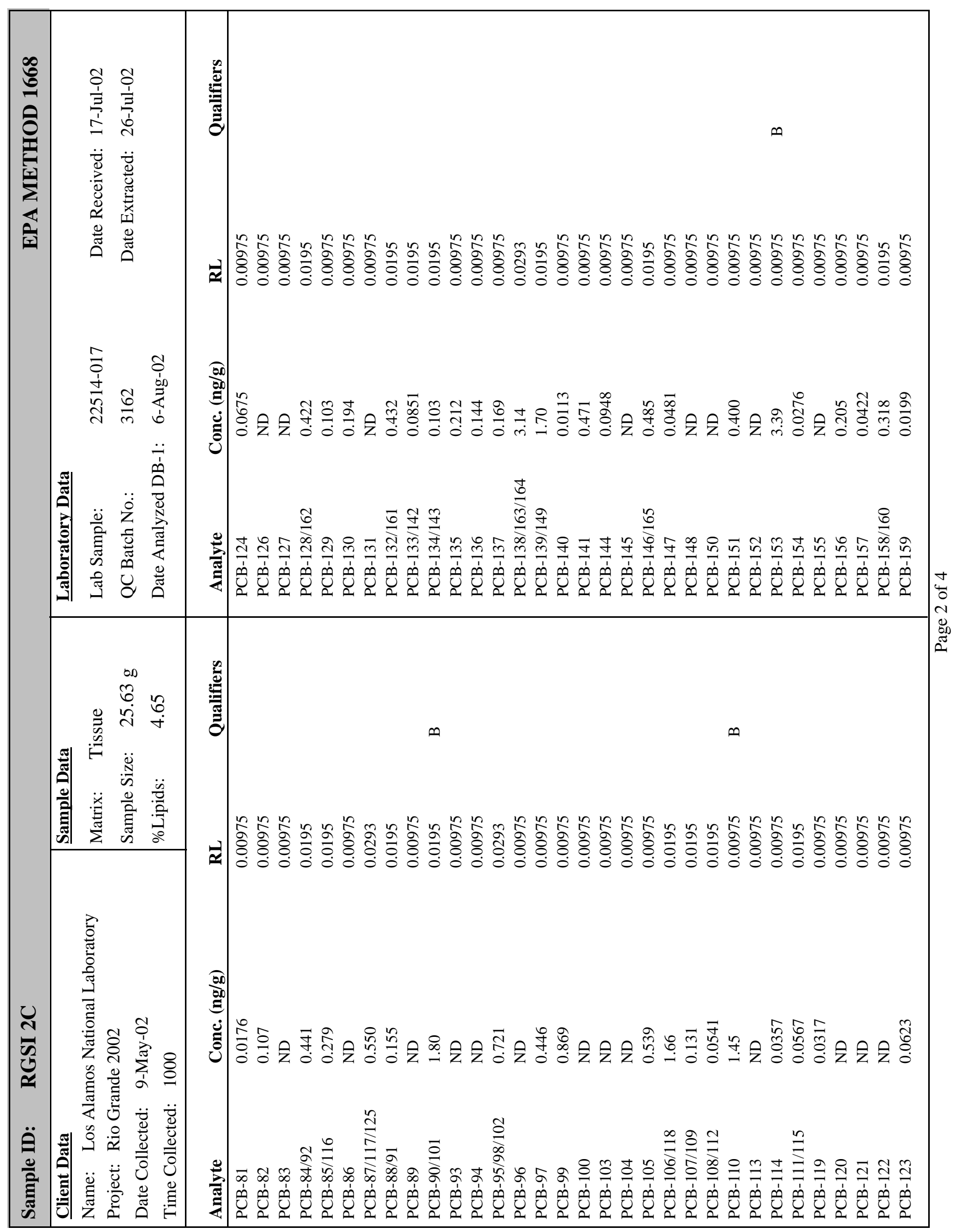




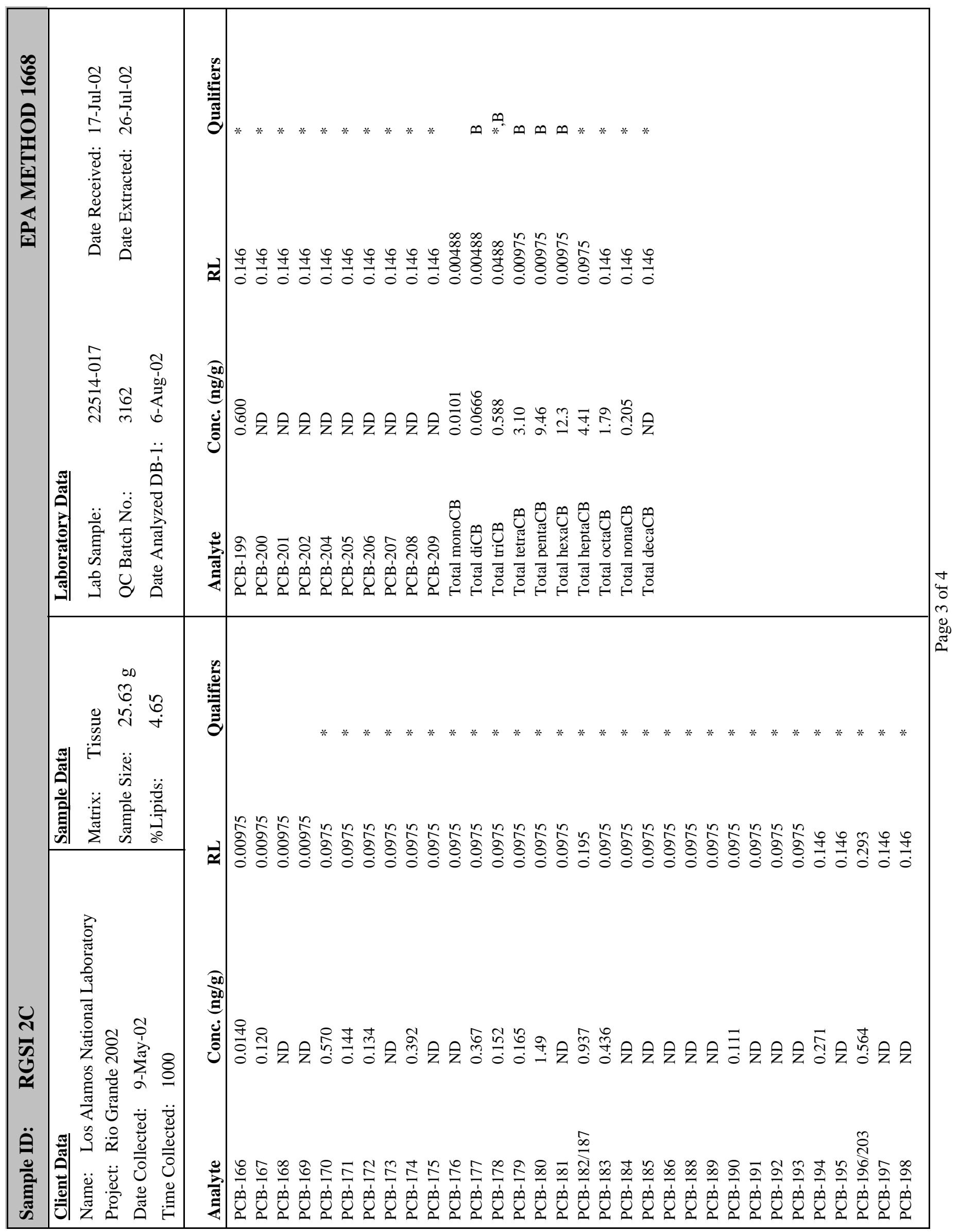




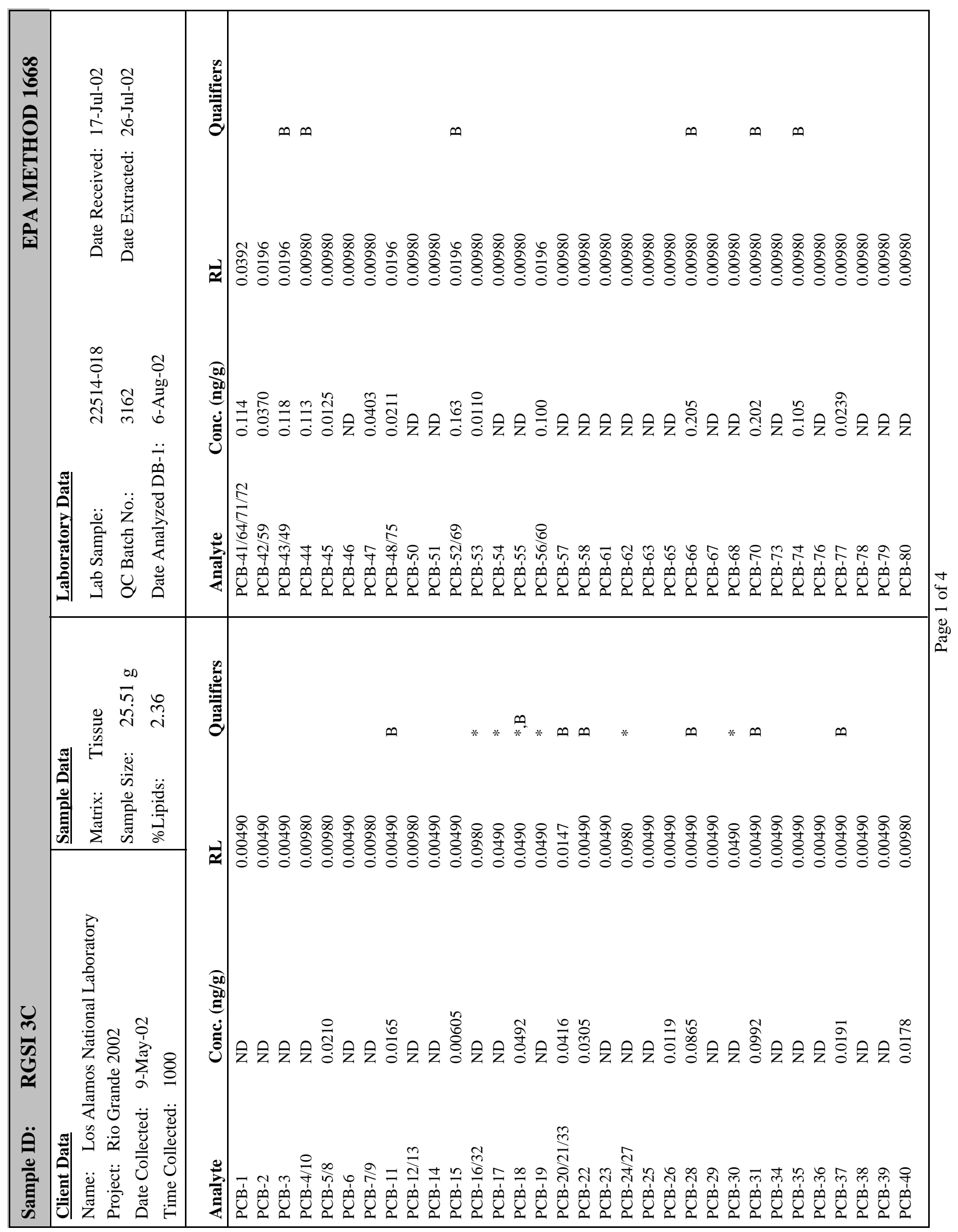




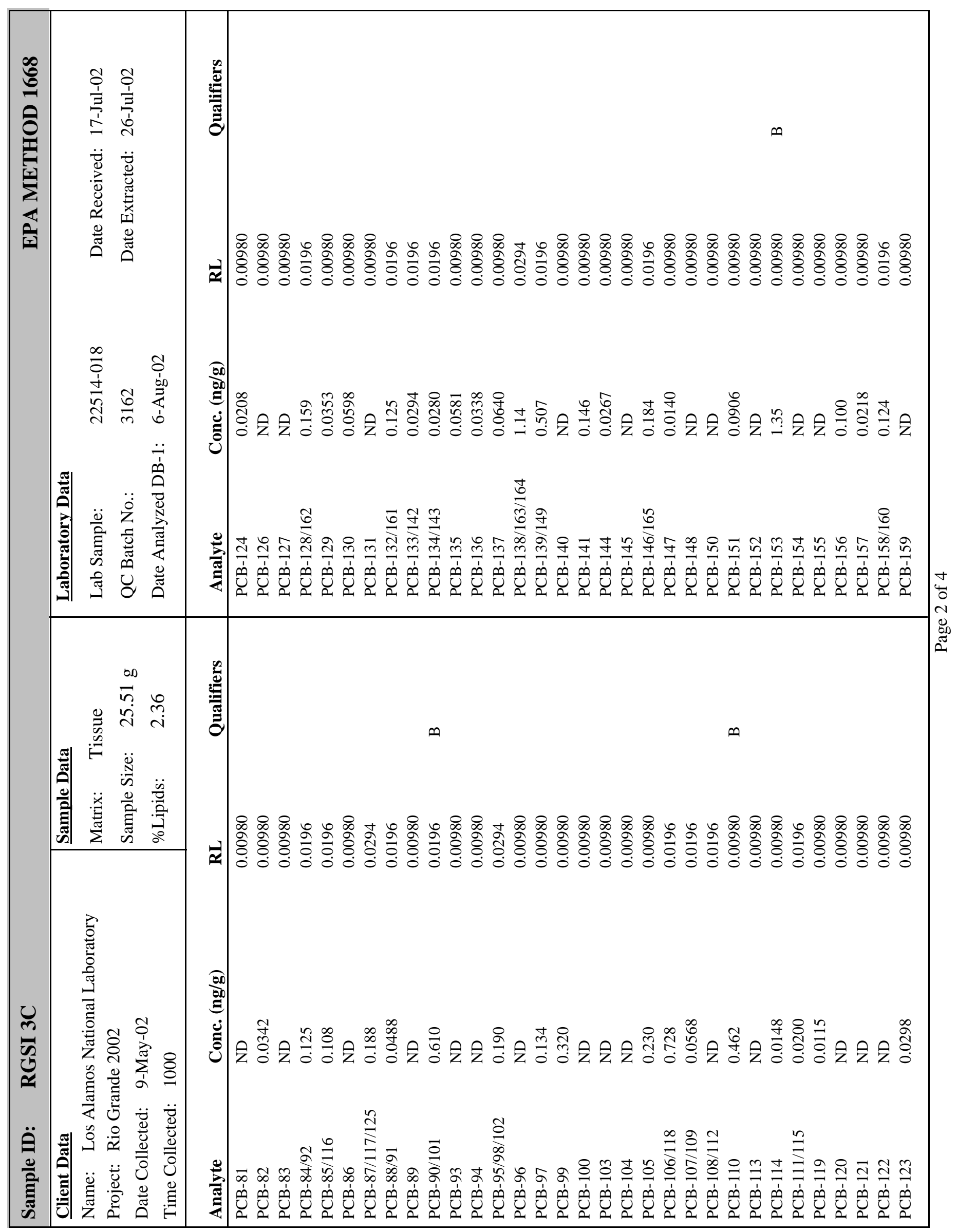




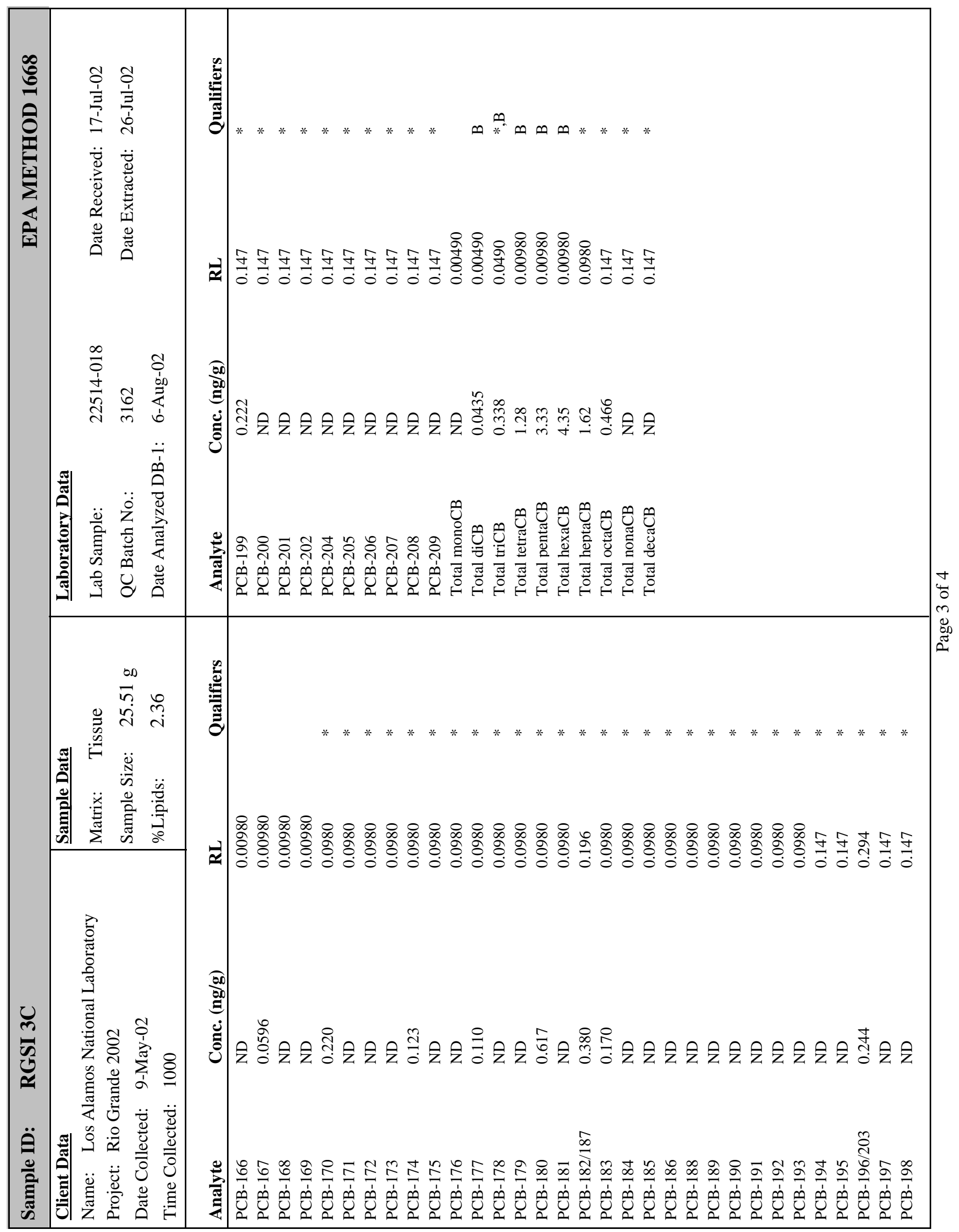




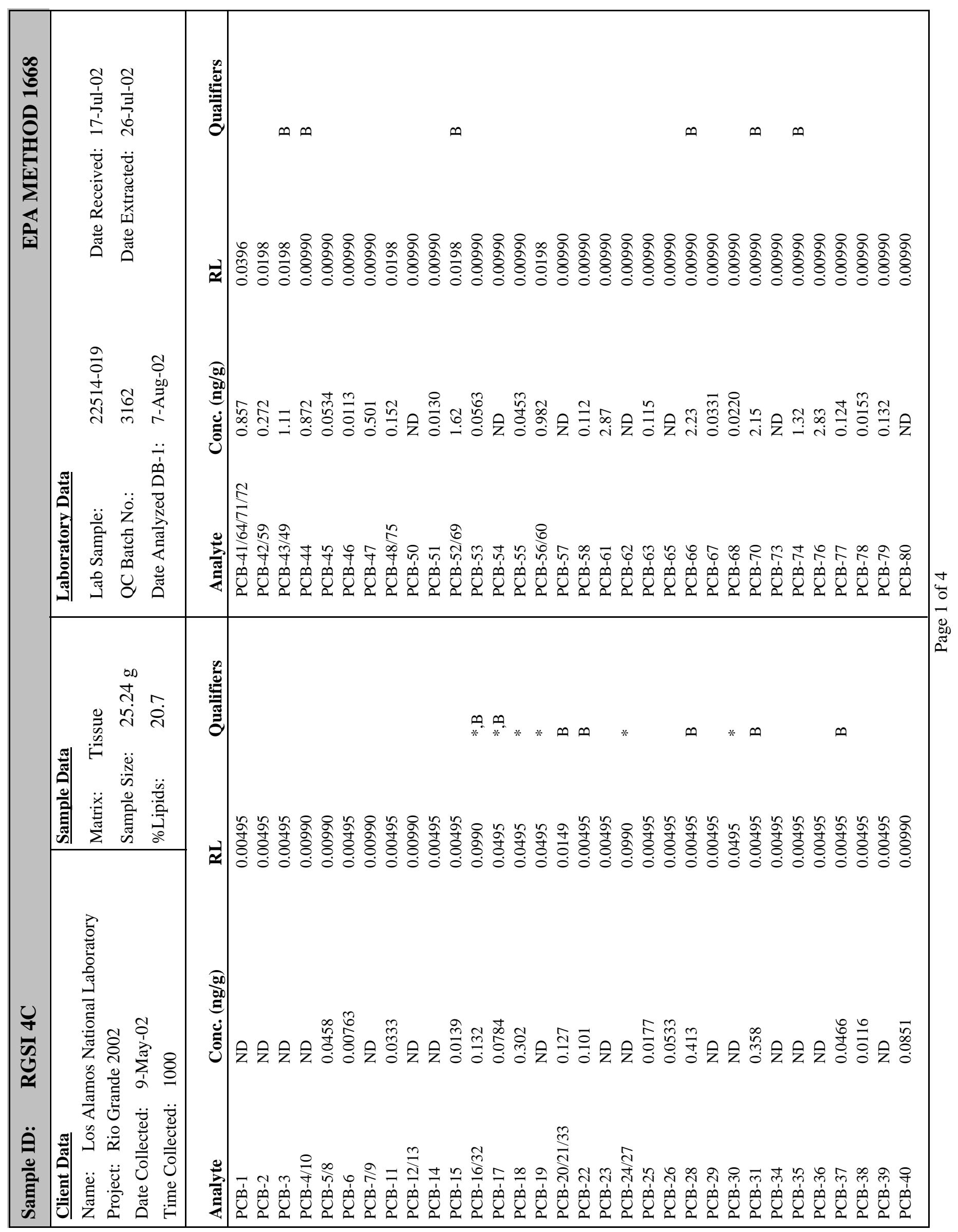




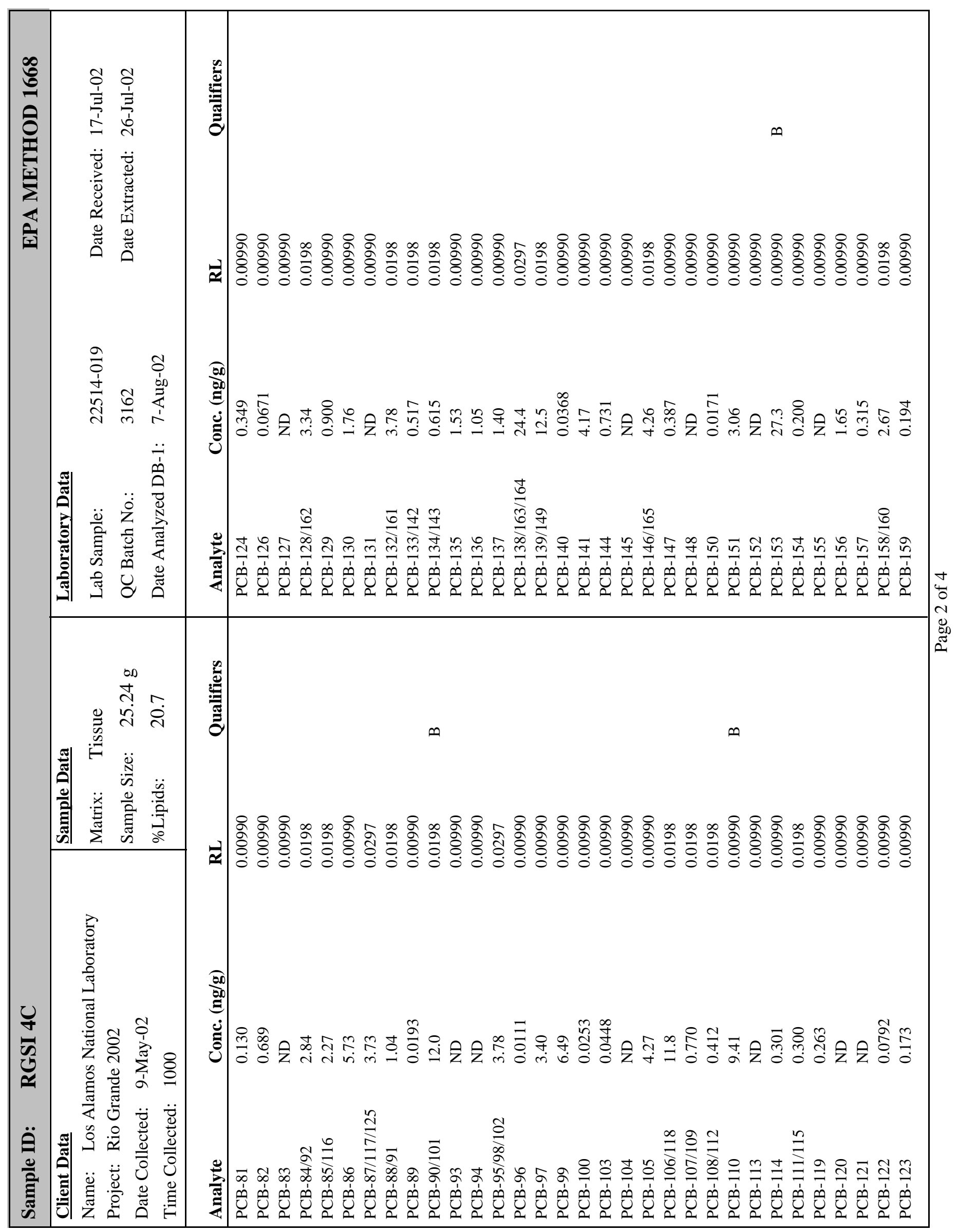




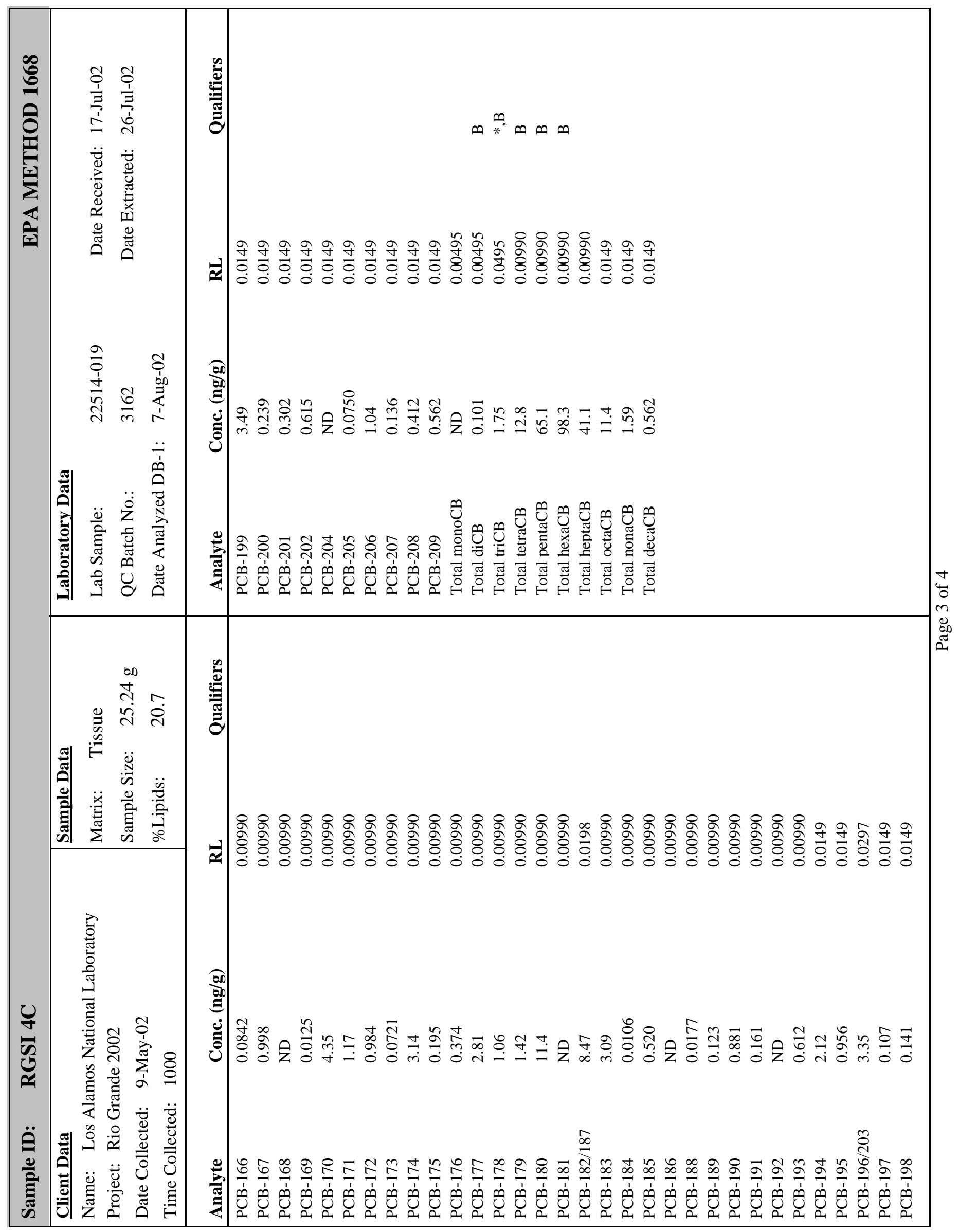


This report has been reproduced directly from the best available copy. It is available electronically on the Web (http://www.doe.gov/bridge).

Copies are available for sale to U.S. Department of Energy employees and contractors from:

Office of Scientific and Technical Information

P.O. Box 62

Oak Ridge, TN 37831

(865) 576-8401

Copies are available for sale to the public from: National Technical Information Service

U.S. Department of Commerce

5285 Port Royal Road

Springfield, VA 22161

(800) 553-6847 
- Los Alamos NATIONAL LABORATORY

EST.1943 